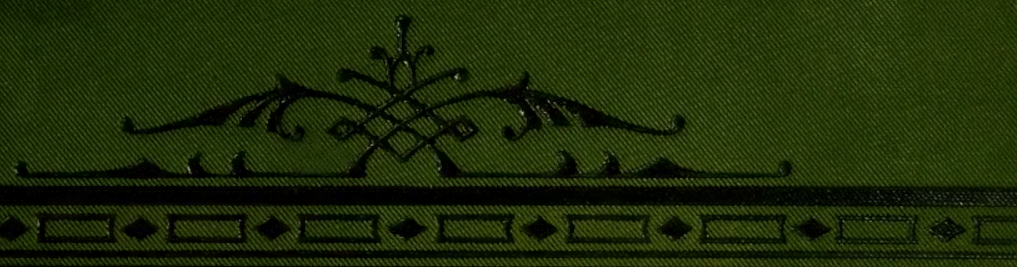

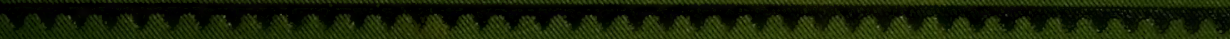

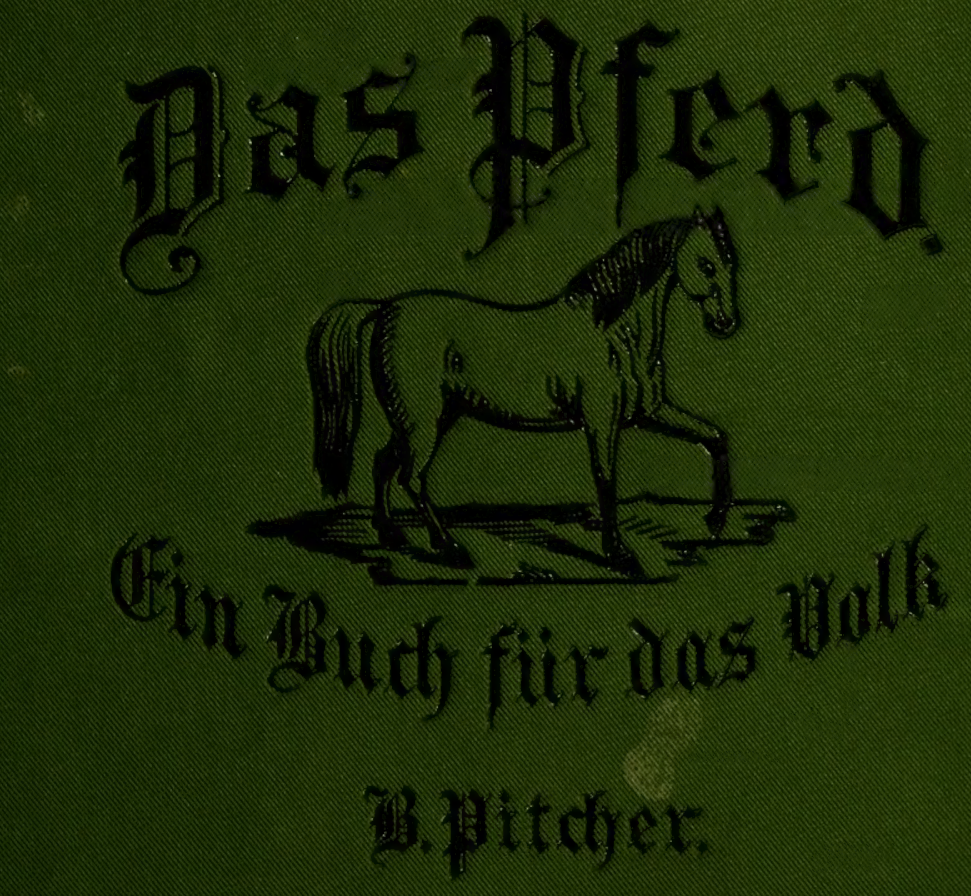

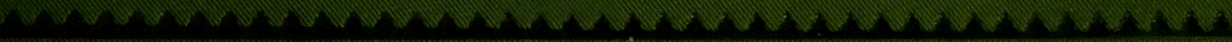

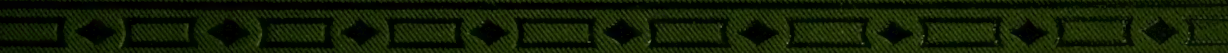

$$
\text { (2) }
$$




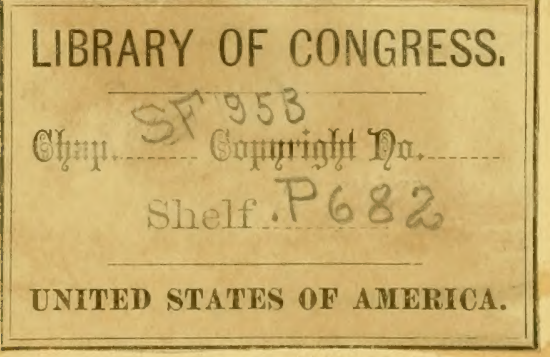






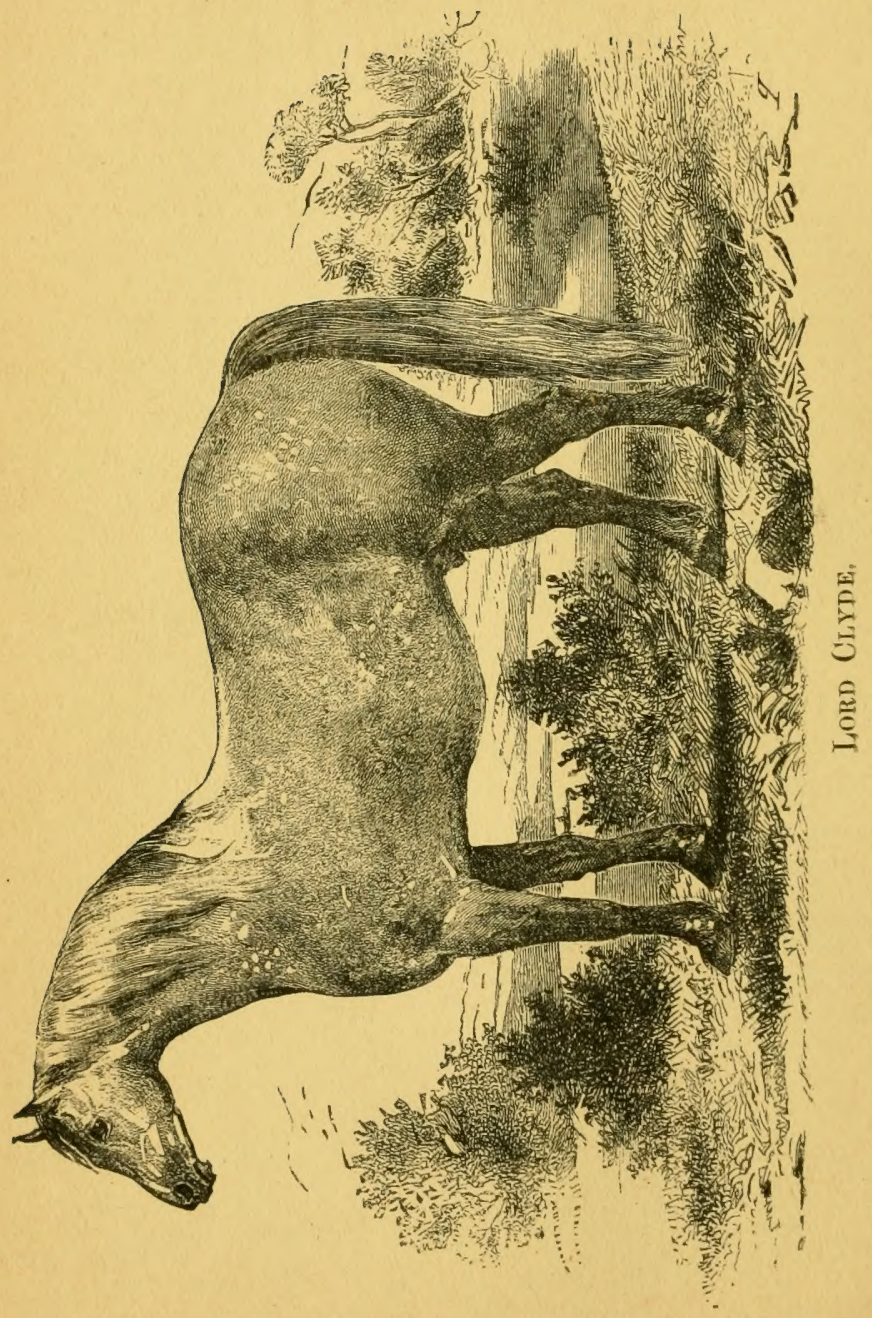




\section{$\mathfrak{d a s}$ derfer.}

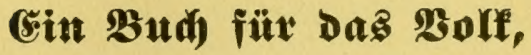

\section{entbaltend:}

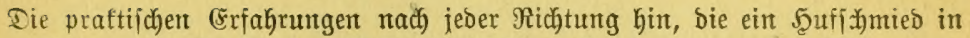
fiebenumbdreiß̧igiäbriger Thätigfeit gejammelt; fomie ntantdbes $23 i f i e n s=$ mertbe über ßferbe und mie biejelben behantbelt, bejchlagen und

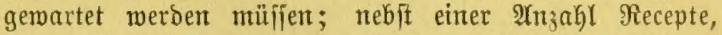
melde ber Berfajier feit Jabren gebraudht, und für Pferbe uno Menichen gut befunden hat.

\section{B. Pִiteher. \\ Mit $\mathfrak{A}$ nthang.}

(Enthalteno:

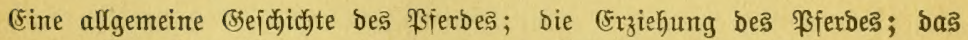

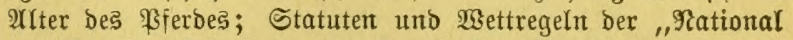
Irotting 2 ifociation." 2 (ngabe ber Mebifamente in Deuticher unb engrifider Spradje.

Dritte, vermegrte $\mathfrak{A}$ uflage, mit 43 in ben Textgeoruten SII it $\mathrm{r} a$ ttonen.

Berlag für ben 2 utbor:

THE GERMAN NEWS

COMPANY, C H I C A G O, 
Entered, according to act of Congress, 'n the year 1880.

By P. PITCHER,

in the Office of the Librarian of Congress, Washington, D. C. .

Entered, according to act of Cungress, in the year 1881.

By THE GERMAN NEWS COMPANI,

in the Office of the Librarian of Congress, Washington, D. C..

Diefes Siud) wiro franco per Foit veriant gegent (Einjentung poit

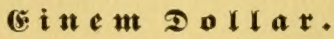

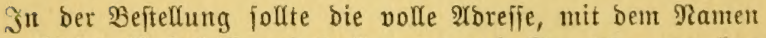
ber nädhiten Fopt:-Dffice, bes Countys uno Staates angegeben jein. 2rofe Beftellutngen ridyte man an

\section{THE GERMAN NEWS CO., CHICAGO, ILLS.}




\section{Dorwort.}

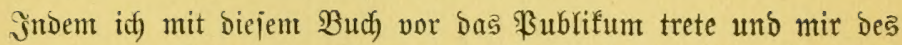
Boruirtheils wohl bemū̄t bin, bas gegen alle Bücher biejer $\mathfrak{A}$ rt herrjat,

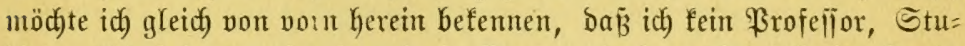
Dirter, Pferbeboctor oder irgend ein Doctor, jondern ein einfacter 5̧and= werfer bin. Was diejes Budf entfält, find meine Erfahrung und meine Beobad)tungen währent eines Beitraumes von fieben uno breiß̄ig Jahren.

Die meiften $\mathfrak{S e r f e}$ über biejen und verwandte B̈egentänoe fint von Männern geidgrieben, bie zwar eine Theorie über bie Sache haben, aber

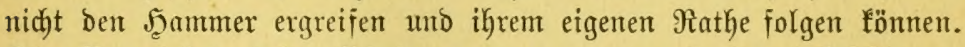

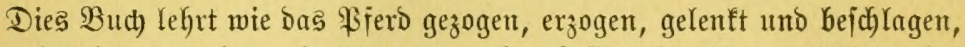
und wie es curirt und gewartet werben follte; baneben enthält es eine

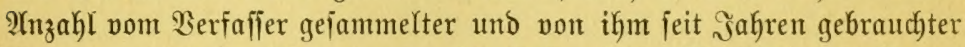

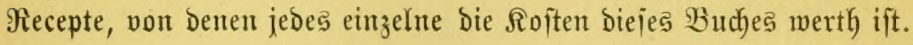

$$
\text { Der Berfafier. }
$$

\section{Dormort jur oritten 2luflage.}

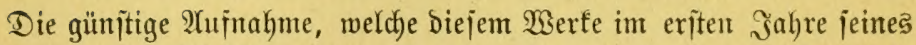
(Erid)einens 孔u Theil geworden, hat bie Şerausgeber veranlä̆t, bieje neue Dritte 2 fusgabe mit bedeutend vermehriem Inthalte und vielen werth= vollen Şluitrationen verieken, erid)einen zu lafien. Wir glauben barin einem vielieitig gefühlten $\mathfrak{B}$ edürfniffe abgeholfen z̆ haben und $\mathfrak{h a l t e n}$

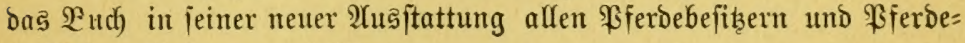
liebhabern beitens empfoblen.

Die $\mathfrak{B}$ erleger. 



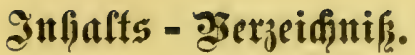

IUgemeite $\mathfrak{B c m e t h}$

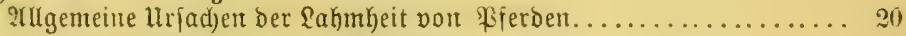

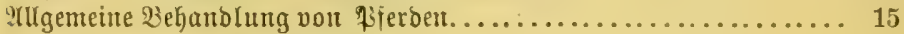

Bemerfungen über Rranfenpflege..................... 18

Bodtige \$ferbe und fitidjer........................... 26

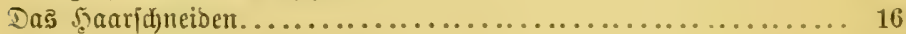

Der zu ¡tramme Spannzügel........................... 19

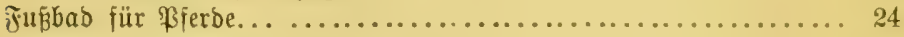

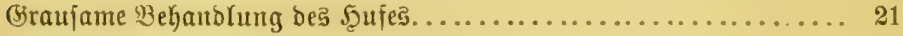

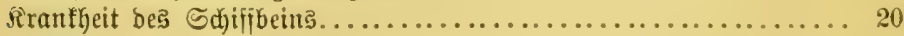

Rabmbeit im Sprunggelent............................ 21

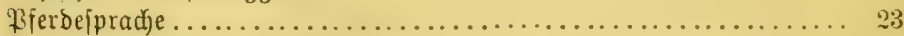

lleberftuţigfeit (Cupped Ankles). ...................... 21

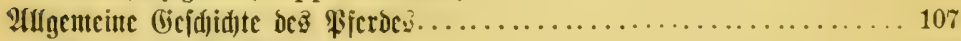

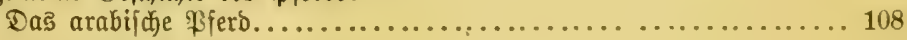

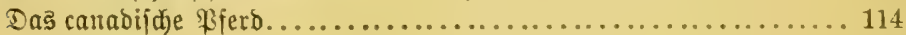

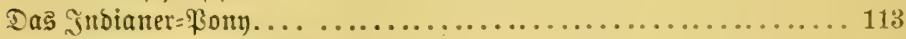

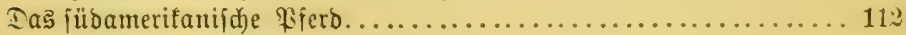

Das Trafehner $\$$

Ią \$ferd vort guter Seerfunjt (thoroughbred)............... 114

Der Miufang, ober bas" norbamerifanifine fiferb.............. 113

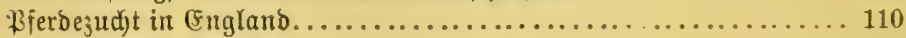

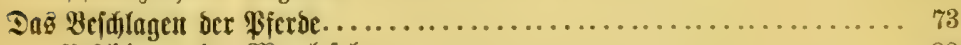

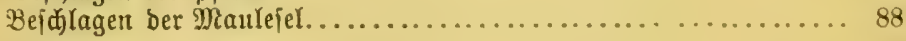

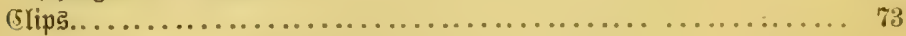

Drudf auf ben Strahl............................... 95

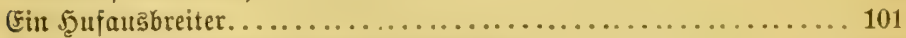

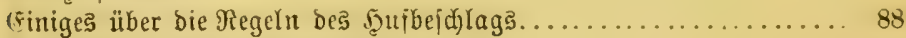

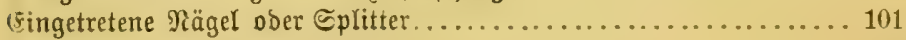

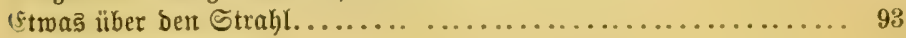

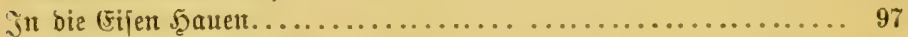

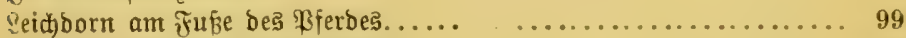

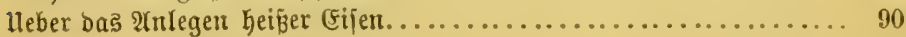




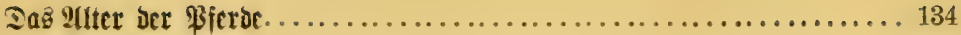

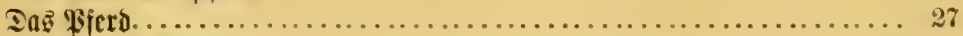

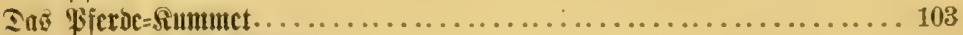

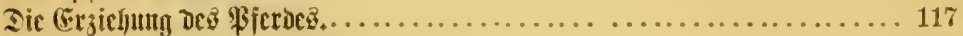

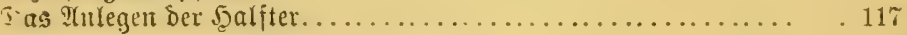

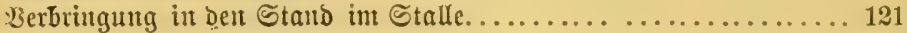

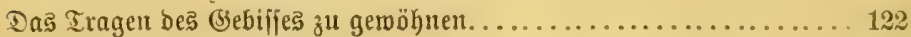

3aumgebr

Dả 2 แโ

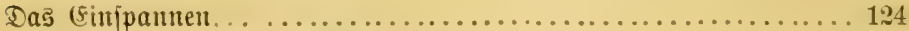

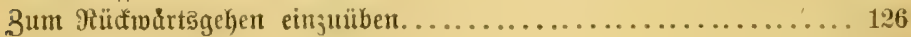

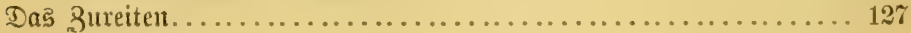

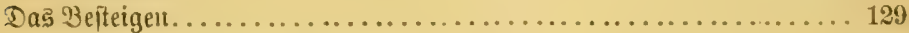

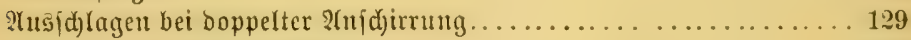

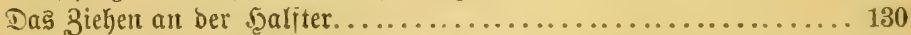

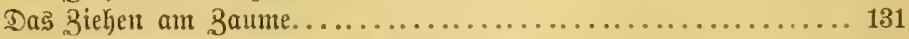

Wie man ein $\mathfrak{B}$ ferd zroingt fid) nieber

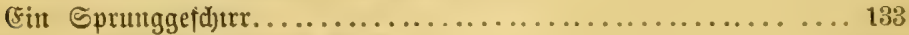

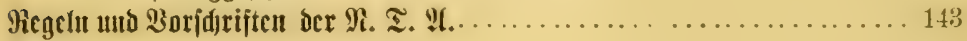

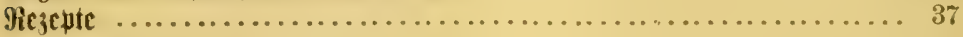

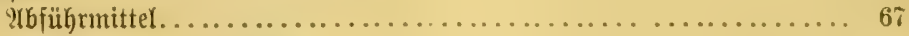

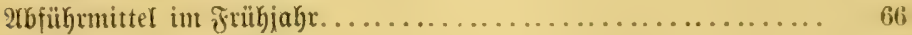

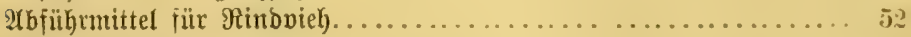

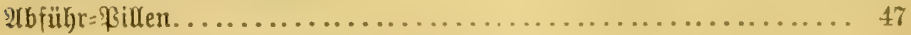

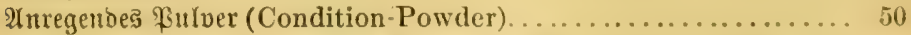

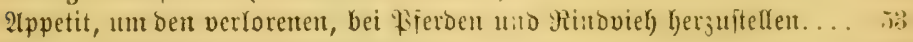

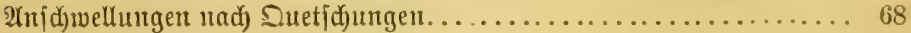

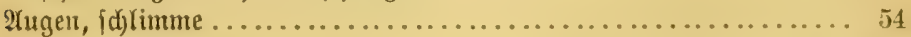

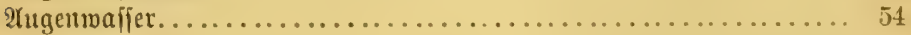

Iugenjalbe................................... 54

Blutbarnen....................................... 68

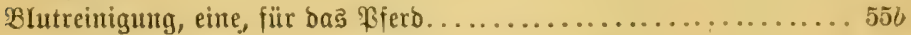

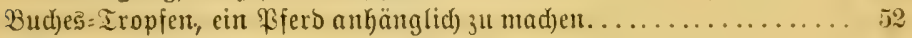

EInitiere, abfülyrende............................ 67

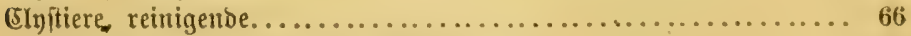

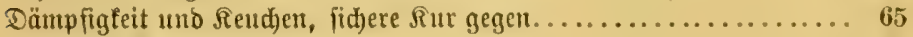

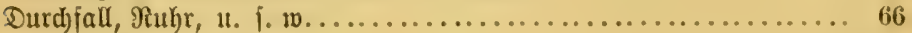

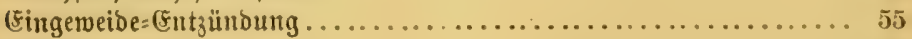

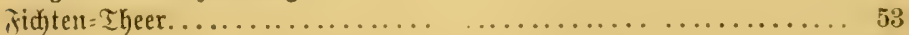

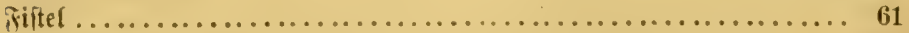

iroid (Lampers) ................................. $55 b$ 


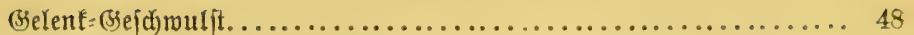

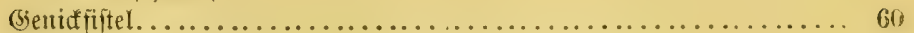

(Beid)wollene Beirt............................ 49

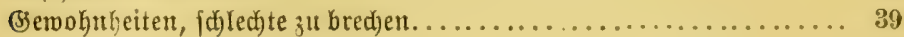

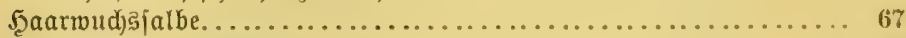

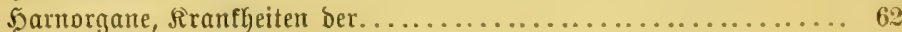

5ämtorthoiben, fid

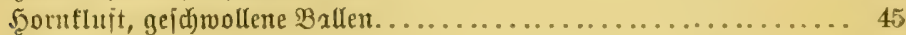

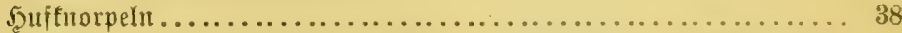

5uffronte, Berletzung Der, Durd) Tritte, Duetid)ungen, ftreifcnde (Eifen

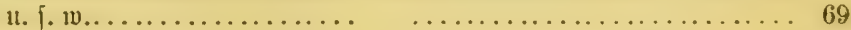

Şuโmajie, verbärtete.............................. 45

Jeuffalbe................................ 43 แ. 47

5uf

Scupten $=$ Pille . . . . . . . . . . . . . . . . . . . . . . . . 65

Siatarrh ober eimfad)e Erfältung..................... 70

Reudjen, fidtere Seilung gegen......................... 65

Rolif......................................... 49

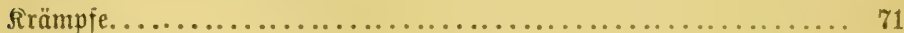

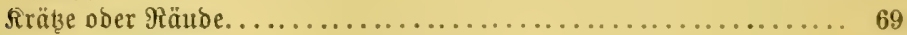

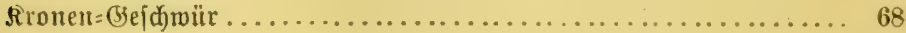

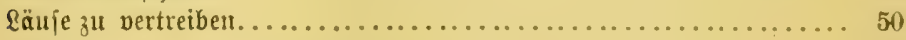

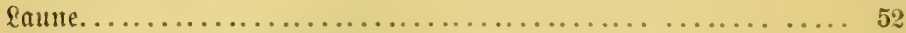

leber=[ntzünoung oder gelber Urin.................. 55

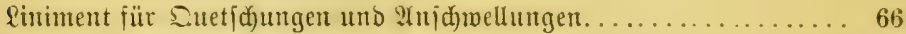

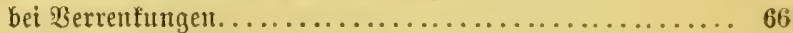

für Eplint und Epat.......................... 51

eit milbes allgenteines.... ................... 46

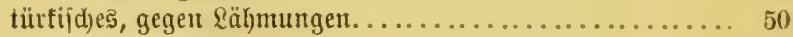

id)merziftllendę............................ 65

" đumarzes Del........................... 48

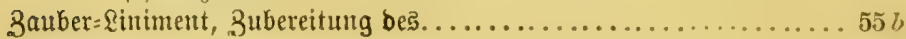

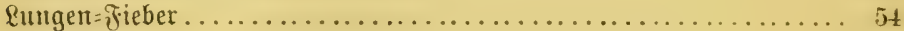

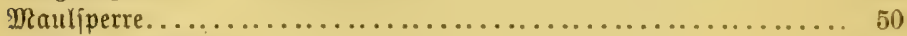

IRagen, überiülltel............................ 6 \%

Magenmürmer (Bots) ............................ $55 b$

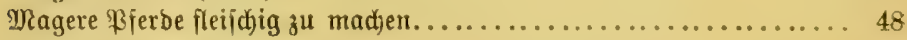

Albfiikr $=$ Billen ..................................... 47

Fiteber "

\$̧uitent "

Räke......................................... 47

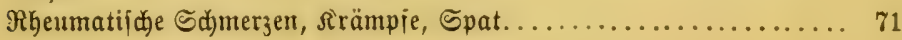




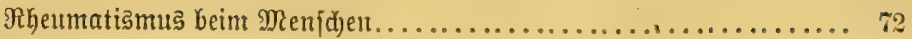

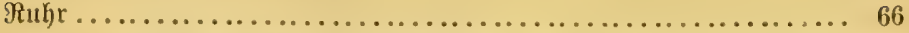

Salbe, gegen Sd)rammen, geidumollene Feijelgetente, fironten = (5e=

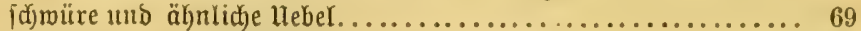

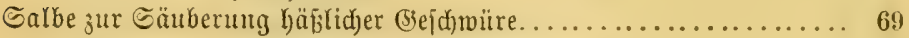

" reinigende, bei (ङejdyüren, Edrammen u. \{. w........... 70

" meißße, gegen (ङeid)roüre, Sdjrammen u. \{. w............ $\sigma_{0}$

" $\mathfrak{a}$ ugenfalbe................................. 54

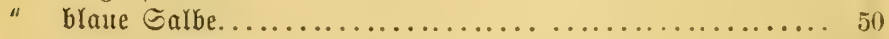

" (Breen Moututain............................. 46

" weike Salbe.................................. 48

" Jృarmud)

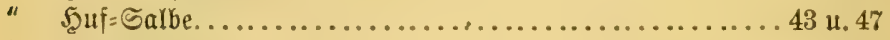

" Seifent=Salbe................................ 45

" Bugialbe..................................... 49

Edjmerzitillendes Fluidium........................... 65

Gpat......................................... 51, 71

Splint..................................... 48, 51

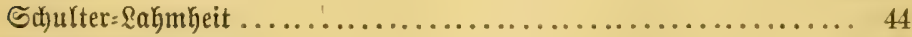

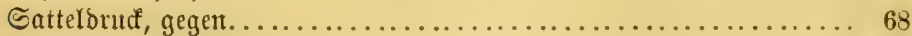

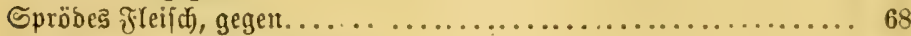

Strid)fäule und ङtrabltrebฏ.............................. 63

Stuten, Rüke, trädhtige........................... 38

Sdymarzes Del= Liniment.......................... 43

Unfrudjtbarfeit bei Stuten, Mittel gegen.................. 37

Ueberbein...................................... 48

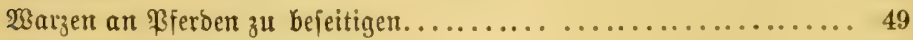

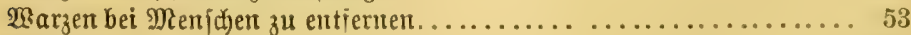

Winbgalle..................................... 48, 62

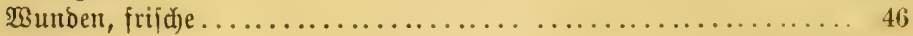

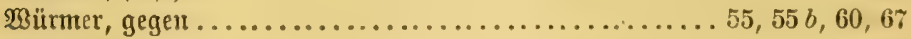

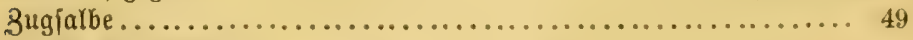

Rezepte fïr 5antwerfer.

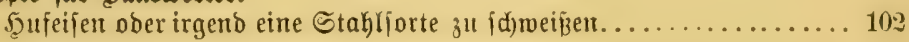

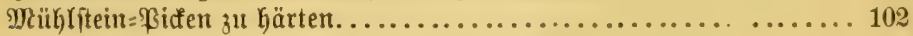

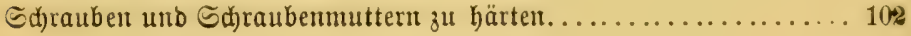




\section{Siffe ber glluftrationten.}

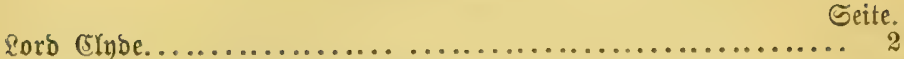

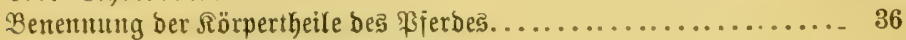

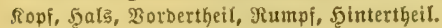

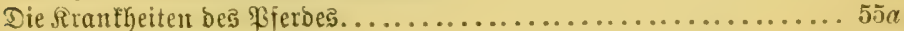

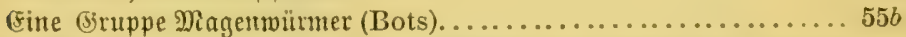

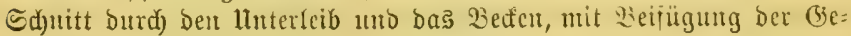

bärme uा ber Reber............................ 72

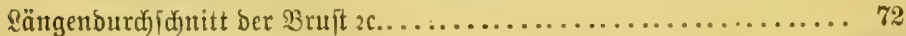

Ein Englijdes Bugpierb............................ 106

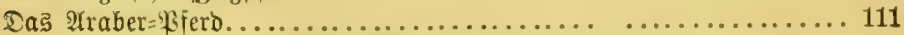

(Das Befidlagen ber $\mathfrak{\text { Pferbe.) }}$

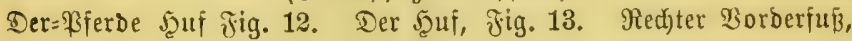

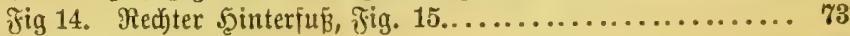

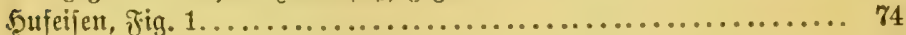

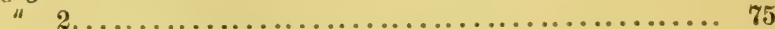

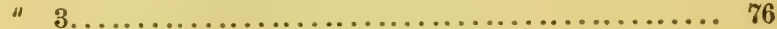

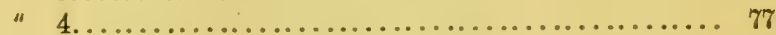

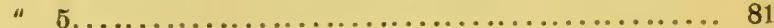

" 6 .

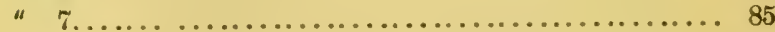

" 8 mb 9.................................. 86

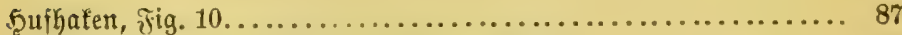

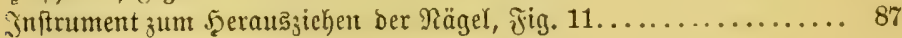

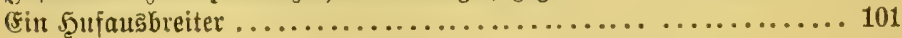

(Die (Ergiehung bes \$ferbes.)

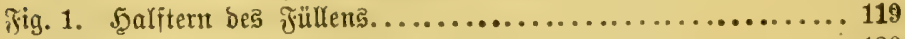

"2. " " "

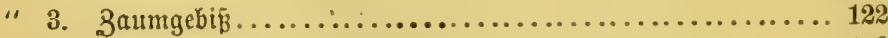

"4. "

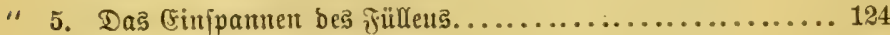

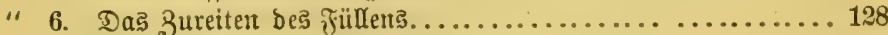

"7. Das Biehen an ber Jealfter...................... 130

" 8. Wie man ein Biferd zum Sieberlegen zmingt............ 132

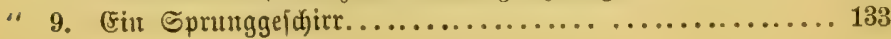


(Das 2lter ber $\mathfrak{B f e t b e . )}$

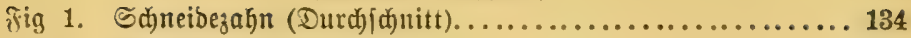

" 2. Mildafdneibezähne.......................... 136

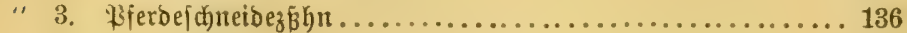

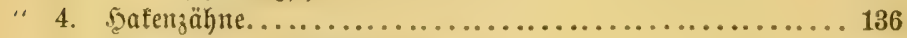

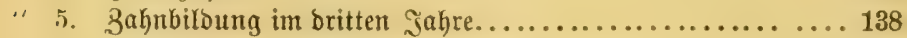

" 6. Mund eines $41 / 2$ গahre alten $\mathfrak{B f e r b e s . . . . . . . . . . . . . . . . ~} 138$

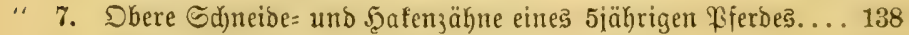

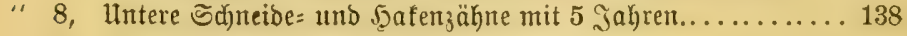

“ 9. Untere 马ähne eines 6jährigen ßjerbes............... 139

" 10. Bäkne mit 7 Jahren................................ 139

"11. " " 9 "

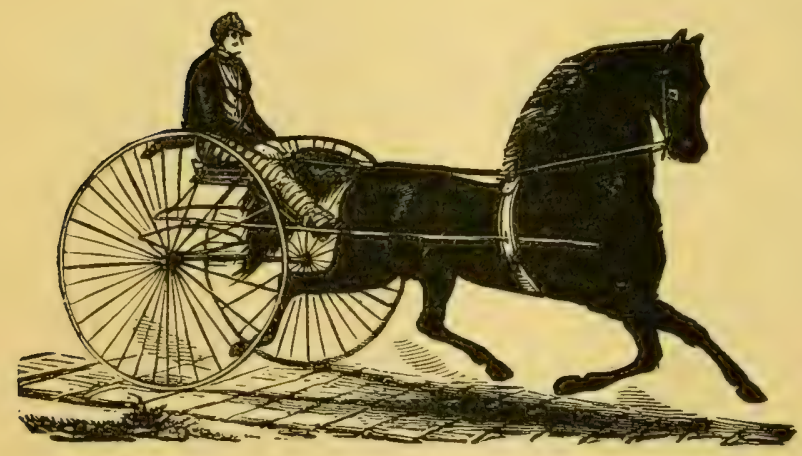




\section{Allfgemeinte Bemet lungen.}

Der Berfafier oreję Berfdene gehört teiner bejon'eren Secte ober

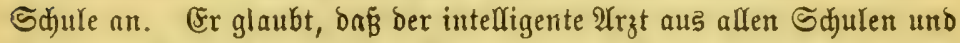
Syftemen, und aus einer jeben je angewandten Behandlungsmeife etwas

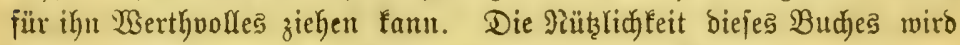
bauptiäd)fid in ben barin enthaltenen praftijhen Fingerzeigen bejtehen.

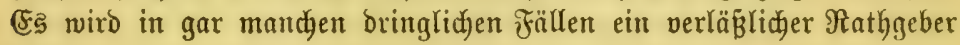
jein.

Biele gewöhnlich) als unheilbar angejehene Rrantheiten werben ats leidyt heifbar befunoen werben, uno sntoere, weldye für fdyer heilbar an=

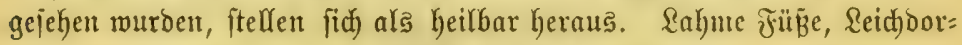

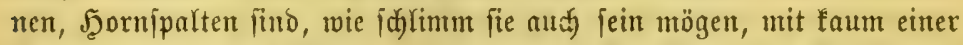

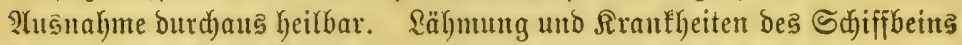

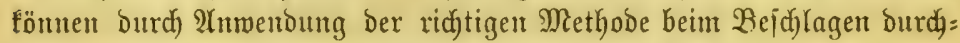
weg verhindert werben. In den aufänglichen Zuftänden fint bie Steif= heit uno Spannung an Rute Yeidjt Keilbar, in den ipäteren Stabien, wo fie nidgt abjolut heilbar fïn, fönten fie bis za einem merfwürbigent Brabe gehoben werben. Der Serfaffer hat ïber bieje Giegenitände $\mathfrak{A}$ n=

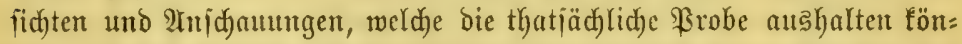
men, unb bas ift mehr als von Bielent gejagt werben fam, bas über ben

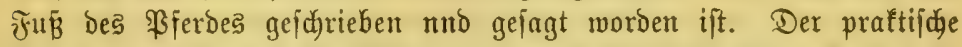

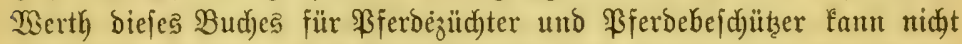

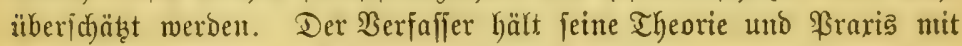

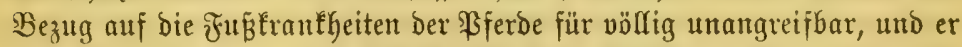

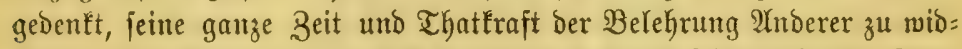
ment, in Der Heberzengung, Daß er, indem er bamit feinent eigenten Jnte=

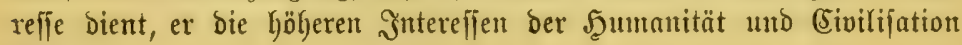
föroert.

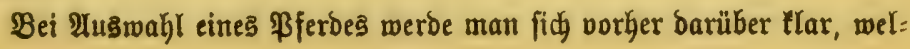


de $\mathfrak{A}$ rt von $\mathfrak{A}$ rbeit man baffelbe verrichten zu laffen gebentt, Denn beim

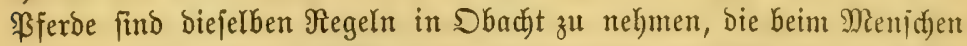

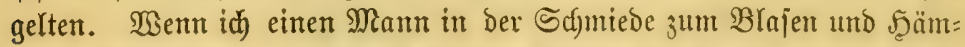
mern gebraudje, fo nehme id) leinen jungen Manm mit enger Biult, ja)lanten (S)iedern und feinem, zarten (Seficht und von nur adjtzig bis

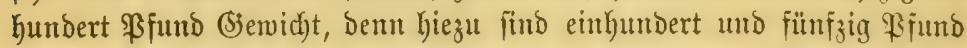
und itarfe Bruft uno breite Sduultern nothwendig. Für barte $\mathfrak{2} r=$

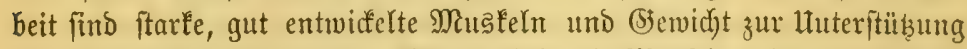

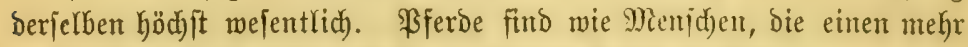

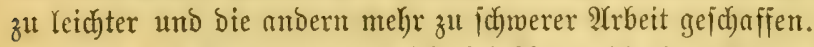

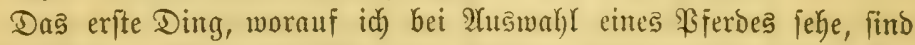
feine Füве. Menn biejelben tiefe Mände, volle, runbe, breite நૃa=

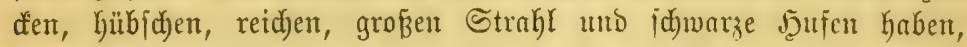
baun thut's; weif̧e Şufen find nidgt fo zäh, wie idywarje. Dam erít

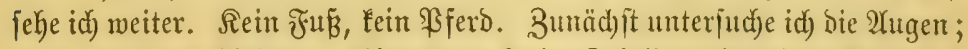

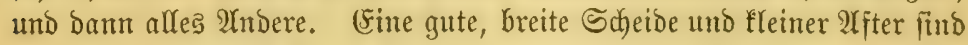

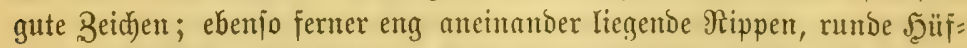

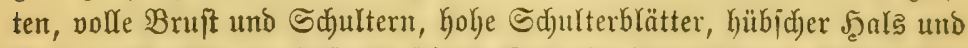

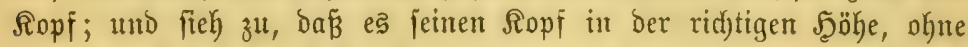

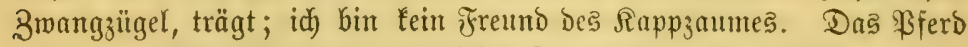
joll feineu Ropf in jeiter natürlidjen Rage tragen, Daun wirb e马 leidjt Inufen. Sieh ja, ba

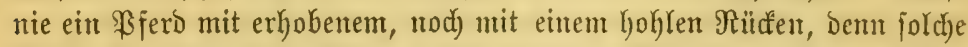

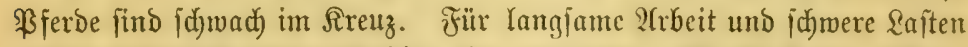
wähle vierzehnhundert pfünoige oder id)werere; für die Farm elfhun: bert bis breizehnhunbert pfündige; für bas $\mathfrak{B} u g g y$ adjthundert bis elf hundert pfündige ßferde.

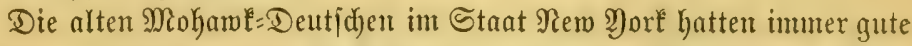

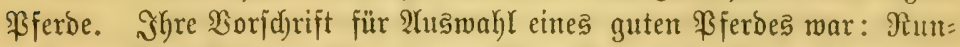
ber bau, furze Beine. Sie jagten, fie mollten midjt jo viel Tageslidjt barunter haben; und einen guten Frefier, Denn was nidjt f̣effen tami.

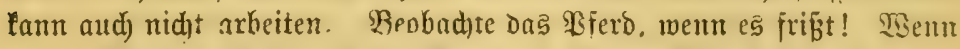

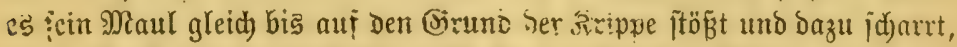

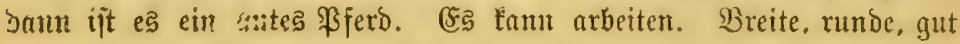

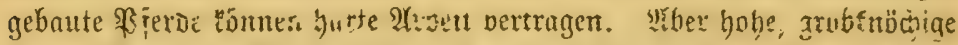
Эiferbe tönnen bie $\mathfrak{A}$ rbeit nidjt thun, und freffen ebenjo viel, menn nidjt 


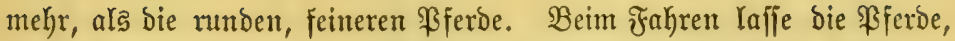

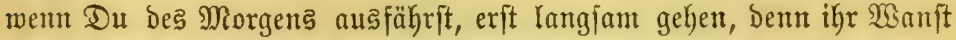
ift volf, und fie fühlen fdywer, und wemn man fie fduntll laufen madft, merden fie viel Sdymerz leiben. $\mathfrak{A} u f$ längeren Touren gieb ihnen oft

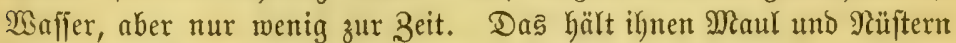
feud)t, und fie weroen leidyt atlymen. Mittag's ftefle Dein \$ferd in ben

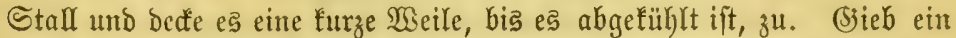
menig mit reinem $\mathfrak{B a f f e r}$ angefeudstete马 Şeu. Nadjoem es abgefühlt ift, gieb ify ein wenig faltes $\mathfrak{W a f f e r}$ und ein menig Rorn. (S3ieb irm Mit= tags wentiger zu freffen, als 2rbends ober Morgents. Bermeibe, wenn

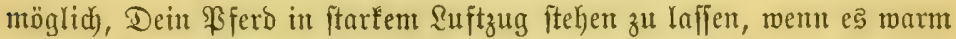
geworben, ohne ihm eine Dedfe überzumerfen; Denn ę fönnte fich erfäl=

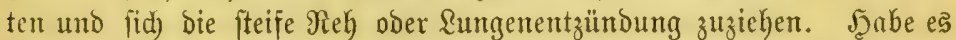

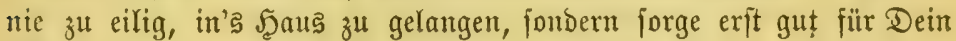
Bjerd.

\section{Ullgemeine $\mathfrak{B} e \mathfrak{h}$ and $\mathfrak{d}$ ung.}

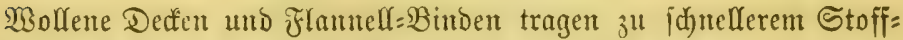

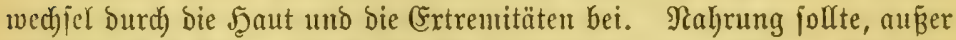

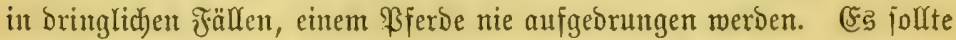
Durd) Secterbiffen zum (sffen angetrieben werben. IHud) bas bejte Futter wirft entzündend auf einen in Hnoronung gerathenen Magen. Rleie,

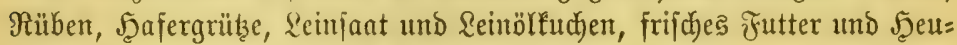

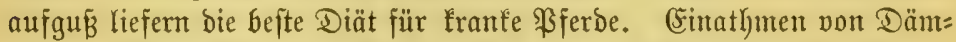
pfen von heifer Sleie ober Seeuthee ift gut in allen \&uftröhrenfranflyeiten. Reinjaat wirkt in Folge feiner $\Re a h r l j a f t i g l e i t$ und jeines Delgehalts lint berno auf bie entzünbeten Sd)leimbäute. Raltes $\mathfrak{W a j p e r ~ e r f r i f a t ~ u n d ~}$ jollte dem franfen Sferbe ftets erreidjbar fein. Bandagen werben ben Beinen zum Zmecte Des Druttes, ber Befeuctung, Der Wärme und des Sdjuţes angelegt.

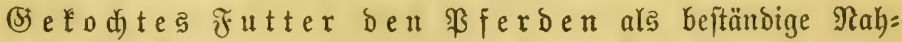

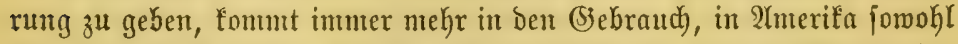

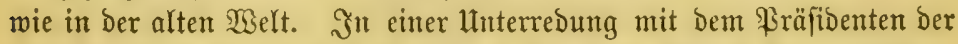
Utnited States Steant Fced (Sompany, Der dieje Fraris Gier einführte, madjte bie Theorie einen bebentenben (5indrudt auf mid), und id habe

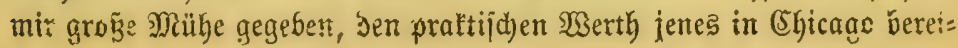




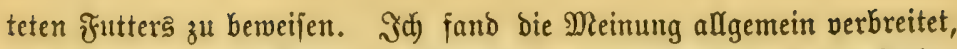
es fei beffer für bas \$ferb; audd werbe ber Futterwerth burd) bas Rodjen erhöht, fei aljo billiger; Kalte außerbem ba马 Thier frei von Rrantheiten,

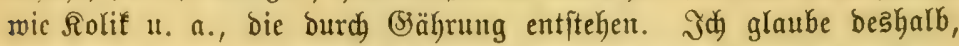

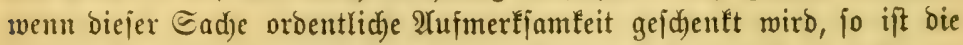
Zeit nidjt meljr ferne, in ber man gefodtes ofutter giebt - nidht als

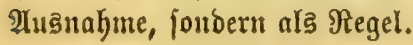

\section{Das $\mathfrak{5} a$ ariduneiben.}

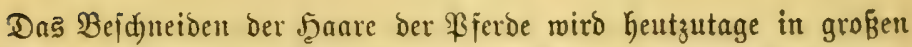

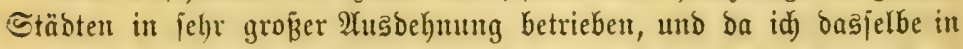

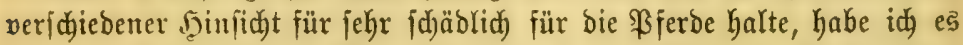
fïr gut gehalten, biefem Biegenjtande in bem vorliegenden Budje etwas

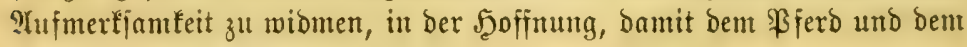

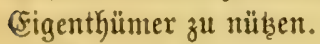

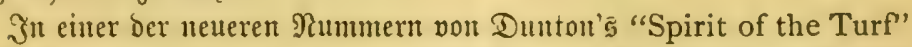
fano idy citten io jähigen und guten 2 rtiffel von Dr. (5). S. Stis über

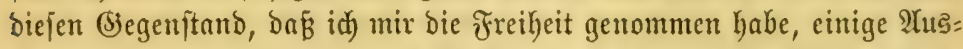
züge baraus z̆l madjent. "Das Bejdnteiden Der Şaare ber Bferbe wurbe

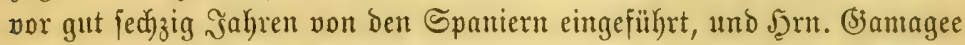

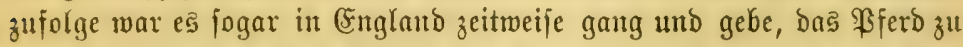

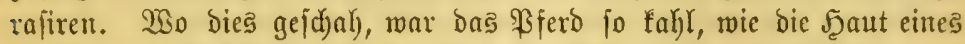

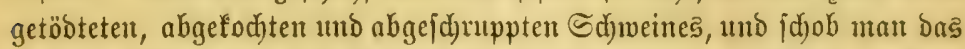
Rafiren Ginaus, bis bas Madjsthum ber Unterbaare anfgetyört, jo brieb Daş \$fero Den ganzen Winter Kindurd) naât wie cin (ETephant. Die Befürmorter bes Şaarjdneidens madjen geltend, uno barin haben fie

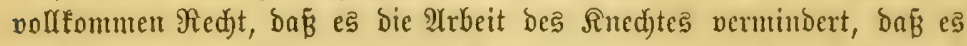

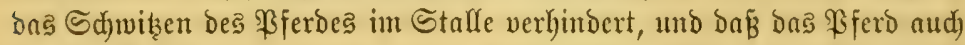

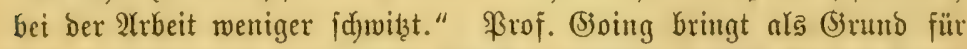

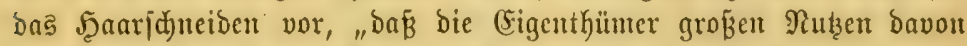
gebabt Gaben müffen, fonft würden fie es nidjt gethan Gaben."

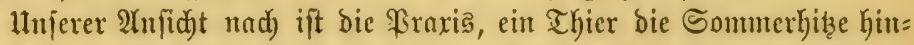
Durd) in volfem Befitz feiness natïrlichen Rleides Kerumlaufen ž laffen,

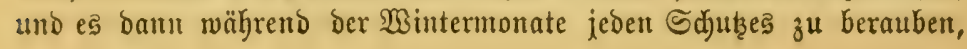




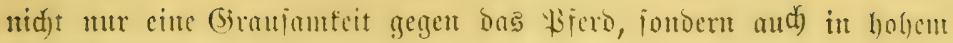
(Jirabe id)äblid).

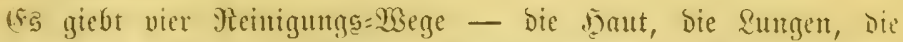

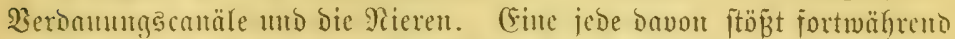
Stoffic aus, deren Berbleib in Sujtem bem Thiere meijt jüblid pein

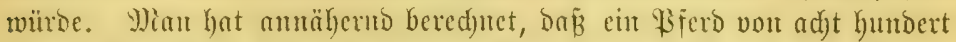

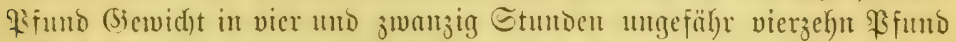

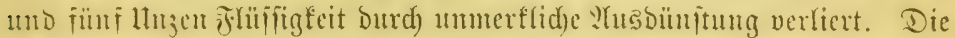

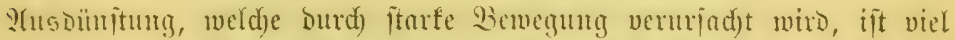

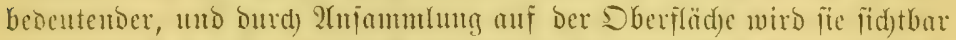

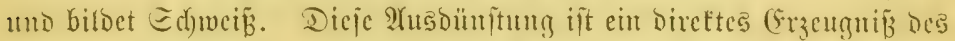

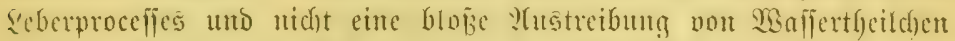
Durd) Die Sant, wie vielfad) angenommen wirD. Wei cinen Piferbe, Dent Das Jaar abgeichnitten, wirb bie Jaut leidyt falt werben, bie Blutgefäje

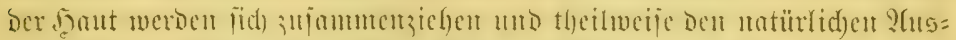

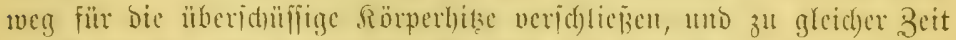

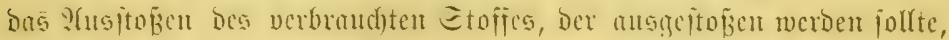

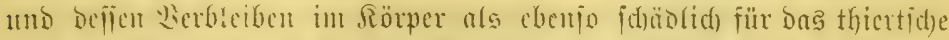

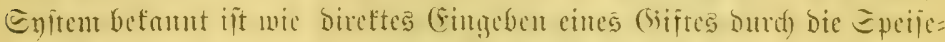

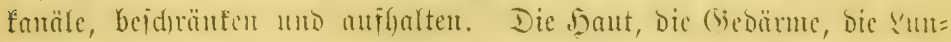

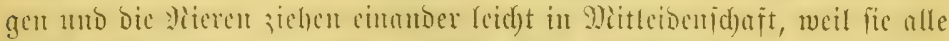

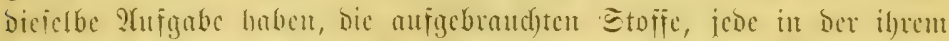

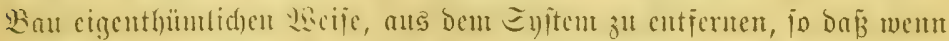

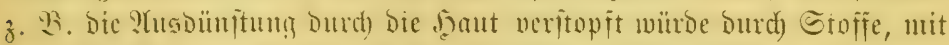

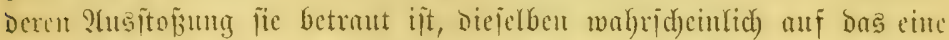
ober andere Der genamten Drgane gemorfen mb Dexen Funftionen DaDurd) geitört werben; utD went cus dericlben, aus im Eyftem

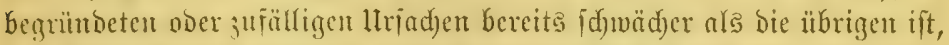
wie ç häufig vorfonmt, io wiro biejes natürlid) zuerit erfranfen. Jut Dieier Beije werden bei ben einen Brerbe bie (Scoürme fich entjünden

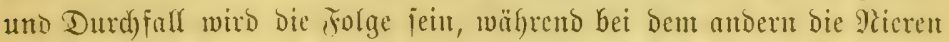

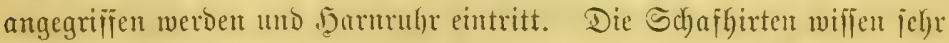

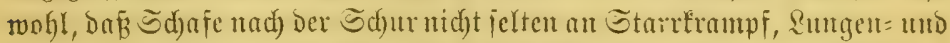
Tarm=(Sntzünoung und citex befonders bösartigen Form von Pothlanf fterben. Die Thicrärzte wiffen aud), Daß̧ Das Befdnteidon ber f̧ante an

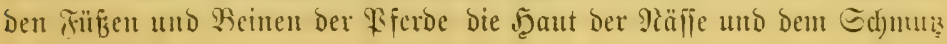




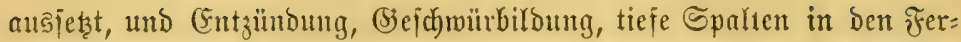

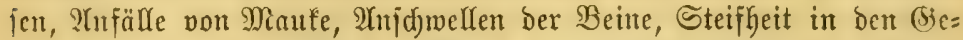
lenten, etc., ctc. veranlä̧t. Wenn berartige patbologilde Buitünoe

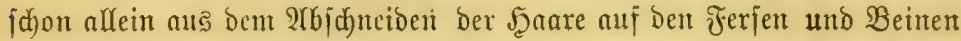
entitehen - mas müffen erft die Folgen fein, wann Der ganze Rörper von

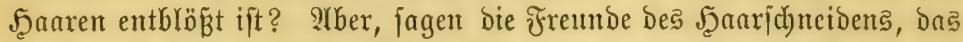

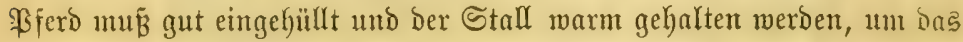

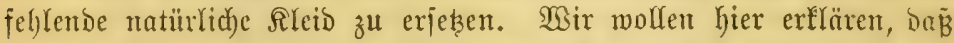
feine nod) jo grobe Babl von Dedfen und fein nod) fo holjer (Sirad von

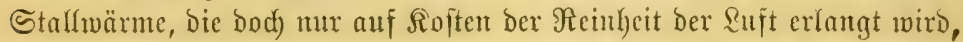

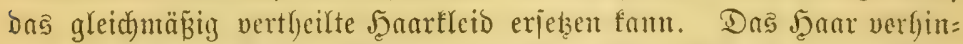

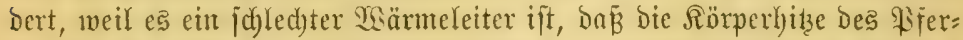

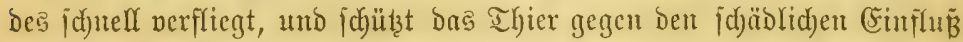

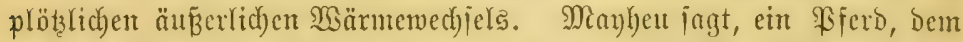

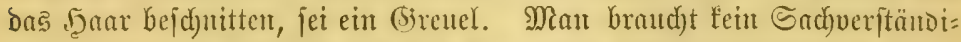

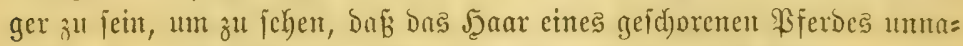

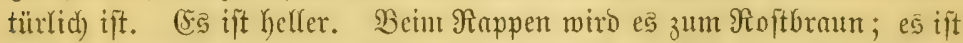
matt uno woiberipenftig, uno hat nichts non ber glänzenden Dberfläd)e,

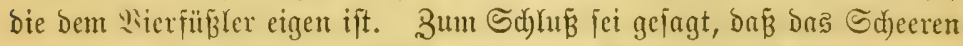
in Ehicago und andereu Stäbten in biejem Winter in jefr beneutenocm

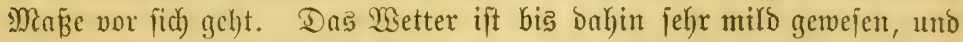
folglidy fint bie Reiben ber armen Thiere nidjt fo groß̧ gemejen. Sonit

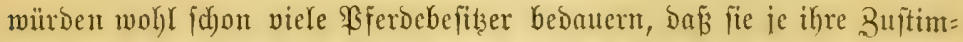
mung zu ber thöridfen Braxis gegeben, bas Pferd jeines natürlidjen Sdukzes, Deç Ђaartleideș, zu berauben.

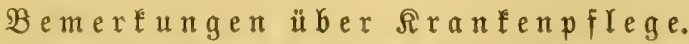

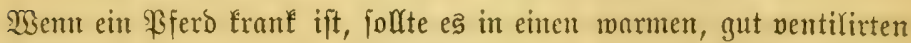
Stall gethan meroen. Nie, went e马 irgeno zu verfindern ift, follte ein Bferd in einen Reller-Stall, eimerlei ob es gefund ober fraut ift, gebrad)t werben. (Siicb ifm niel \&uft - bie ift billig. (5jieb Deinem franten

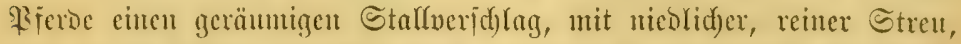

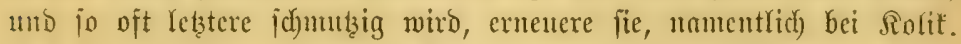

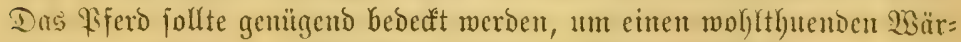

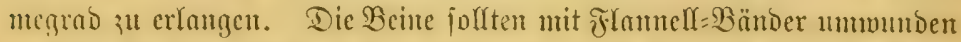
merist, bie von Beit zu Zeit abgenommen, und nad)bem man bie Beine 


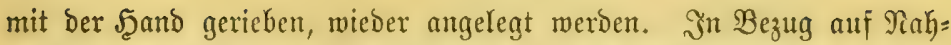

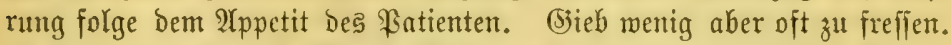

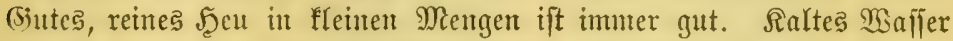
unb Şeuthee jollten nid)t vergelfen werben. RTeie-2Yufguß ift in ben mei=

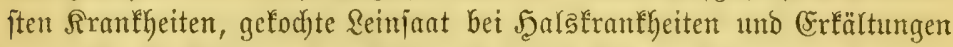

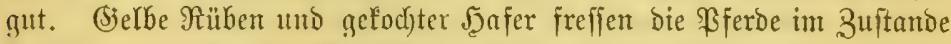

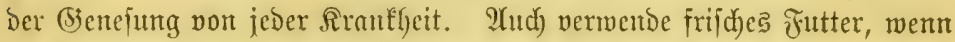

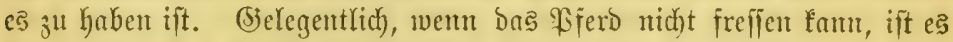

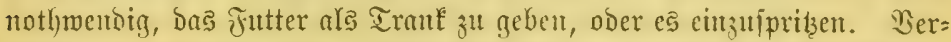

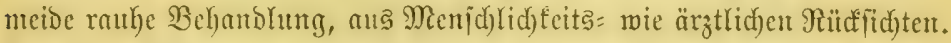

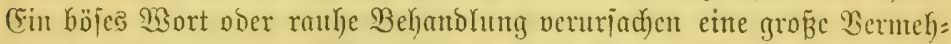

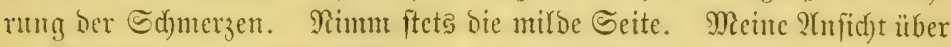

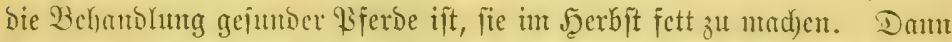
finto fie halb über ben MSinter hintüber, wern man fie, wie es ftets geides hen jolfte, in ciutem wormten Staffe hält. Berjudje bics, und fiteb, ob Du nidjt Dein $\mathfrak{B}$ fero mit faft ber J̧älfte ber jomft nöthigen Menge Futter burdib ben Winter bringit.

\section{Derzu ftramme Spannzügel}

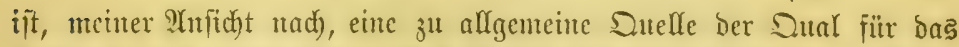

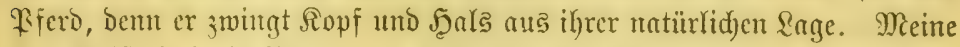

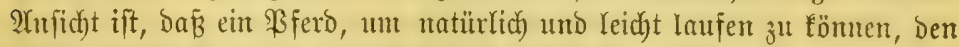
frcien (Biebroud jeines Ropfes und Salies haben jollte. Daun mur ift

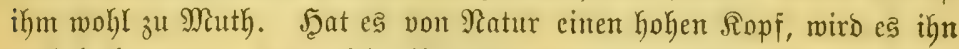
aud hooth tragen; went nidjt, ift alles, was man burd) ben Spanntriemen erreid)t, groß̧e Quaten für ifgn. (Eintge befanpten, fie gebrauchen ben

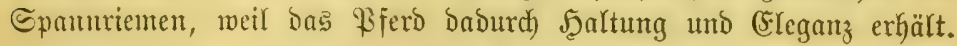

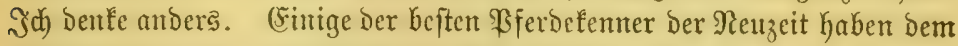
Epannriement unb namentlich) Dem über ftarf angeppanten, mit Fleinern

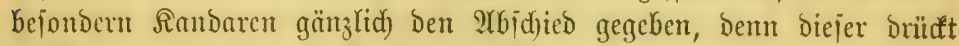
bireft gegen bie obere Badfe ober bie Maulwölbung und wiro bei anthal=

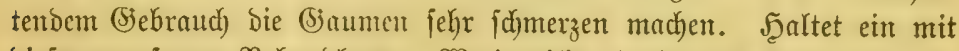
biejer graujamen Bebantołung. Wer's nidjt glaubt, bå̉ ę graujam ift,

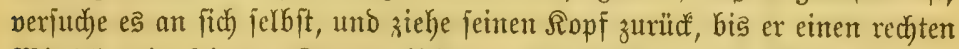
Minfel mit feinem Rörper bildet. (Er wiro bann nidht mehr ent= ftellt fein, ars cin $\mathfrak{B f e r b}$ in ber bejdriebenen \&nge. Seder \$ferbebefitzer 


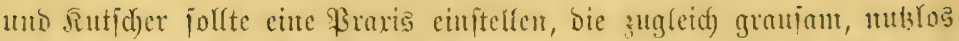

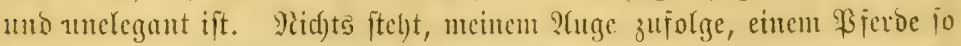

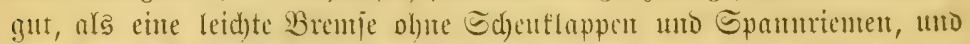

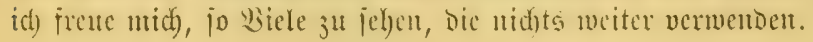

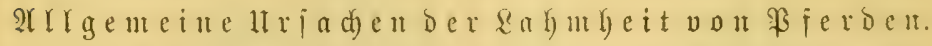

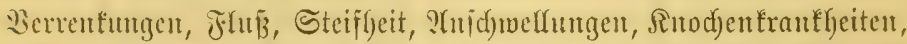

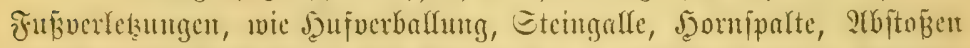

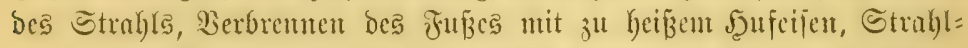
fäule, Struflfrebs. Sd)led)t paffende Summets mad)en die Ed)ultern

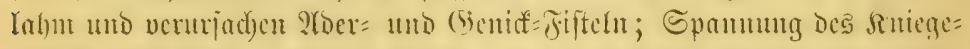
Ienfes mitro Durd) zu lange Beluen utb ju niebrige Şaten verurjad)t.

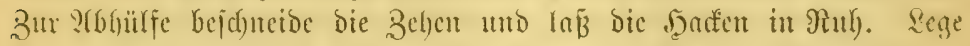

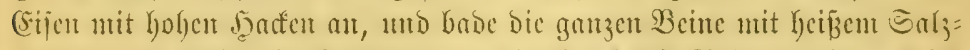
wnifer, und reibe bie Selgnen gut mit Plad Dil Riniment ein. Dies

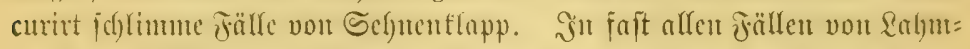

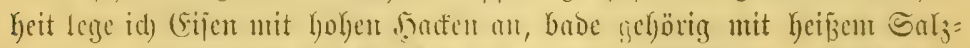

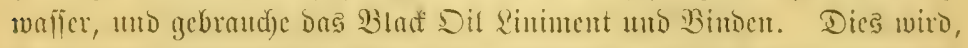

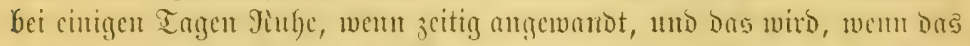

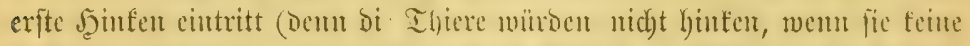

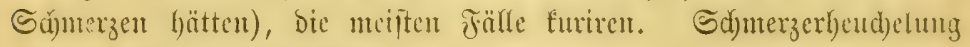
fommt bein Siferbe nidjt vor.

Der Sejer wird bie verjudeonen Mittel unter ber geeigneten Heber= idhrift futoen.

\section{Srantheit des Sdiffbeing.}

Dies iff einte Rrantheit bes Edjiffbeins, das mit Dem hohlen Theil

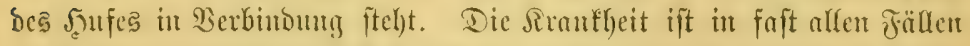
burd) Bujamuenzichung Des Fubes verurjadyt, woburd) aud bie Sebnen,

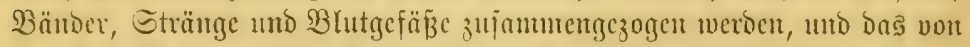

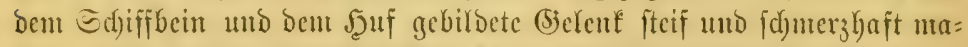
d)en; beiut Raufen wiro bies (Sielente Der RetGung ausgejelzt und es ent=

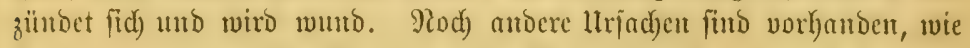

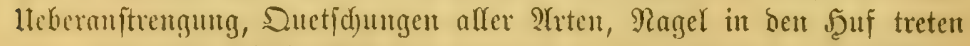

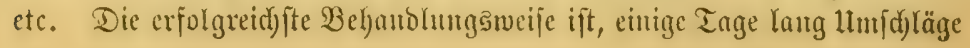


mit Reiniantmefl zu madjen, und im marmen Ealzmaffer zu baben.

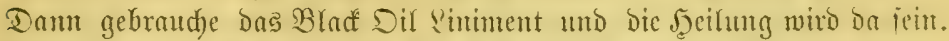
Dies nimmt die Sdymerzen fort und Defnt ben Fuß aus; nicntals jiefe

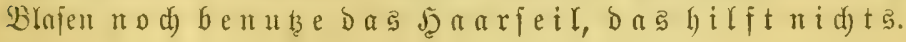

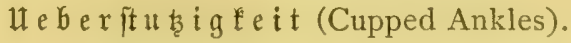

Dies mirb burd) !leberanjtrengung bes Feffelgelentes verurjad)t, und ment man nidyt fofort Danad) fieht, werden bie Sehnen und bैänder

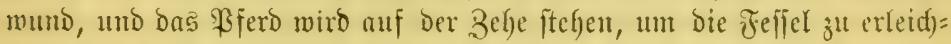
tern, und in Folge bavon weroen bie Sebnen fidh jujammenziel)en. Die Behanolungsmeije ift zuerit (Eijen mit hohen Cisjpitzen anzulegen, Dam

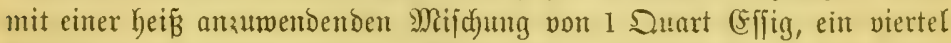
Bfund Ealpeter und eine Ituze Wermuth zu baden und cine jefre ieite Binbe anzulegen. Wenn fofort angemnot, wirb bas \$jerd in furzer Beit wieder wohlauf jein.

\section{Rahmbeit im S}

Diejelbe miro burd) Thagleiten peranlab̆t, weldyes eine lteberipantung ber Sntejdeibe perurjadyt. Die bie Sdyeibe ungebenben Bänder thun

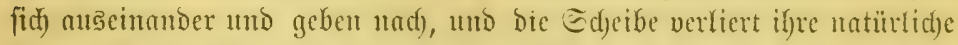

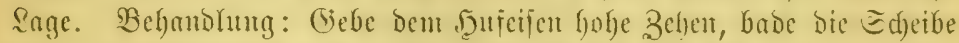
oben anf und nub herum mit ciner fo heí wie möylidy anzmendenden

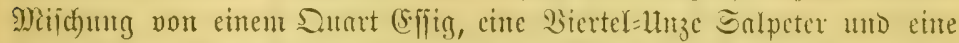

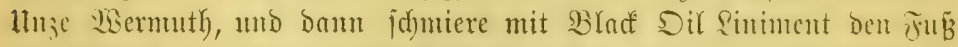

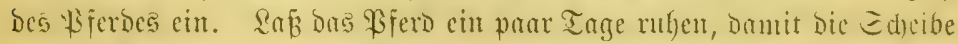

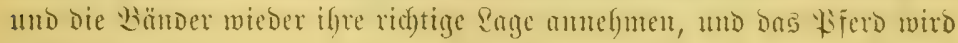
gebeilt fein.

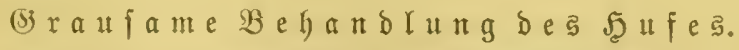

Die Behandung Des Prerdehufes ift cin (Segenftanto, Dent id einge= henoes Gtudium gewiomet Gabe, bem id) habe mebr als breisig Jahre lang Fiferde bejdagen. Wen bie Seler mir geftatten mollen, ihnen

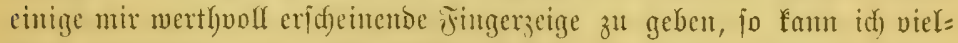
leid)t bas Mittel fein, bem Pferde forwohl rwie dem (5igenthümer einen Dienft zu leiften, unb erfterem bie Dual zu iparen, bie ce jetzt in jolge 


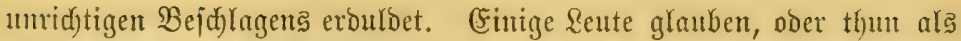

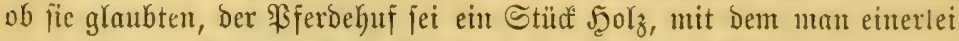

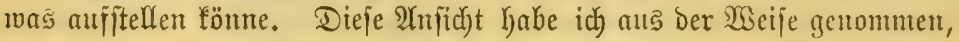

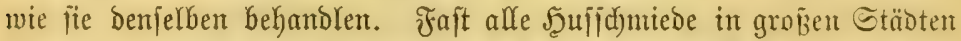

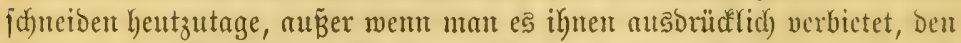
Strahl, die Braces, bie Solylen und die Jeaten ab, lafien bie Bebe

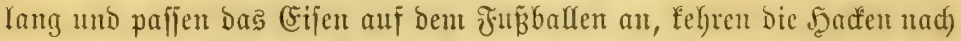

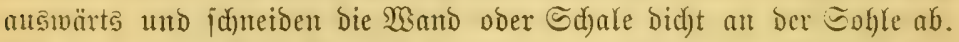
Eic mad)en Das (Eijen bia ganz nad) hinten eingebogen unb brentren ben Jup̉ mit bem heipen (Eijen bis es fitzt. Sie bringen aud) Dornen (Clips) an Beken und oft and) an ber Seite an, und brenten auch biefe

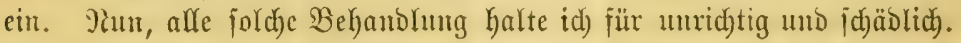

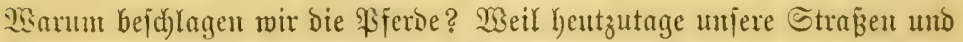

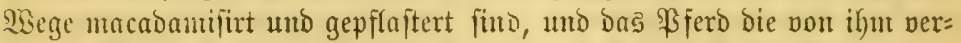

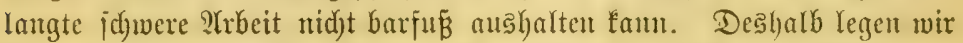

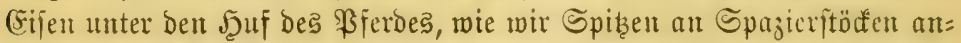

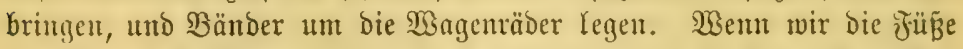

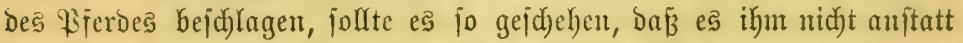

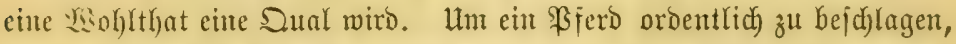

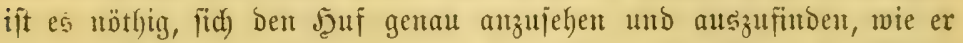

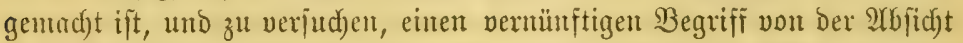
bes Sdjöpfers zu exfangen, als er ifn madfte und ifn zu laffen, wie von

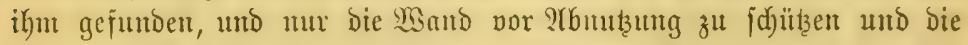

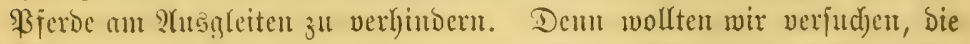
Patur zu verbejieru, jo würben wir, Dente id), Mifberfolg haben. Der

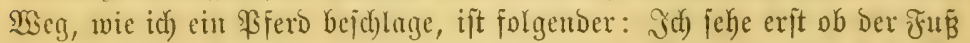

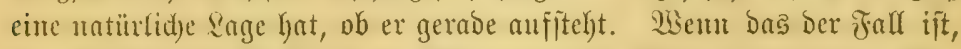

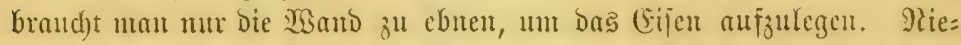

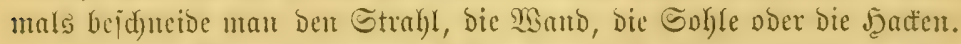
Mau laije bie \$atur igre eigene Irbeit thun. Bufrieben gelafien werden

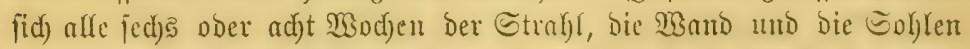

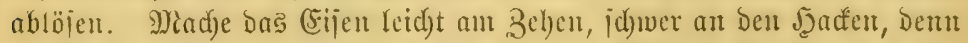

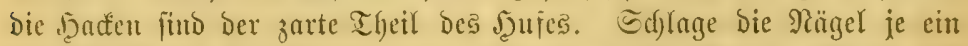

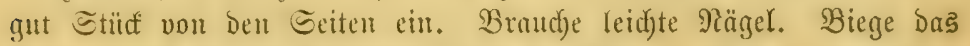

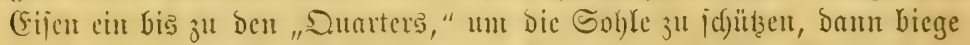

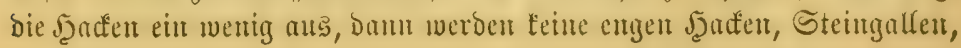


Şornriffe ober Rähmuntgen entiftehen. Frefie bas Gijen talt an und

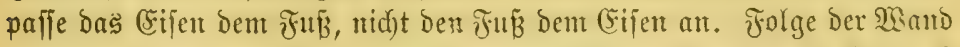
genau. Madje bas (Eijen jo breit wie möglid). Biege bie Şaďen nadh

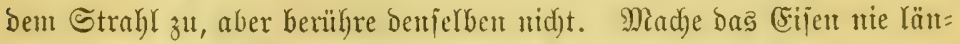
ger als der Fuß ift. Rientals verwende Rutbeijen; Diejelben find unter

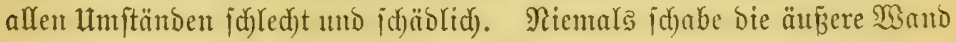
ab, Denn baburd) wiro bie Politur ober (smaille, weldi)e biejelbe bectt,

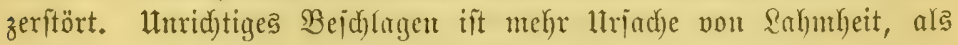

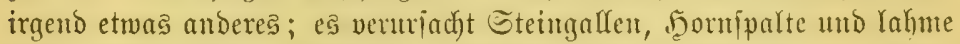

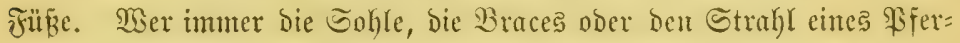

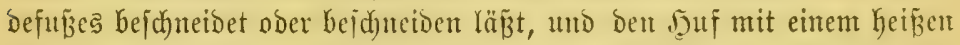
(Eijeu an ben Seiten ober vorne brennt, madyt fid) einter (5raufamteit

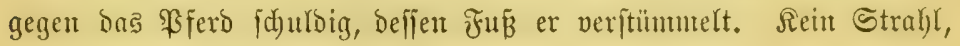

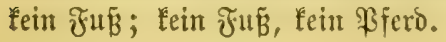

\section{$\mathfrak{B}$ ferbefpradi)}

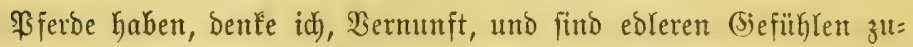

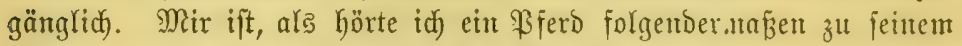
(Figenthümer ipredgen: Sie und idd) wir fint \$sartnere - wir haben jeber unjere bejtimmte 2 trbeit zut verrid)ten, aber id) bin ber fitfle (Sompagnor:

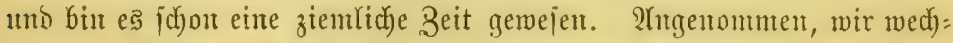
ielten bie \$räzze. Du wirit eingeidjirrt und angefpant unt zieljit ben

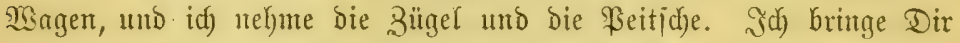

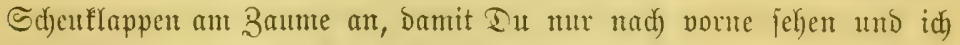

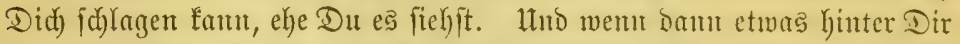

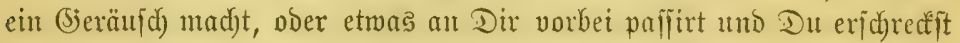

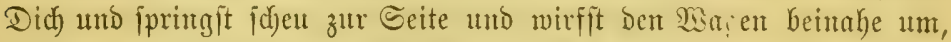

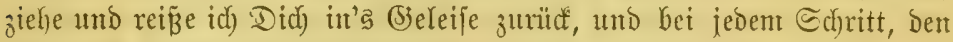

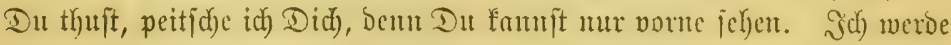

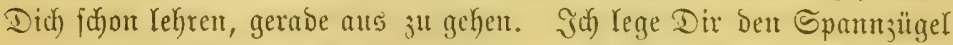

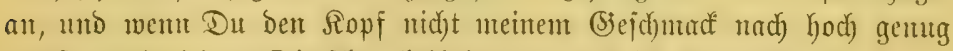
trägit, twerbe id) es Dir fidon beibringen, wemt id) Dir autd) besharb den

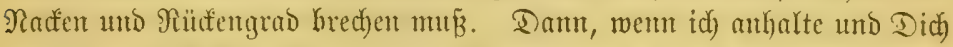

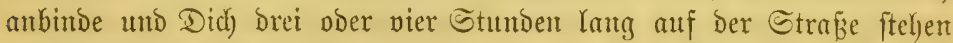

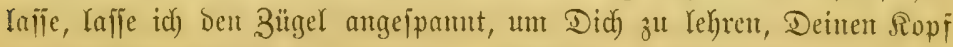

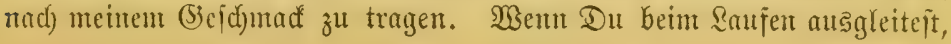




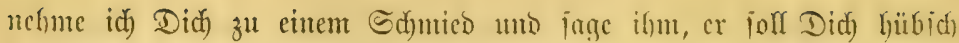

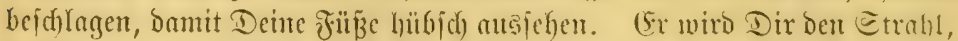

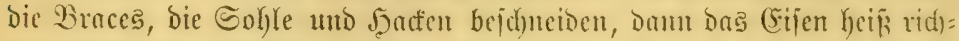

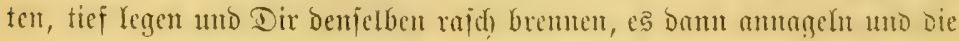

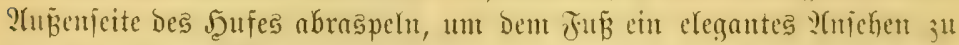
geben, unt menu Du nidyt ftillitef) fut einen Raut von Dir giebit, nerde

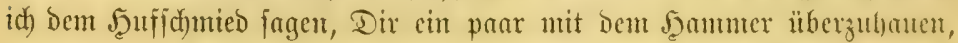

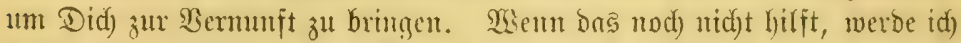
Did) halten, mälrento er Dic Bremie in Deinc Raje bringt. Damt, Dente ich, wirft $\mathfrak{D} u$ fteben und Berunnft aunchmen. Wesu Du hernach (af)m

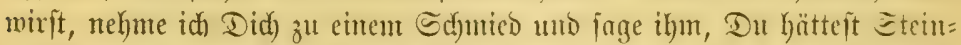

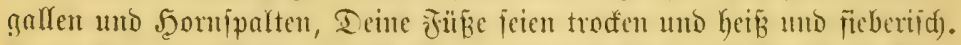

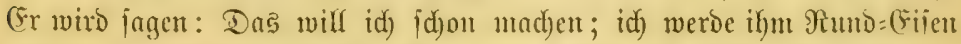

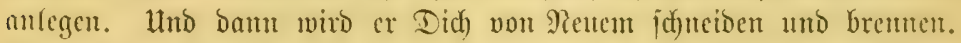
IEem (Du bann nod) nidyt wieber befier wirit, werbe idf Didf jum Thier=

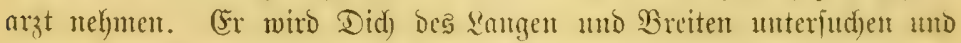

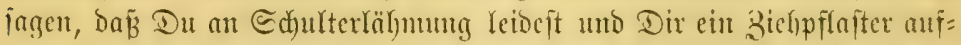

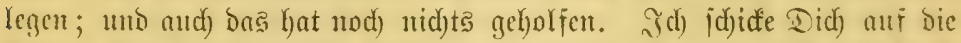

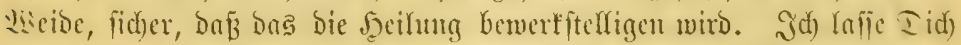
cine Beitlang Dranzen - Du bift etwas befier. Jad) hole Did) wiener

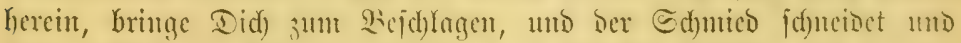

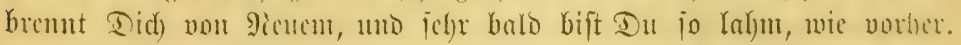

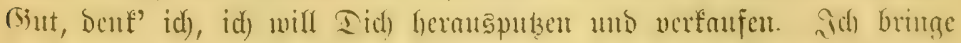

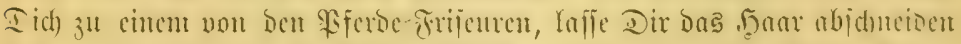

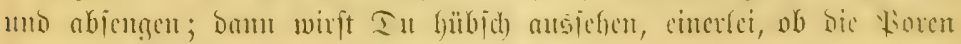

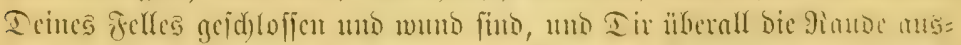
brid)t. Du hajt nichta ju fagen - In bift mein Eigentlyum. Du bijt

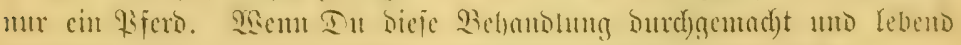
beftundu hajt, wirft Du wiffen, was i(t) burd) Did) gelitten babe.

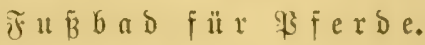

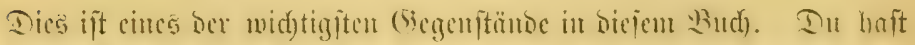

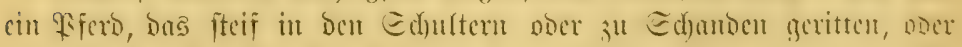

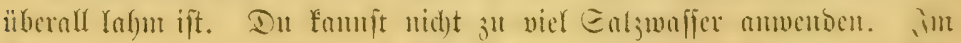

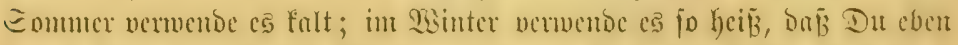

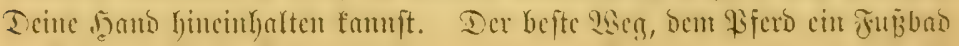

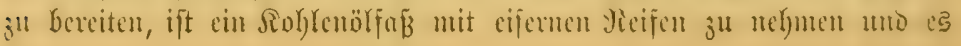




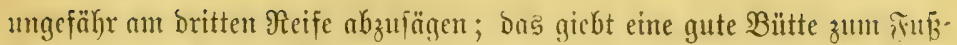

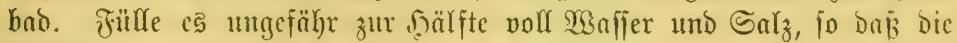
Flüfingteit cine Rartoffel trägt; ftelle Dein \$iferd in einen Stall in bie

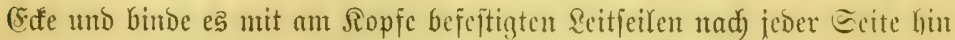

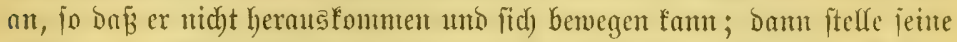

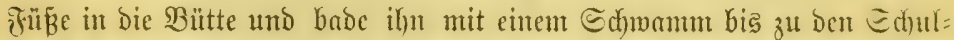

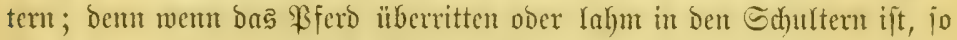
iit es lalum bis auf ben Jyuf himunter, weil bie Musfelitränge von ben

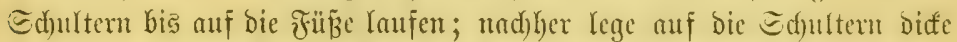
Dedfen un ummidfe bie Beine mit wolfenen Binden, um biejelben in Eanweip zu bringen. Dies ift faft unentbelyrlich in jebem Stalle, zum

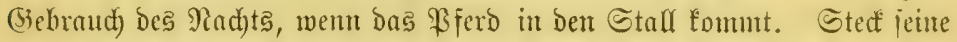

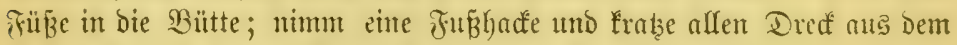

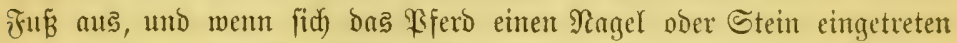
hat, wirft Du ifn fidker finden, uno zugleidy wirft Du Dem Juß Feudtig=

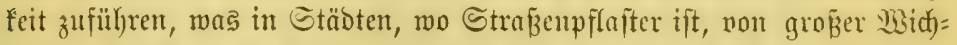

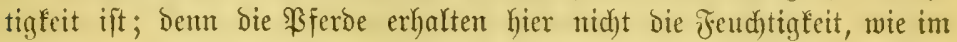

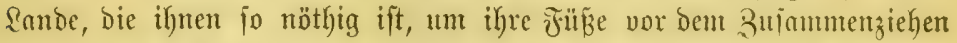

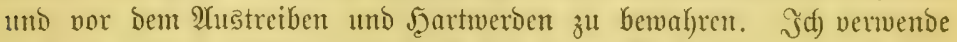

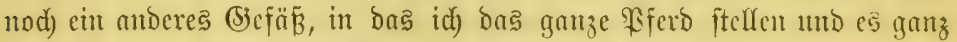

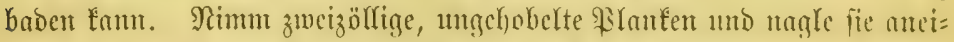

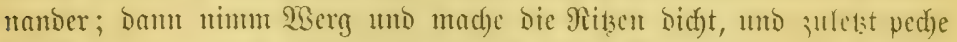

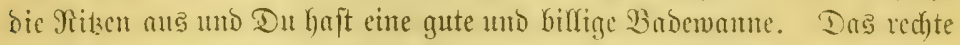

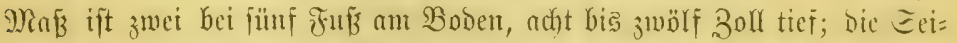

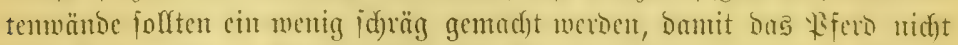

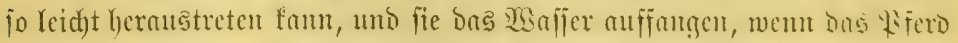

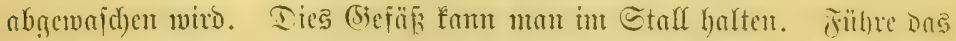

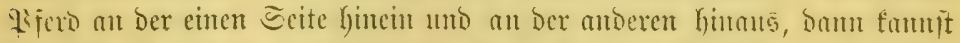
Du um es ferum gelangen, un is zu baben. Biratd bies, und Du

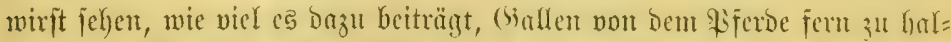

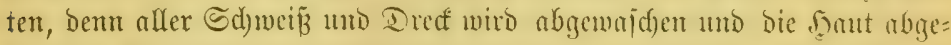
härtet. Bernentoe Salzmafier gerabe wie im andern Fall. (Ss gicht nod)

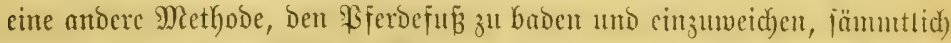
vermittelft des Bandeftiefela. Cinige nelymen Reder mit hölzernen Bosen; andere cin Drathgeflecht, in bas cin Edwoum gelegt ift. (5iegen eritere hate

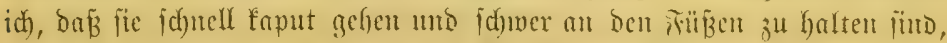
gegen bic Keţteren, Da 


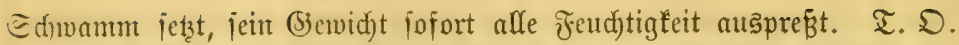
Furlong in Sficago veriertigt jek̨t ben einzigen vermünftigen Stiefel, ben id) geieken habe. Derielbe iit aus biegiamem (5ijen verfertigt und po eit=

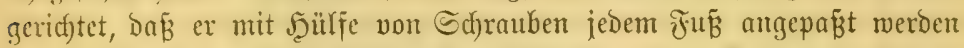
fam. (5r ijt bauterbajt, billig und mafferbidht, und wirtjam gegen Stein=

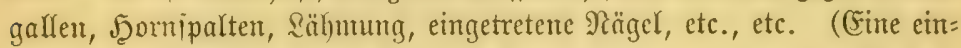
gehende $\mathfrak{B}$ ej Mache ente Stobe bamit.)

\section{B o f i ge $\mathfrak{B}$ ferde und $\Omega$ ut $\{$ der.}

(Finige Reute glauben, Daß̧ es Siferbe giebt, bie von Ratur bodig find.

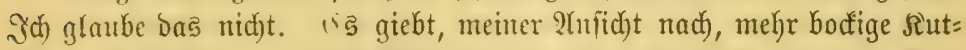

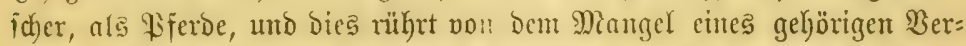

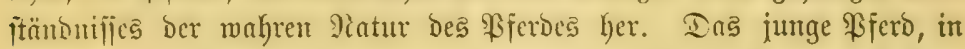

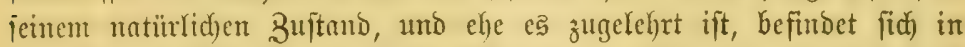
Ifnmiffentheit über bas, mas ber Menjod von ifm verlangt, und mú

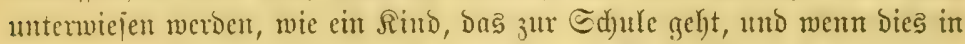

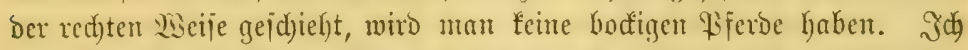

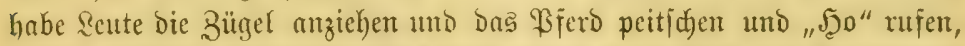
uno bie \$eitiche anmenoen und baffelbe Ding thun jeken, um fie vormärts gehen zu madjen. Dns ift bod) nid)t rect)t! Wie fam cin \$fferd wiffen, was Du von ifm willit? :!noere laben mebr auf, als bas wierd zieken

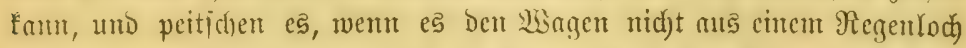

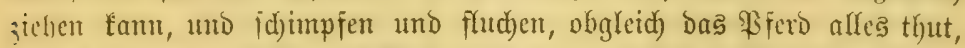

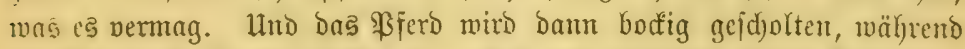

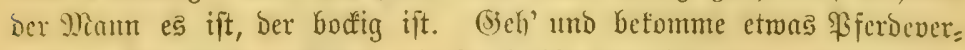

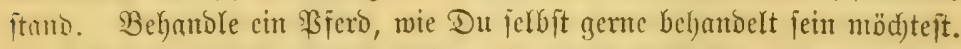
Ient Dir Du jelbit würbejt mübe und jetstejt Dich hin, um zu ruken, mo Deir Jeen föme und thäte Dred in Deine Dhren ober mbute ein Simbel Strol) und jündete es an, um Did) sum Yufitehen und arbeiten 311 buvigen. Was würdeft Du benten ? Du wïrbcit jefyr gencigt jein,

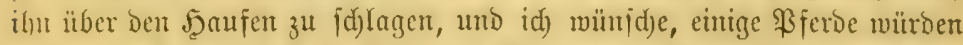

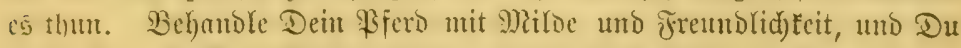
wirit Eeme bodtigen \$ferde baben. Jaalte Dich jelb't im Baum; labe ctmis weniger nuf. Rlopf' Dem Brerbe cinige Mrale freunblid) auf Den

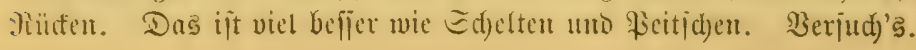




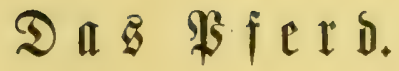

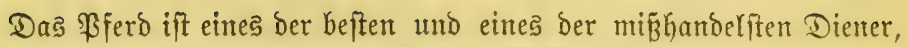
welde der Sdjöpfer uns zur Benuţung gegeber.

Bon ber Beit an mo e马 genommen und an bie 2Trbeit gejtellt ober ein:

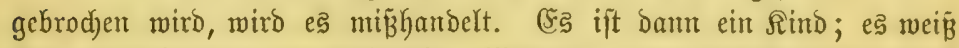
nidft, was Du von ifm verlangit. Wem Du ifm bas (b)ejdirr anlegit

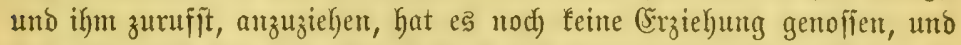

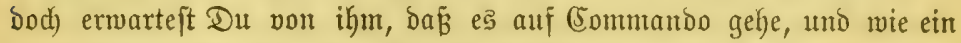

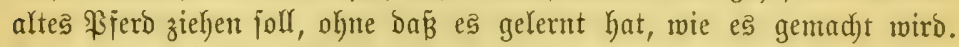
und wenn es ridjt gleid) gefjordet, wirft Du zornig und nimmit bie \$seit=

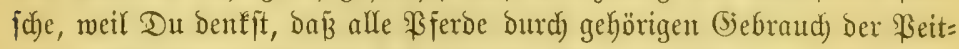
ide gelehrt werben mülfien alles das zu thun, was Du von ifnen ver= langft.

Dies, Dente idf, ift eintes ber idflimmiten Fehler, Denn wie fann bas

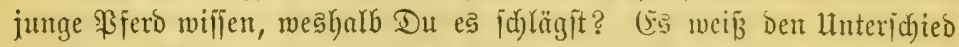

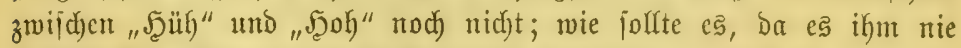

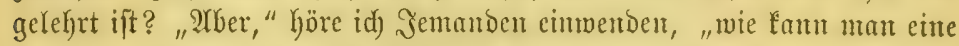

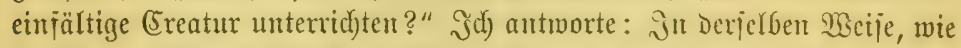

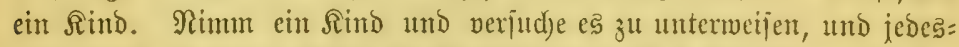

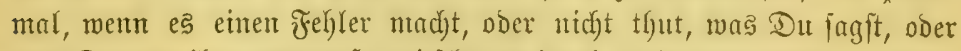
was $D$ u vou ifm erwarteit, peitfiche es burch, und was wiro die Folge pein? Das Rint mürbe itets bie Feitjoje erwarten, und wem Du fie

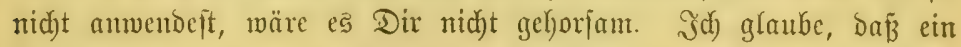

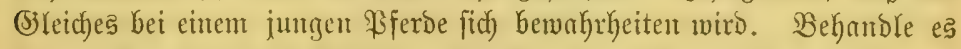

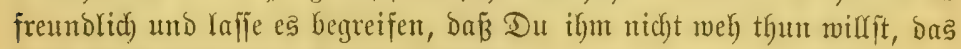
wirb Dein gehorjamer Diener merben.

Id) finde bics bewahtheitet beim Bejd)lagen junger Bjerbe. Waem 


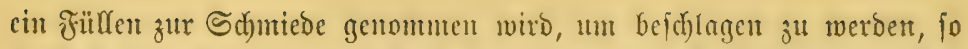

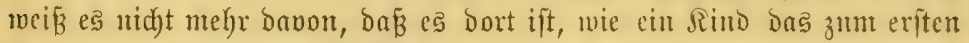

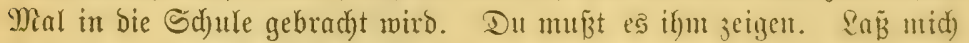

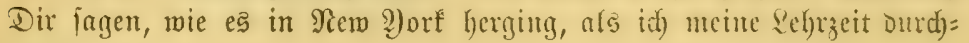
machte.

Wentu ein Fitflen nad) Der Sdhutede gebrad)t wurbe, um zum erịten Mal Bejulagen zu merben, jo mu[ste Der (Eigcntbüntr vor allen Dingen ein Duart Bramtwein bejorgen, che Die Sdumiede Das Fitllen angreifen

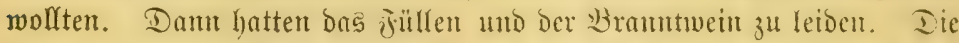
Tortur beginnt. Das Füflen ift an eitrem ifun fremben Dot; es hat

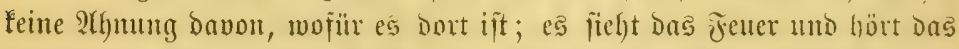

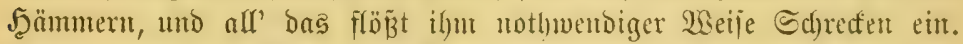

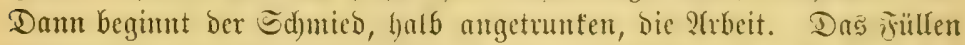

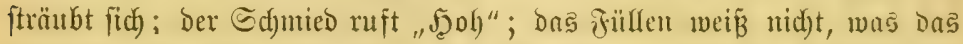

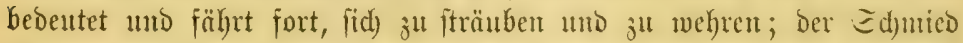

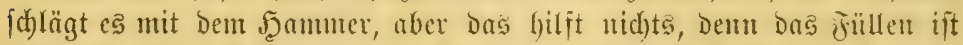

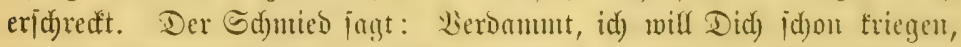
uno legt ifm bic Brempe an Die \$iaje, un brei ober vier ftnte Wiämer halten es, wälrend der Echuticd die (sijen muflegt, — wic, ift diejent eimerlei; irgendwie, mur um Das jülllen log zu merden.

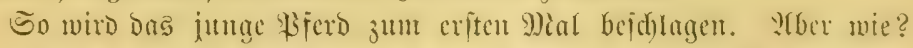

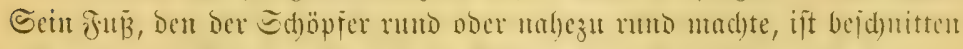

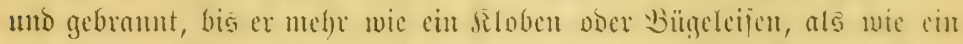

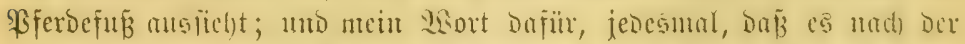

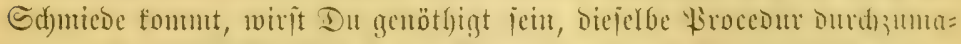

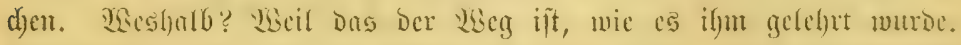

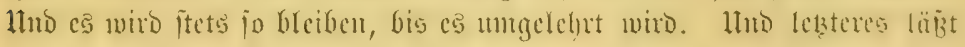
(iic) thutt.

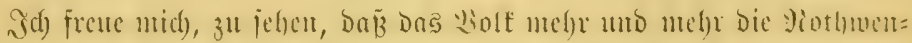

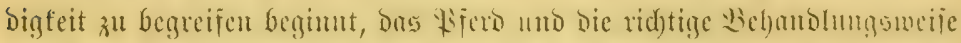

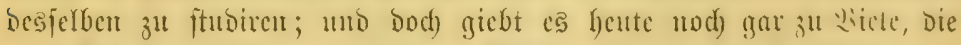

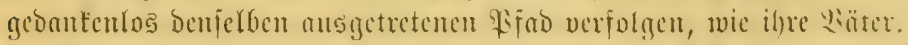

孔d) will (5ud) jagen, wie cin junges

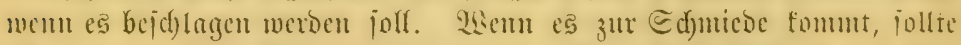

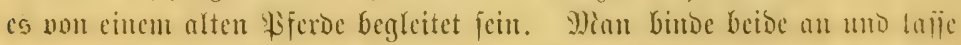

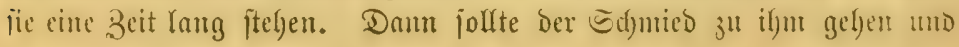




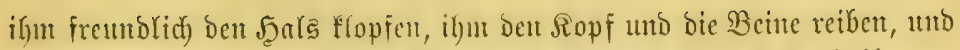
in menigen Mimuten wirb bas \$ferd Dem Ed)mied faft alles mit ifht zu

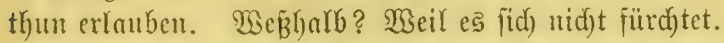

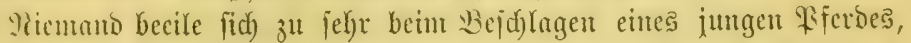

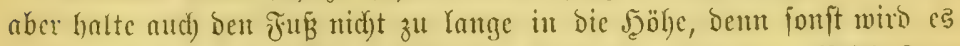

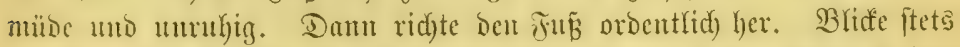

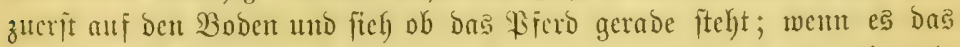

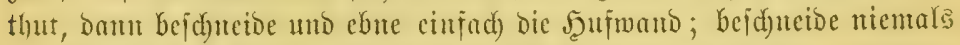
Den Straht ober bie Braces, ober bic Soljle, bent wem Du bas thuft,

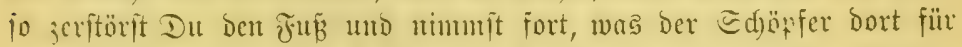

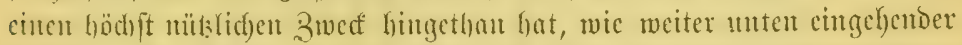

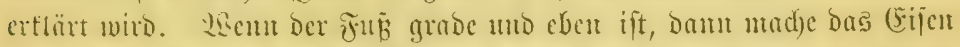

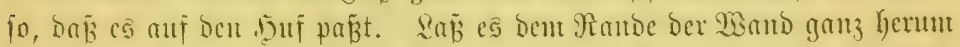

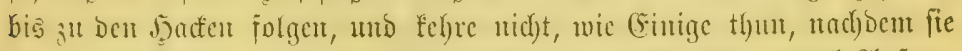

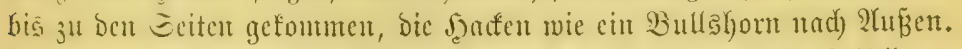

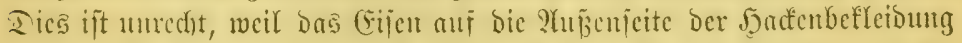

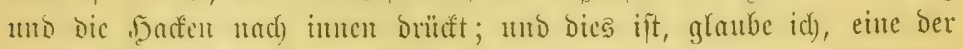

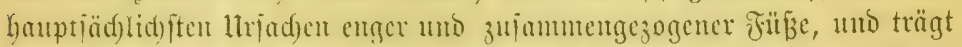

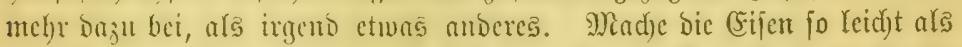
möglidg, biege fie nad) untent ein bis urabe ben 5 gaffen; bant madje fie flad) ober ein wentig nad) oben gebogen. Forfs Du (Eisipitsen verfangit,

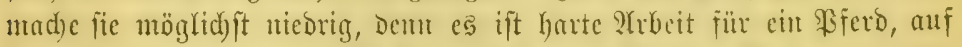

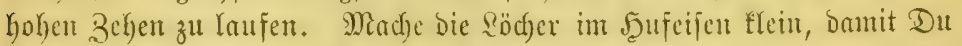

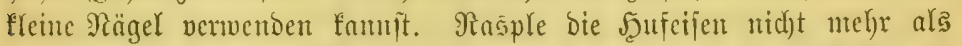

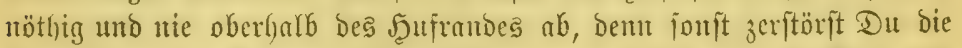

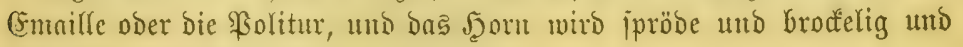
wiro fid zufaumenzieben und toot werben.

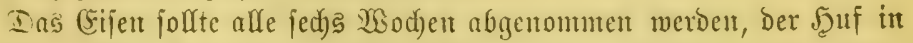
geföriger Weife beid)nitten unto bas (Eijen wieber aufgelegt werben; Dent

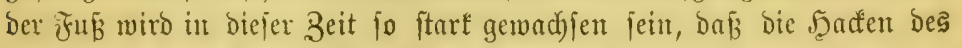

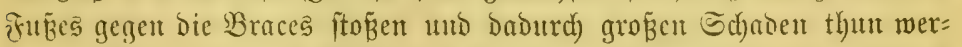
beıt. "2(ber," höre id) J̌emanden jagen, "verYangen Sie von mir, baß

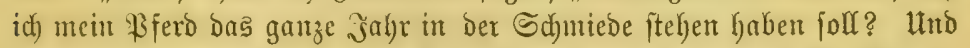

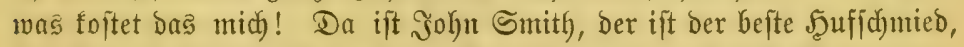

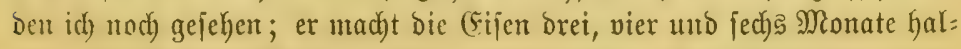
ter. (Sx ift meen Maun!" Wir werben jehen, ob er es ift ober nidjt. 


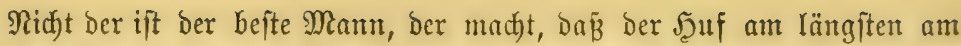
Fub bleibt, fondern Der, Der ben Fü in guter Dronung hält und Dnढ Bjerd Keidyt Iaufen madjt.

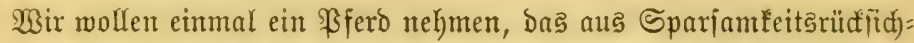
ten jeine (Eifen lange angehabt hat, unb wie funden wir es? Cs ftolpert;

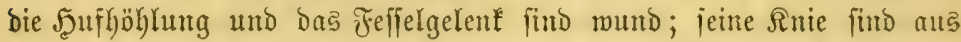
bem Siclent; ; es geht ftolpernd einker und in furzer Beit merben bie Bein=

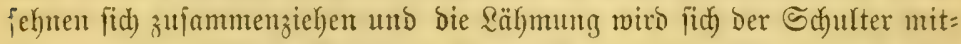

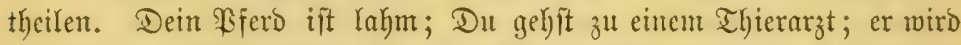
Das Bferd zur Yrder laffen, ifm Bugpflafter anflegen und es in ben ङtall idjicfen, und Dir zebn ober jtwanzig Dollars Dafür abforbern. IInD Du giebjt Did) zufrieden, weil Du 2rfes gethan, was Du thun founteit. Du liejit zum Doctor, Dem unwij̄enden Seufidumied, anjtatt ber Der= unnjt (jebjör zul geben, Die verlangte, baj Du Dein Piferd oft bejd)lagen und Den Fuß in gutem 3uftande erfalten jollteit. Dein \$iferd ift bahin. Wer ift Dein Freund Jit bas Sparianfeit?

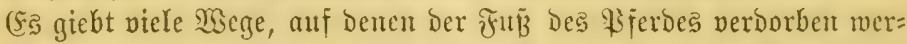
ben faun, wenn wir alles glauben roflen, was über Den (S) genftnto idjon gejprodjen und gejdrieben ijt. (Einer jagt jofort, went ibu ein

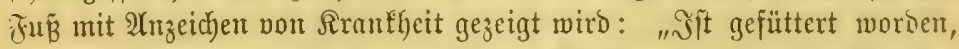

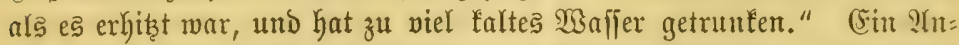
berer: "Es hat zu viel auf einem harten Boben geitanden." (Sin Drit=

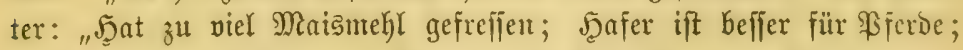
Mais giebt zu viel Şiz̨e." arber ber edjte Bierbefenter ruft jofort aus: "Es hat's Donnermetter gehabt," wwas auf gut Deutid heipt: (5s hat zu viel gezogen.

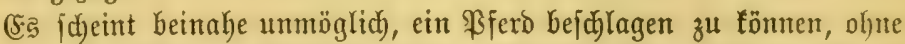

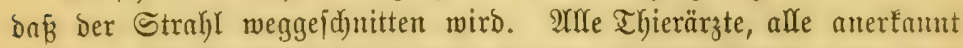

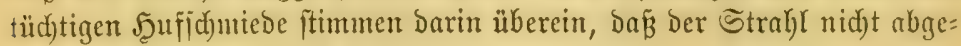

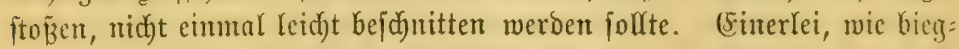
fan und meid) Der Strafl ift, bejdneide ifn an affen Seiten glatt, utD in zwei Tagen miro er troden und hart wie Rnodyen fein. Man fann eben jo gut alle Blätter von cintem Baum Geruterifdneiden und erwar= ten, Dá̉ Derjelbe fortfommen foll, wie ben Strahl abjdyneiden und cinen

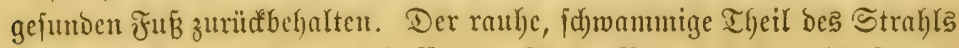
ift für ben $\mathfrak{B f e r d e b u f , ~ m a s ~ d i c ~ B l a ̈ t t e r ~ f u ̈ r ~ b i e ~} \mathfrak{B a ̈ u m e ~ f u n d ~ — ~ d i e ~ \& u n g e . ~}$ 


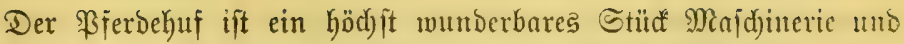
erregt weit melyr Struten und Bewumberung, als bie jüüe aller andorn

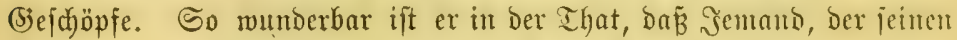
Bau und jeine funttionen nidjt eingehend ftubirt hat, faum glauben

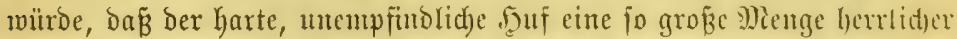

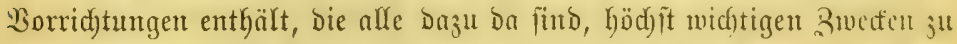

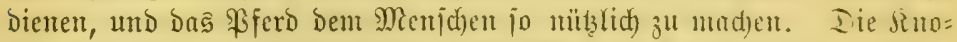

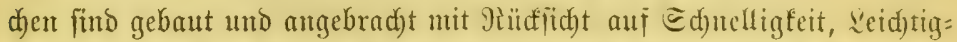

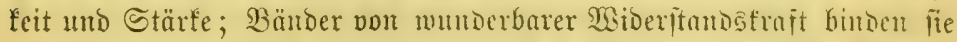
jo feft zufanmen, Da $\bar{B}$ eine Tremung fait abjolut unmtöglid) iit, wäl)=

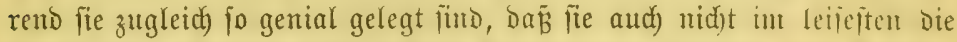

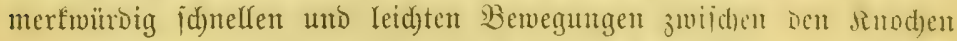

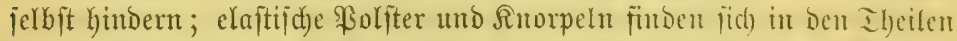

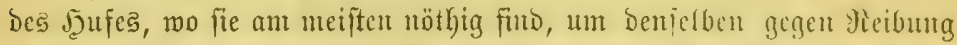

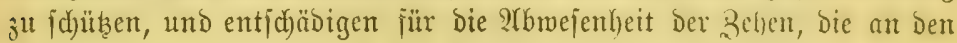

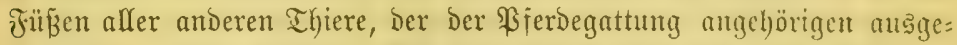
nonmen, gejehen werben. Trfe bieje Theile find mit einer tebentigen

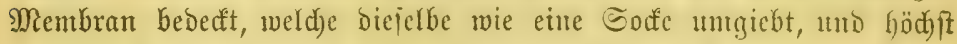
empfindlich und auberbem mit einem reidjen Nieţwert ber feinjten Blut=

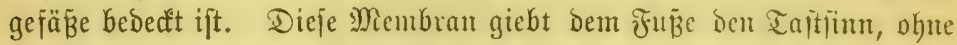

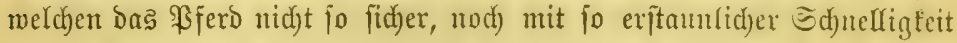

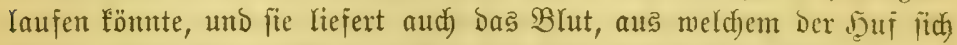

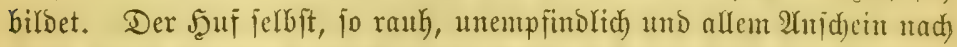

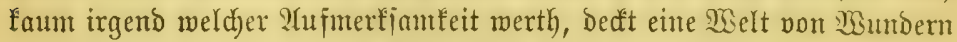
auf, went wir bie in feittem Şntrern zu finbenten eridjöpit haben. (s.

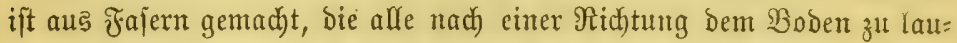

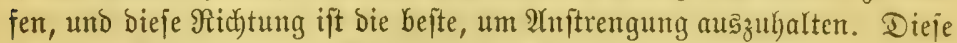
Fafern find auperorbentlich fein und am härteften und wiberftandşähiga ften an ber äuß̈eren Oberflädge; jebe Derjelben bildbet eine Stufe, Die aue

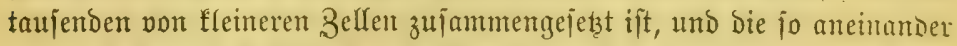
gelegt fino, Daß̧ fie Stärfe und Dauerhaftigfeit verleifen, während bie

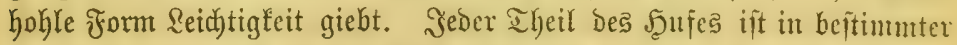

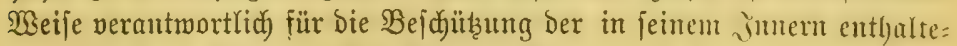
nen lebendigen Theile. Die $\mathfrak{W}$ a n b ift ber Theil, Den wir jehen, wem bas Pferb feft auf bem Boben ftelyt. Eie wädjit von oben herab, von

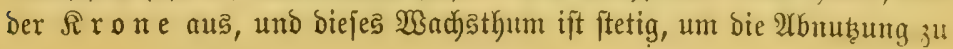




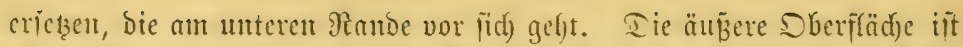
im natürlidjen Buitande prad)twolf, bidyt und gratt, und ïberbaupt ijt bie

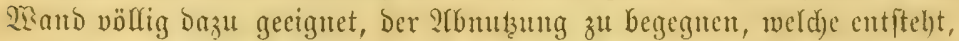

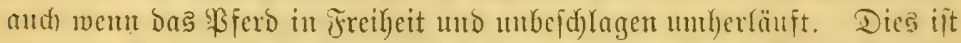

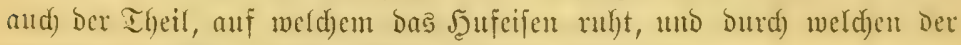

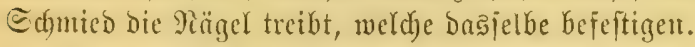

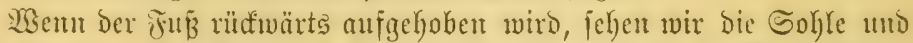

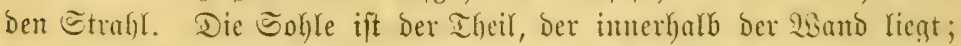

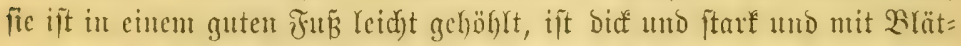
tern non Kojen Jorn bei Fierben bedeeft, Die nod nicht unter Bebandung Des Erfinticoes gewejen find. Der Strahl ift ein weidyes, Dreiediges Stür Jorm, bas in Der Mitte ber Eohle, ber Datfe zu liegt. Derjabe

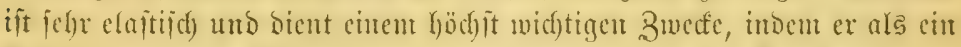

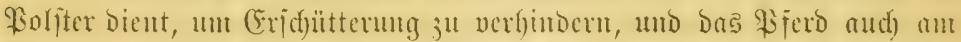
Zusgleiten verfindert. Die Eofyle, ber Etraht und Der untere Jiano

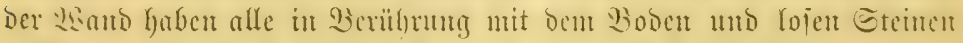

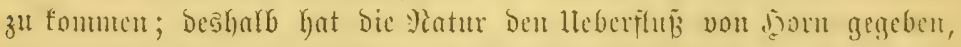

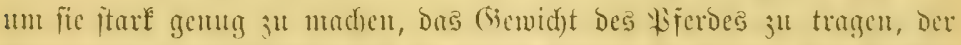

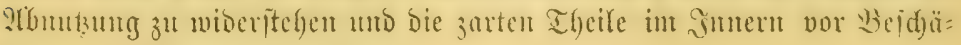

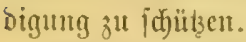

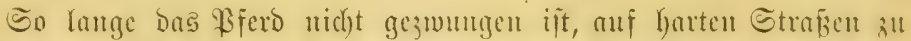

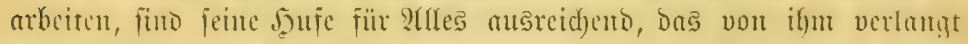
miro. Stber unjere (Sivilifation verlangt, daj wir gepflajterte und maca=

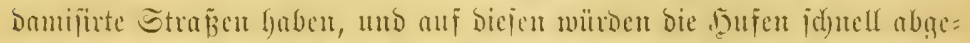

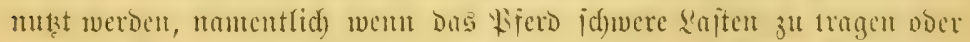

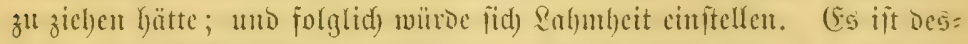

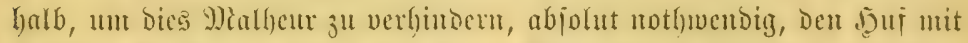

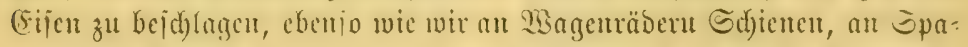

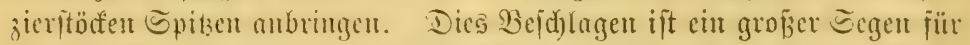

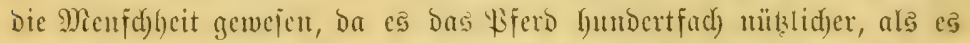

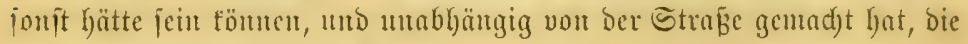
zu betreten es gezmungen ift.

Die 3ahl Der Durf) unvern̈̈rfiges Beid)

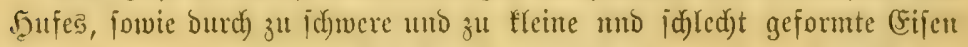
gequälten uno ruiniten Bierde ift mberedyenbar. Der Strabl, bie

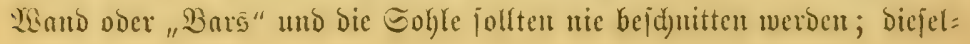


ben blättern ab, wentu fie eine gemifīe und ridjtige Didfe erlangt haben, was ungefähr cimmal monatlich gejd)ieht. Hno ba biejelben mit ben

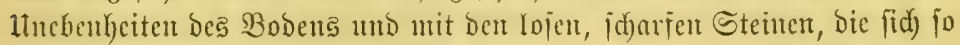

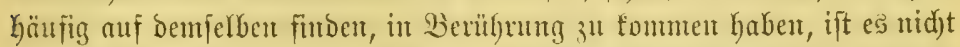

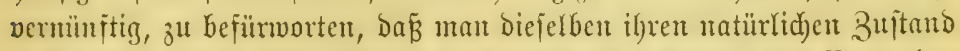
beibelualten läß̈t? Wer immer bie Gohlen oder Braces nder SBars ober

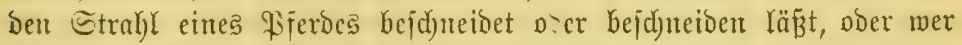
Dornen am (Eijen anbringt, cinterlei, ob vorne ober an ben Eeiten, mad)t

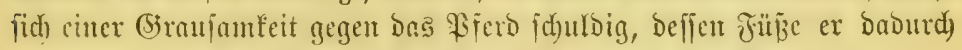

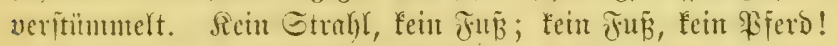

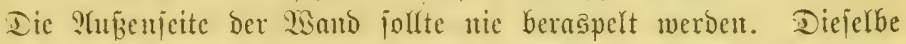
svirb baburd) zeritört, Dünn unt bröfelig. Man jolfte fie fitets ifre

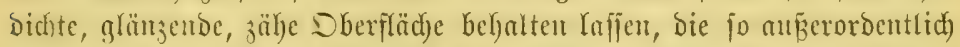

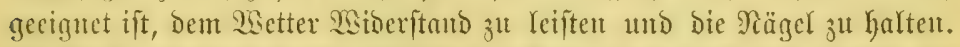

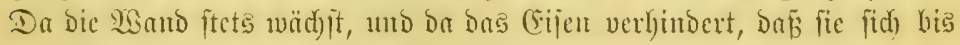
auf ifre natürlid)e Rage abülist, io jollte, went bas alte (Eijen abgenom=

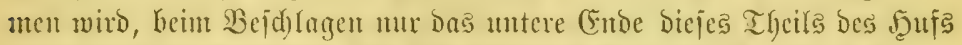
beruntergernspelt werden, bis bas lteberma berunter tift, wicht mehr.

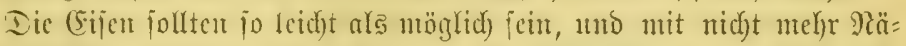
geln befejtigt werdon, als genügt, un fie feftiulyalten; and jollten fie

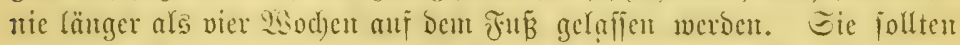

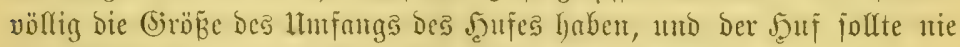

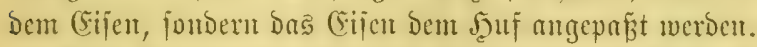

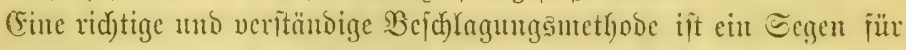

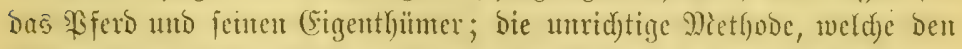

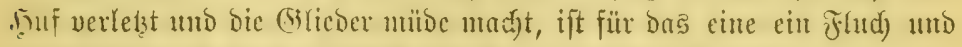
cinc Dual, und für ben mbern ein Derluft und viel Sorgent.

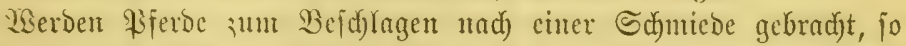

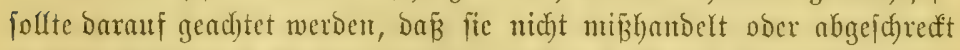

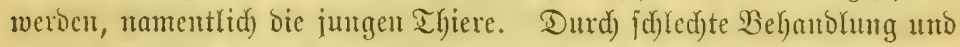
Untgeid)idflidfeit bein Beid)lagen merben fie oft fo furdhtian ober aud)

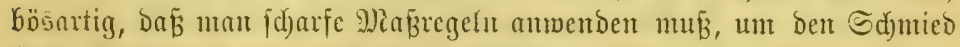
beint Befdlagen vor (Befabr zu idülzen. (Sinige menige freundidde Morte, Rlopfen auf bie Sdylter, Strcideln ber Silicber und ein wentg

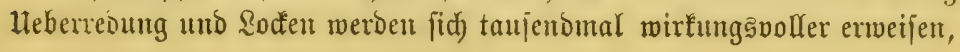




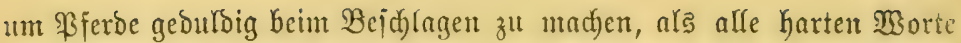
und Flüide, Sd)läge, Bremjen und jonjtigen mneritündigen und eirtes

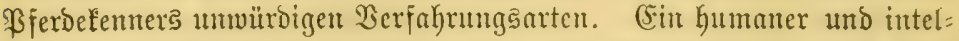
ligenter Şufidgmied ift ein Segen für jencs Sienremmejen; aber einer ber barid ift, nidyt beobad)tet uto uidyt baranf aus ift, fid in jeiner io

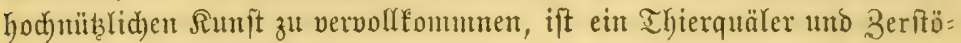
rer fremben Bigenthums.

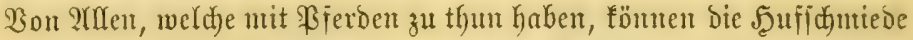
ant meiften zum $\mathfrak{W}$ ohlbefinden biejer guten (Sicjdjöpje beitragen, inbens

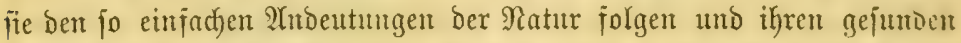
Berftand und ifyr eigenes 14theil walten lafien, anjatt ber Dummen uno

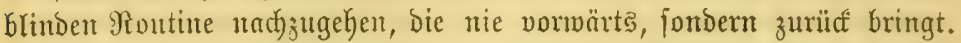

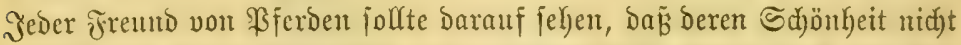

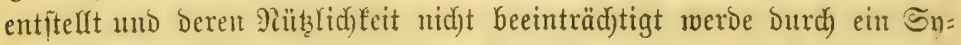

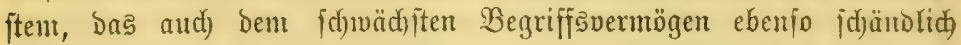

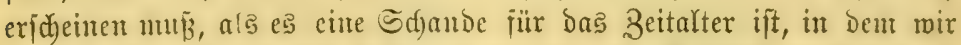

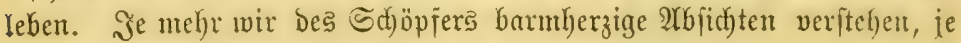
weniger geneigt weroen wir jein, biejelben zu vereiteln.

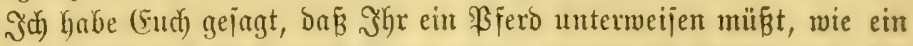
Rind, uno id) will (5ud) aud) fagen, wie. W̧enn ein Füllen zwei bis

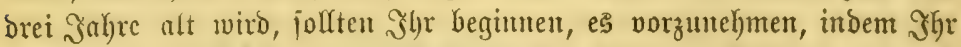

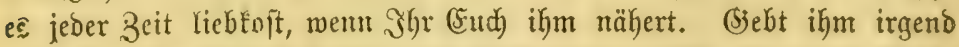
cinen Ramen, es viro bald barauf hören lernen; gebt ifm einen s/ais= folben, etwas Salz oder (Sira马, went inmer es fidc) (Eud) nähert, uno es wirs (sud) fehr bald lieben Kernen. Dann begine man nad) mo nad)

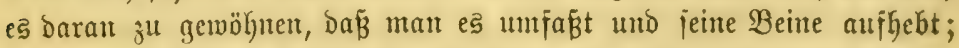
man lege ifn einen Şalfter an und fïlyre eș; bam lege man ifym den Stangenzaum an unt bringe es in Den 5yofraum uno lel)re ifm burch millde Mittel, nidyt mit Der Peitid)e, Dasె Mort "J5o=oh" (Whoa), Das midytigite Bort, Das bem $\mathfrak{B}$ fero gelehrt merben fann, weil, went grabe cimmal etwas nidht in Dromung ift, und man unit ",50=0h" es fitilfitehen wirb, ba eక gelehut murde, bies zu thut, jobald es crtönte.

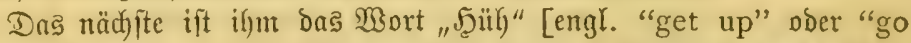
ahead"] zu Yehren. Die Strnge jollte hier cine Wodje oder zethn Tage lang täglich eimmal, aber mur auf furze Beit, vielfeid)t ein ober zwet 
Stumben, angelegt merben, bamit es nidht übermilbet werde. Dann rege ifm volfftündiges (Siejdirr an und laffe es bantit eine Beitlang auj einige Tage im Şof umber ínfen. Dant nimut eiten Baumfloks ober eine Shleife, ipante es baran und treibe es in Syofe unther, bis es ben 3wed des (Siebifiles fennen gelent bat und gehorcht, went bie Bügel angezogen werden; Dann ipame man es mit eitem alten Bferbe vor einen Sdyltten ober Magen und treibe es rangjam, itets in Sdyritt.

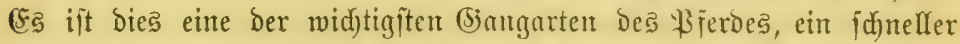

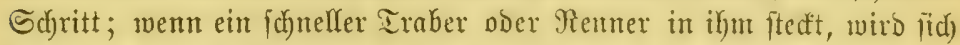
ons jdon von jelbjt zeigen. Nie verjud)e aus eistem $\mathfrak{B}$ ferbe nthr zut

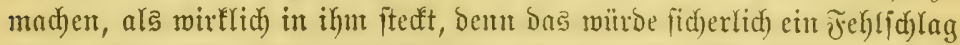
jein. Into laf̆t mid) nod) bies eine jagen: Bei Bebandung junger

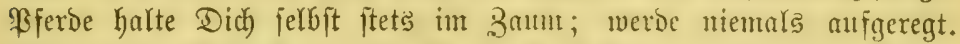

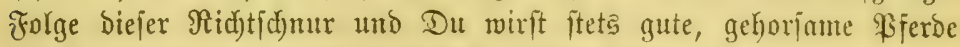
haben, mit Denen Du ficher irgendomo fahren fammit.

Эn Bezug auf $\mathfrak{A r b e i t a p f e r d e ~ i f ̣ t ~ r e i d j l i d j e s ~ F u t t e r , ~ f t e t i g e ~ 2 T r b e i t ~ u n o ~}$

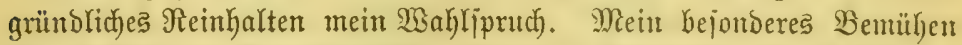
ift, bie Bferde troden abzureiben und reil zu befommen, ehe fie fid) zur গuke begeben. Salte einen (Fimer mit Salzmaficr und cinem Duart (Sffitg Darin ftets im Stafle vorräthig. Babe Damit türbtig bie Bruft,

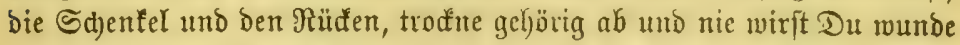
Bferbe haben. Nimm einen Fub̆haten, frabe die Şuje bamit gehörig aus uno majdye fie nadber mit Salzmalier; ftede fie in bas Mafjer und

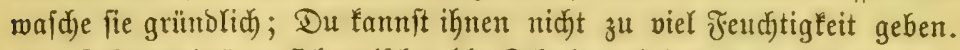

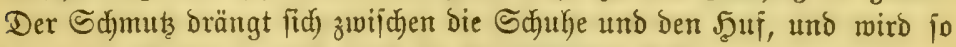
hart, wie (Eijen, folglich mú er ber Fubjohle Sdymerzen verurjadyen;

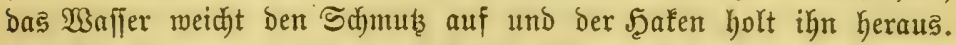

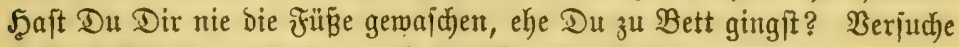
eș beim ßferde und fief) zu, ob e's nicht "Danfe" jagen mürde.

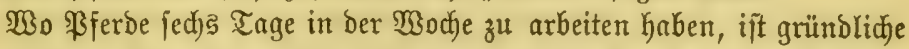
WBartung zu ifrer (Sejunbheit abjolut unentbehrlich. Je fiärter fie gefüt= tert merden, Defto widjtiger ift es, fie zu reinigen. Die Meiften brauchen

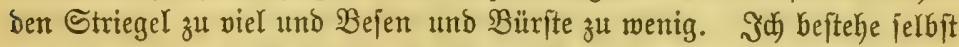

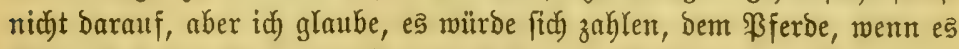
Mittags in ben Stall gejteflt miro, bas ganze (Stejdirr abzutebmen nno 
nidgt in zu grop̧er (5ile zu jein, zum (Efjen zu gelangen, jondern es trocten abzureiben, banu mit Salzwafier zu baben, und nad)ber mit einem Tud je grünolid) abzutrodituen. (5. ift mix fraglid), ob von hutoert Farmern ciner völlig würoigt, twie viel er burch fräntfliche Pferbe no basurd) ver=

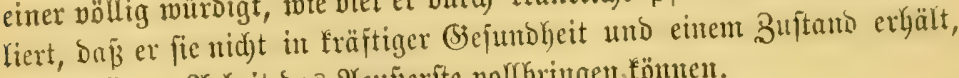
in bent fie an $\mathfrak{A}$ rbeit bas $\mathfrak{A}$ enperfte volrbringent fömen.

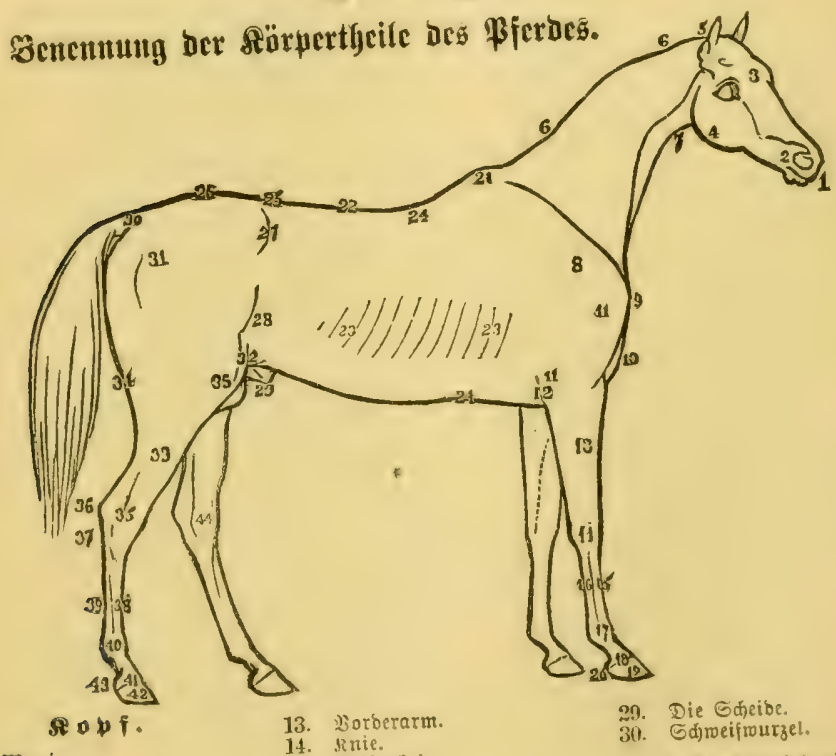

1. IRunb.

2. 9üiftern.

3. Borber = ROp

4. Riefer.

5. Edieiter.

\section{s) a 15.}

6. 6. றährte.

7. Suftröhre.

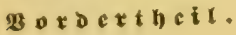

8. Sdutterblatt.

9. Borberite Spibe ber Sdulter.

10. Bruft.

11. 11. Süfte.

12. Errbogengelent.
14. Rnie.

15. Sdienbein.

16. Sriffelbein.

17. Fefict= ober Röthengelent.

18. Rronbeix.

19. Ђँा.

20. Eoble.

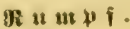

\section{Tुbiberrift.}

as. vituder.

23. 23 . Mippen.

21. "2. llufang des Brufte=

w. ftent?, Gurth.

25. Die Yenben.

3t. Das Rren.

27. Die Silften

28. Dte 25 eidue.

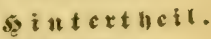

31. Süftgelent.

3:. Evrunggelen!.

33. 33. Rnteidseibe.

34. Badenbeir.

35. 5üftbeit.

36. 5ade.

3\%. Ĕhiförmiges Beit.

is. Edicribein.

39. Sriffelbein.

40. Frefielgetent.

41. Jronbein.

42. 5uा.

43. Eohile.

44. Srt too fid ber Spaty aniebt. 


\section{DRecepte.}

\section{Ifyicrärztlidifes.}

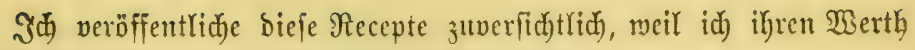
burd (Erfabrung it nollfer Weife erprobt habe.

Mittel gegen llufudtbarfeit bei Stuten.

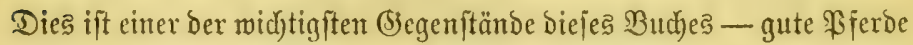
zu züd)ten. Du hajt vielfeidyt eine Stute, bie gelähunt ift; ;ie taugt nidyt mehr zur $\mathfrak{T r b e i t , ~ a b e r ~ i f t ~ v o n ~ g u t e r ~ \Re a f f e ; ~ f i e ~ h a t ~ D i r ~ m e k r e r e ~ j o b o ̈ n e ~}$ Fü̈ffen getragen, uno Du magft fie nidyt töbten; aber fie ift alt und will nidyt melyr tragen. Was jollft $D$ u thun? Du jagit: "Jid) habe bie bejten Sengite zu ifhr getalfen, bie zul finden waren, und es hat nidjts geforfen." Nun, idh Denfe Dir zeigen zu f̈önten, wie man bie ältefte Stute, und wäre fie zmanzig Jahbre alt, žun Tragen bringen und jebes

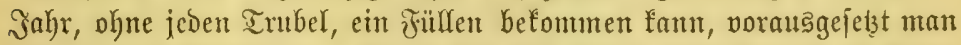

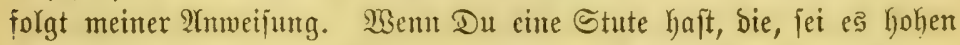
YYters Doer, wie Du benf́ft, 1tufrud,tbarfeit halber, feit längerer Zeit fein Fïlfen gebabt hat, bie aber nod) roffig wirb, fo unterjudje fie, inbem Du Deine Santo in bie Miutterideide, Die Finger ausgeftredft unt nach)

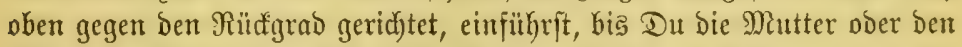
Mund ber Miutter erreid)ft. Es ift bies ein fleiner Rlumpen vout ber

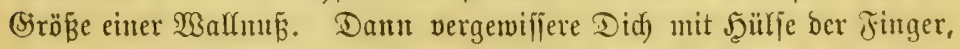
ob bie Mutteröffrumg geidgloffen ift. Sift fic $\mathfrak{e}$ S, fo öfine fie vorfichtig uno reidft, erft mit einem, banu mit zwei, bant brei Fingern, bis Du fidjer bift, bnź fie offen ifit, und bie Mutter ben Santen aujuchmen fann. 


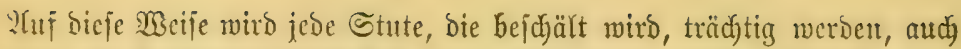

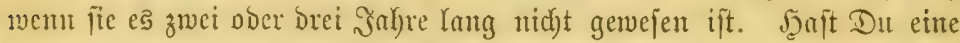

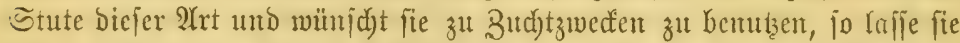

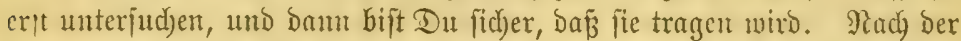

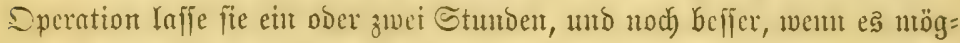

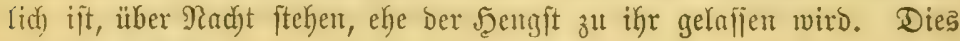
id lägt nie fehl.

\section{Träd) tige Stuten, $\mathfrak{x}$ übe etc.}

2rlle träd)tigen Stuten un Rühe find ungcfähr mit brei Mronaten nad, Be; inn ber Irächtigfeit oft einem vorzcitigen Mild)zuflü zu Dent (5uter

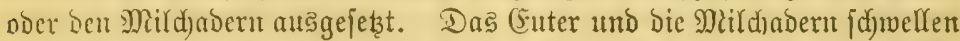
an, beginuen ju fdymerzen unt merben fieberijd, und wiro nid)t Jeülfe

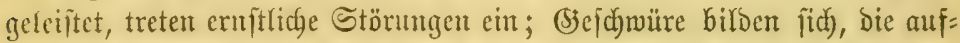

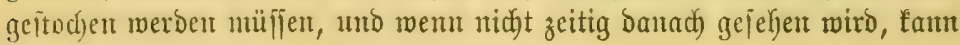
Tod eintreter.

Mitter. - Nimm Mcid)e=Seifen Salbe, nadjbem vorker bie (Suter noex. Mildaberu reid)lidf mit warmer Seifenlauge gewajden und abge= trodinet finto. Dann rüttle Die (Fingeweide und Urin=Drgane, went nidjt Ubbülfe eintritt. Dies ift immer gut; unb babe bie Renten mit Blad Dil Riniment, um bie 9 (b)jocioung zu fräftigen.

\section{Sogenante Sூufrorpern.}

Dies tift eit Rlumpen Docr eine Berbärtung an Der S̈menfeite bes Borocrict)enfels obcr am oberen (snde Des Borarms, nabe bem Reibe, und

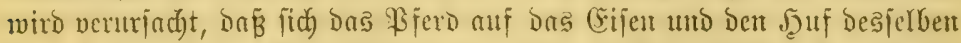

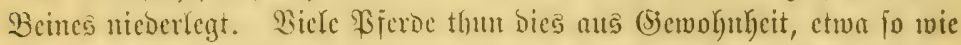

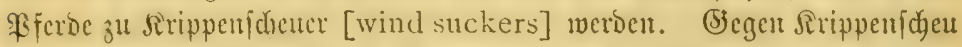

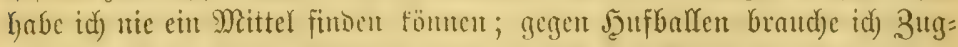

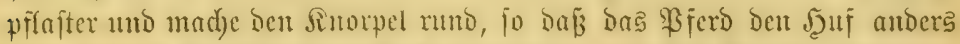
legt, weil es ifn idnurergt. Das Bugp flafter wird Den Rntorpel entfernen.

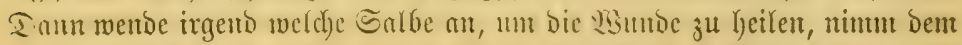

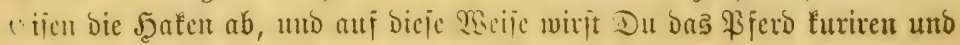
ifm sie üble (s)emolnnkeit verleiben. 


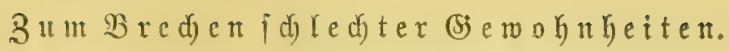

Dic Sdeutlappen verbiuderu, da $\bar{B}$ bie Bjerbe or =

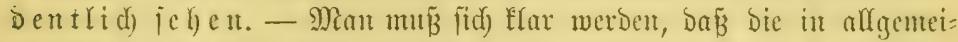

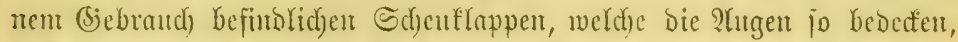

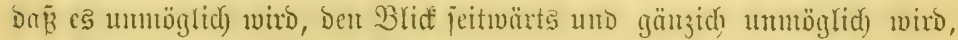
nad) linten zu jeljen, bieje Folge haben milffen, und wir werben bavon

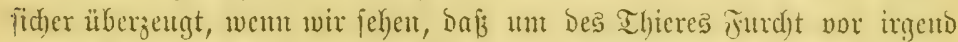

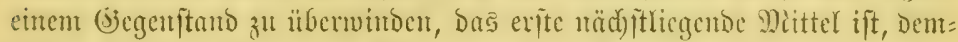

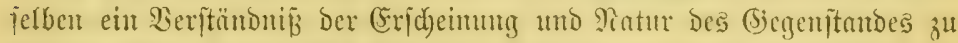
geben. Sdyeutappen find mur bam itattbait, mem es wünichenswerth

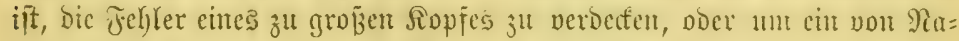

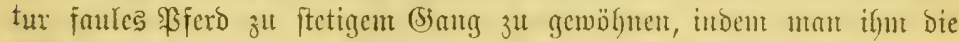

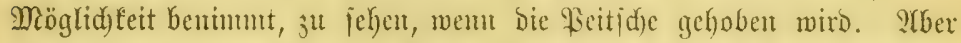

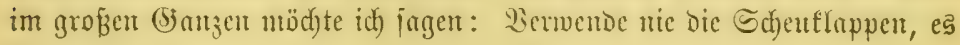
ift zmeifelsoknte untred)t.

Das $\mathfrak{B}$ ferd mú den (5iegenfta

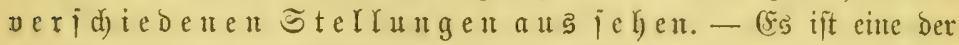

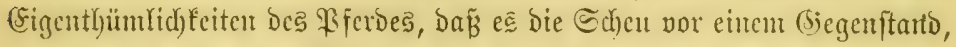

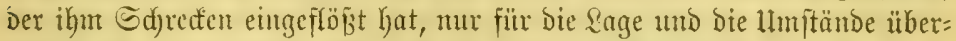

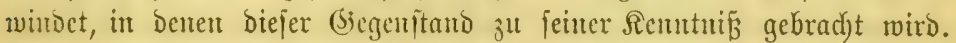

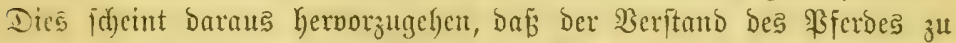
gering ift, unt fid) einen $B$ egriff pon einem (Siegenijtant über bie unter feinte Beobactutung geftellten Iage madjen z̆ fömen.

Gede neue Beränderung ber Stellung verlangt fait ebenjo viel Bor:

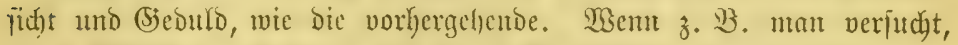

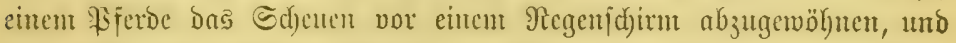

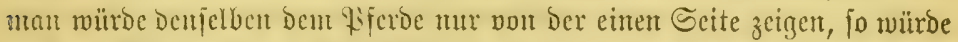

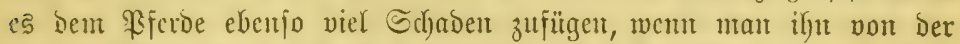

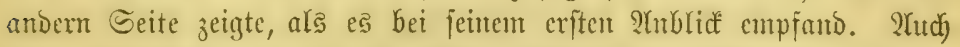

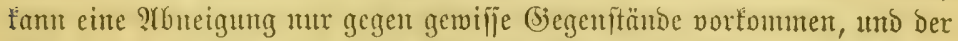
W3iberjtano wiro mu unter gerwifjen Unfitänden ftattfinden. (5: lant

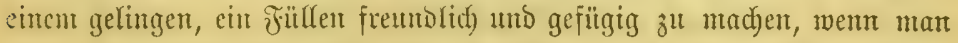
es von ber einen Seite lent, aber es müroe fid webren, mollte mant es

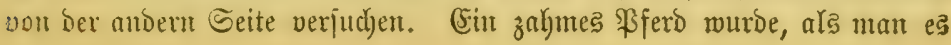


3um eriten Male nor ein Dedtbuggy ipaunte unt e

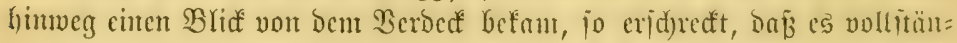
big uncontrolfirbar murbe und fidf lostifs und bavou ramute. Itus bod

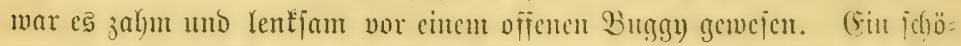

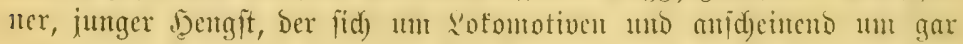

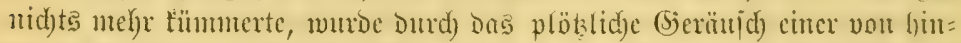

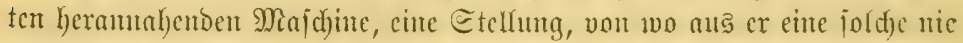

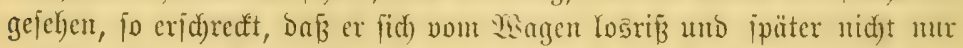

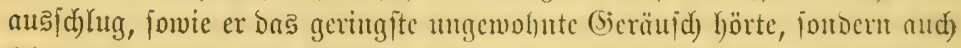
feine Rofomotive mehy lören wollte. Das burd) Dic Rofomotive bervor=

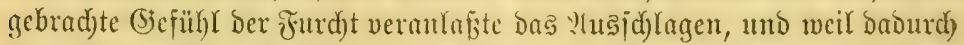

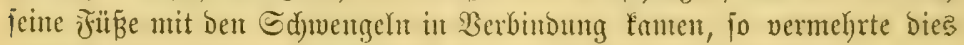
feine Furd)t, indem er Den $\mathfrak{B a g e n}$ nit ber Rofomotive verwedjelte.

(Sine feurige, aber fanfte Stute wurbe nad) ciner Sdjmiebe gentm=

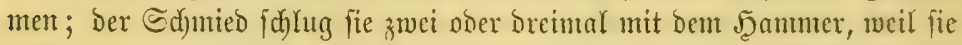
nidyt, wie er es haben wollte, fitanto ober ben Juß reidyte. Dies veriente

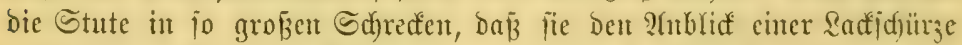

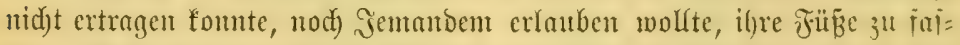

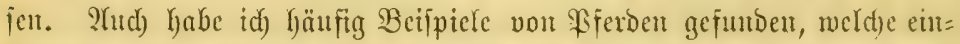

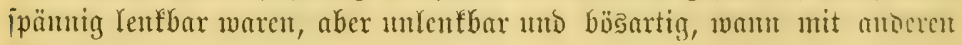
Bferben žljammengeppannt, uno umgefehrt.

Dieje (Ëgentfümlid)feiten mad)en bic von Der (Exfahrung ertuiejenc

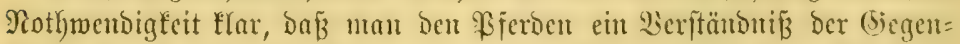

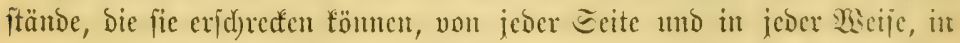

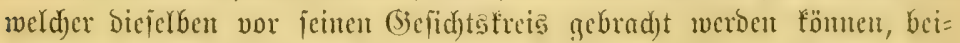
bringent пmü.

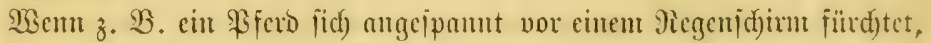
fo fant es in feinem Buftande gelel)rt werden, fid) nidjts barans jut ma=

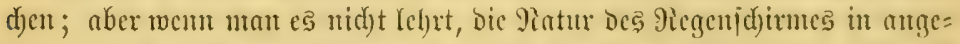

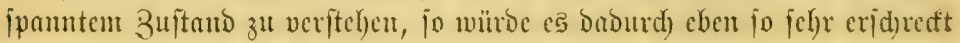
werben, als went es nie eiten Sdjum gejeben.

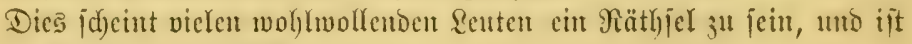
oft bie Uriadje von viel $\mathfrak{A}$ erger.

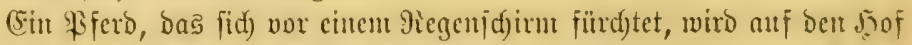
gebrad)t, um ifn mit bem Dinge bef́amt $\hat{j}^{u}$ mad)en. In ganž furjer

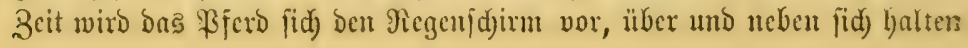


Iafien, ohne unjecheinetto irgento mic fid) Darum zu fïmntern. Der Ëiguts=

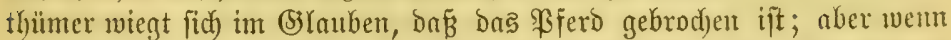

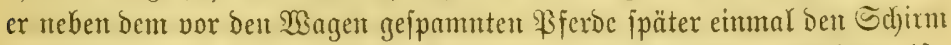

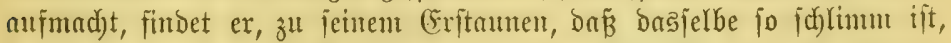

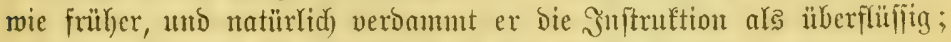
unb ofye meiteres Madjocufen wirb bie Sache allerbiugs berartig et= jheinen.

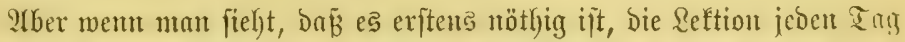

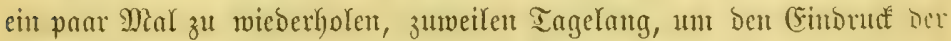

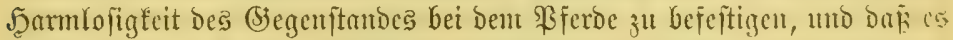

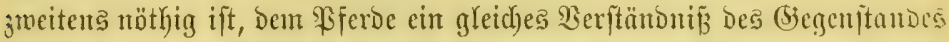

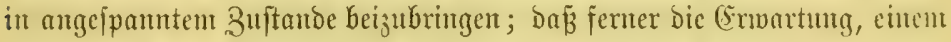

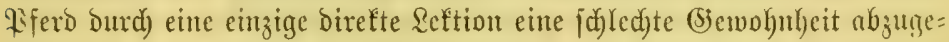

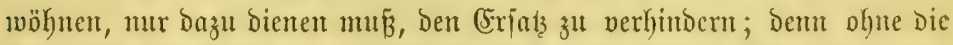

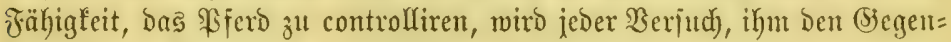

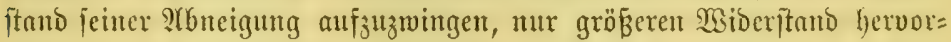

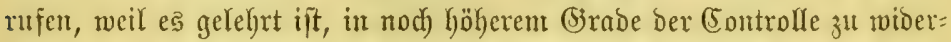

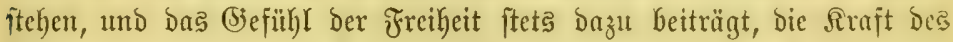
Thieres vor unbefannten (Siegenftänden zu vermefren. Die Bemüljungen Des (Eigentfümers, Das \$Fferd bireft unter Controlfe zu befommen, und von einer fo unoortfeiffaften Stelfung aus, fömnen gerabe bie giejultate herbeifübren, und boun hält man es Ginterher für unutöglidy, bas Pferd gehen zu madjen, weil man bie Urfadjen bes Fehlid)lagens nidjt ver: fteht.

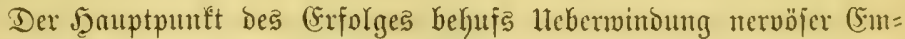

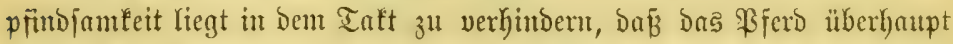

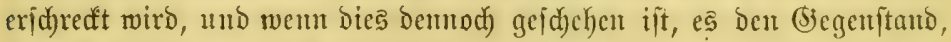

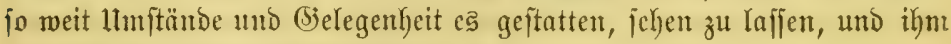
beizubringen, baß berielbe harmlos ijt.

Man Iafije es Den (Gegenftand jelyen, und bringe ilyn in veridjiebenen

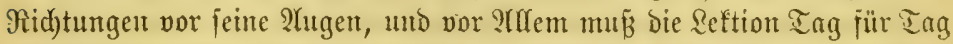
wieberfholt merden, jo lange bas Tfjier irgent weldye fartht vor ber Eache

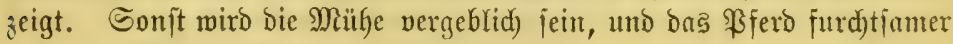
und unlentfbarer merben, als frïher.

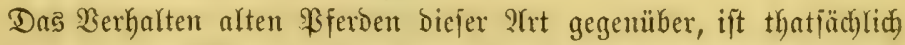

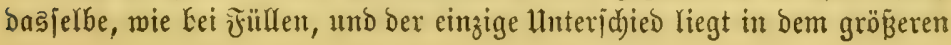




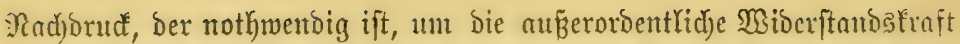

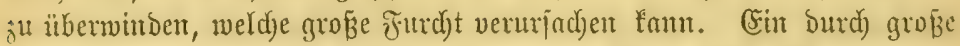
Furdjt vor irgento eirem (Siegenftono erregtes Pfero miro nicht nur mit Der ganzen Energie Der Beraweiflung verjud)en, fid zu befreien und Yos: jufommen, fondern in höd)ft bö̧artiger Wrije fämpfen. Ju ber That,

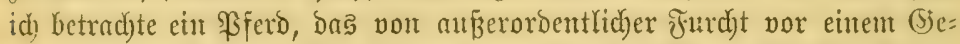

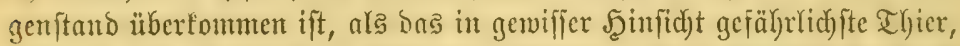

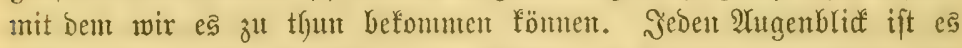
bereit, jeine ganze Stärfe in ben Sampf un Freiheit einzufeżen, un

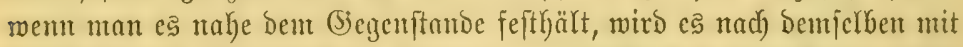

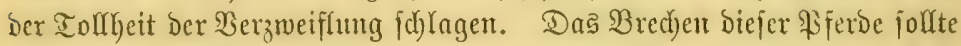
io hart wie möglid) gemad)t werben burd) gründlides Iraintren mit Seil unb Jealfter. Man żieke ben Strix fo ftramm als möglid) an. Das Bferd wird Dadurd) fo außzer Faffung gebrad)t und unfäbig gemad)t ver=

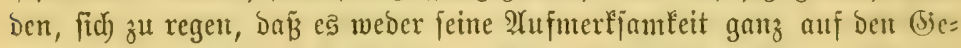
genftand concentriren, nod) feinem Maul wiberfteben tann. Sft ein

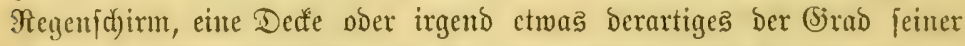

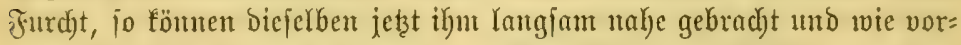

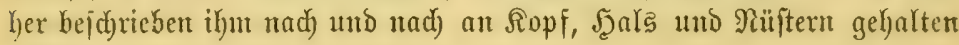
weroen.

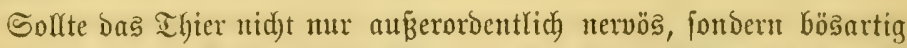

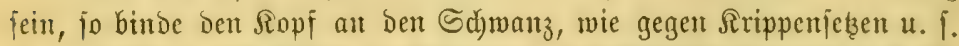
w., und Galte das \$fFerd in Bemegung, bis Miderftand unmöglich ift,

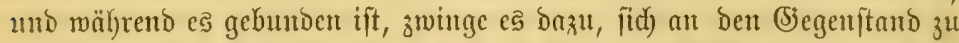
gewöhnen; ifm erft aflmählig gröp̧ere Freibcit gebent, und wiederthole Dic Reftionen jo oft als nothwendig cridjeint. Benn ein Berbectwagen bie llijade ber Futht ift, fo exlange völige (Entrolle bes Maules mit

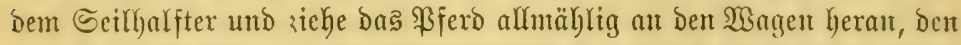
men flappern Yäß̈t u. f. w.; Dam bringe es zmijd)en bic Deichjel, brelje eș wicter nad) Dem Wagen herum, bewege die Siabel auf und nieder, jd)lage bas Berbect auf und ơ u. 1. w., und wieberhole bie Rettinu nath

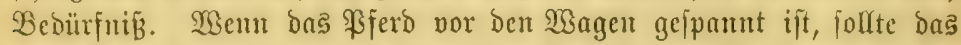

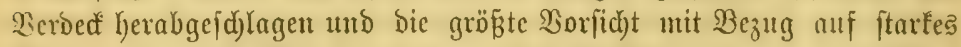

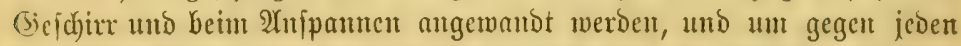
möglidjen Miderftano ober Unfalf gefidjert zu jein, befeftige man eine Struppe an eincm oder beiden ber Sorberfüßze, แnd leite bie Snden über 


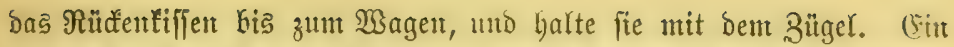

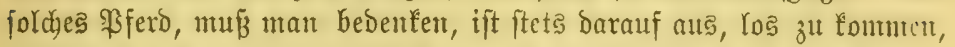
unt ba es nid)t immer möglid) ift, es mit ben Bügeln ju halten, jo miro ber Zortheil, es vermittelyt ber Fitíbe zu controlfiren, unentbelnrlich. Das

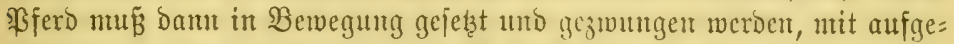
id)lagenent ober herabgeid)lagenem Berbecte, fid) ber (Sontrolle zu unter=

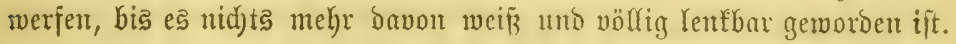

\section{$\mathfrak{5} u \tilde{f} \mathfrak{a} \mathfrak{L} \mathfrak{b} e$.}

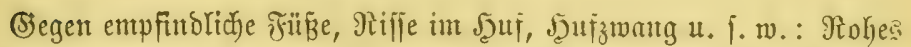
Scinöl ober reines Rlauenfett, je ein halbes \$int; Terpentin, vier 14 = zen; Theeröl, fed)s ltzzen; wilden Majoran, Drei Anzen. Altes wobl

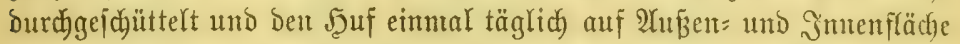

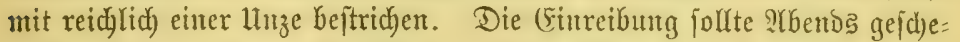
hen, nachoem man zuvor ben J̧uf rein gewajd)en uns abgetrodinet hat. Das Mittel hilft bejonders in Fälfen, wo längere Sahmbeit und Seh)= nen=\$ujammenziehung eingetreten ift. (5.5 Durdjoringt bie Scommaife und zieht Den Rrantheitsftoff heraus. Währeno ber Beljantung barf

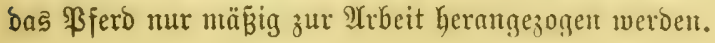

\section{Sd) warzes Del Riniment.}

Ein halb ßint Terpentin= Spiritus, cin \$int rokes Reinöl, eine halbe

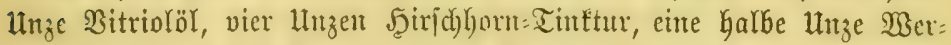

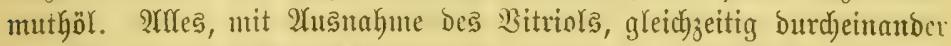

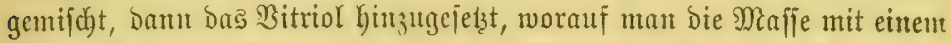
Stiel von Nadelfolz umrilfrt, bis fie wieder erfaltet ift, Dent beim $\mathbf{B}^{11}=$

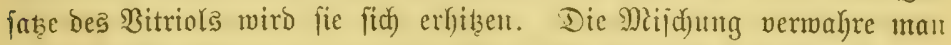

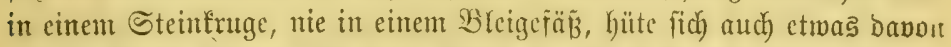

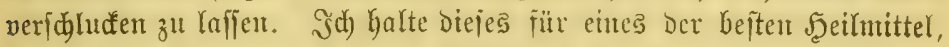

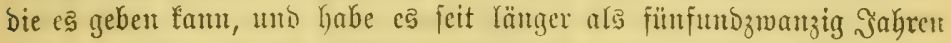

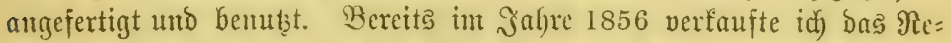
cept an einen (Siefdäftsmant in Sebar Rapios, Joma, für fünfzig Dol=

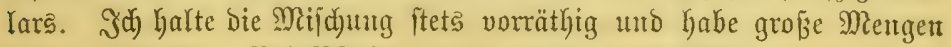

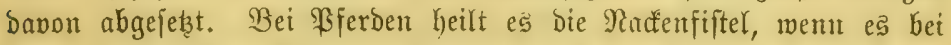
beren anfänglidjem $\mathfrak{A} u$ ftreten angewantot wird, währeno biejes Hebel 


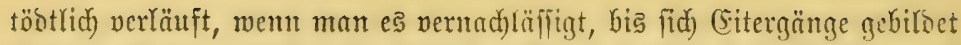

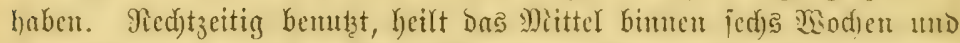

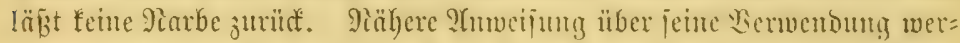

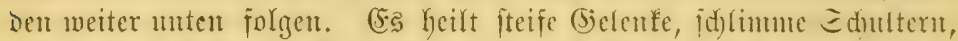

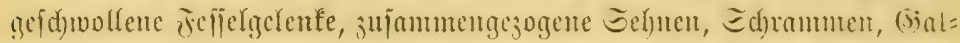

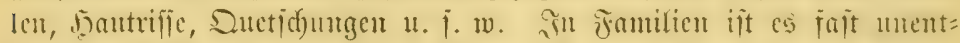
behrlid) als Mittel gegen Berrenfungen, Eduitte, Duetidumgen, amge=

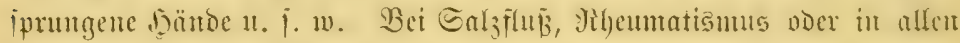
anderen Fülfen, wo Eimreibungen angewenbet merben, gat es uie bie Wirfung verjagt.

\section{(5)urter=?ahmbeit.}

Man veranlafie einen (Siegenreiz, indem man etwa fünf Boll unter= halb Des Miderrijts an Sdyulterblatte eineu (Simjunitt mad)t, falje Dam

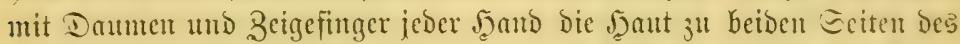
(Eimichnittes uno ziche fie auscinander, jo ba

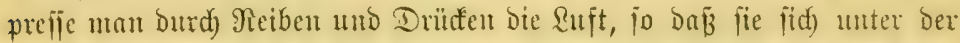
Şaut über Das ganze Sd)ulterblatt vollitündig vertheilen mú. Viun= mely reibe man eimmal täglid) unto juwar ftart und reid)(id) mit ben sini=

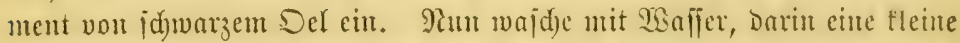

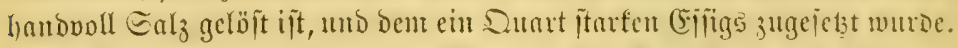

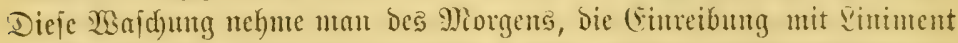
bes 9lbends vor. Die Deilung wirb in allen, felbit veralteten jällen ein=

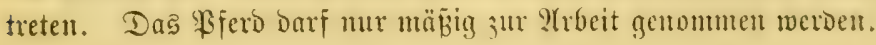

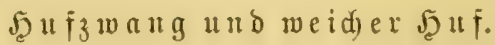

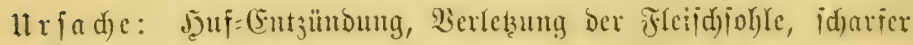

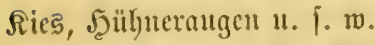

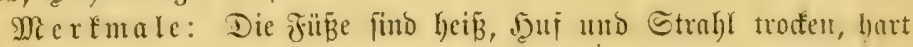
นnס zuјammengezogen.

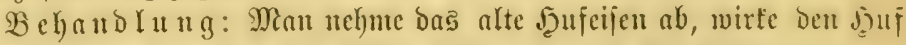

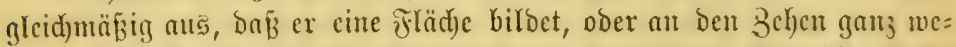
nig verticft ift, fdumeide aber femenfalls in ben Strahl ober bic weid)e

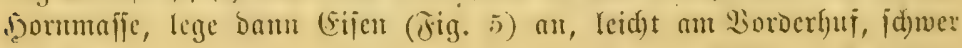

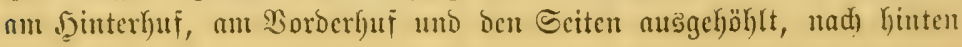




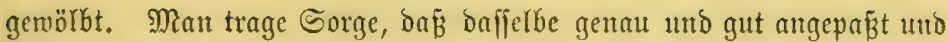

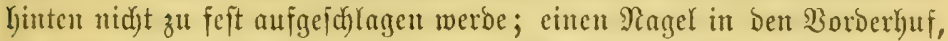

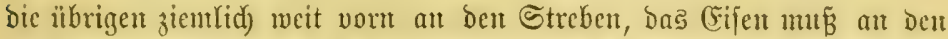
Ballen fo weit als möglid) aủlegen und nad) hinten jebre meit herumtge=

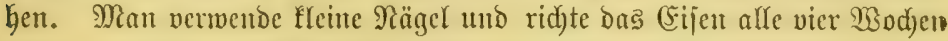
wicber juredift. ('jebraud)e fdjwad)e Rauge unto Furlong's Babe= itiefel.

\section{Berbärtete $\mathfrak{J u}$ fmaffe.}

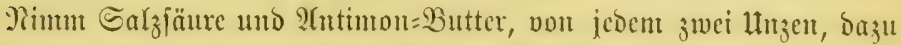

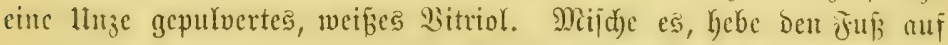

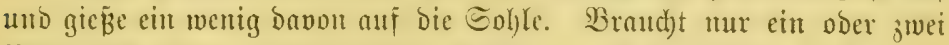

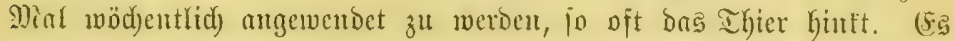

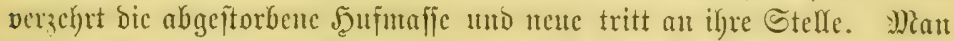

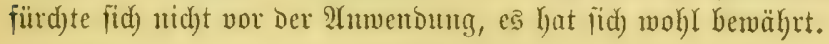

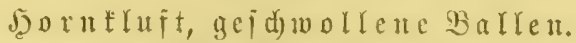

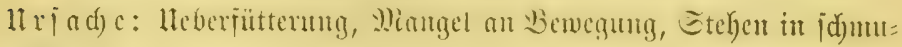
thigen Ställèt.

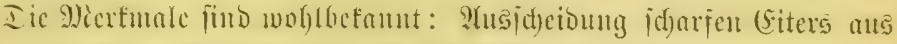

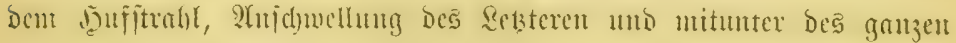

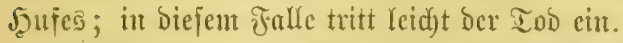

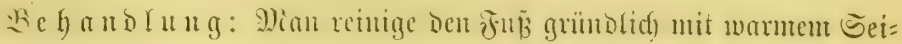

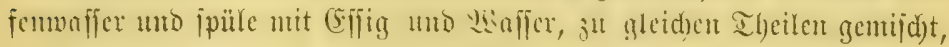

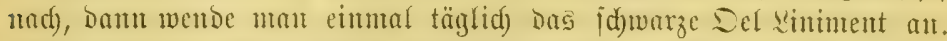

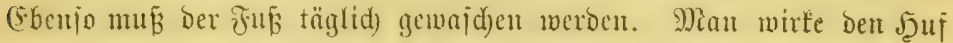
etwas tiefer aus, als mat vor bem Bejchlagen thut suirde, uno thue

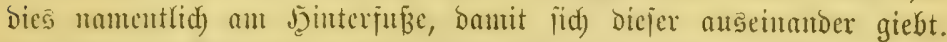

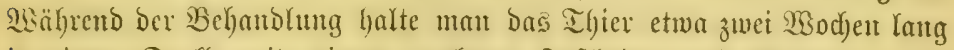

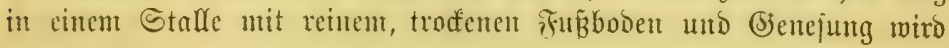
eintretert.

$$
\text { Seifen= Salbc. }
$$

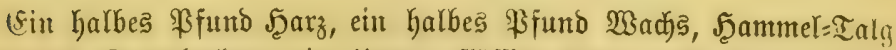

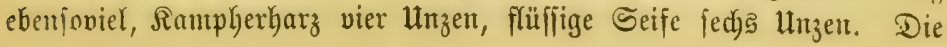


erften brei Stoffe röje man in cimer Pfante zujammen auf, fïge bam, währeno fic fid abfühlen, bie übrigen hinzu, bringe bic Mifdung in cine Bled)fanne und halte fie bidjt verid) lofien. Dies ift eine ber beften Sal= Ken für Den allgemeinen (Sicbraudd), Dic man fent. (Biegen jdymerzhafte

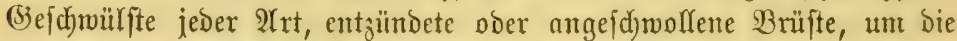

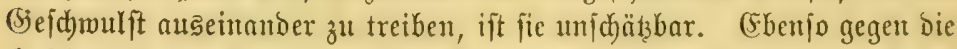
(Seidjwulfit ober Werbärtung von Rukeutern. Man wajd)e bas (Euter uno reibe es brei ober vier Mial mit ber Salbe cin, jo wirb bie (jejd)muljt

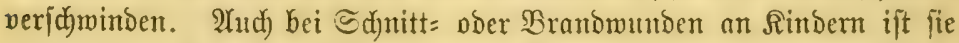

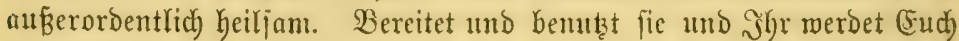
überzeugen.

\section{"(5) reen Mountain" Salbe.}

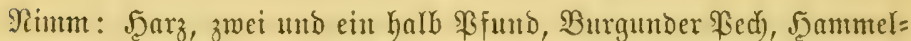
Talg, Bienemmadjs, zmei 1tuzen von jebem, Sdhierlingstannen=Del,

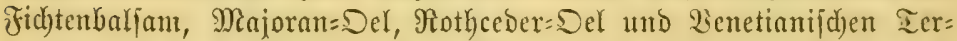
pentin, von jebem eine halbe llnze, Mermuth= Del ebenfoviel, fein gepul= verten (Srünjpan, eine 1lnze. Die zuerjt genanten Dinge fdymelze man mit einander und jebze bann bie verjojiedenen Dele hinzu, nad)dem man zuvor Den (Siünjpan mit ein menig Del verrieben bat. Den (Siünipan jeţe man fo, während die Majle fid) abfülylt, biejer hiuzu. Dann nehme man bas (Sanze heraus, madje Stengel, wie bie von Molaffezuder, baraus und Galte fie zum (siebraud) bereit.

\section{Ein milbes, allgemeines liniment.}

Rlauenfett: ein Duart, Terpentin= Spiritus : ein Pint, Immoniac=

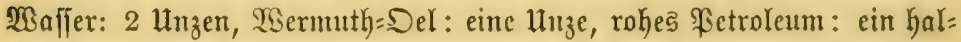

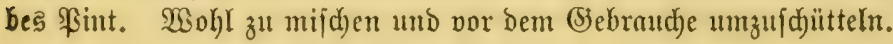

\section{Bei frifden $\mathfrak{W}$ unden.}

Man jtille zunäd)ft bas $\mathfrak{B}$ \}ut, indem man $\mathfrak{A r t e r i e n}$ unterbinbet, ober

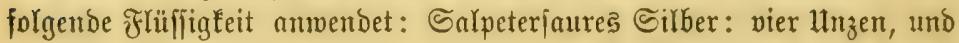
eine Unze Regenwaffer. צNan majd) Damit bie Munbe und näke bann

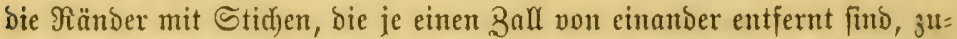
jammen, wafdje bam bie Umgebung rein, uno jollte fid nad) Berlauf 


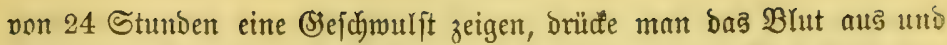
madye eine (5inreibung mit fdwarzem Del=Riniment. Man halte Den \&eib offen.

\section{$\Re \mathfrak{a} \mathfrak{h} e$.}

Me exmale: Das Thier ift fteif, feine Jü hẩufig uno if̣t Durîtig.

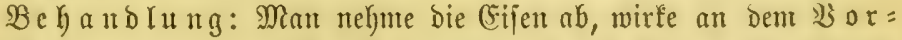

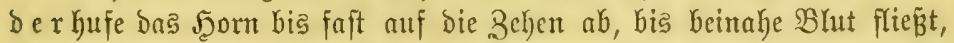
dann laffe man bic Behe tüd)tig ausbluten. Die (sijen lege man bis zum folgenoen Iag nid)t wieber auf, Denn wenn Das Thicr nidht beller

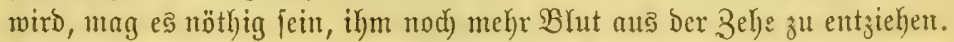
Mandbe thun bies an anderen Rörperftellen, aber in alfen Fällen von

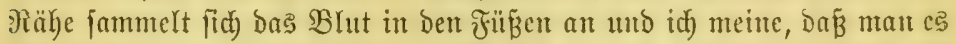
von bort entziehen jolnte. Demuäd)ft gebe man Folgendes: Sine halbe

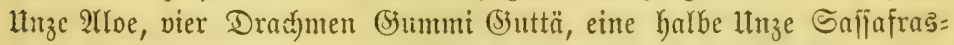
Del, hieraus forme man eine Bifle, gebe barnach fo viel Saffafrabthee, als bas Thier nur faufen mag, babe bäıfig jeine Beine mit warmem Waffer und reibe fie trocfen. In zwei bis brei Tagen wiro (Jienejung eintreten.

\section{$\mathfrak{S} \mathfrak{u} \mathfrak{f}=\mathfrak{S} \mathfrak{a} \mathfrak{l} \mathfrak{b} e$.}

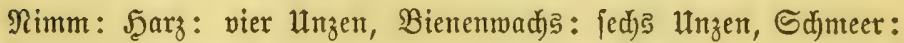
ein \$funt ; fdymelze es ineinander und joüüte bie Maffe in einen Topf mit orei Unzen Terpentin, zmei Unzen fein gepulvertem (Sinunjpan uns

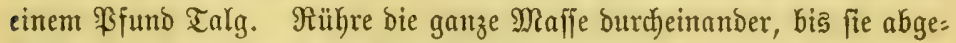
füblt ift. Das Mittel madyt ben Jुuf gefdumeibig und bält ifn gejund,

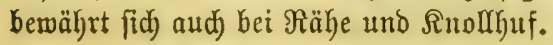

\section{$\mathfrak{A} \mathfrak{b} \mathfrak{f}$ ü $\mathfrak{h} r=\mathfrak{F}$ ill $\mathfrak{l} \in \boldsymbol{n}$.}

(Sine Galbe Anze Aroe, vier Drachmen (S)mmi (Suttä, zmanzig Tro= pfen $\mathfrak{W a c h b o l d e r = D e l ~ t n e t e ~ m a n ~ m i t ~ e i n i g e n ~} \mathfrak{I}$ ropfen Molaffe zu einer Sugel zujammen, midele bieje in bünnes झapier und öle fie. Siehe bie

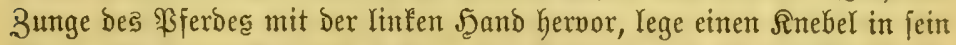
Maul, fojiebe bie Rugel fo tief in Den Sdjlund, bis fie verid)ludt ift, 


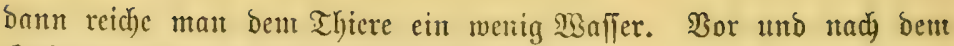
(Sebrand) gebe man ctwas Sileienfaufer.

Das magerfte $\mathfrak{B}$ feróf feifdigzu maden.

Nimm: Salpetcriäure zwei Drachmen, Saleratus zwei unzen, Sar=

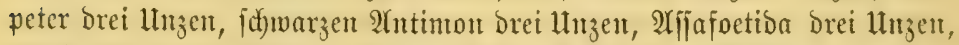

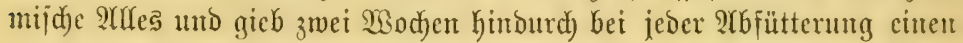

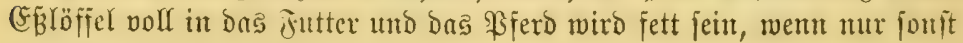
eș gut gepflegt unto gefüttert wiro.

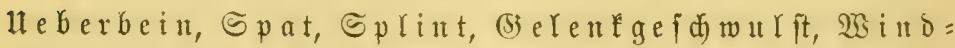
gatren.

Beh a n olu ng: Majoran=Del, Job= Tinftur, Steinöl, Rampher=

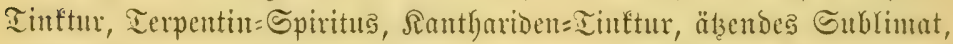
(Eeder: Qel, Sroton= Der, (Euphorbiumbarz - von jedem cine ltmje mit

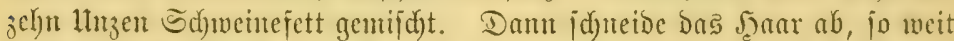
bic franfe Stelfe fid) criftecft, unt reibe biefelbe leid)t mit der Garbe cin unb zwar brei Tage hinter cinamser cimmal täglict). Dam fetze brei

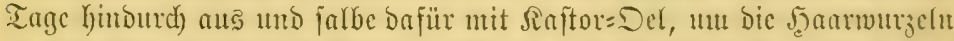

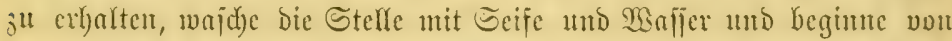

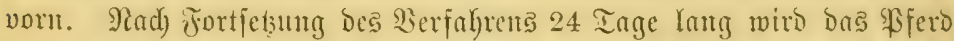

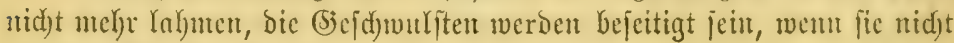
auf bem Sinod)en felbit wurzelit.

\section{Meíze Sarbe.}

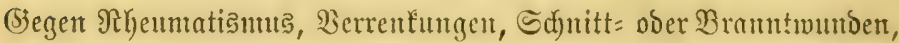

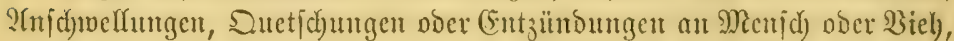

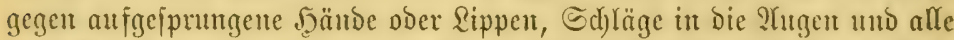

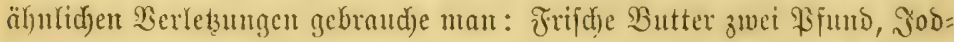

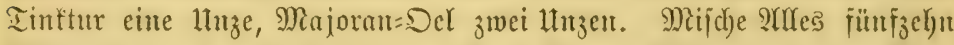

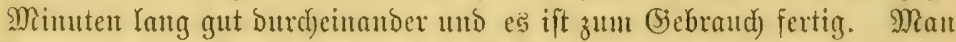

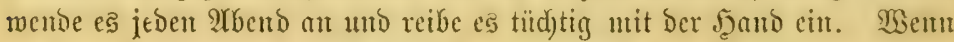

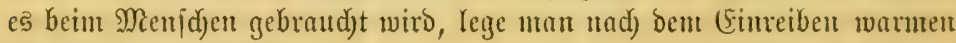
Flanell auf bie Stelle. 


\section{$3 \mathfrak{u g}=$ ธa a tbe.}

(Ein halbes \$int Arffohol, ein balbes \$int Terpentin, vier lluzen 2ummoniac:Waffer, eine llnze Majoran=Del gemijd)t. Man juncidet an ber Stelle, wo die Salbe gebraudyt werben joll, bas Jeanr ab und wendet fie alle brei Stunden an, bis fie Blajen zieht. Man wiederbole bies alle adyt Tage, wenn öfter, werden bie Jaarmurzeln getöbtet.

\section{Solit.}

Merfmale: Das \$ferd liegt au Loben, ipringt aber oft auf, jeine Flanten fliegen, Dhren und $\mathfrak{B}$ eine find falt.

Urja dy e : Bu viel faltes Waffer evi,alteu, Das jutter gewedjelt, eine grop̧e Majןe Säure im Magen.

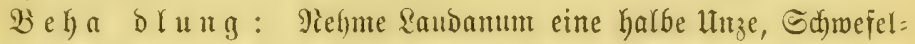
Hether eine llnze, ein Bint laumarntes Waffer. Flöbe Dem Thtere die Maijd)ung ein, unb wenu nad) 40 bis 50 Miunten feine Befferung eintritt,

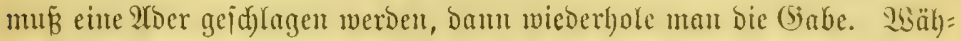

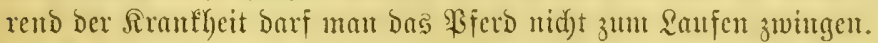

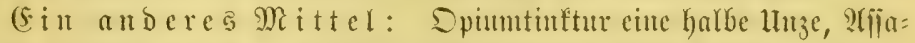

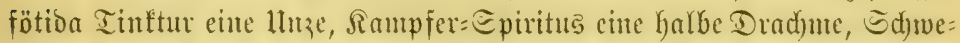
feläther eine Itnze, Sanentmepfeffer= Iutftur zmei Drad)men, Salpeter: ätheripiritus eute ltnze, rohes Reinöl $1 \frac{1}{2}$ Pinte; mijhe und gebe bas (अ)nze auf einntal ein.

Warzen a n \$

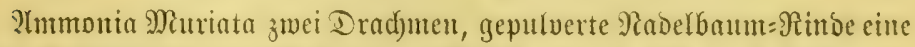
Unze, Schweinefett zwölf Unzen. Mifdue es gut und es ift fertig zum (Siebraud). Heibe täglich bie Marzen bantit ein und in furzer 3eit wer= ben fie vergeken.

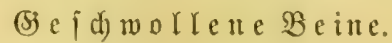

Sie eridjeinen in Folge einer äup̃eren, itumpfen Berleţung ober we: gen Unthätigfeit Des Blutinftems, und ftellen ein Wajperjudtartiges 2 ei= ben ber Beinmusteln bar.

Be a nofung: Mau mende alle brei bị vier Stunden bie Rug= jalbe an, bis Blajen entftehen; nad) Berlauf von fechs Stunden reibe man mit irgend einem meid)en Dele ein. Nach ad)t Iagen maiche man bie Stefle mit marmer Seifenlöjung rein uno beginne mit ber Behand= lung von vorn. Went joldjes it biejer Meije brei ober vier Mal fortgejest 
ift, greife man zu ber meip̄en Salbe; jollte bieje nidgt wirken, neלme man die Spat=Medizin.

\section{Rä uje zuvertreiben.}

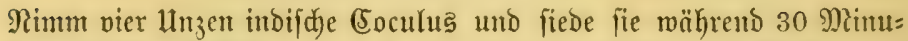
ten in ztwei Sunrt (5ffig, Dann waid)e Damit bas Thier an Stellen, wo

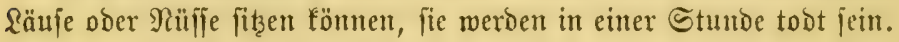

\section{$\mathfrak{Q} \mathfrak{a} \mathfrak{h} u \mathfrak{u} \mathfrak{g} \mathfrak{e}$.}

Turfije)es Rinment. - Hefifemünz= Del cine llnze, rothe (5edar eine

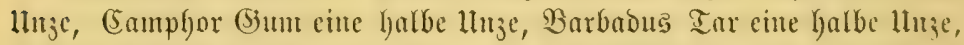
Zobelia=Tinftur vier 1lnzen. Bermenge und ichüttle es gut, und reibe es framm cin bei affen \&äfunutgen, es wirft unbertroffen.

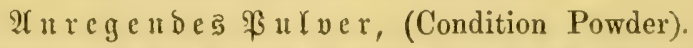

Bodfahornimen vier Unjen, Jugwer zwei Llnzen, Sielbwurzel juei Unzen, 2lija fötion zwei Unzen, Salpeter (rein) vier Unzen, Bappelrinde vier Unzen. Futverifïre, mijde und gib, wemn nothmendig, breimal täg=

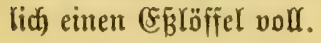

\section{Bla ue Salbe.}

Nimm cinte Galbe Hnze (Sin̈npan, eine Unze blancs Bitriol, vier Unzen Şarz und cine Unze Ierpentin=Spiritus. Artes miro fein Durd)= einander gemaklen und gut mit einem \$fund Sd)weinefett gemijd)t, fo ift es fertig zum (Siebrauch. Die Salbe ift gut zur Berwenoung, nadjoem

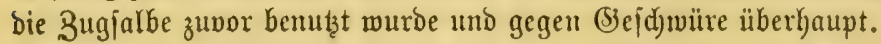

\section{Ma urperre.}

Nidhts hat jo feljr Der Rumit ber beften 2lerzte geipottet, als biefe Sranfheiţerjdjeinung, fowohl bei Menid)en, als bei I Theren.

Bor länger als 30 Jabren lernte ich) von Dr. Menjo N3hite in (5herry Balley, Rew Yjork, folgendes Mittel Kenten, und es hat fid) nod) immer berwährt, menu es jorgfältig angementet murbe. Die Urfache ift gewöbn= lic) Zutritt Der Rälte in eine Wunde. Dą erîte Erforbernifi ift Blut=

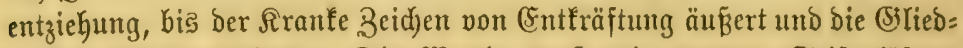

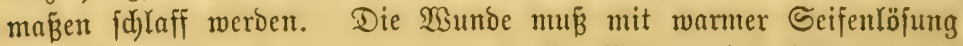

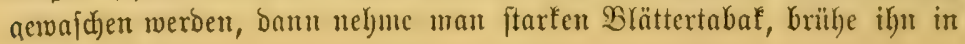


K) det. Die Rnppen milfien ftets feud)t und warm gehalten meroen, fie Ën=

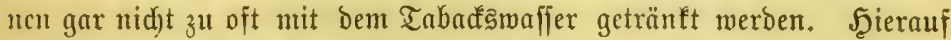

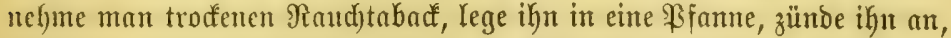
binfe mit einem $\mathfrak{B l a j e b a l g e ~ o b e r ~ e i u e m ~} \mathfrak{B}$ feifenrobre hinein und Galte die Rifanne unter bie Rnje bes Thieres. In furzer Frift merden fich feine Rimbadten öffucn, bann lege man einen Rnebel bazwijhen. Man reiche Donn alfe ject)s Stunden zwei Unzen 2 fjafötion und eine (Siabe abjühren=

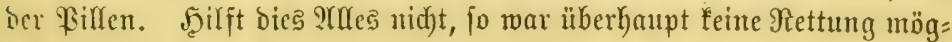
lid). Wenn feine Wunbe zu funden ift, fo lege man eisten gropien $\Im a=$

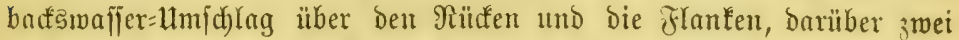
ober orei warme Deden, reibe bie (3)ieber mit ftarfigefättigter, heiper

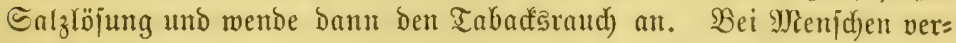
fahre man ähnlid, mur verwende man eine mit Tabact gefüllte Ihon= pfeife, vermittelft Deren man ben Dantpf in bas (5iefid)t Des Rranten bläft. Der Brwed ift, dem ganzen Snjtem (Erleichterung zu veridafifen.

\section{Sidere $\mathfrak{R}$ r ber 5 ämorrhoiben.}

Teu Bere $\mathfrak{A}$ w

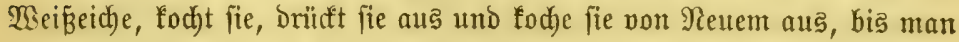
ein halbes \$int felyr biden (5xtraftes hat, onn fetze man ein balbes \$int deŝ älteiten Spedtes, den man ausgebraten hat, hinzu, todje es Durdjei= nander, bis es fïc) bei bem (Erfalten innig vermijd)t hat, bann führe man von ber Maffe jeben Mrbent mittelft bes Fingers burd) ben 2 ffer ein, bis

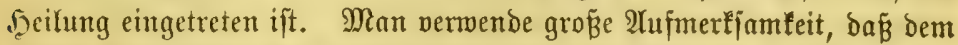
Thiere feine idyser verbauliche ober aufregende Nahrung gereidyt werbe. Obiges Mittel heilt fidher Glinde, mie blutige Sämorrboiden in allen Fälfen uno mehr oder meniger furzer Beit.

\section{Splint=und Spat= liniment.}

Man nebme eine weithalfige Flajde und thue hinein: Majoran=Del jechs Unzen, Rampherbarz: zwei Ulnzen, Merfurialjalbe: zwei Unzen, Jodjarbe: eine llnze, famelze es zujammen, indem man bie Flajhe in einen Reffel mit heifem Waffer febst. Bei Salffpat ober bei Splint mende man es vier bis fünf Iage lang zmeimal täglich an; bie $\mathfrak{S a b m b e i t ~}$ 
mito vergehen. Berifut bies Mittel, es allein ijt zweintal fo viel werth, wie der $\mathfrak{B r e i s}$ diejes ganzen $\mathfrak{B}$ udjes.

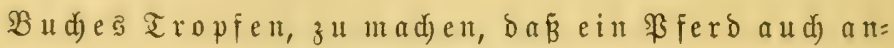

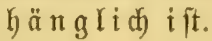

(5rgreife Des Bfferdes (5iefdröte, ober Ruthe ober bie Warze, bie fid an ber intmeren Seite bes Şinteridentels befindet, frake ganz janft baran, gieb ihm ein Kleines Stüd Zudfer, 2Tpfel oder Rartoffel oder thue

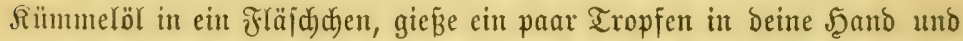

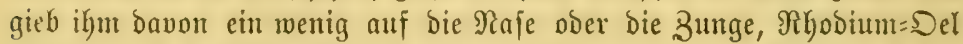
fam man in Derfelben Saeife bentizen. Berwahre jebes (Einzelne in be=

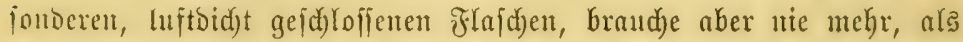
ad)t Tropfen auf eimnal. (jiteß̧e ein wentig Rümmelöl in bie Şand unto

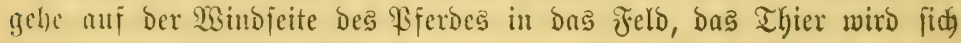
fangen uno fefthalten laffen.

Ubführmittel für æindoieh.

Barbaboes=2Uloe: zwei Drad)men, TSemitem=Rali (Fotafin= Tar= trat): eine Galbe Dradbute, Junguer und venetianifde Scife: jebes eme

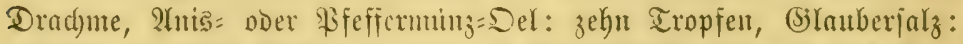

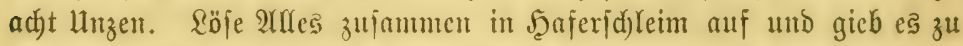
jaufen. Soll das Mittel beim Siferde angewendet werden, fo nimm vou affem Sbigen bic Doppelte Mienge, anggenommen an Salz und

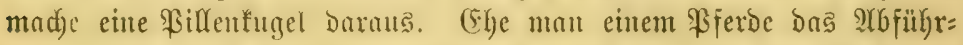
ntittel giebt, muß man ilbu wentigftens zwei Tage lang ftatt Mais ober Şafer abgefochtes Rlcienjunfen geben, Dazu Waffer, bas eine Zeit lang in ber Märnte geitnutien hat. Währeno ber Bebandung fahre man mit bieier (5ruälynug fort. Sollte bns Mittel binnen 48 Stunden nidjt wirten, gebe nod) cimmal einte balbe (5abe bavon.

\section{\&aune.}

Mertmale ub SEChandung: Wenu man glaubt, baß ein

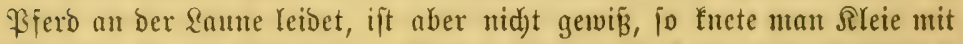
jafwacher Rauge zujaumen. Jif bieje nidjt zu ftart, jo wiro es reid)lid

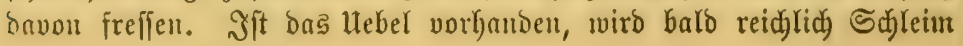




\section{ธd) lim ine $\mathfrak{A}$ ugen.}

Bleizuffer: cine halbe Unze, Jeutzufer: eine Unze, feines Salz: eine

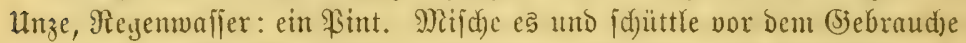

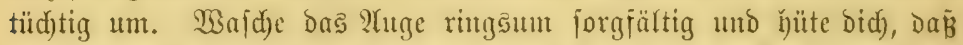
nid)ts von ber Flüffigfeit cinoringe. Das Mrittel heilt alle bebentfidjen Fälle, aud bei ben Menjad)en.

(Ein anderes $\mathfrak{A}$ ugentwafier.

Blcizuder, Bint= Sulphat, blaues Bitriol, 2raun uns Rodhalz, eine

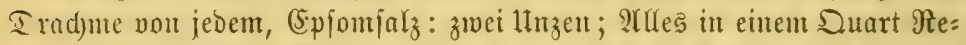

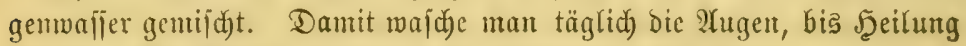
erfolgt. (Ein Mittel, gleid) gut für Mienjden uno Ifiere.

\section{$\mathfrak{A}$ u ge $\mathfrak{j} \mathfrak{a} \mathfrak{l} \mathfrak{b} e$.}

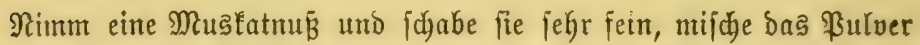

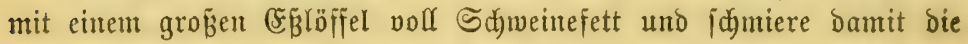

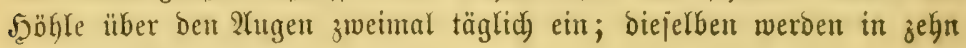
ober zwölf Tagen gejun jein.

\section{$\mathfrak{R} u \mathfrak{g} \in \mathfrak{n}=\mathfrak{F} i \in \mathfrak{b} \in \mathfrak{r}$.}

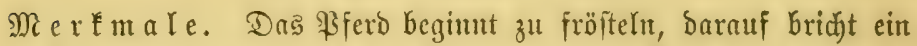

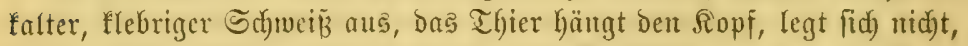
hält bie 3orberbente weit jeitwärts gejtrectt, ftöhnt, wenn man es zur

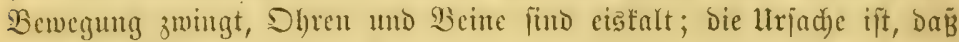
man Das \$ferd an cinem falten, zugigen Drt jteben, oder ifm ju viel

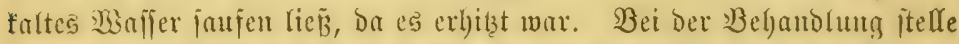

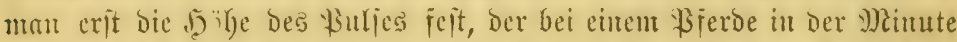

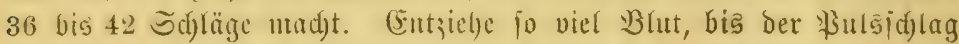

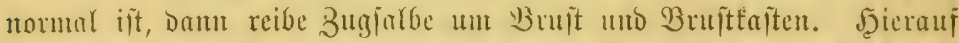
ninm :)conit- Tinctur, Salpeteripititus uno Eaubanum, eine Itıje von

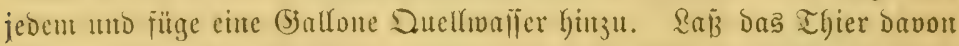

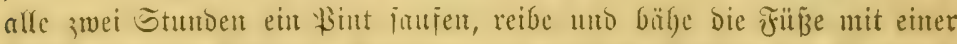

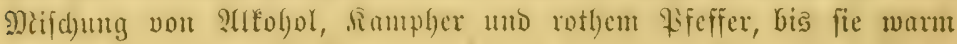
werden; gieb Dam 2Bafjer zu trinten, in Dem junge llmenbaun=9imbe 


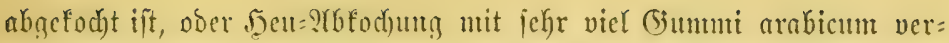

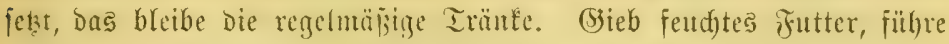

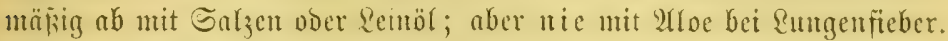
Mit biejer Befrandung fafue fort und bas Thier wiro gejuto werden, weru es red)tzeitig in Behandung genoumen wurbe.

\section{Reber=eratzündug ober gelber uritu.}

Micrtemale: Dic Ylugen laufen und werden getb, ebenfo bie Rim:

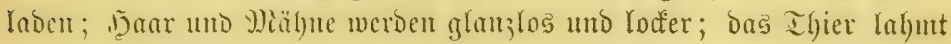

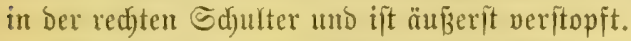

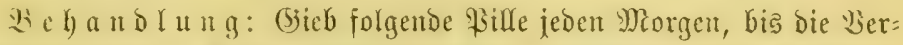

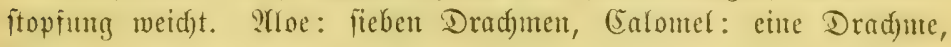
Sngmer: vier Drndumen, bazu genug Syrup, um eine tüd)tige Bille on=

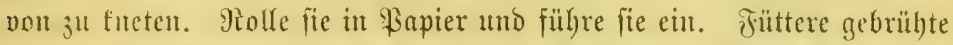

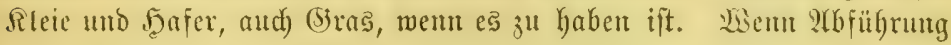
exfolgt, höre mit ben \$illen auf und gieb zwölf Tage Gindurd) Miorgents

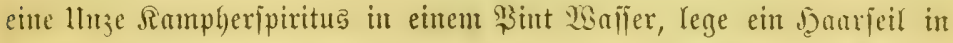

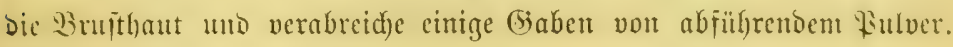
Fïhre bus Thier it'ş Freic.

\section{Wï $r \mathfrak{m}$ e r.}

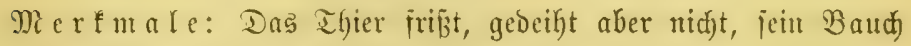
fdjmillt an, fein Şaar miro ftruppig.

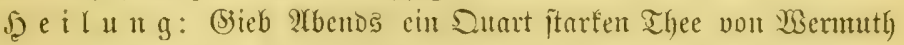

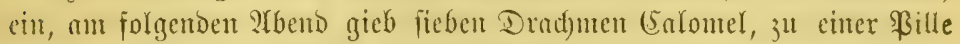

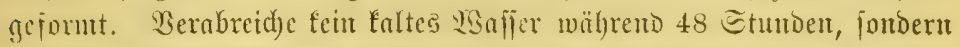

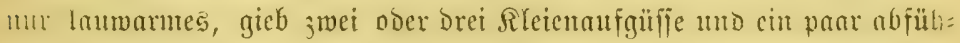

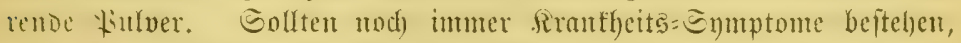

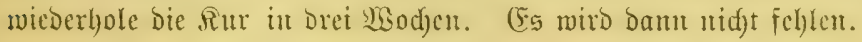

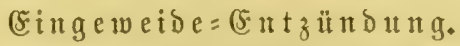

It r f a

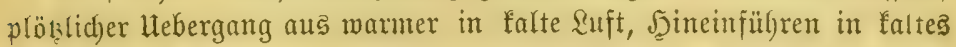

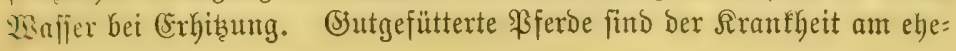
fien unterworfen.

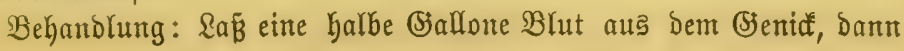




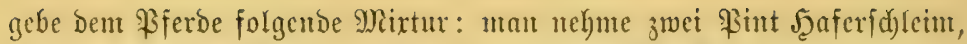
1 llnje gemahlene Ireibe, 4 llnzen jog. japanefijd) (Erbe (catechu) und Drei Efrupelu Dphum. Man widoerfole alle fedjs Etunden bis bas

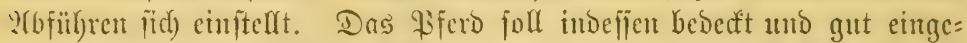

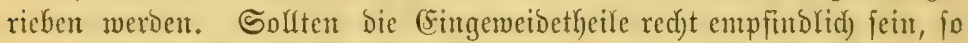
ift es angemeffen, ein 3ugpflafter über bie Singemeide zulegen.

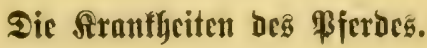

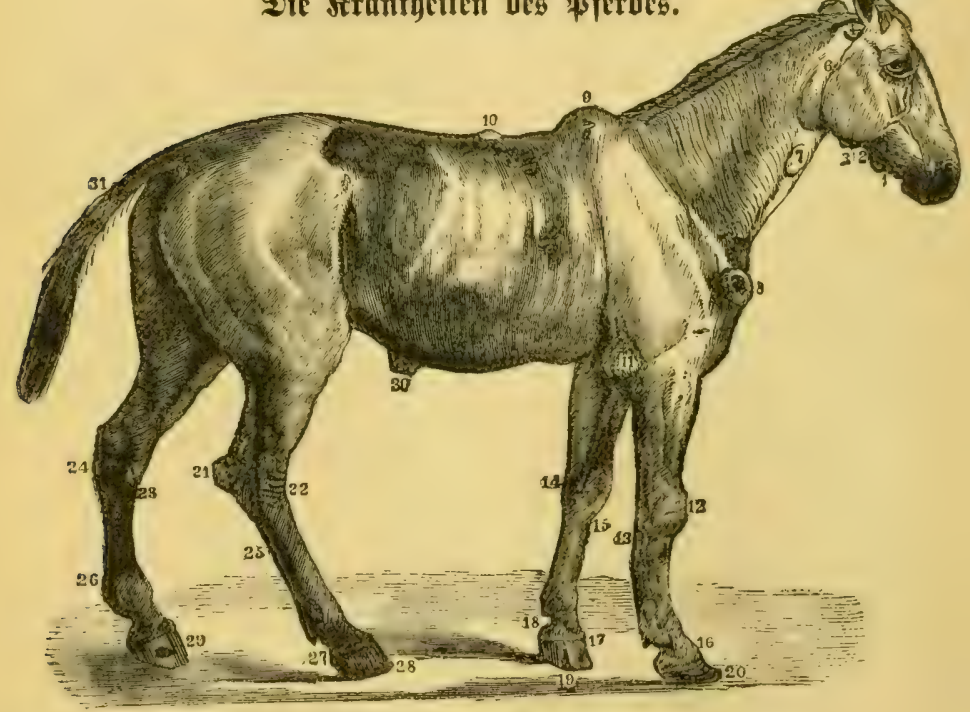

1. Der 3 einfraßz am unterfiejer.

2. Die Bahnififtel.

3. Die Epeidelfititel.

4. Gejdroulft, herrübreno pom Drud bes̄ 3aumes.

5. Die (\$) ntiatbeure.

6. Die (Ent 3 ünbung ber SGtenbrüle.

7. Die (sntänbung ber Burgelaber.

8. Der Beulen = Edwamm, herrühreno vom Diude bes siummets.

9. Der Wisiberrifitaben.

10. Der Eattelorudé.

11. Die Etollbeute.

12. Die §̊nieverbärtung (Rnicidmanu).

13. Der Eehnetlap.

14. Die Majpe.

15. Der tiephaden.

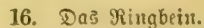

17. Die Su fnorbel= Filitel.

18. Der Etelajuis.

19. Der 5ornipalt.

20. Der Jinollitik.

21. Die (Gefdirulft an Sprunggelente.

22. Die Maipe.

23. Der Epalh.

24. Die Jajentade.

25. Die Eehnenandáductung.

26. Die iflügalle.

27. Die Mrauce.

28. รir Sdjicnipalt.

29. Ter 5ornipalt.

30. Der Mabelbrudi.

31. Der Mattenfimatis. 


\section{Dex Frofd d . (Lampers.)}

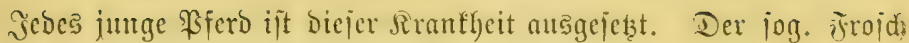

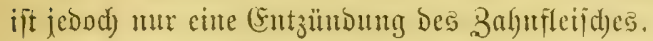

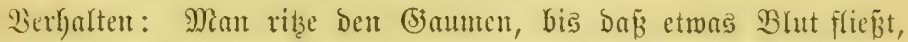

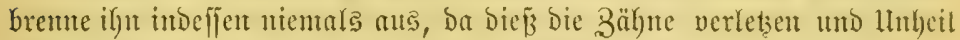

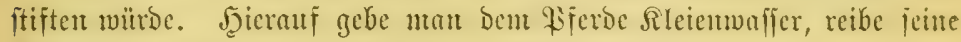

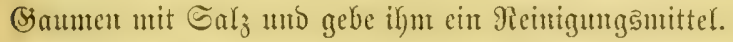

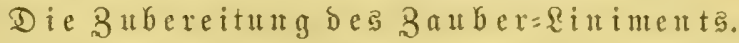

Man nefme jwei ltuzcu Spieföt (oil of spike), chue ltuje Sriganöl, (oil of origanum), zwei llıjen Terpentingeift, brei Unzen S̈̈в̈̈̈l, jwei

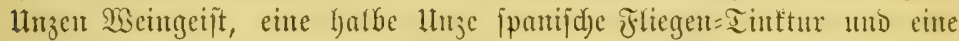

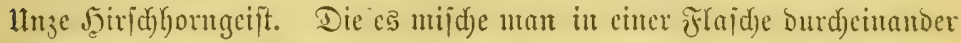

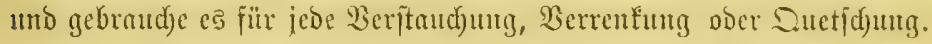

(5ine $\mathfrak{B} \mathfrak{l}$ treitugung für bas $\mathfrak{B}$ ferd.

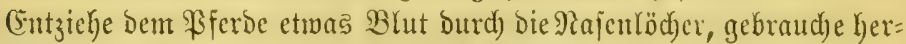

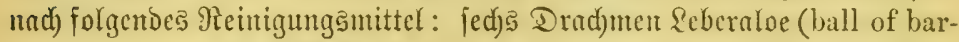

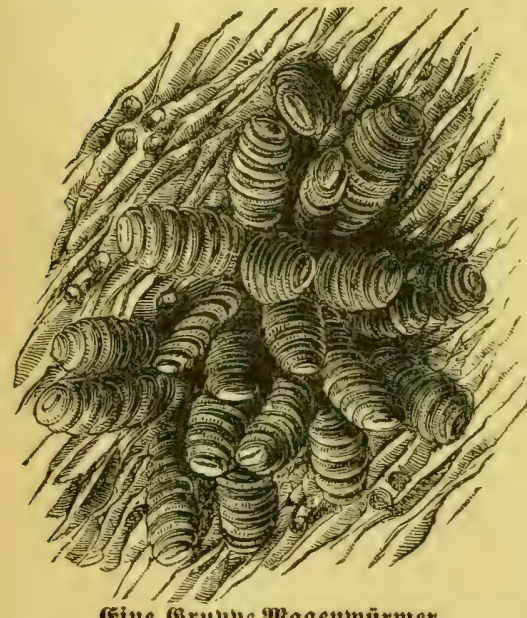

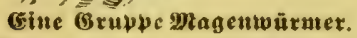
badoes aloes), 3wei Drackinten pulverifïter S̃ngwer, und einte Drad)me pulnerifiter Enzian. Yierundz̧wanzig Stunten nady Dent Eingeben lafie man zmeimal täglich eines ber nadjftelendoct Bulver folgen : eine lluze idjwar= zer Artimon, eine unb cine halbe Unze Salpeter uno żei llnzen Edermeferbrïthe. Man mild)e afle zujammen und theile es in adjt ßulver ein.

Mage nњ ï r mer (Bots).

Der Magenwurm bei $\mathfrak{B F}$ fer= Den brieb bis vor wentigen inkly=

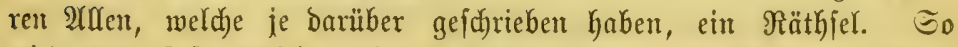
wirb man faft täglidi) nod) von Pferdebefitzen und Farmem gefragt, 


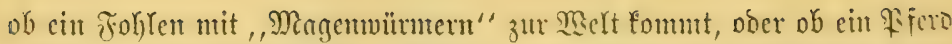

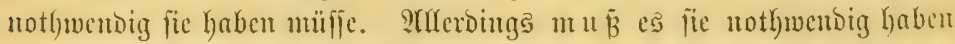
und würde obne fie nidjt lange leben tönten. Sie fund eit Theil bes

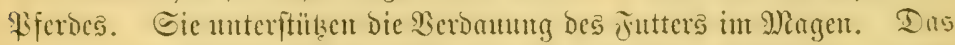

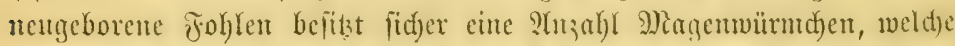

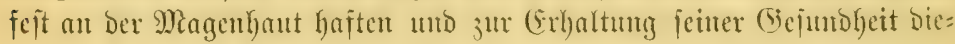
nen, uns fie verlaffen bicien Jalt nidft, mag man bie giftigiten ober fein=

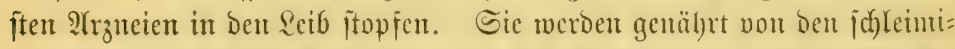

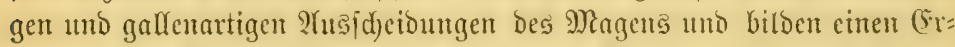

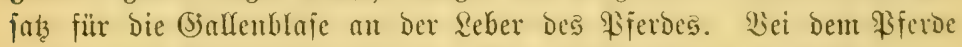
fe hlt bieje (Siallenblaje nänlid). Arber vorbanden ijt cin (5iallengang, Der fid) Durd) Den Mittelpunft ber Reber zieht, und bazu bient, bie (jal=

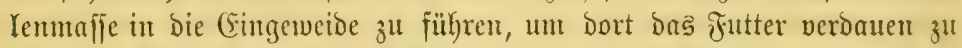

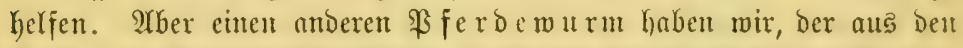

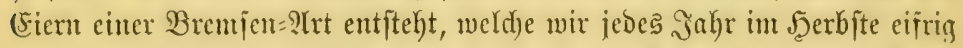
bejäätigt fehen, bieje (Fier in Das Musfelfleijd) ber Edultern, Beine

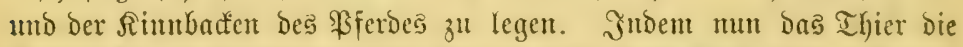

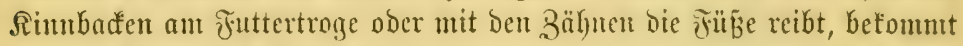
es bicje (Sier in Das Maul ober unter bas Jutter, mit weldem fie in oen Magen gelangen, wo fie aubfried)en uno bie Wümter fich an ber interen Magenthant fejţängen. Die je Wärmer fund gelb und bilden eine inmentige Armec, beren Streben barauf geht, das Biferd zu töbten. Sie fönnen ç aแch aй Dreierlei Beije: Dả Ihier fan Deren poviele im Magen ausbrüten, baß̄ fie fïd in oberen Magenmunde in jold)er Mienge

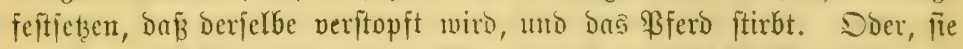
verjeken volljtändig Den unteren Miagemmub, jo Daß Rolif cintritt und jo Der Tod herbeigefülyt mirb. (Endid) tömen fie bie Magenmand Durd)=

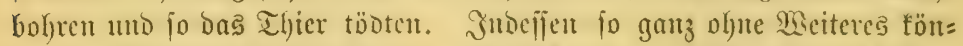

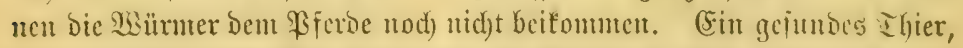

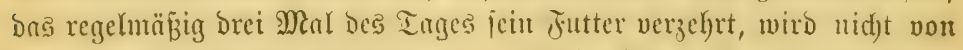
ben gelben Mürmern getöbtet werden. Scin Miagen ifit nid)t verjäuert,

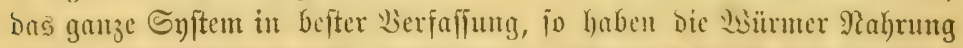

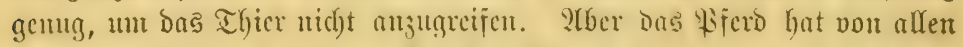

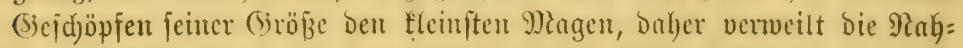

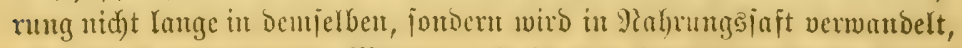
gebt Durd) Den unteren Magemumo in Den Bwölffingerdarm, nimut 


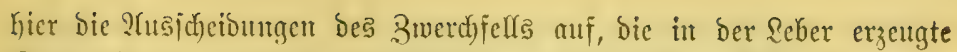

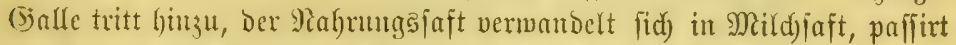
bic flcinen und bie grofien Cringeweide und wird auf biejem Mege ver=

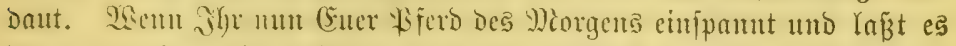
Den gan; teruną gemöbnt ift, am Mittag ijutter zu reichen, jo woiro balo jein Mas

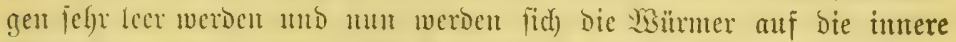

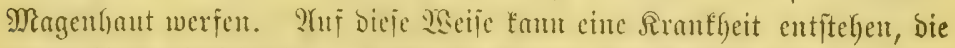

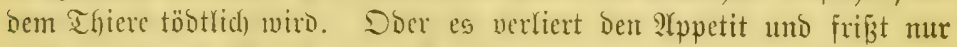

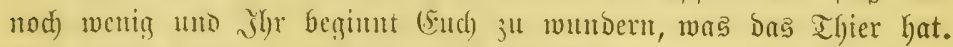

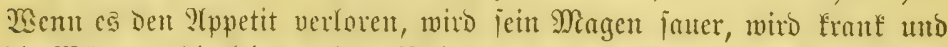
Dic NGünter, bic feine nubere Rahrung mehr haben, greifen bie Magen= haut nu, Dem indem Dic Rranflect bes Bferbes beffen Reben bebroht, io

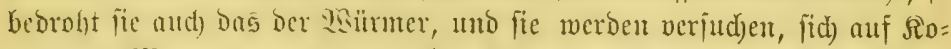
iten bes Mingeng ju retten. (5ireift zu ben Maserfen von Yjountt, mit Prof. Epooner's ?tumertungen, Denen Beat'man's, Magee's und Sterv=

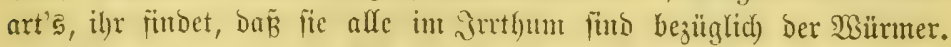

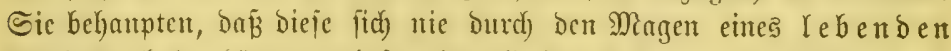

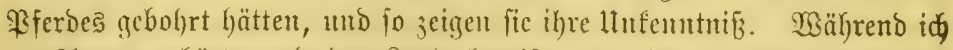
zur 2rmte gehörte uno bas sand bercijte, traf id) auf Bferbe, bie jeit zefn Miunten toot waren, uno bod) hatten fid bicje (ü) on burd ben Ma:

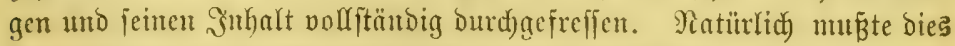

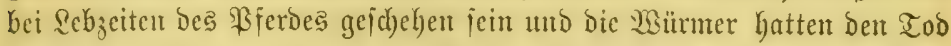
vermiad)t. Tun haben wir fajt alle bic idärfiten und giftigiten $\mathfrak{A} z=$

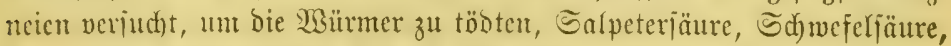

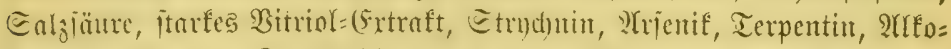
hol unb affe jene Stoffe, bic gegen anbere Wismmarten wirfiant fint, bieje ?rt aber fann thatiäd)lid) non eincr bis ju 24 Stunden in irgend cuncm bicjer Stofie leben. Mian ficht, daf mon mit foldyen Medicinen

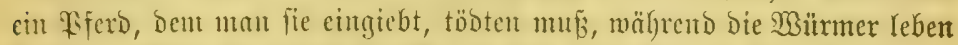

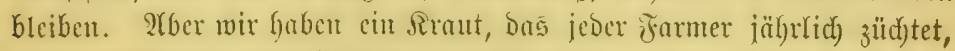

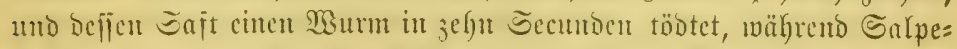

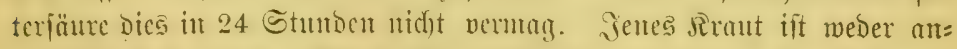

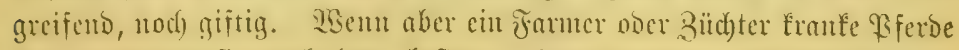
hat, fo ienben jic nad) bem beften - jogenamuten - Biferdocoftor in Der llugegend. (E) fommt und unterjud Das shier. Bielleidyt ijt er 


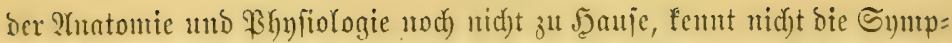
tome ber verjofiedenen Sirnffeiten, Denen bas \$ferd untermorfen it,

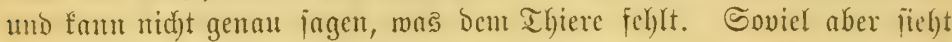

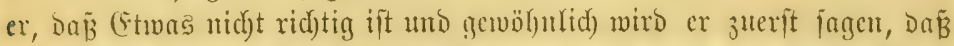

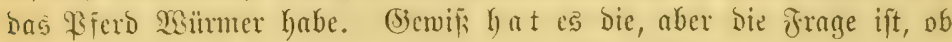
fie jur 3cit Deffen (Sejundgeit bedrolyen. Sid) will jeocm vierzehnjät)ri=

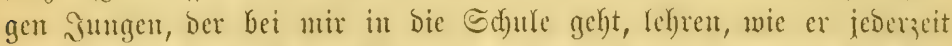

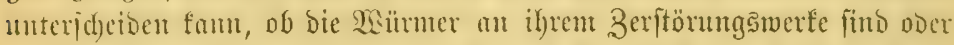

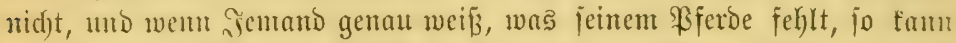

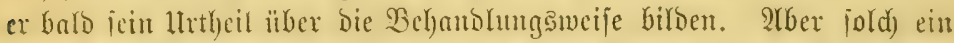

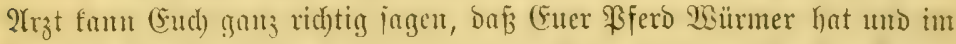

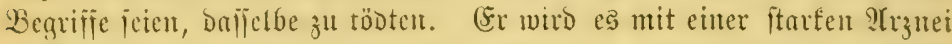

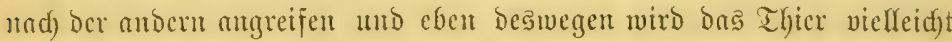

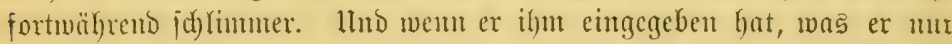

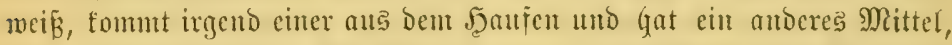

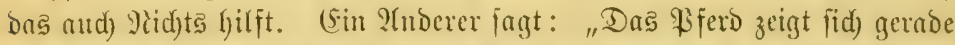

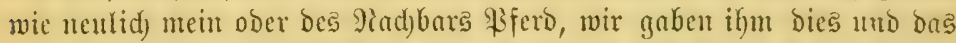

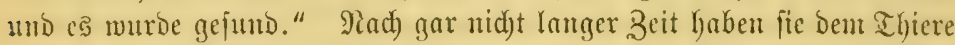

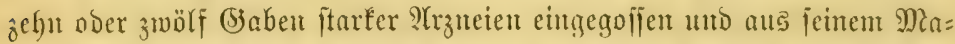
gen einen P(potheterlaben gemad)t und walyrid)eintich töbtet bie Mebicin

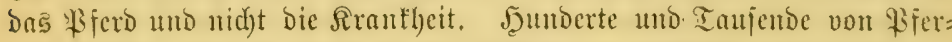

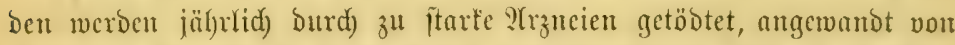

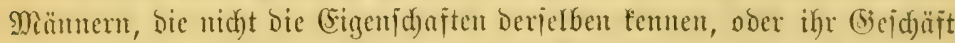
nid)t veriteben. $\$ \mathfrak{b}$ cin Ifier= ober ein Menid)enaryt feinten Fatienten Menicin verorbutet, ftets jollte er im Stande jein, zu erflären, suche

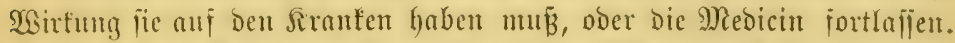

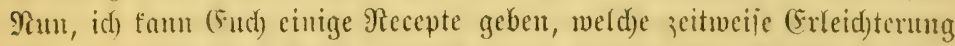

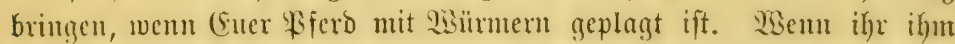
aus Dom Maule Blut entzieht, ober aus Der Raden= Wene ein Duart

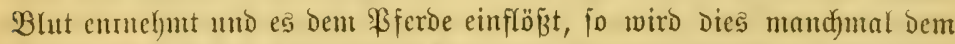

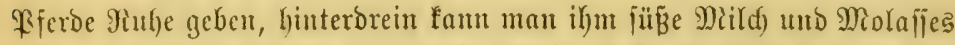
geben, eine balbe Stumbe ipäter gebt ifm ftarfe Salbei=2lbtod)untgen oder

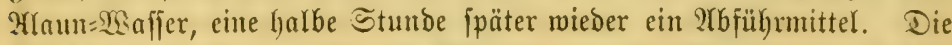
Ditild uno Der Surup lofen bie Würmer, von ber Magentwano abzulaj=

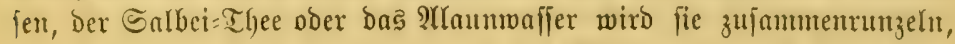

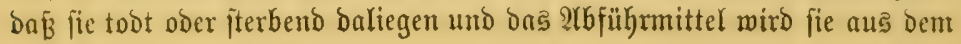


Rörper treiben. Dann mag man Dem I Yiere die Dberlippen emporzie= Gen und mit Terpentin= Spiritus reiben, Den Bruftfaften und bie Border= Brult aber mit Terpentin und burd) Dieje verjojebenen Dperationen wird in 15 bis 25 Miunten bem Thiere Jeülfe werden. Arflerbings nux einte zeitweilige. Biele 23ürmer bleiben nod) in Magen zurüর, und werden zu irgento einer Beit, wo biejer Yeer noer verdorben ift, Die Wände vieder

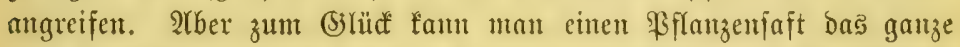

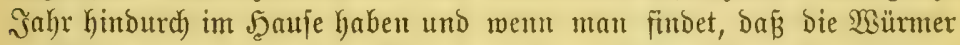
ein Pferd wieber plagen, jo flöbe man ifyn cin Duart biejes Saftes ein. Sobald berjelbe in ben Magen gelangt, werben die Wümmer bie Junen= haut loshlaffen und fid an ben Gafte volljaugen, mie bie Sd) räud)e, aber Das (Sias, weldhes in bem Safte enthalten ift, wirb fie auseinander

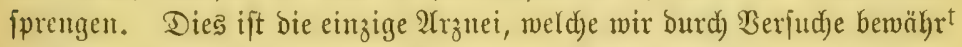

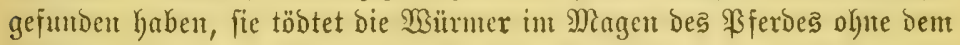

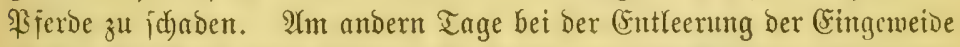

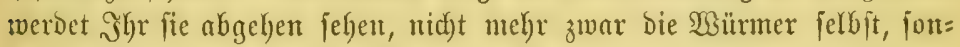

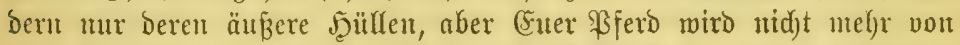
ihnen geplagt werben, bevor nidgt mieber ein Serbit fommt, wo wieberum Die Brentjen ihre (Sier an bie crmähnten Brätze legen, bie Cier mieber mis Dem Futter in Den Magen tommen, Dort austriect)en und biら näd)iten Gommer bort verbleiben. Dann ift bie 3eit ba, wo fie freinillig mit Den (sxcrementen abgehen, fidc) in Mijtgaufen ober (Srbe verfried)en und Dort eine Wandelung, ähnlid) wie ber Scibenwurm, burdhuad)en, fie rie: gen in tobtenäbnhichem (Sd)lafe Drei bis fünf Wod)en lang, Dann berftet, wie bei ber Seujarede, bie hornige Sdjale und heraus fommt eine neue

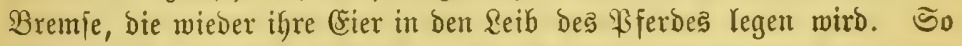
pflanzen fid bieje nid)tsmutzigen gelben Würnter, bie fo mandyes werth= volle Bferd töbteten, fort von Seneration zu Sieneration. OYber man fann fie jhon im (Ei töbten, wenn man die Stellen bes Musfelfleifd)es, wo fie liegen, zmei bis orei $\mathfrak{M a l}$ mit Terpentin= Spiritus majd), bą ver=

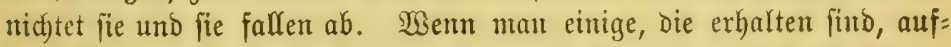
Gebt, fie in bie fladje Şand legt und Darauf ipeit, fo werden fie binnen zmei Minuten ausfried)en. Wenn man einen lebenden Wurm aus bem

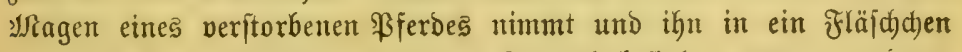
thut, in beffen Rorf fid) ein winziges \&uftlod) befindet, wenn man bann

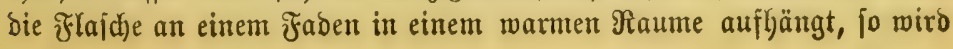




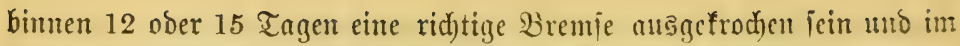

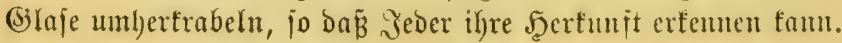

\section{Die eriten Merfmale bei Mürmer.}

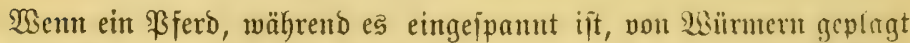
ift, wird man bemerten, wie es bäufig mit einem ober bem anberen Wor=

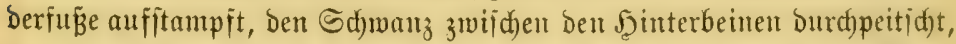
untuhig wirb und raid von einer Stellung in bie andere wedjelt. Wient utan es ausjpant, legt es jid) auf Den $\mathfrak{B}$ oben und wälzt fid von einer Seite auf bie andere, bleibt aud) auf ben Flanten liegen, die Najemipibe Ginter fid) nad) Der oberen Rörperjeite brehend und Sdymerz verrathent. Dft zerrt es bie Sberlippe nad) antmärts uno menn şar biejelbe unter=

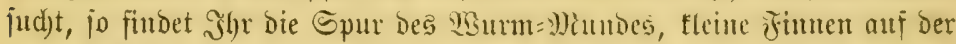
inneren Sd)leimlyaut der Sberlippe, melche bei gejunden Bierden oner

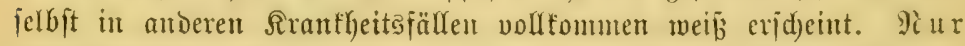

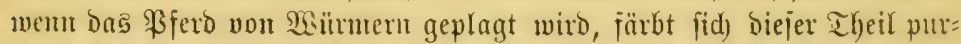

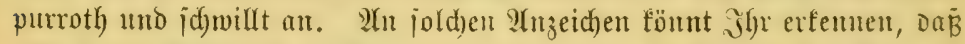

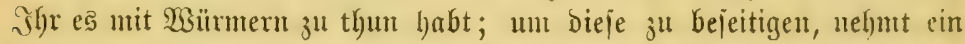

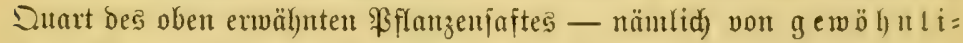

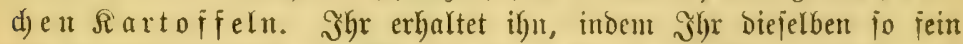

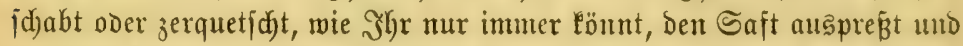
ifu dem $\mathfrak{B}$ ferde eingiebt. Diejes Mittel wird in jeden Fafle binnen

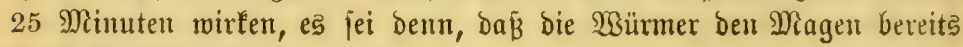
ourd) lödjert hätten.

\section{(5) e ni f $=$ Fifitel.}

Unter alfen Hebeln ber Welt ift bie Gieniafifitel bos gröpte. Sie wiro herbeigeführt burd) eine Duetfdung Des Nadents ober irgend eitten

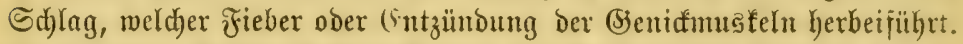

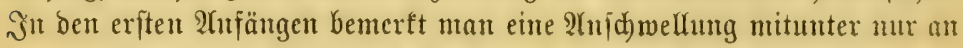

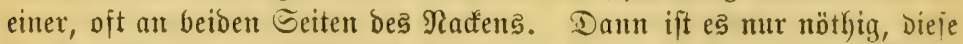

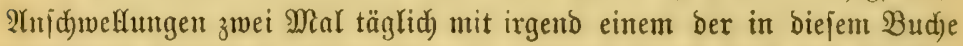
erwäbnten Riniments einzureiben, in wenigen Iagen mirb fich bie (bie=

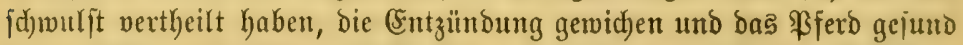

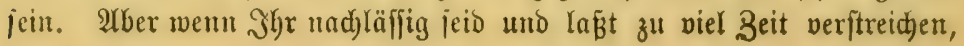




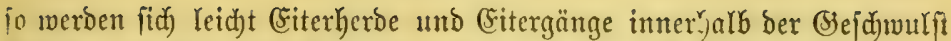
bilden. In biejen Falfe murbe bis vor menigen Jahren bas Hebel aud vort den beften 2Gutoritäten für unbeilbar gebalten in jofern, als i.nmet

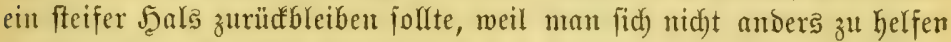

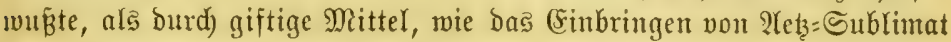
in Das Jnnere Der (Sicid)wulit. STrjenif aber und Gäure irefien fich ein

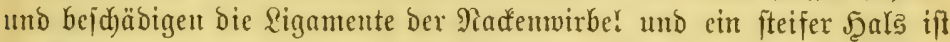

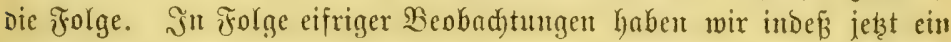
Mittel gefunden, weld)es ftets vollfitünoige Jacilung idaffit. 3unäd)ft

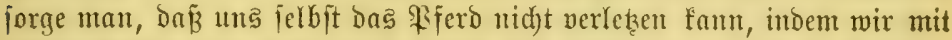
feitent (Siriffe jeine Dberlippe faffen und niederzerren und eines jeinet

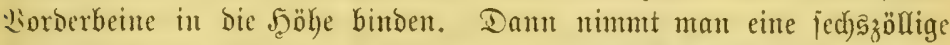

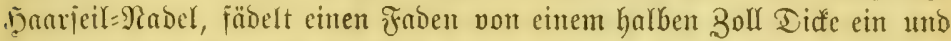

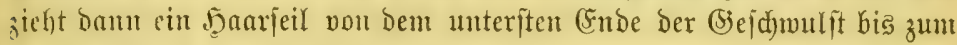

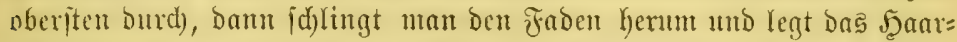
jeil feit. Jeierauf bercite man folgendes $\mathfrak{B a j}$ dumittel: THmonia Mu= riata 2 Inzen, Terpentintpiritus uno Seinöl 4 Unzen, Theeröl 1 Unze, QReb: Sublimat 1 Inze, Majoranöl, Job= Tinftur 1 llnze, Rrotonöl 1

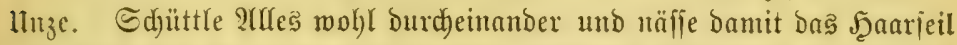
żwei Mal täglid), indem man eら babei jebesmal vouftändig kerauf und

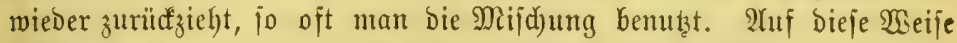
fahre man fort, fo lange nod) biffer, gelber (Fiter heransjtrömt. Sobals

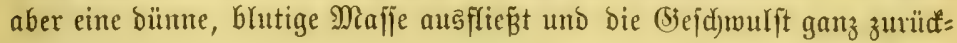

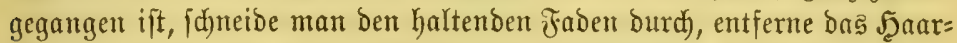
jeil und majdje mit einer löjung von ventianijdjer Seife in marmem

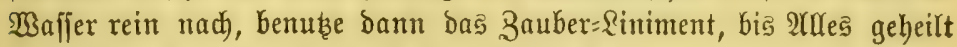

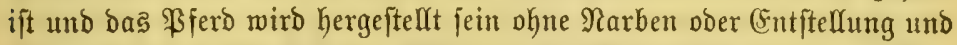
feinen fteifen Raden haben. Währent des Gebraudbes ber lẹteren Me= bizin waja)e man täglich die Stefle rein, das wiro bie Jeeilung bejdyleu=

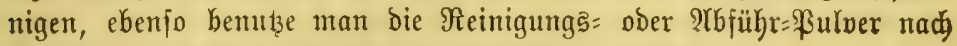

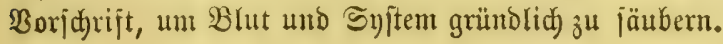

\section{Fiftel.}

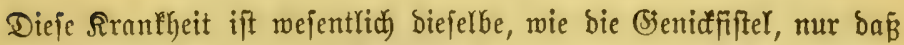
fie anderजwo ifren Sib̨ Gat. Dafielbe Berfabren wiro aud Gier Şeilung 
bringen. Man befolge baher genan bie Boridyriften, wie bei ber (Sientä= iiitel, und man wito jebe Fiftel Geilen fömen, nur twenn biejelbe zwijd)en

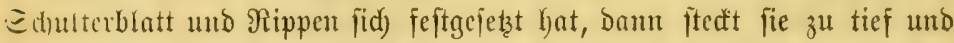

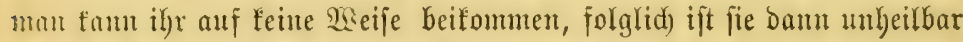

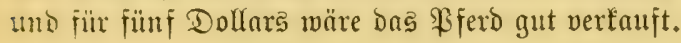

WB in b a liten.

Cine halbe llıze Majoranöl, eine halbe Unze Terpentinjpirtus, eine

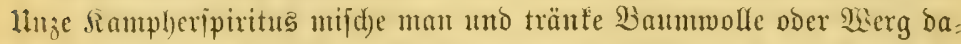

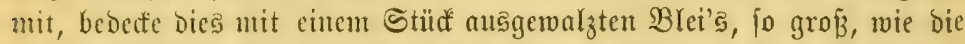

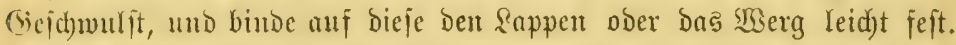
Iäglidy cimmal nelbme nan bafjelbe ab, tränte es von Reuent und lege es

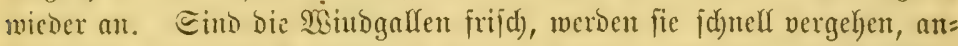
Serufalles wird ibre Befeitigung länger bauern, aber fie erfolgt ficher.

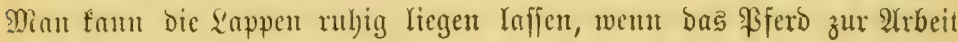
berutist wirb.

Rranketten ber S⿹arnorgane.

Rieren=(5utzüudu

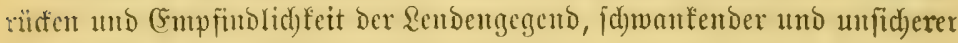
(3)nug, Beriud)e zu uriniren, ofjue (Erfolg.

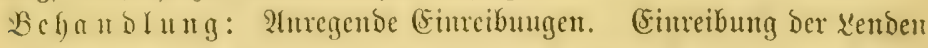

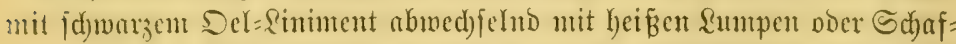
fcll. (5icb: Enlpcterjpiritus cinc llnze, Sampleripiritus cine halbe

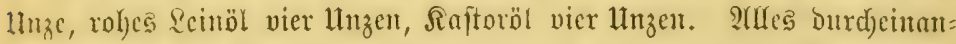

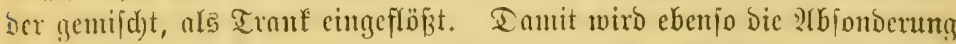
ans Den Cingeweiden, wie dic bes Uring bewirft. WBenu es nicht binnen ciner Stumoe mint, mieberbole man die Gabe. Mian unterjude bie

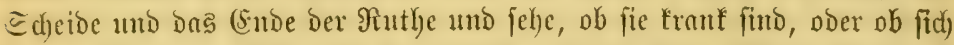

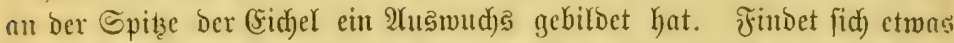
incrgleidyen, fo waid)e man bie Sdyeide mo ben Benis mit warmen Sei=

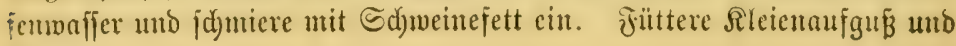
(S) rünfutter.

\section{(5in a no res Mitter.}

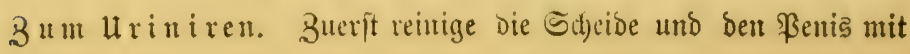


warmer Seifentöfung uno ipüle mit faltem Şaffer nach. Sdymiere tïd)= tig mit Sdymeinefett, nimm bann: Sotaffia=9itrat eine Unze, Fotaffia= Ucetat eine Hnze. MRifaje uno löje ę in cinem \$ist warmen Majiers,

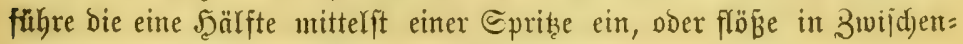
răumen von zruci bis brei Stunden ben Meit ein.

\section{$\mathfrak{B} \mathfrak{l} \mathfrak{u} t \mathfrak{l}$ a $\mathfrak{r} \mathfrak{n} \in \mathfrak{n}$.}

(E⿱

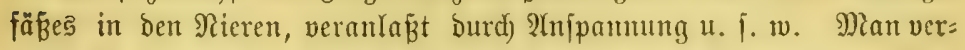
meibe alles, was Utrinbilónng veranlaffen ober veritärfen müß̄te. Slan

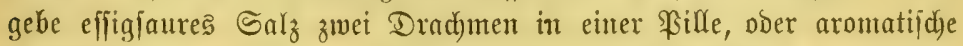
Sd)weferfäure cine Drad)me im Irinfwaffer täglid) żmei Mial, einige Tage

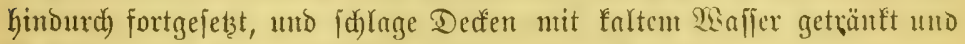

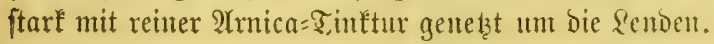

\section{Stridfäure un Strahltreb}

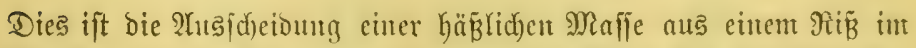

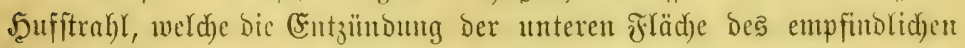
Theiles bes Suffitralyles anzeigt. Dabei wird, ftatt ber J̧ormmaffe ober

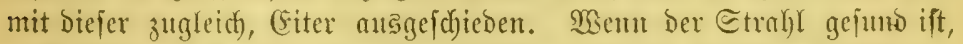

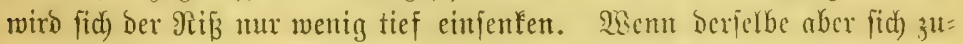

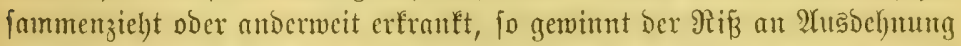
unb bringt häufig bis auf bie empfintrichen J̧orntheife vor, und Durd) foldd' eine unnatürlid) vertiefte Spalte wirb ber (Giter gebrängt. Die

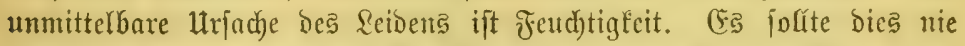
vergeffen merben, fonft wiro fich Mandjer zu einer falfden Befantohung

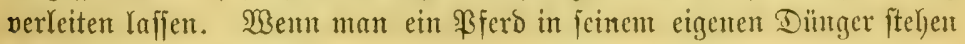
läß̈t, fo wiro unfehlbar bie Strahlfäule eintreten, wie überhautpt ftets ba,

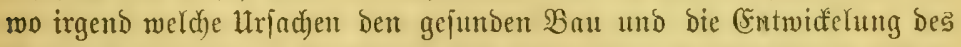
Strahles angreifen. WBir finden Das Hebel öfter an ben Şinter= als an

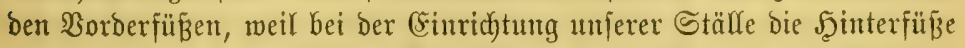
immer megr ben verberblidjen (Sinvirfungen bes Düngers uno ber Hrin=

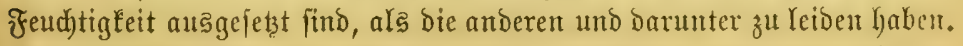

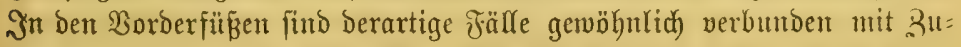
jammenziegungen ber 5ुufmaffe. Der Drud auf bent Etrahl in Jolge 


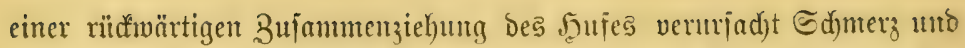

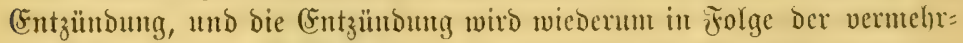

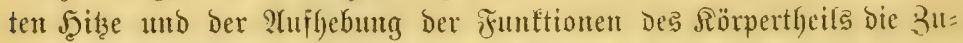

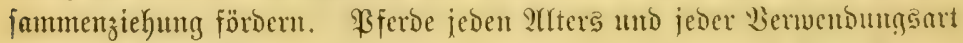
finto ber Strahlfäule unterworjeı, jogar unbcid)lagenc fohlen töm von ifgr befalfen weroen. Das llebel ijt nicht immer mit Safunfleit ver=

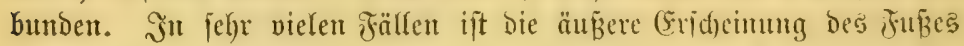
faum ober gar nidjt verändert, und bns llebel kam nur bei gentuer llt: terjudyung entbefft werben, ober aud) Durd) ben eigentfüunlichen (Sientd)

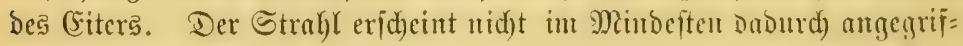

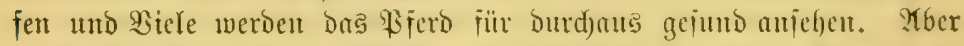

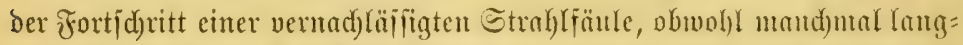

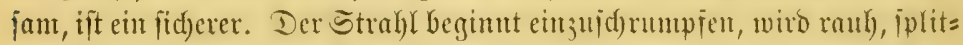

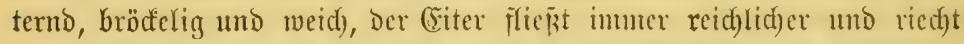

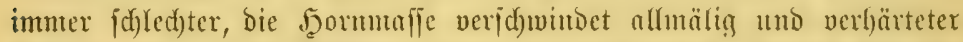
Sdjlem tritt an jeite Stelle; Dicjer fällt gelegentlich ab und Der em= pfindlid)e Theil bes Strahles liegt blos, eitue fdymammige, törnige Jialie

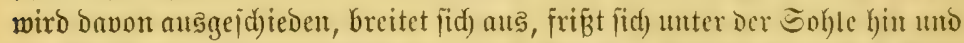

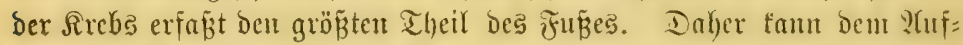
treten Der Rranffyeit gar nid)t id)uefl gemug entgegengetreten werben, แno

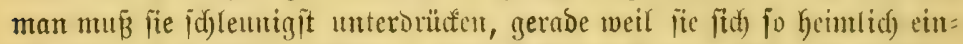

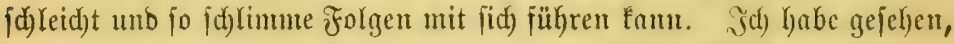
wie in Folge vou 2ernad)läffigung Der ganze Juf zerftört wurbe uno io

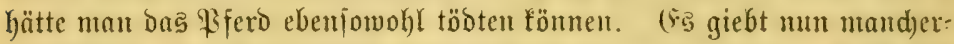
Iei Mittel, ber begimenden Strahlfäule entgegenjutreten. Faị jebe Anwentoung eines jujammenzichenton, aber nid)t ju jehr äßzenden Mit-

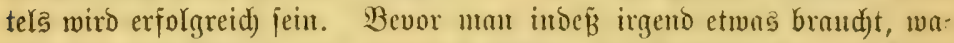
jde man ben Stragl uno ben Fub tüd)tig mit Seifenwaffer uto fratze ben (Eiter rein aus, man idjucide alfe themen Stiftd)en bes Strahls weạ nuo trodite benjelben, bann aber halte nam ben Fuß vou jeber ?trt vou

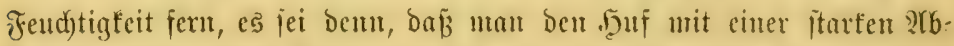
fod)ung von gleiden Theilen Sabad und Rated)ugummi beizte. Ties ift gut, benn es zicht ftarf zujammen und nimmt bas ?llfali ber Ecife mit weg. Dam kalte man ben Fun in bic Jöbe und tröpfle in bie Mitte des Strabls und rings un bicjen julbit (5arboljüute, dicje bects man mit Jidjtentgeer. Dic Gïme töbtet Das llebel und ber Ihecr hält 
jebe Feudutigfeit und allen Sdumuts fern. Dieje Behanblung nun fort=

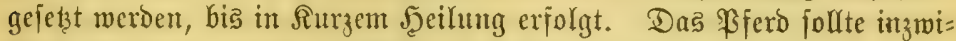

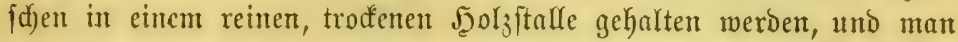

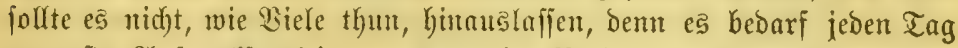

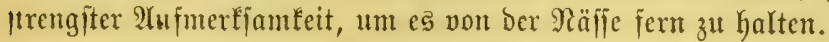

$$
\text { S2u fte n = } \mathfrak{B} \text { ill } \mathfrak{l} \text { e. }
$$

(Biepulverte Brechmurzel (Jpecacuanja) breiniertel llnze, Rampher=

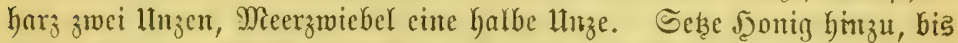
ess eine functbare Maffe wirb, forme baraus adyt \$illen, gicb eine jeben Miorgen.

$$
\text { Fieber }=\mathfrak{B} \text { irte. }
$$

Bred)meinitein eine Galbe Unze, Sampherhar eine Galbe $\mathfrak{H}_{\mathfrak{z} z e}$, Sal= peter zmei ltuzen. Mifhe bies mit Reinjamentmegl uno Syrup uno madje adjt Willen baraus, bavon gieb eine ober zwei täglid).

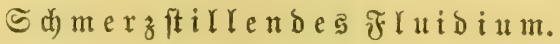

Dasjerbe ift Gcfier, ała bas von ßerry Davis, ober ein anderes, $b$. idi) je habe ammenden fehen.

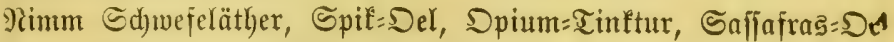

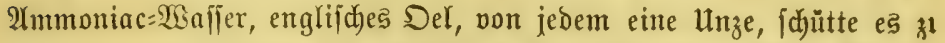

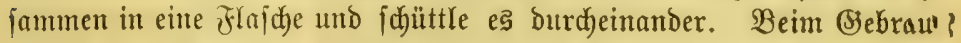
farütte man bavon in bie Fand und reibe bie fidmerzenbe Stelle jat p ein. Dics bejeitigt alfe ftechenden, fdharfen, bohrenden Sdemerzer

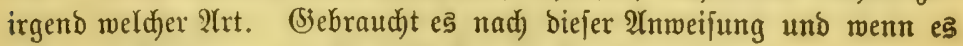

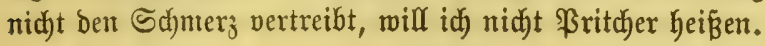

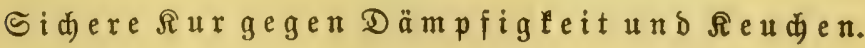

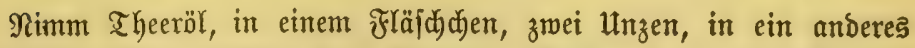

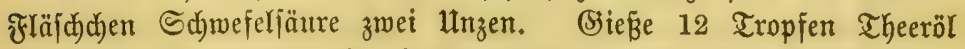

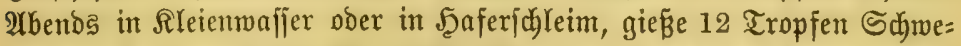

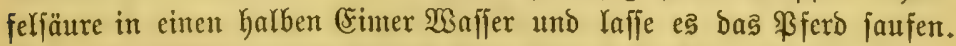

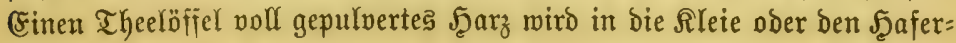
fdjleim gegcben, in weldjen bas Theeröl gemijobt wurbe. Stieb bem 


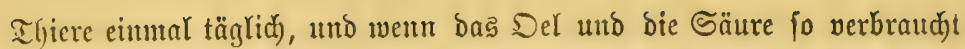

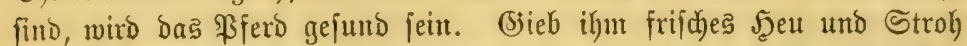

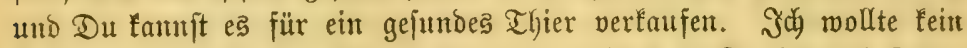
\$ferb um einen Dollar billiger weggeben, weil es an Seuden und Däm= pfigfeit leibet.

$\mathfrak{A} \mathfrak{b}$ fü $\mathfrak{h} \mathfrak{r} \mathfrak{m} i t \mathfrak{t e l} \mathfrak{i} \mathfrak{m} \mathfrak{F} \mathfrak{r} \ddot{u} \mathfrak{h} \mathfrak{i} a \mathfrak{h} r$.

Ulm \$Ferde im frühjabr proentlid) abfübren zu laffen, bamit fie glatt uno gejun ausfehen, nehme mant: Sdjwarzen, gejdmefelten Spießs= glanz 2 unzen, Salpeter 2 unzen, Sdjwefel 2 unzen. Mifdje arkes

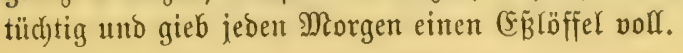

Liniment für $\mathfrak{Q}$ uetidungen u

Itnumoniatwafjer 2 Unzen, Ramplyeripiritus 2 unzen, Majoran=Del

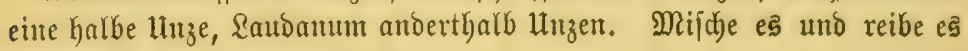
tüưtig ein.

\section{Einanderes.}

Bei Betrentungen mehme man: CFin viertel \$fund Salpeter, eine Unze WBermuth, ein Quart ftartent Effig. Miadje alles zufammen beiß,

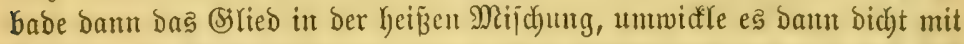
Tübern, fend)te biefelben an, lege trơfene barüber und fahre fo fort, bis bie (Stejdyulfit fid gelegt lyat.

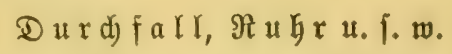

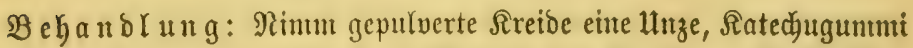

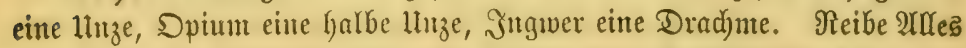

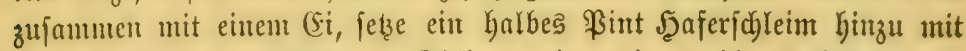
einer Unž Edjwefeläther. (Jieb es eill, wie es bie Utmftänbe ver= langen.

\section{Reinigende Eryftiere.}

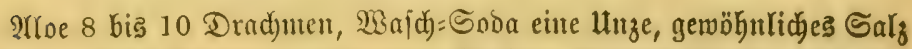

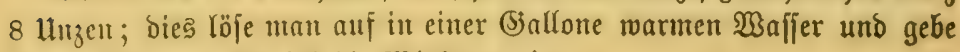
bavon (Sly)ftiere, bis fich bie $23 i n f u n g$ zeigt. 
abfürende (sinfiere.

Bmei Quart laumarmes Waffer, fechs ltızen Epjomjalz. Şäufige

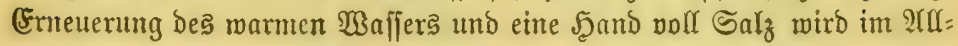
gemeinen genügen. Den Umftänton bes Falles entiprechend zu be= nukูen.

\section{Áführungamittel.}

Raftoröl adjt ltnzen, Sirontonöl 10 Tropien, Dem Thiere eingeflb̈ß̈t, und wenn es nidft alsbald wirkt, in einer Stunde mieberfolt.

(E) a n

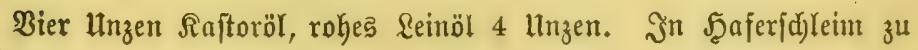
geben.

Ueberfürter Magen.

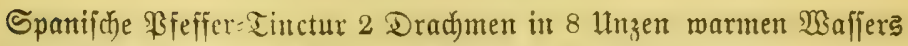
alle fünfzelyn bis zmanzig Minuten gegeben, bis (Srleicbtennt eintritt.

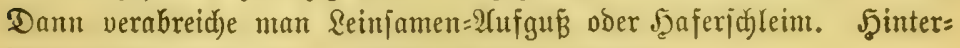
brein ift für einige Beit jorgfältige Diät zu halten.

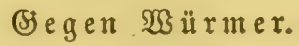

SBenn ein ßferd gut fript uto babei Dod immer magerer wiro, gebe

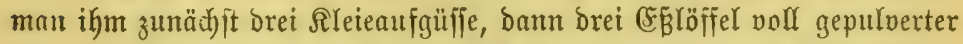
Bappelrinde int Futter ein Mal täglich brei Tage hindur(h), wäbrend ber nächften orei $\mathfrak{T} a g e$ zwei Mal bavon täglid) und wieber ein Mal währent ber folgenden orei Tage, fo lange, bis man eine Befferung bemertt und Maffen von Würmern abgehen fiełt.

$$
\text { Şa armud } \mathfrak{s}=\text { Salbe. }
$$

Sarbolfäure eine Unze, Sdjweiuefett ad)t ltuzen. Dber: JoD eine unze, Sdneinefett vier linzen. Miifbe es gut und rcibe es ein, toern

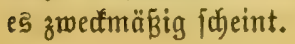




\section{(5) egen ธattelorud.}

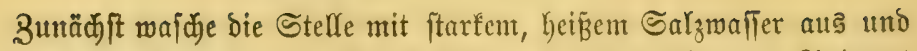

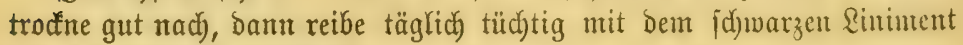
ein, bis Jeeilung erfolgt ift.

(5) egen $\mathfrak{A} \pi[$ d wellugen $n a d) ~ S u e t ; d) u g e u$.

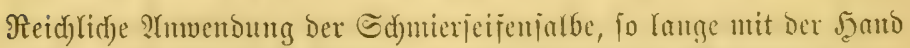
einzureiben, bis fid) ftarke Märme in bem betroffenen Sï̈rpertlgeile ent= widfelt.

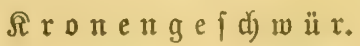

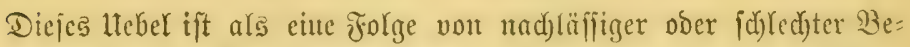
handutug, ober ber Berleţutg ber grof̧en Beugejelute ober ciner Heber: anitrengung bezcidynet worben, Doch fann es entitchen in jolge irgento

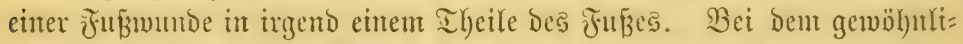

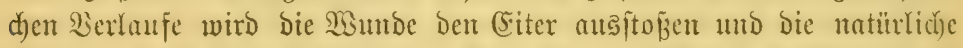
Sceilung wird babutrd) bebingt. Der (Eiter, weld)er aus Mumben im

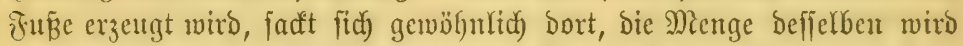

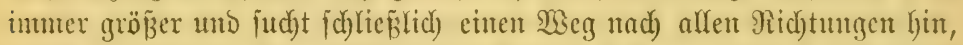

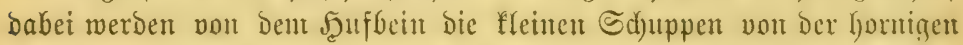
Sgantmafle abgeiprengt, wird bic Sinfte ber hornigen Goble von ber flei= fdjigen Sohle gelöft, ober es frif̈t fidc) Der (Siter tief in bon interen Theil

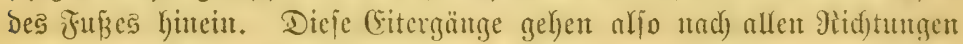

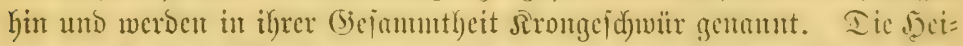
lung wird in ber Nicife erreicht, Daß̧ man 2leşmittel in bie Eitergänge einffülyrt, bis biejelben meggerüunt füto, ober, wem bas ltebel nid)t meit

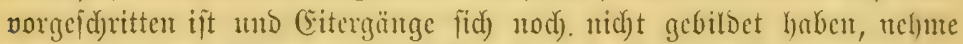

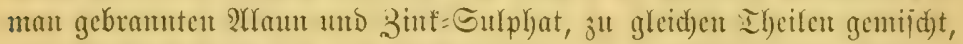

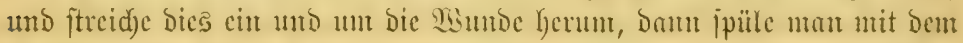

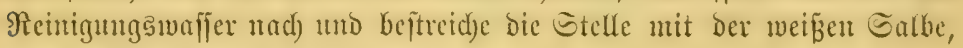
um bie આbheilung zu beföroern.

\section{(5)egen ipröbes Freifd.}

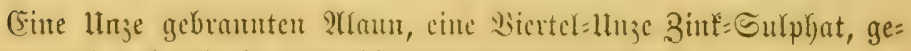
pulvert uno auf unb ritgg un bic fpröbe Stelle acitrut. 


\section{Ein anderes Mittel.}

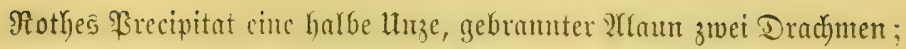
oder calcinirtes weiß̈es Bitriol und 2 fraun.

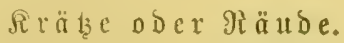

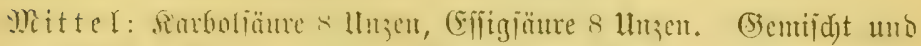

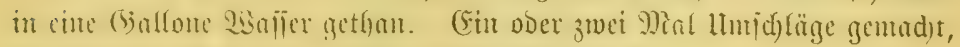
in merom jelbit bic idnuicrigjten fälle bejeitigt jein.

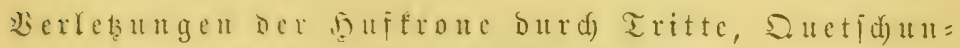
geu, itreifende Eijeu u. i.

Mittel: Gid) hatoe nod) immer ant beiten bemälyt gefunden, wemt

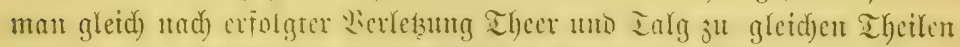

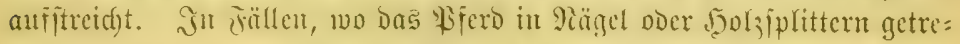

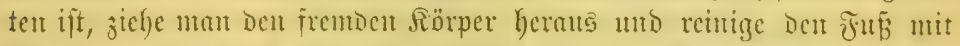

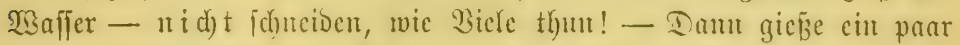

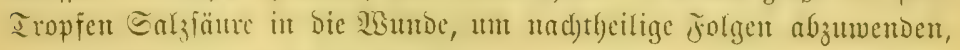
unt fitreide I I

Salbe gegen 6 dranmen, geidruortene Fefielgelente,

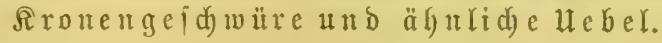

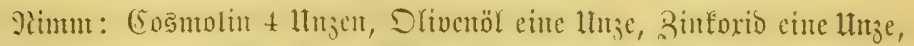

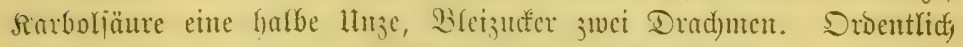
Durdjeinamber gentidyt und tïd)tig in bic munden Stellen cingerieben,

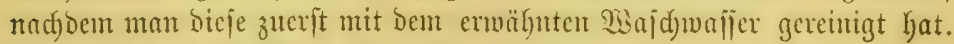
Mian wird bas Mittel gerwif werthuoll füben.

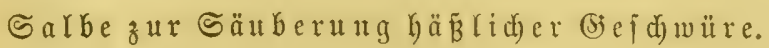

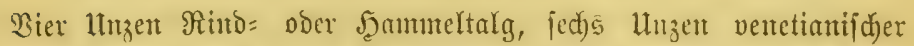
Terpentin, zwei unzen rothes \$recipitat. Tüd)tig gemijd)t ift es fertig für ben (Siebraud). Buerit reinige man bas (Sefd)wür mit warment Sei= fenmaffer, ipüle bann nad) und wende bam bie Earbe an. 
B̧ei в̈e Salbe gegen (5)

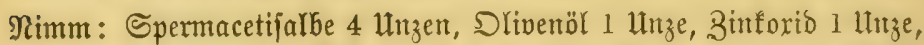

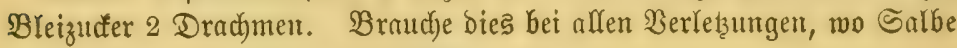
verwentot wiro, und reibe bieje tüdotig eint.

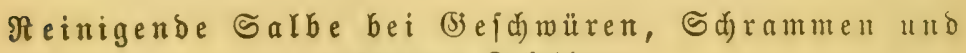
offenen Sdäben.

Arlaun 4 Drachmen, Birffiulphat 2 Scrupel, Earboliäure 1 thıze,

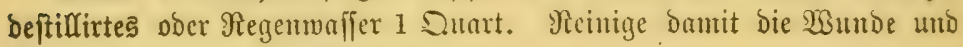
Preidge Ginterher meiß̨e Salbe hinein.

Ratarrh ober einfade Erefältung.

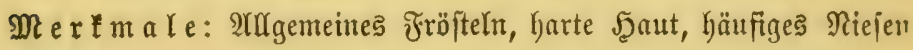

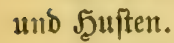

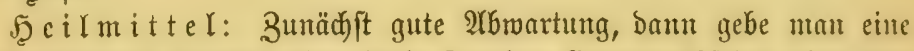
halbe Dradjme Ingmer, eine halbe Drad)me (Sanenne=PFeffer ober eitre

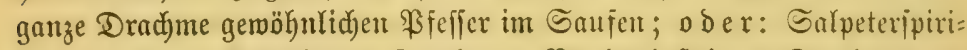
tus eine Unze, Rampher 2 Drad)men, Bred)weinftein 2 Drad)men im

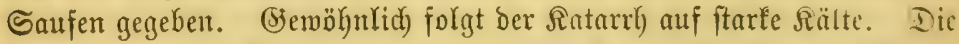

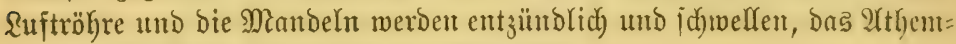
holen wirb jaymer unb ebento bas Sdyfuctent.

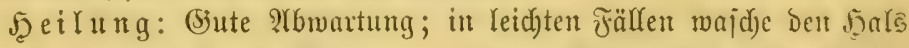

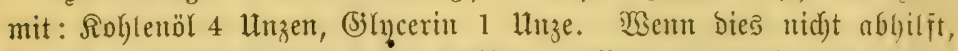

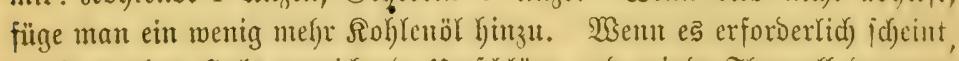

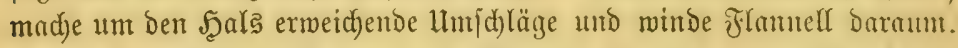

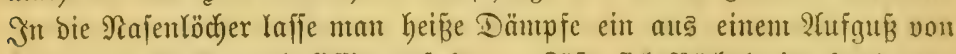

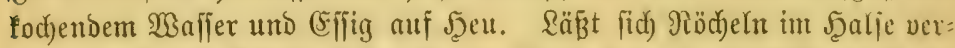

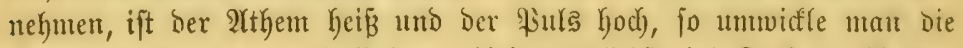

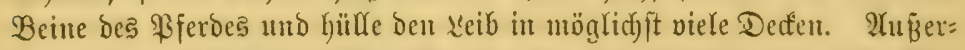

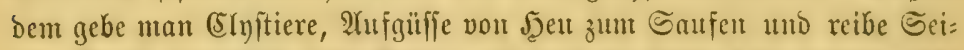
ten, Bruft, \&uftröhre uno Rethle. Sollten bie Fübe falt Gleißen, gebe

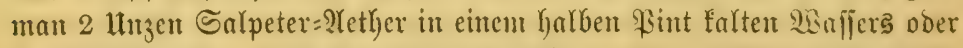

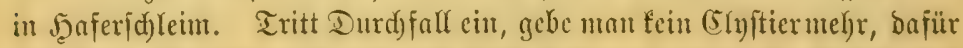

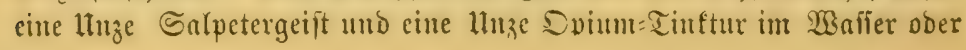




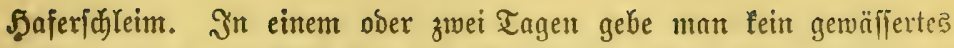

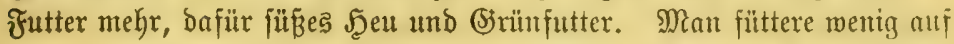
einmal, aber oft. Bei bejonberer Eshwäd)e gebe man 2 Dradjuten gepulverten Ingwer unb 2 Dradjment gepulverten Booldenjament brei bis

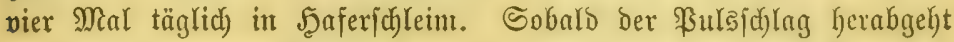

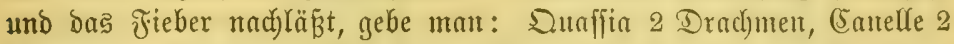
Draddmen, Gngwer eime Drad)me, nad) zwei ober brei Tangen füge man bicfer Mifaung eine Dradjme (Sifenjulphat Ginzu. Man vermteibe falte Tränle แnto jorge für warmen Stall und Rager.

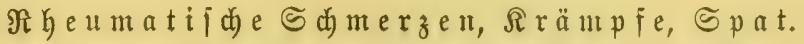

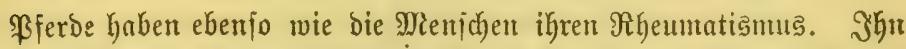
zu vertreiben, muß man biefelben Mittel brautden. Man halte bą \$ferd in einem reinen Stalle und wajde bie $\mathfrak{B}$ eine pder jonft angegrif= fene Rörpertheile reidylidy mit heiß̈em Salzwaffer, bant mehme man ein Faß

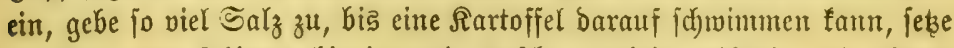
dic đ̛üße des Thieres Ginein und wajd)e, tüd)tig reibento, mit einem

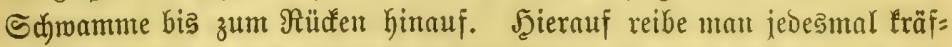

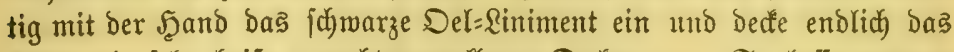
Thjer mit fehr heíz gemadgten wollenen Ded̛́en zu. So laffe man e?

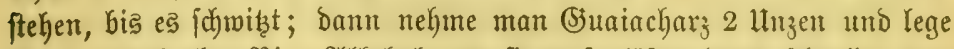

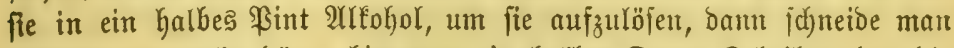
Meerrettigmurzeln büm, bis man ein halbes Duart Sdjeiben hat, bie

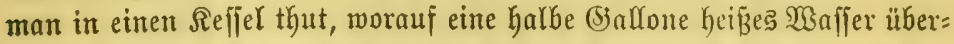
gegofien wiro. Nun lafíe man ben Reffel feft zutgebedét Den ganzen Tag

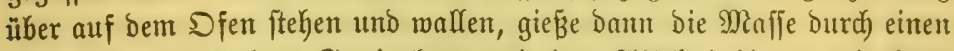

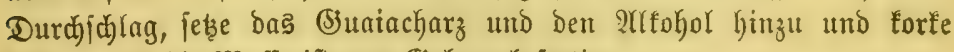
feft zu, und bie Maffe ift zum (s)ebraudf fertig.

Man giebt ein halbes \$int brei Tage Ginter einander 2tbenos mit dent RYeienjaufen, bamn einen 2tbent um Den andern, bis bas Hebel geljoben

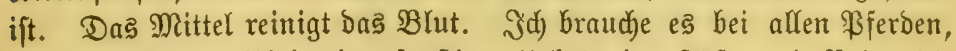

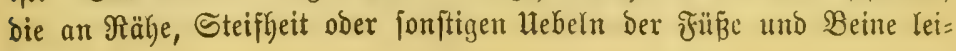
ben.

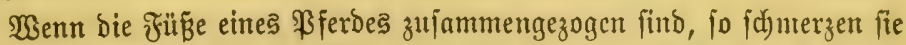
mefhr pber meniger bis zur Sdjulternhähe, Denn bie Sehnen gehent von 
Der Mitte Der Sdjulter bis zur J̧ufiohle und Dem Sdyfffbein; ment id) baber Rafuntheit heilen foll, fo arbeite id inmer von oben berab. Bei

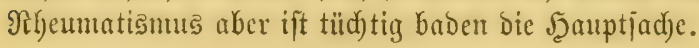

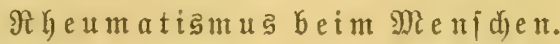

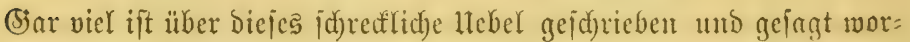
ben, uno Jeber behauptet, fichere Secilmittel zul haben. In mentige

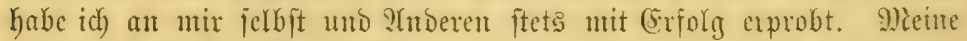

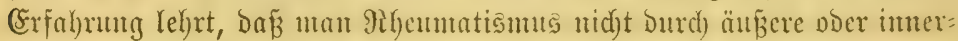

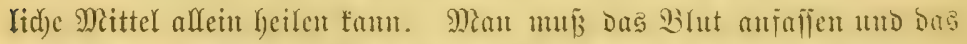

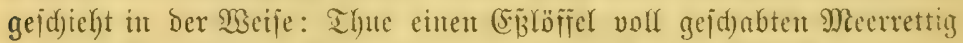

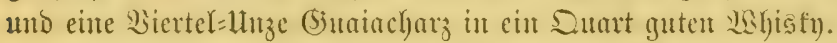

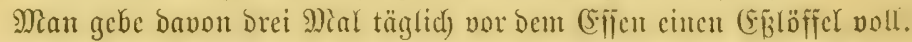
Dant reibe man tïd)tig und reid)lid) bas iduwarze Del=?

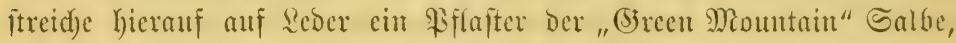
bies lege man auf bie junterzente Stelle unto lafie es liegen, fo lange es

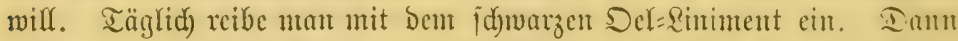

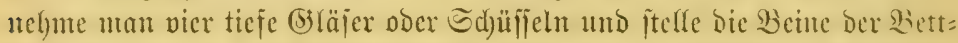
ftelle hinein, unt bie Glectricität ber Groe von bent fiörper abjulbalten, fibzt man lange auf etum Stuble, jo ftelle man biejen ebonjo. Dies ijt flax, einfad) und billig.

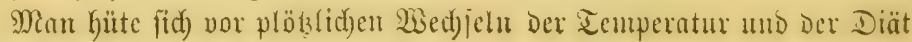
uno idy ftehe für bie \$ูeilung ein. 


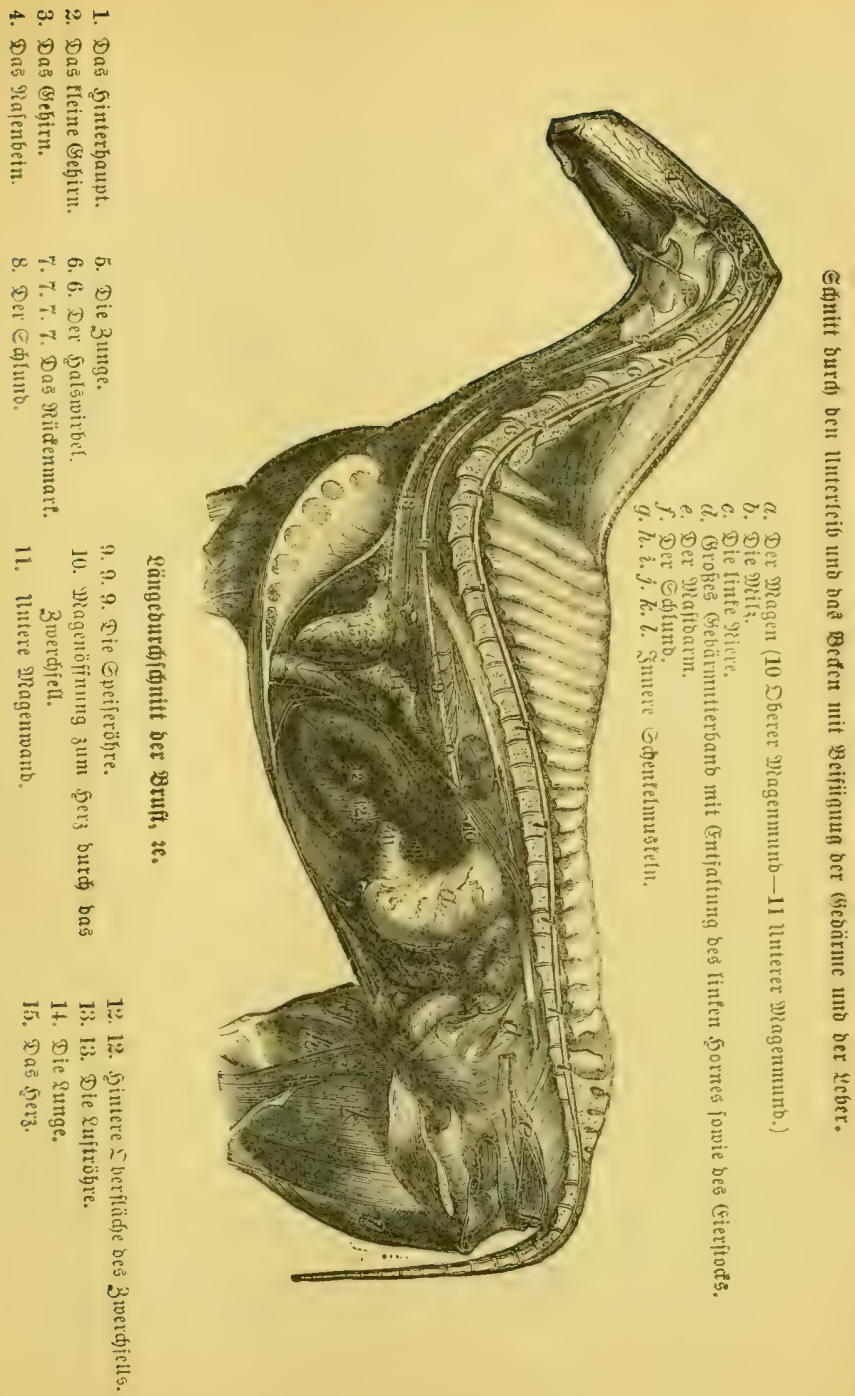




\section{Der Pferdefuf.}

(3um Rapitel. „Das Bejulagen ber Bietbe。")

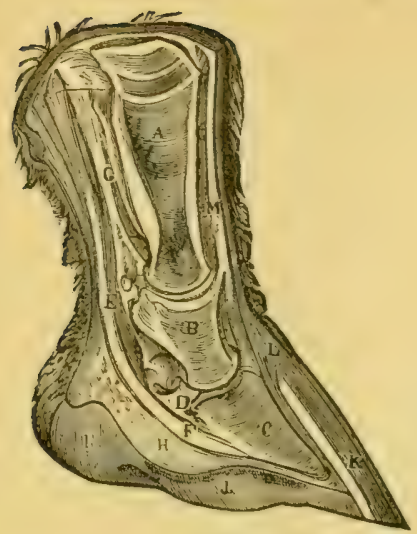

ซิig. 12.

A. Felfelbein.

B. Rronbern.

C. 5uibein.

D. Etrablbein.

$E$. Etrediehne.

F. Beagejegne Deß Rronbein.

G. Beugeithne bes șujbeins.

H. Straht*ifien.

I. Ffteijbball.

$h$. 5ornjoble.

L. Jorntwand.

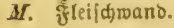

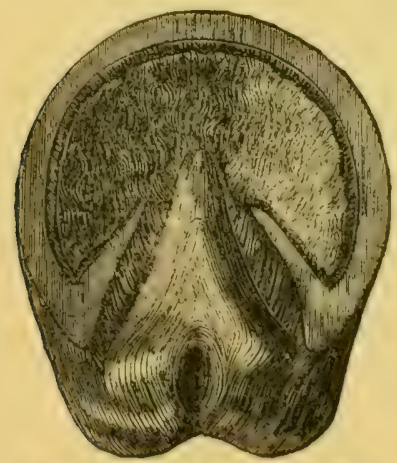

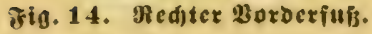

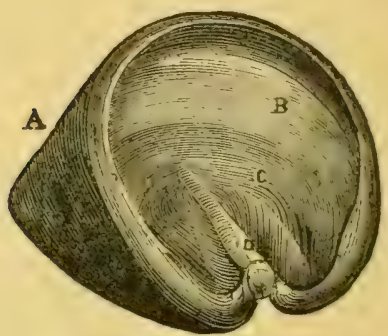

รig. 13. จex қนท.

A. Die üuliere 5ornfläd)e.

$B$. Die innere \$oเnfläche.

C. Die inuere offäde ber zoble.

D. Erhöbung meldie bem froid entiuriat.

E. Das fronbarto.

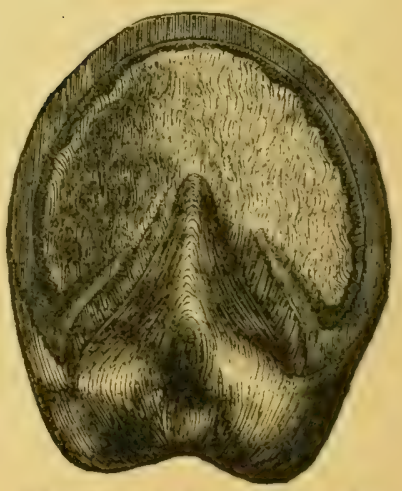

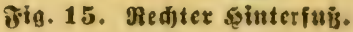


hervorgentien, ber gar bals jid) bis finauf zur Fü

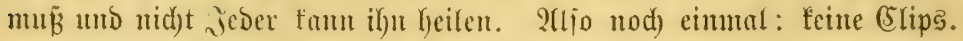

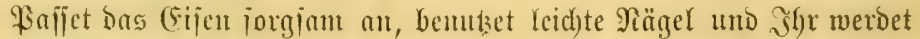

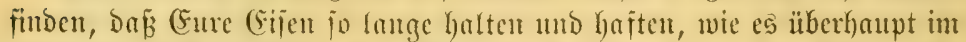

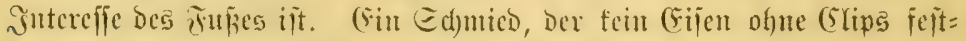
bringen tam, follte hungelaen und bas juerit lemen. Die bier abgebil=

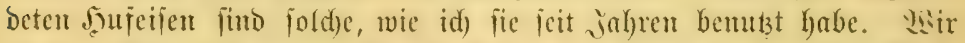

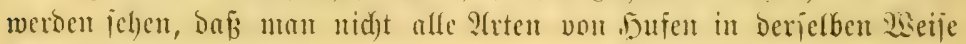
beid)lagen fann.

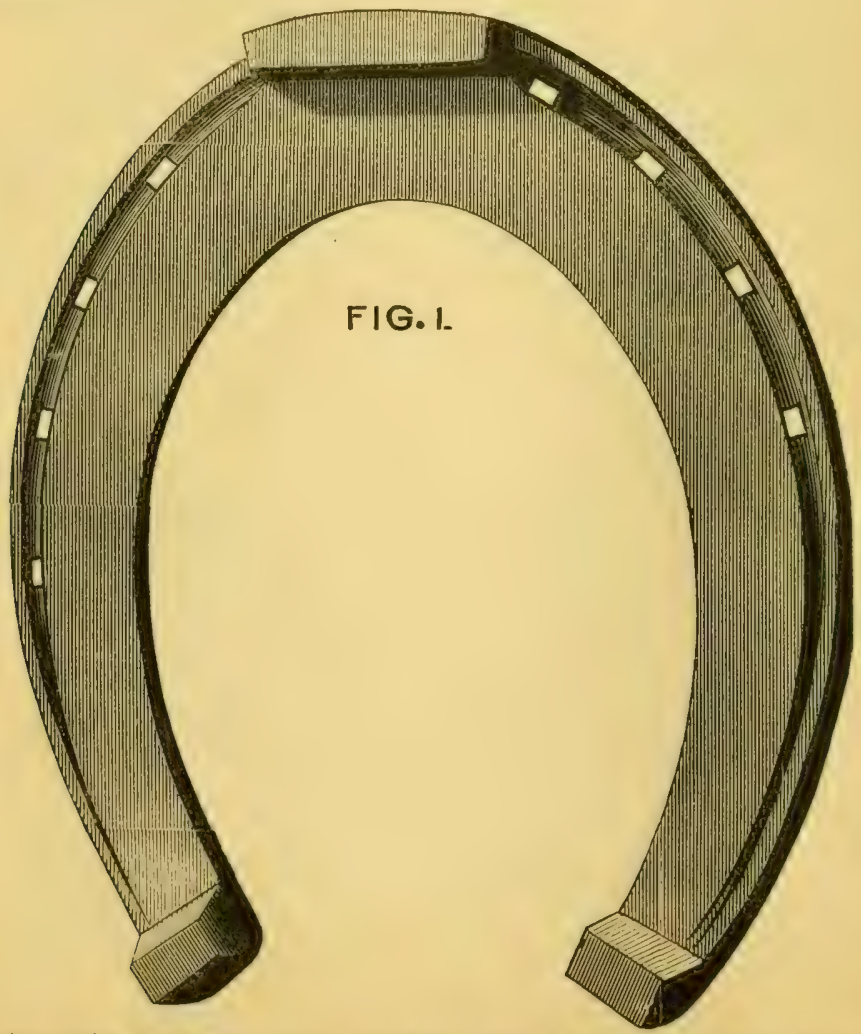

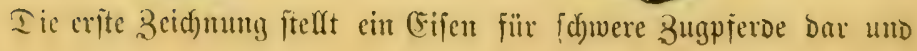




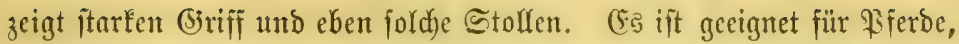
bie auf Garten Straß̧en bedeutende Raften zu zichen haben. Das Eijen

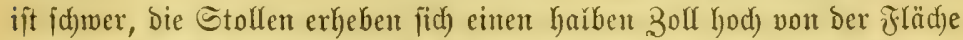

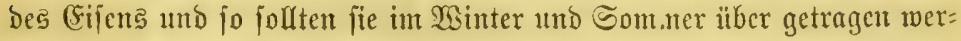

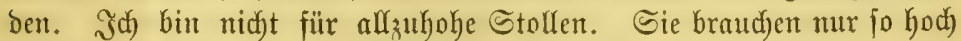

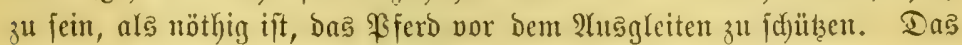
(Eijen jelbit ift etwas ansgehöhlt bis in bie (Siegend Der Stolfenanjäke,

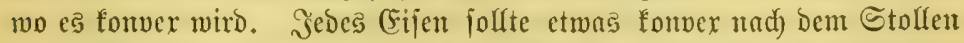
z" gearbeitet jein, Denn wenn es einmal loder wird und mit ben Şaffen it unmittelbare Berillynug foumt, fo wiro es bicjelben nad) aușmärț brängen, währent es biefe nach Snnen sufammendrülfen mürde, went es

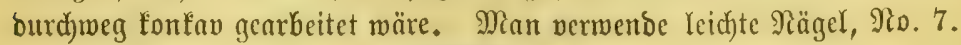

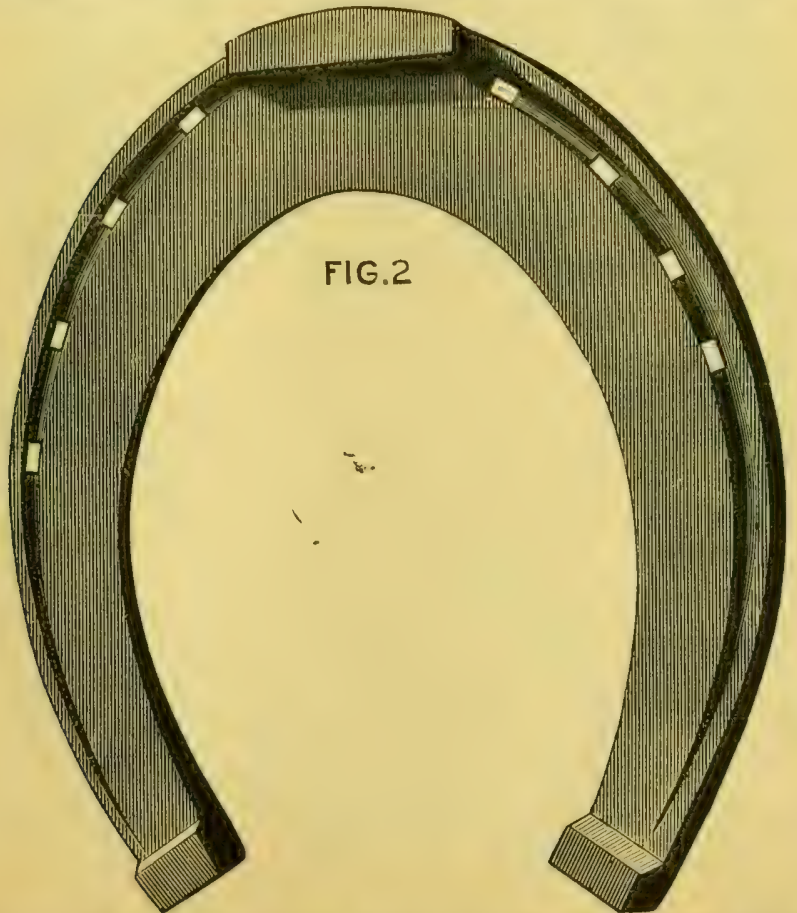

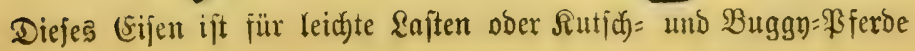


beredtunet. Die Gtolfen find einen Biertel = 30 ll hod), vorn fontav,

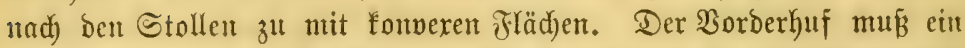

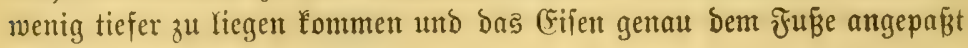
merben.

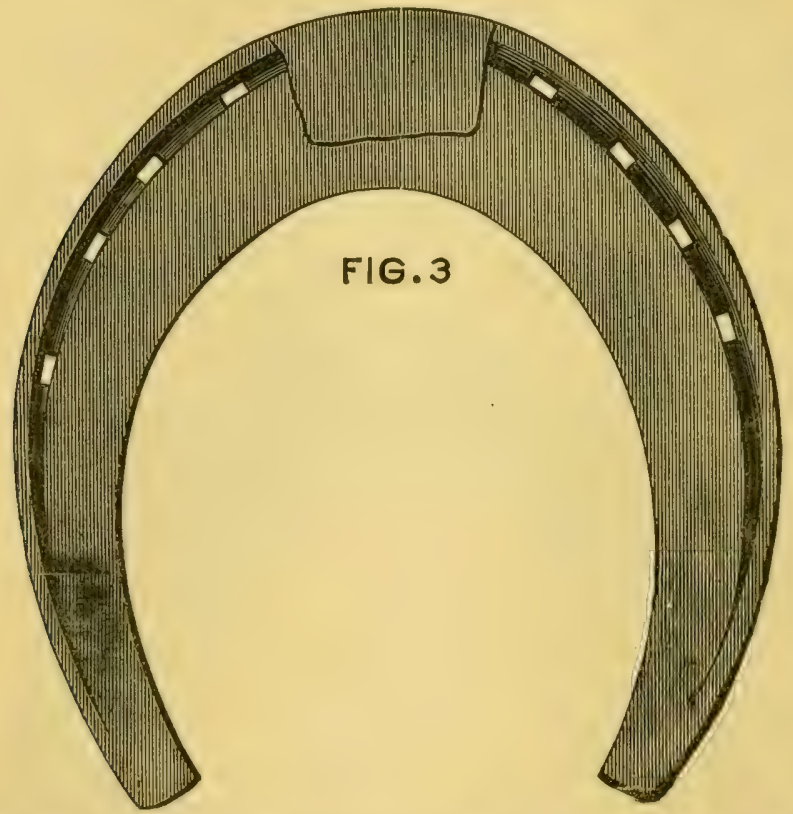

Dies (Vijen pajjt jür \$iferde vor Dem $\mathfrak{B}$ ugg und vor leidtem $\mathfrak{B a g e n , ~}$

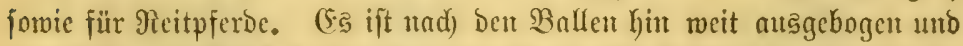
abgefläd)t, cin Stüd fladjen Stahles ift m ber Borberjeite angebrad)t,

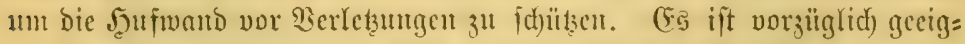

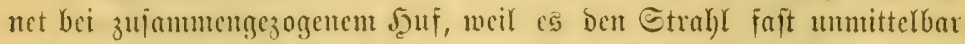

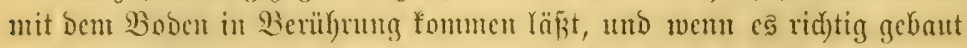
und bie Stollengegend fonver geformt iit, bie Siaflen barb ausbehnen

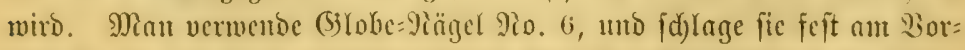

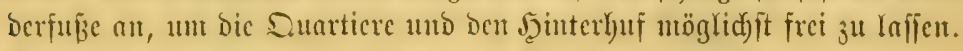
Picmals folf man ben Etrahl ober bie Etreben veridanciben.

Jigur 4 zeigt dos (sijen für \$fferbe, weld)e geneigt funo, beim ₹aufen 


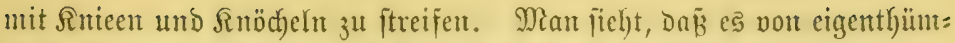

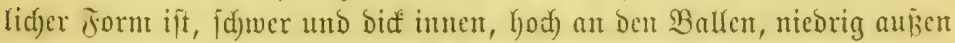
unb nad) vorn. Mian forme bas (Eifent, wie ç Fig. 4 zeigt, an Der ill = nenjeite vielleid)t ctmas weniger gewölbt; am Vorberquartier befdueide

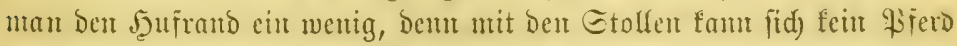

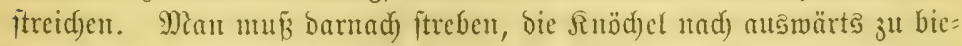

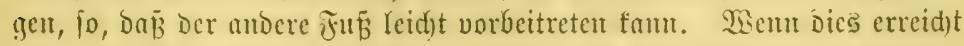

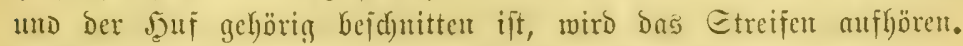

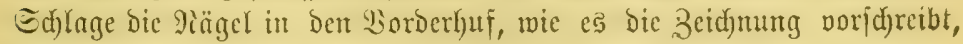

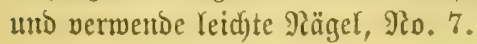

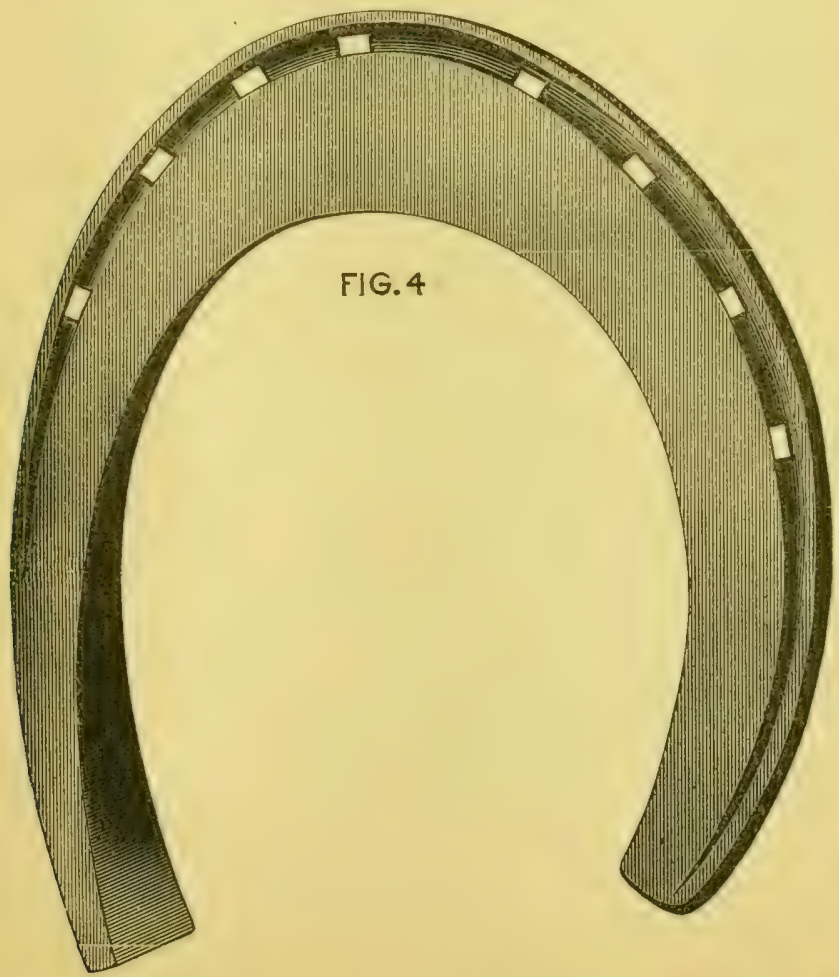

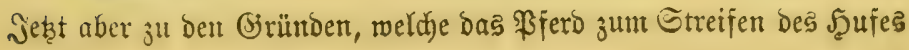




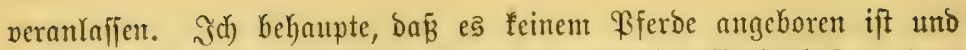

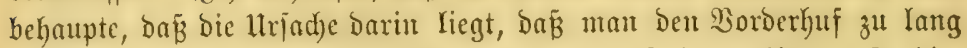

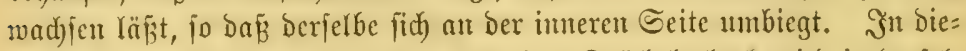

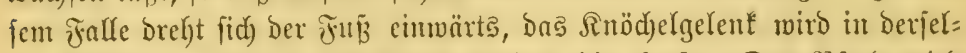

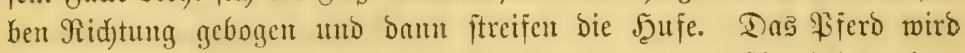

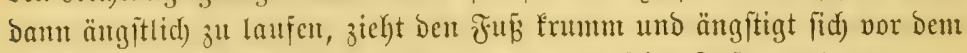

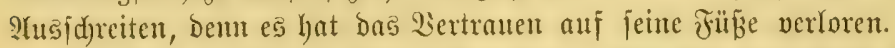

(Ȩ giebt aber nod) weitere Urjad)en. Mandjer jagt, mein Biferd

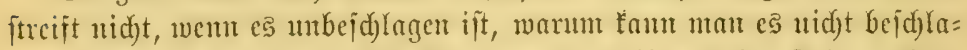
gen, Daß̄ es aud) nid)t ftreift? Mrlerbings liegt ljier oft Der Febler. Man

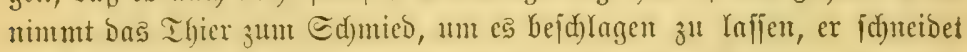

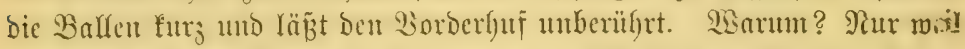

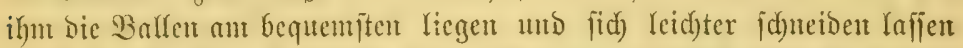
(Ex jief)t nidht barnad), of Der Jeuf an Der unteren Fläd)e eben ift, fombern

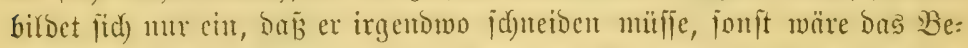

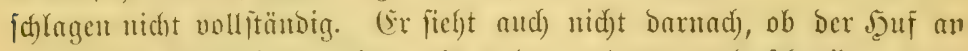
cincr Ecite jidf breiter auslegt, als an ber anderen, und iduncidet, menn

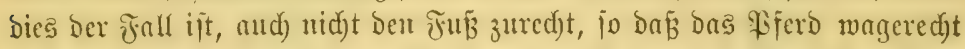

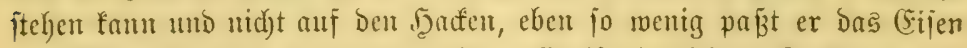
forgfältig uno genan an, wie er jollte. (5) ijt cine job̈une Sadbe, zu wij= jen, wam und rvie viel man jodnetoen un wann man anflyören muв́.

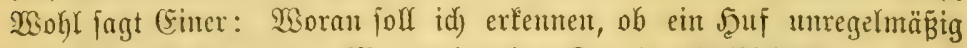

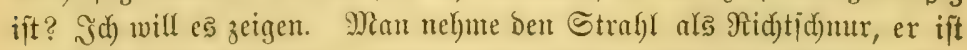

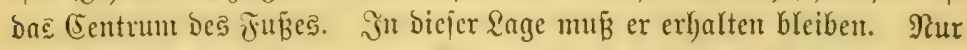

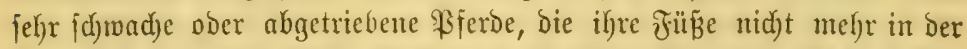
(S) emalt lyaben, ober joldye, Die man zul fdnellerer (Szangart, als fie reijten

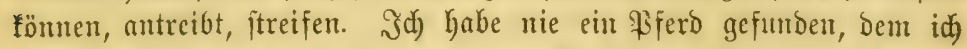

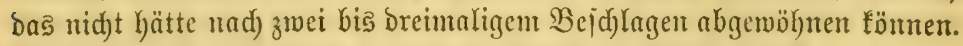

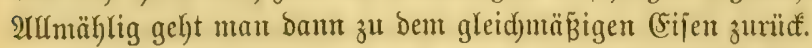

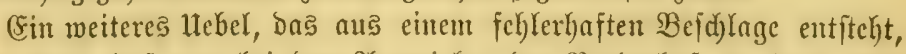

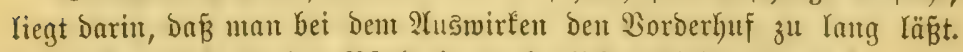

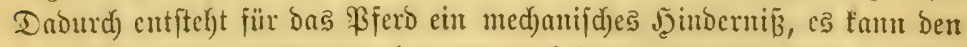

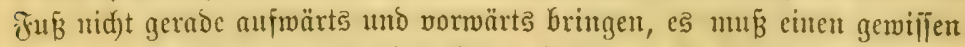
Bogen bejdreiben uno auf bieje Weije ftreift es bie Siöthe bes anberen ษัธิือร. 
Sange Borberbufe verurjact)en aud Stredung Doer Berrentung ber Beugeichnen und anderer Theile, und fo biegt fid) Gald das Snic vorn Keraus in eine Rinte mit bem verlängerten Borberbufe. Dann wird fid die Beugejehne entweber vertürzen, ober bas ringförmige Rigament ant Ginteren I Geile Des Rniees fid zujammenzieben, und fo baben wir einten edhten Falf von Snteverfrïmmung, ein llebel, weld)es leicht hätte vermie=

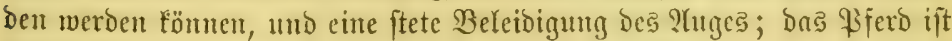
häufig frant, bis man bie Dperation bes Selynenjd)nittes vorgendunten

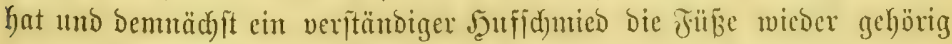
in ben Gtand gejeßzt lyat. (Erft bam fan bas Thier wieder feiten or= Dentrichen Dienft thun. Dr. (Suming, cin jefrer erfabrenter Manu im Sufbejd)lag, fagt ïber Den Rad)theil Des verlängerten Worberlyupes:

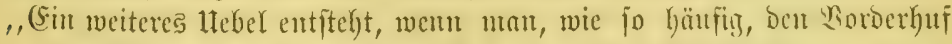

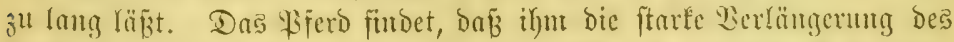

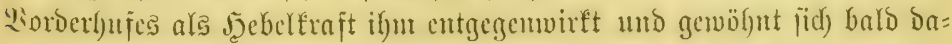

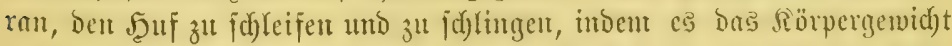
nuf bas cinte ober antore Duartier legt. Nod) mehr ift bics ber Jall,

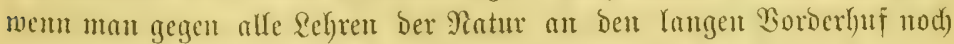
einen fleinen rumben Stahlthopi vorn anfungett. Durd) eine berartige

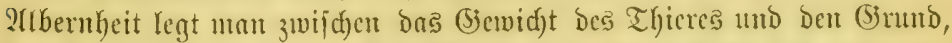

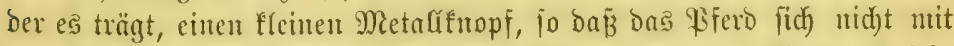

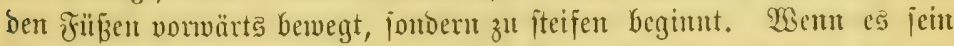

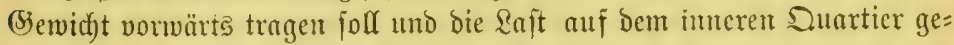
ruht Gatte, jo mird ber biffe Theil ber Feffel nad) Junen gewendet und von bem 3uftande bes anderen Funes getroffen werben. Jaatte bas

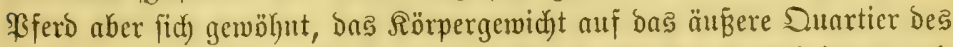
Şufes zu legen, jo wiro ber innere Bogen bes (Gijents mad) imen und aufmärț gebreht, แno bas Thier läuft (5’ejahr, bas andere Bein zu ver=

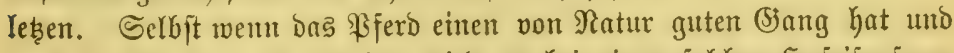

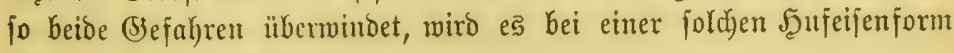
ftets von benjelben bebroht.

Der Borberfuf hat von ber Ratur nidht jene Berlängerung nad vorn und nad) unten, wie die Sdymiede fie herftellen, effer umgefehrt. I ie Şornfohle bes Borberhufes ijt gemöhnlid furz abgeitubt und in ber Mitte

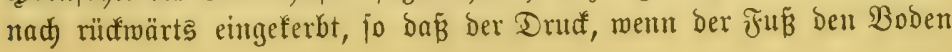


betritt ober Das Thier fein (S)endid)t fortbemegt, fidf) über bent ganzen vor=

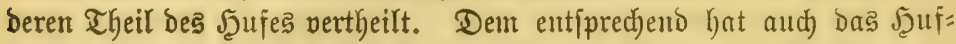

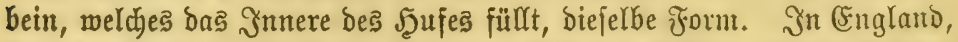
Frantreich und mo jonft nan Thierargt=Sa)ulen befitist und bem झferde=

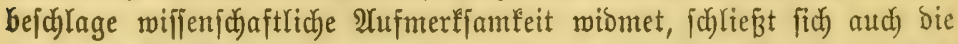

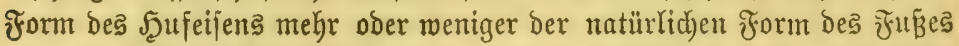

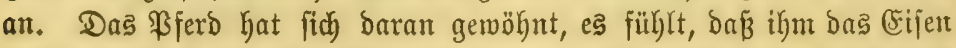

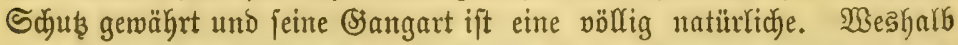

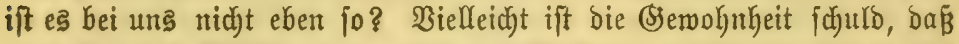
man bei bem Bejulagen zu viel das Meffer zum Reinigen Des ફొufes braudit.

Utber es ift unmöglid, bemfelben mittelft bes Meffers in alfen Thei=

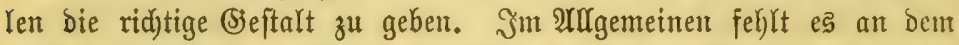
nöthigen Studium auf Seiten ber Schmiebe, fie verfteken zu wenig ben

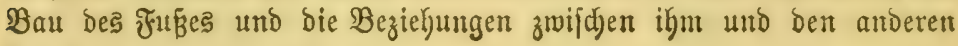
Fortbewegungs: Drganen. 


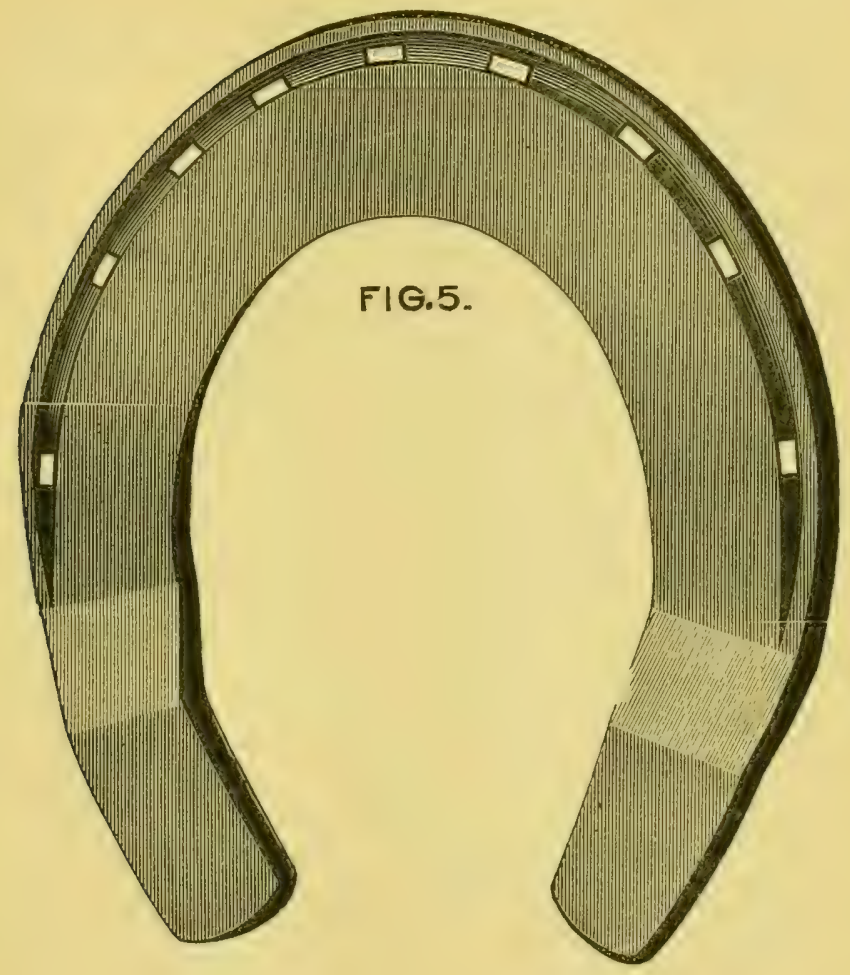

Das (sijen in Beidnung 5 ift von eigenthümlidfer Form, aber ge= genwärtig von böd)ftem 2iuben, wenn man bebentt, wie vicle fiferbe an

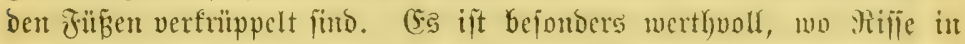

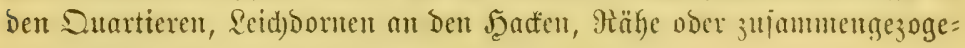
ne Jyaden workanden fint.

Das (sijen ift meine Erfinbung uns in feincm sserfe juwor bejdrie= bent worben. (Ss ift fajwer gearbeitet, bamit cs nid)t ipringe, bagegen

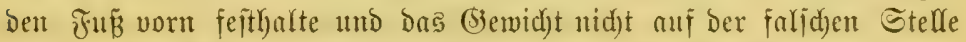
hafte. Bei Borderhutf=Riffent wähle man das (Sijent in Fig. 6.

HFeroe mit Riffen in Borderfuf und Den Duntieren beld)lägt man

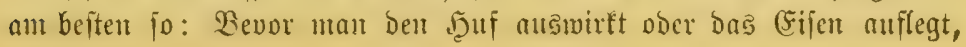




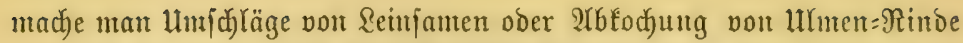
uno bieje Untid) Yäge laffe man minbeftens 12 Stumben lang licgen, Denn

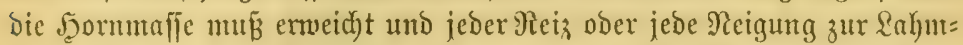
heit entfernt werben. Dann entferne man mit bem abgerunbeten (5noe

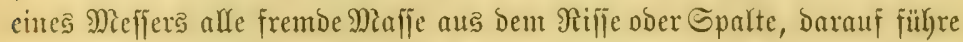

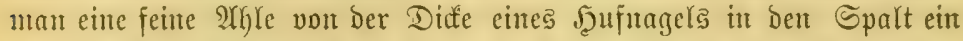

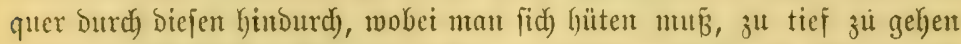

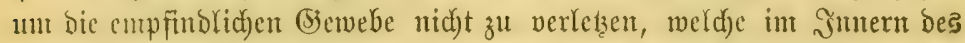
Şufes liegen. Dann fülyre man in das mit ber ?rhle hergeitellte Sodh

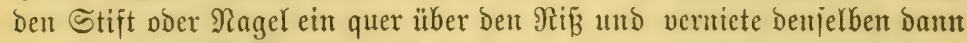

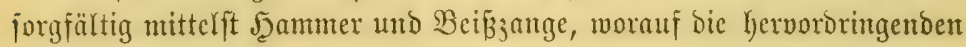

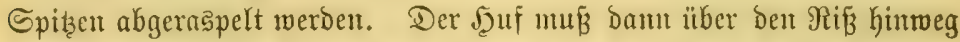

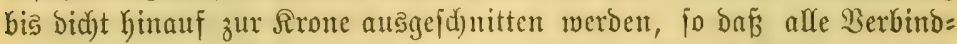

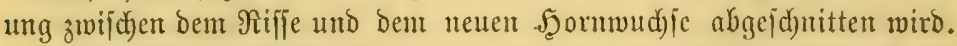

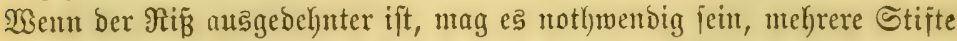

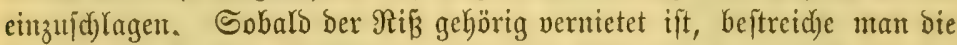
Stelfe mit ftarfem f̧irfd)horngeift ober Fidytentheer, baun halte ign burd) bäufiges $\mathfrak{W a j c h e n ~ m i t ~ l a l t e m ~} \mathfrak{W} a f f e r$ fübl. (Fin (Sijen, wie in

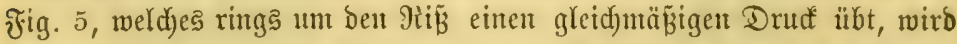
Dann aufgeid)lagen, un bic Duartiere zu jüüten, bod barf es nidj) auf benjerken ruben. Drei Nägel ausmendig, brei nuf ber Jutnenfeite und brei in ben $\mathfrak{B}$ orderfun, alle jo weit wie möglid) von ben Stollen entfernt. Dieje (sijen=Form ift unter fold)en Unftänden bie beite bie man findent fann. Man benutze fie unb balo wird bas \$ferd einen gejunben Juß Gabent. 


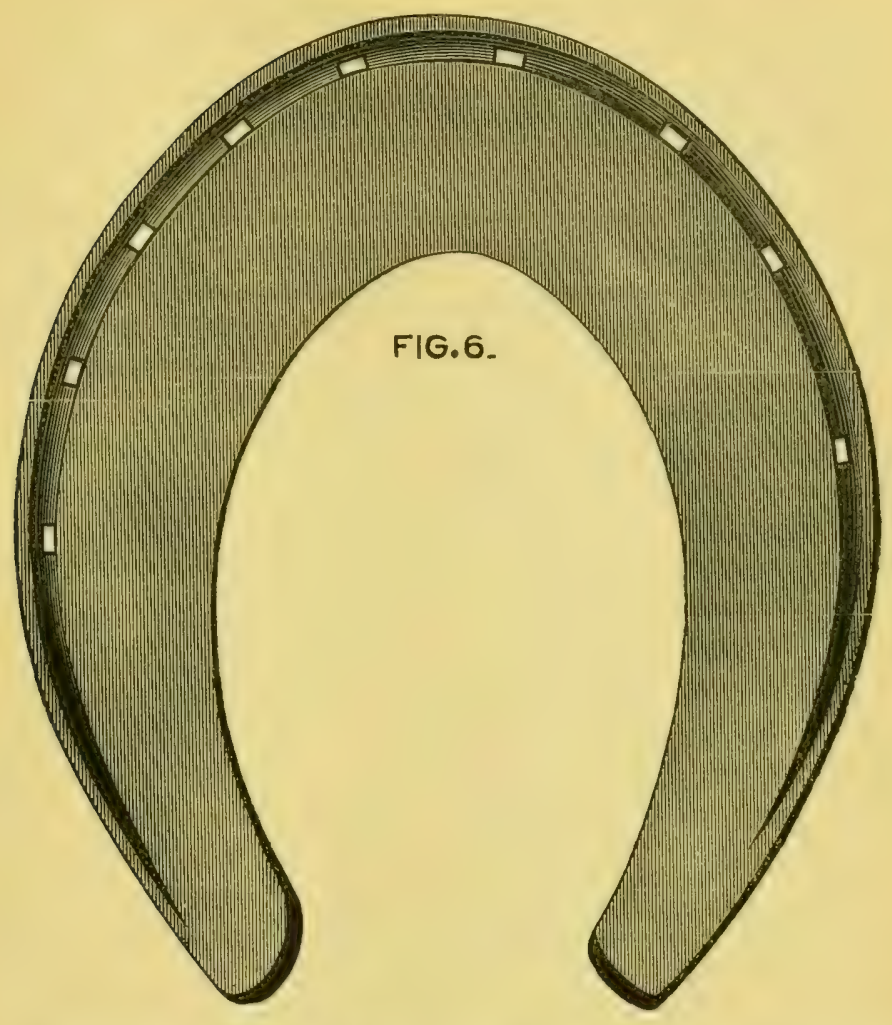

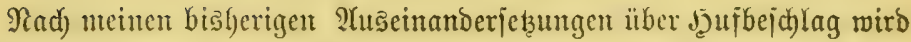

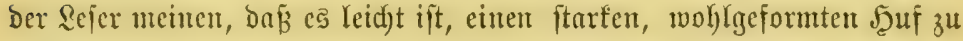

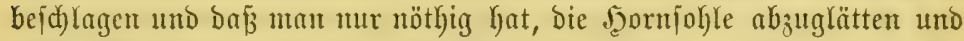
Ioffere Joormiubftan, wo man fie findet, megjud aben. Wemu aber bie Jomoble cincs Jubes nidyt fonfav, jondern platt ober fonvex ift, jo ijt lie itets and bümer und meniger in Stande Dnut zu vertragen. Da马

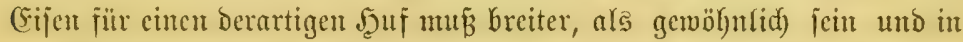
Der (5egend Der Derbindung ber Jgorn= ober Flcijd)fohle flach aufliegen,

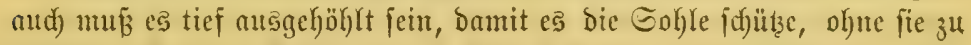

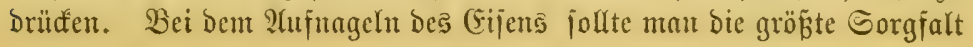


Dermenten, fonft faun Yeidyt ein Nagel in bie empfindlidben (5iemebe ein= bringen und Das Thier ift "pernagelt."

(Enolid) findet man mitunter bie Tüße bes ßFferbes verfdieden ge= formt, entweder meil eine angeerbte Diapplition Gierzu vorlag ober in Folge idyled)ten $\mathfrak{U}$ tfziebens ober anberer Urjadyen. Daher jollten alle

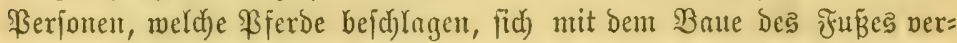
traut madjen. Jn unjerem Beitalter be马 Fortjdyrittes, mo eine Berbefie=

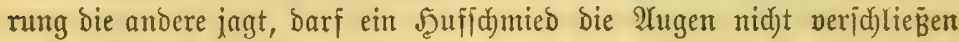

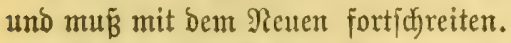

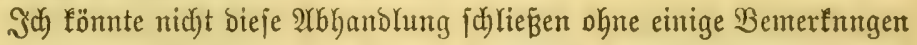
über ben vielgeidmähten Stand der Sirobjdmiede anzufügen. (5s ijt meine Heberzeugung baß̧ fie jebr oft ohne vernünftige Urjadje geläptert werben. Sehr oft wirb ein \$ferd, bas fürzlid) bejd)lagen murbe plöțlid

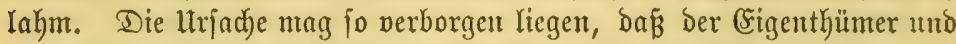

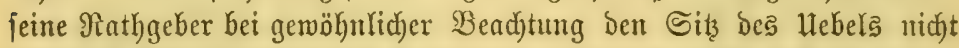

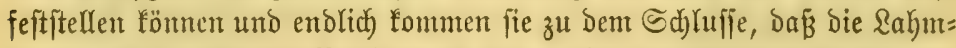
heit bie Folge id)led)ten Beid)lagens mar. Dies braudyt Durdyaus nidjt ber Fall zu jein, Denn manche Thiere fund zu Fuß̈trantheiten geneigt, meld)e

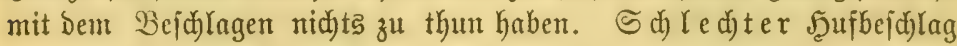
fommt aud) Deshalb häufig vor, weil mandbe Sdymiebe fid nicht ent=

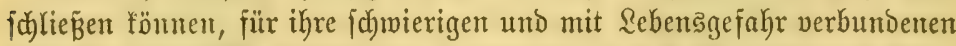

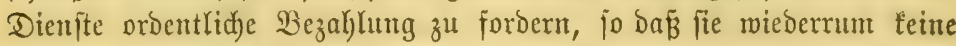
tüchtigen (Schülfen harten fönten und wenn, wie mitnnter, ein Samied nur ein mentig an Den Füben herumflappert und fich bafür cin Butterbrod

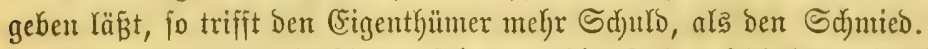

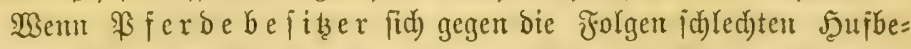

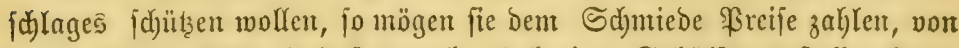

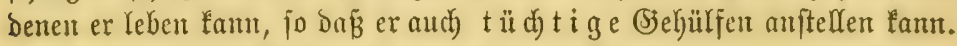

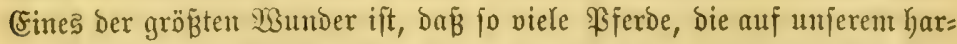

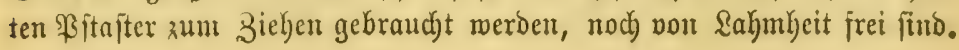




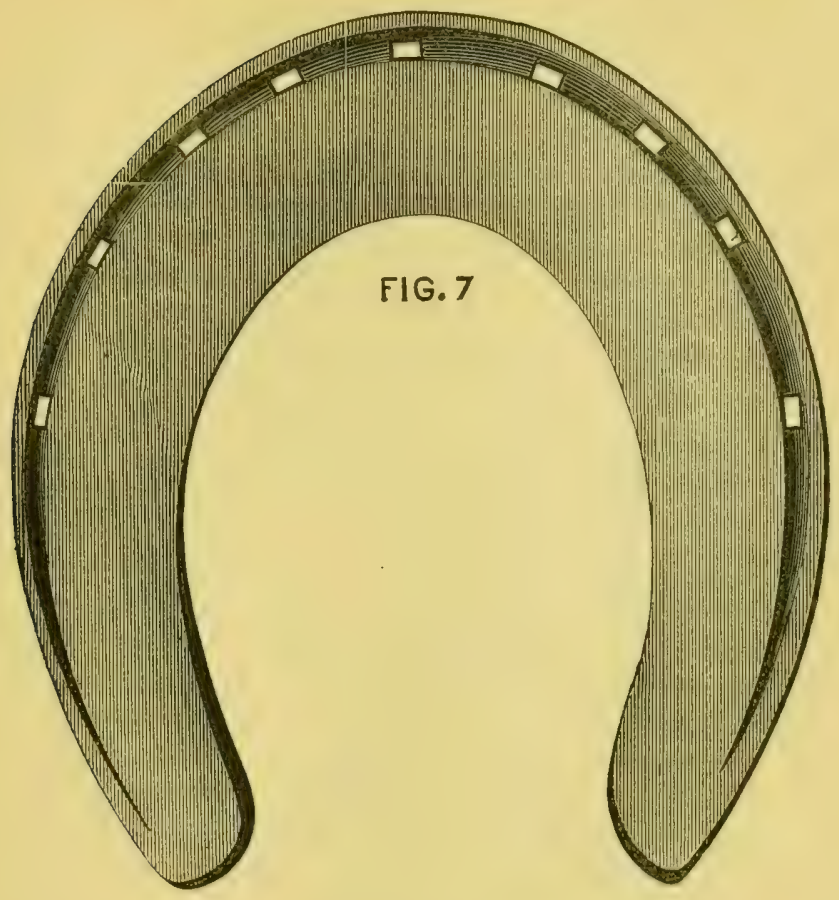

Dies ift cinte Sufplatte für ben Borberiduly cines Irabers. Sie ift

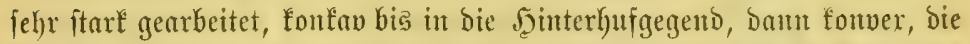

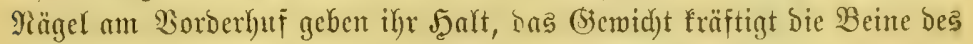

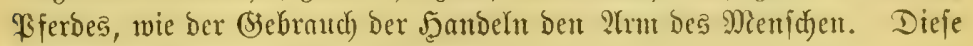
Eijen find allgemein befannt. 
86

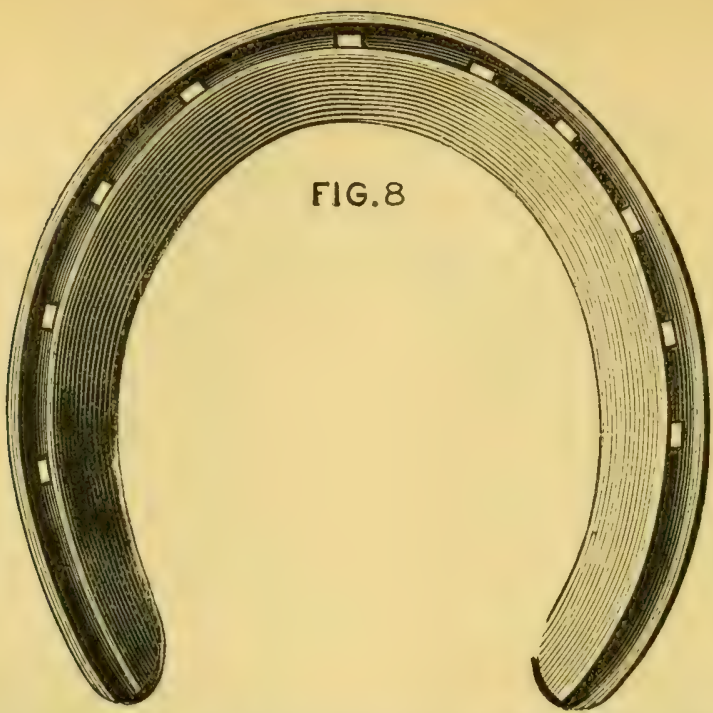

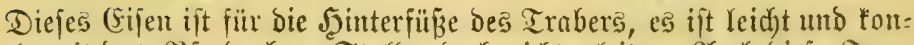

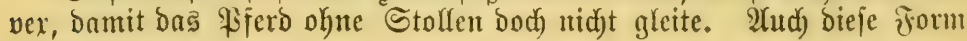
ift befannt.

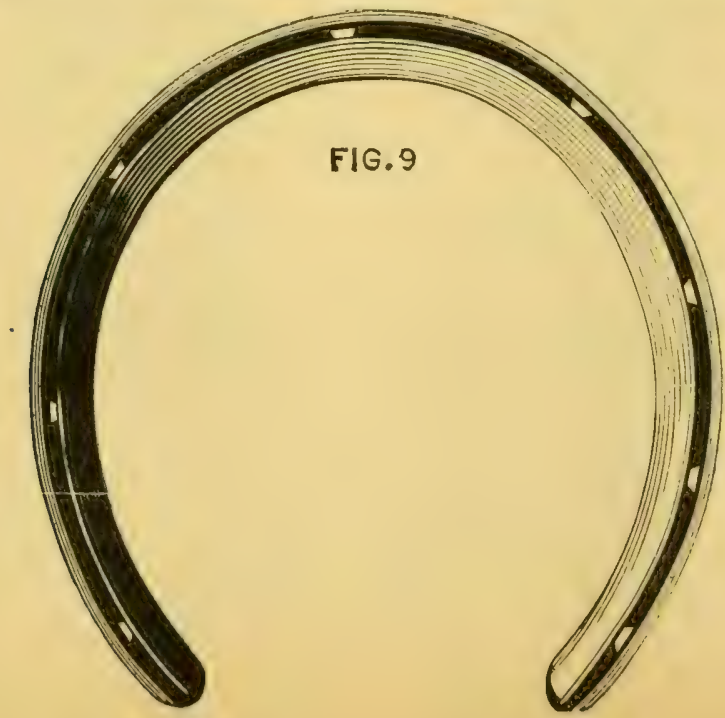




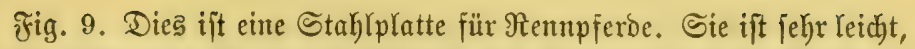

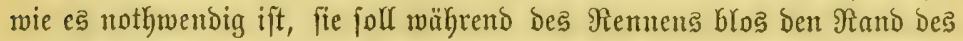

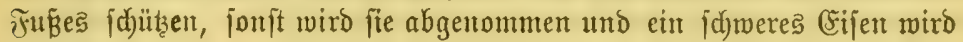
angelegt.

Dieje (sijen merben alle von mir gefertigt. Nidjt jeder Şufidumied braudet fid jeine (5ijen jelbjt zu fertigen, Demu baß "National Stahlei=

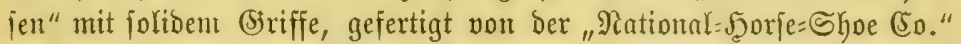

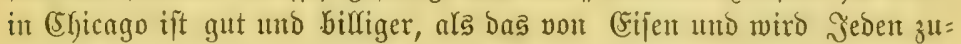

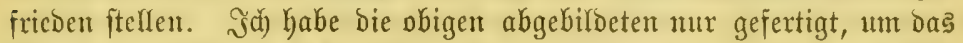

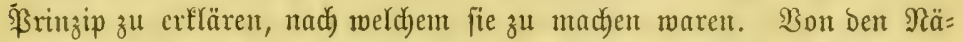

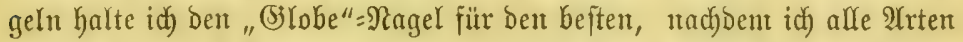

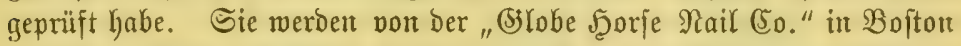

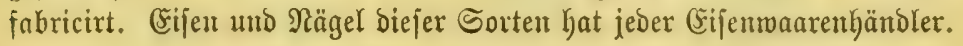

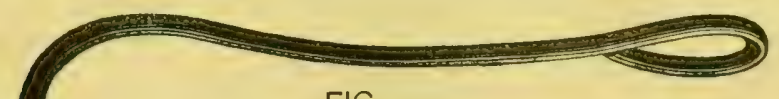

FIG. 10

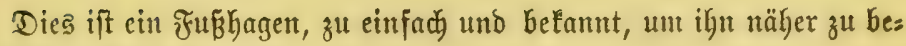
idsureiber Man verwende ifn.

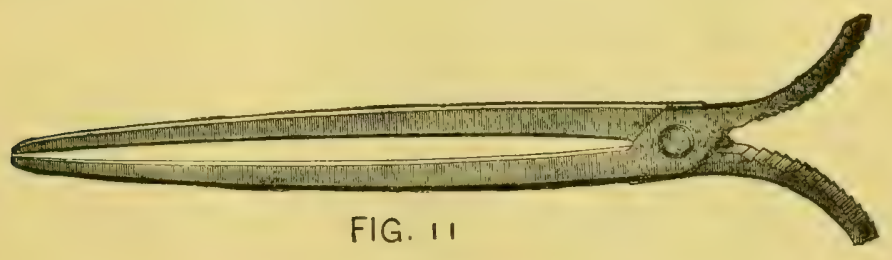

Dies Sniftrument bient zum Şerauszielyen ber Räget aus bemt Şufe,

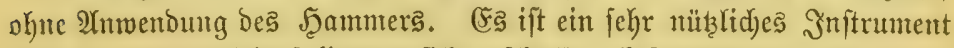
und alle Şuff(d)miebe follten es fid) anjdaffen, bejonsers went fie es mit

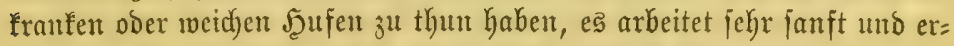

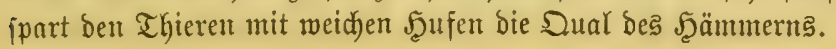




\section{Be fdi lagen ber Ma a lejel.}

Wie man bas Pferd bejclägt, habe id bargelegt. Sin Maulefel ift

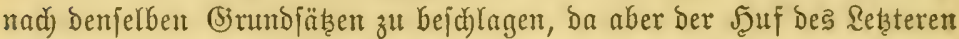
melgr geneigt ift, vorn fich auszulegen und die Rörperlajt auf Dem hinte= ren Theile des Şufes ruht, aljo Das Bebengelent und bie Fefjel megr in Anjprud) nimmt, als bei bem Siferbe ber Fall ift, jo muß man bei bem

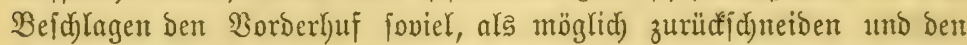

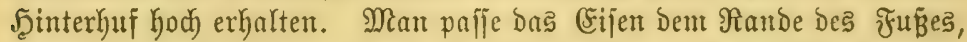
namentlid nad) Ginten zu, an, ziebe aber nidjt, wie fo manthe thun, bie

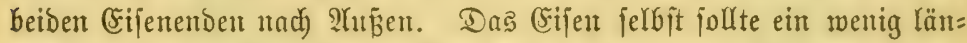
ger jein, als ber Şuf, unt bie Ballen hoch z̧山 halten. Şöhle bie Stol=

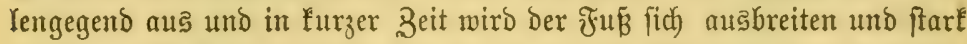

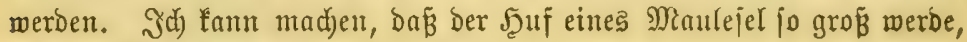
mie ber eines $\mathfrak{P f e r d e s . ~}$

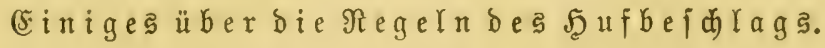

Der Rejer miro miffen, bañ die Meimungen über bie befte Methobe

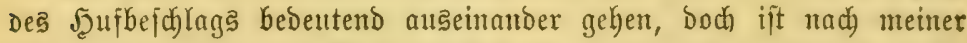
Heberzeugung basjenige Snftem bas befte, meldyes barauf berednet ift, bie natürliche funttion ber Füßre, ifre Stelfung un Bewegung zu er=

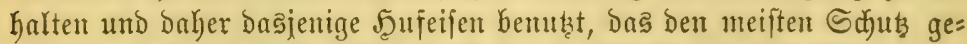

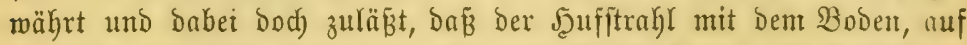
meldjem Das IGier fteht ober über ben es fich bewegt, in Berïhrung fomme. Befondore Borfdriften lafjen fid) in Der allgemeinen Runjt be马

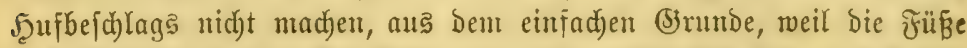

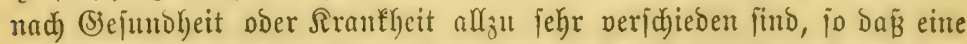

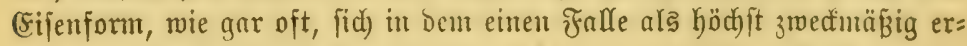
weijen mürbe, währens bie nämlid)e fid) in eintem anderen falle gerabe= 子̊ verberblich ermeijen möd)te.

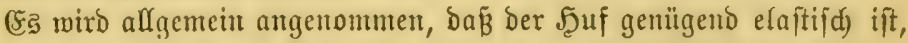

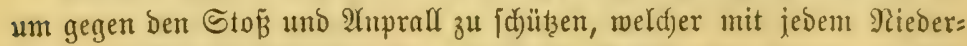
fetzen Des Beines verbunden ift. Diefe CSTafticität, wie wir fie an bem gejunden, frei entwickelten J̧ufe finden, wirtt nad) unten und nadh fin= ten, fie ift faum wahrnehmbar, aber bas ift fehr meife angeoronet, denn 


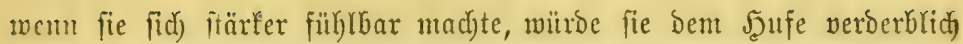
jein und dic Mäglidjfeit, ofute Sdjaben ein Sijen anzubringen, mürbe febr gering jeint.

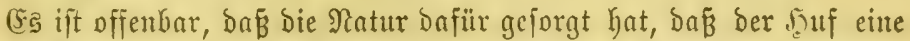
gewiffe Bemeglidfeit habe, beghalb ift er an bent Jacten offen und ba= zmijden befindet fid) eine weidje, elaftiche Subftanz, ber pogenamute Jeufitrabl, meldyer dieje Bemeglidject ermöglidjt. Wäre eine foldye

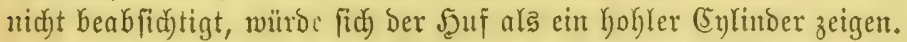

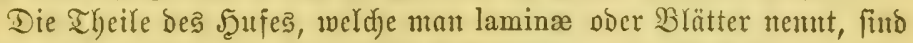

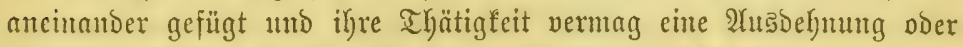

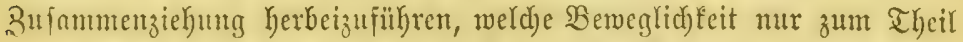

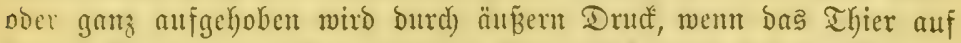
Gartem Boben geht. Itm mun biejer Sieweglidffeit bes Fußes nicht ent=

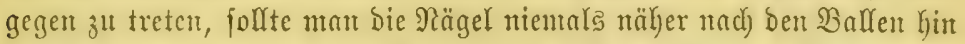

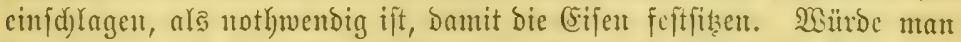

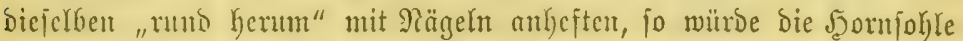

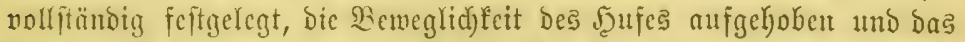
Thier bald Yalum merben. Sft find blos brei Nägel nothwendig, bas

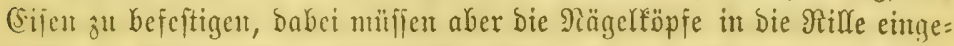
fentt und bic Spitien gut verutetet merben; ift biç nidgt ber Fall, baun wiro bas (Eifen loder, da burd) bie vielfad)en Stöp̈e auf Die Ragelföpfe

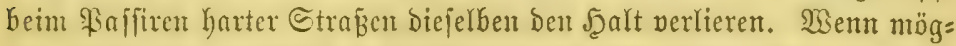
lid), jolfte Der Şufftral) in Berübrung mit bem Boben fommen, Dent

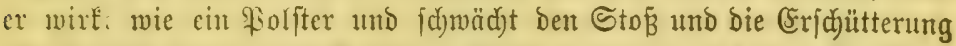
$a \mathfrak{b}$, bie fid) fonft leim Inftreten fühlbar mad)en mübten. (Er bildet

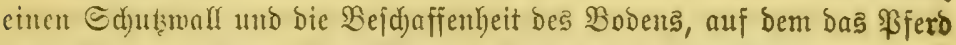

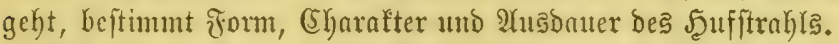

So finten mir gewöhnlid) bei Dem unbejdylagenen Johlen, wenn fonit ber J̧uf gefund ift, Den Strahl wohlgeformt, ftart entwidelt uno

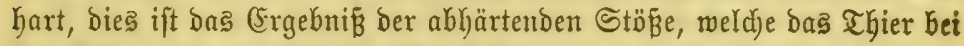
Der SBewegung auf harten Straß̉en gegen ben Şufftrahl empfängt.

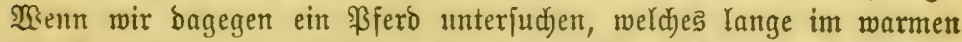
Strlle geitanden hat, jo finben mir, baß̉ ber Strahl bäufig unvolffänoig ift, forwhl ber Struftur, wie ber Funftion nad. Die Ratur fduf ben

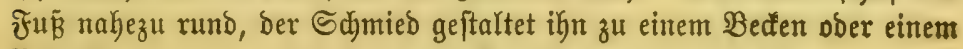
Blätteijen, wic man ihn Denn nach) Belieben verunftalten fann. 


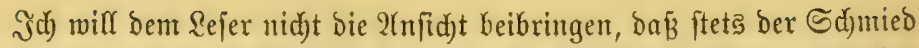

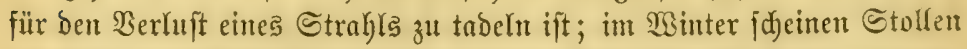

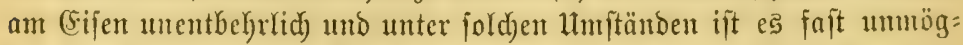
lid), bie Berührung bes Strahls mit Dem $\mathfrak{B}$ Doen zu vermitteln, Darunter

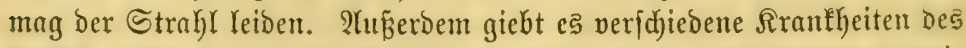
Fubes, welde prookl ben Strahl wie ambere Theile bes Jubes angrei= fen fömmen.

\section{Heber bas $\mathfrak{A}$ Iegen hei Ber Eijen.}

Şeife (Eijen, wie fie oft anfgenagelt merben, werbrennen leidgt bie

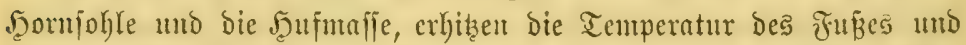

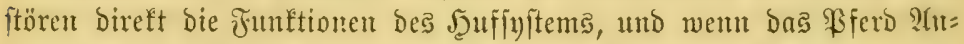

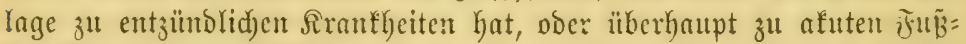
franffeiten genteigt ift, fo wirb bng hei verborgene 2Hulage zur Entwidfung bringen.

Damit Der Raie fidf entren genügenton Begrifi von Den Theilen Des Fubes mad)en fömue, um fich jerbit ein Urtheil ̈̈ber bas (Siejagte zu bil= Den, bemerfe id Folgendes: Bermittelit Des Mifroffopes entbedt mun

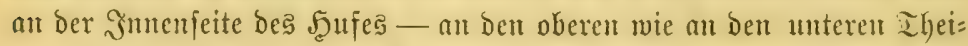
len - eine groß̧e Bahl von fleinten Röd)ern, wie in eintem Siebe. Dieje nennt man bie Solhlenporen. Mit biejen in Berbindung itehen bie entpfundidaen (Simebe, zujammengejebct aus harten Fajern, Die man papillae - Warzen - nemt, fein organifirte Strufturen, beftebeno auঙ bem zelfenartigen, venöjen, arteriellen un nervöjen (5zerwebe. Afngenom=

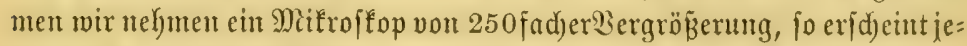

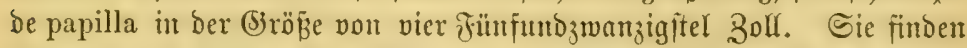
fich auf der ganzen Dberfläd)e ber fleijáhigen Soble. Die Fapilfen

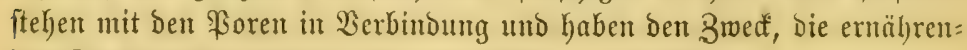

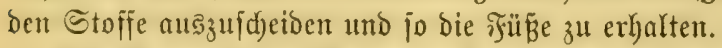

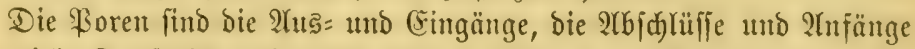

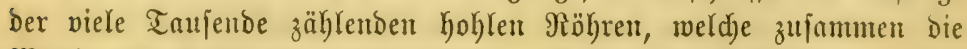

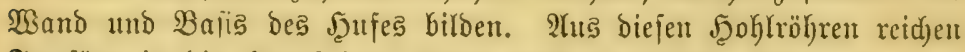

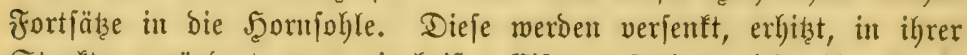
Etruftur verändert, weun ein heibes (Eijen aufgelegt miro; ibre funt= tionen müffen baker nothwentig geftört merben. Jn ber Rrufte, ober

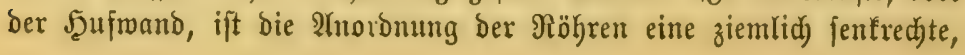


Sie unteren nehmen an Ränge zu und ziehen fid abwärts unto vor=

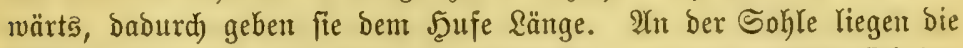
Röbren horizontal und find viel zahlreidjer. Daraus erflärt fict) ber

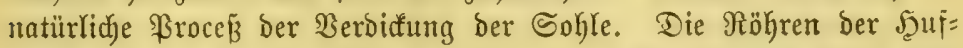
wand und ber Sohfe ftehen mit einander in Berbindung; weut nau

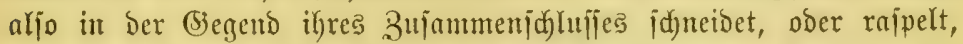

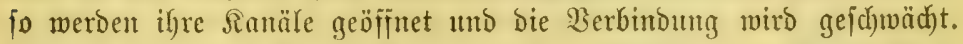

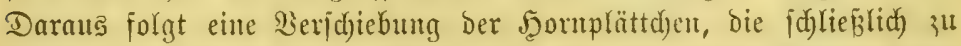

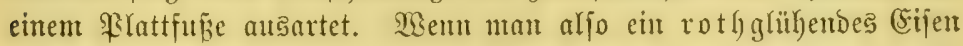

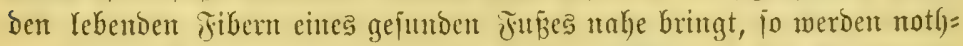

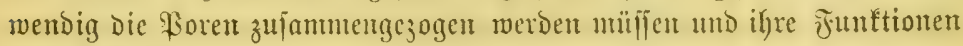
geftört werdent.

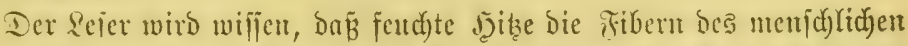

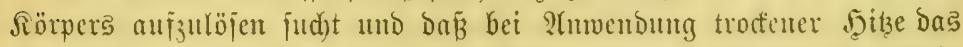

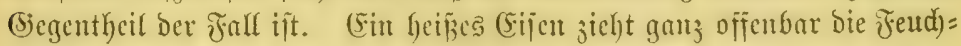

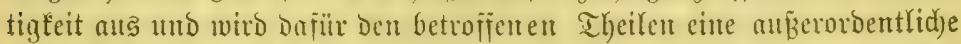
Menge Sisärmeftoff zufüfren. Dantit wiro ber Fun nicht alfein mit

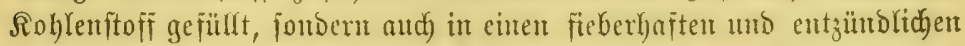

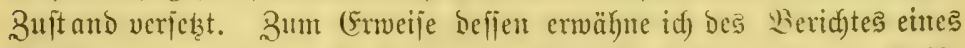

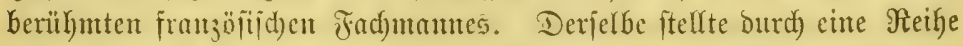
von Unterfudyungen feit, Daß̉ Die Şufwand wie bie Sohle Reiter bes

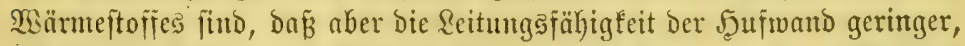

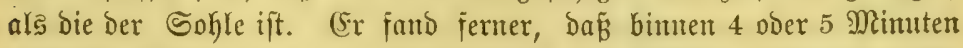

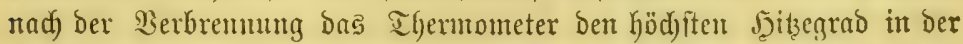
Sohle anjeigte. Še bünner mun bie Şornwand ift, um io nuchr Şike

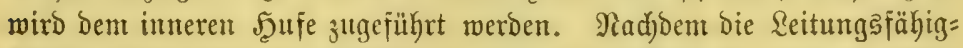

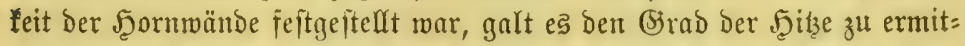

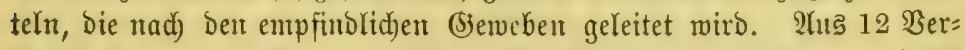

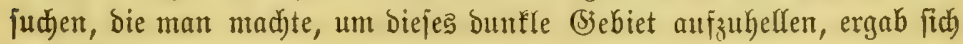
folgendes:

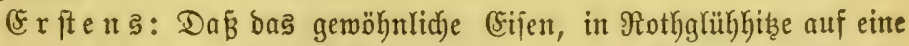
Şornfohle von einent Boll Didfe gelegt unı für eine Mimute bajelbft ge=

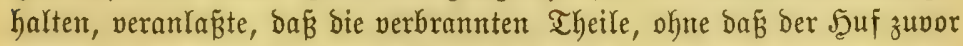
ausgemirft war, brei bis vier Grad Wärnteftoff an bie warzigent und bie Netzgemebe abgegeben hatten.

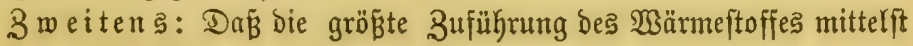


bes Thermonteters zwifunen ber vierten und fechiften Minute nach Âtufe: gen des heißen Fijens bemerft wurbe.

Dritteng: Daṕ bie Sohre, bie bis auf Dide von einem brittel Zoll abgeraspelt war, fo bá fie unter bem Drưd bes Daumens nad)= gab, bie zeritörten Warzengemebe blosgelegt zeigte, went bas rothglüb= ente Eijent eine harbe Minute aufgelegt blieb.

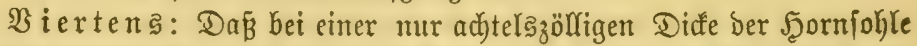
bie $\mathfrak{B}$ arzengemebe jowohl, wie bie Netzgewebe burd ben Märmeftofi zer= ftört murben, wenn bas glübende (sifent nur eine halbe Minute auffag.

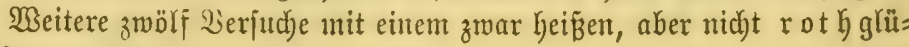
henden ergaben:

(Fr ftens: Das f d warze glühende (Eifen, alf bie Sohle gelegt,

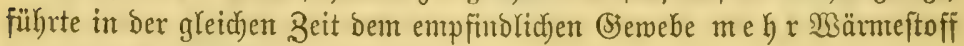
zu, als bas rothglühente that.

3weiten 3: Das fdjwarze (Eifen bramute bei gleidjer Diffe ber Soljle ftärfer und tiefer ein, als bas rothglühentoe.

Dritten 3: Dieje Beobadytungen beftätigen, was jodon 1857 ber

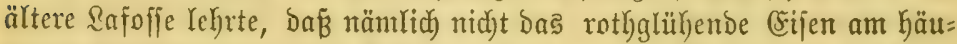

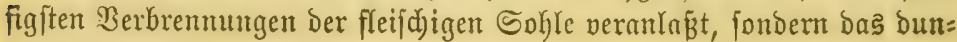
Hel glühende.

Mandye Sadjueritänbige beljaupten, Daß̧ went die verbrannten Theile ber Solgle unmittelbar barauf mit ben geeigueten Serf $_{3}$ eugen bejeitigt merben, bie Berfrentung unb ifre Folgen aufgehoben jeien. Sd babe

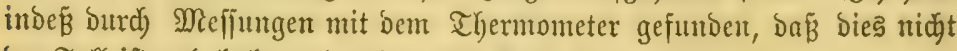

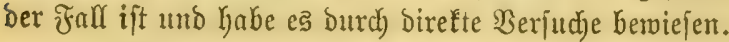

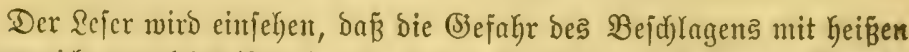

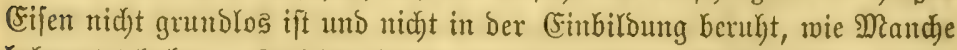
behauptet Gaben. Freilidi) Gabent wir eine Menge Büdber über Şufbe:

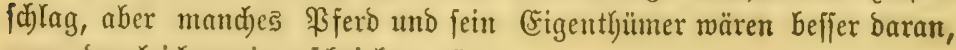
wenn bergleiden nie gejdyrieben wäre.

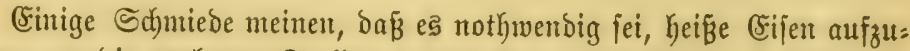
Iegen, um bie untebenen Stelfen zu entodecten, weld)e bei einem fehlerbaf: ten 2 U⿻上丨क guten $\mathfrak{B e r l}$ zeugen famn eine ebene Soblenflädje herftellen, baher braud̆t

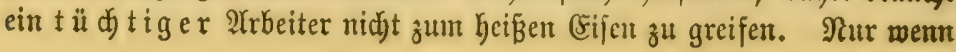




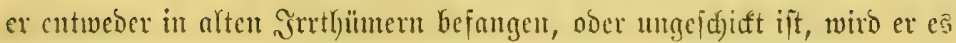
thun wollen.

Jeber a titäu bige Sdymied jollte arjo bie heißzen Sijen bei Seite

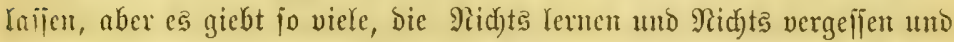
bei Dent alten Sdylendrian bleiben. Cinzelne Sdymede jollen bie heipen

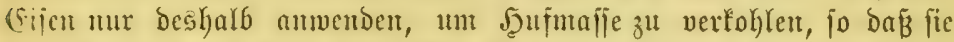

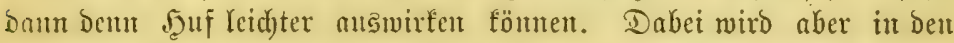
nucipten Fällen zu viel fenmunafle entjent werden und bann hat bas Rifero reiche Füipe.

So hat bent mad) bem obigen fein Sdymied cine (Entid)urbigung

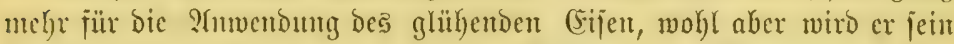
(sicidjäft ftetig baben, weun er ben Geboten ber Wermunft und Der

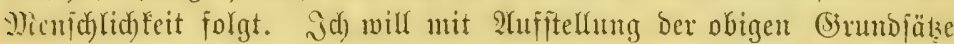

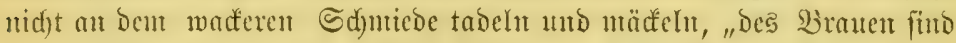

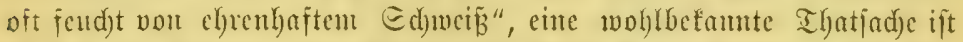

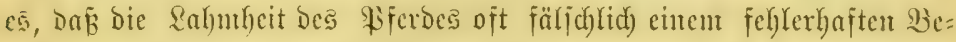
id)lage jugejdrieben wiro. Sit genug zeigt ein Piferd furz nad) Den

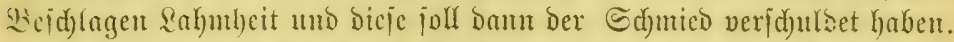

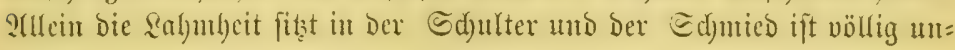
jduldoig.

\section{Etwa 5 ï ber ben ङtrahl.}

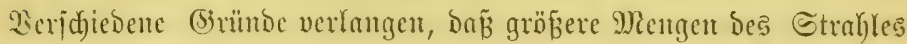
nid)t weggenommen werben. Sn bem gefunden Soufftrable befindet fid

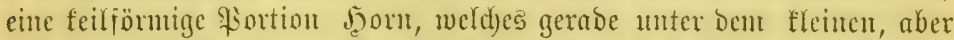

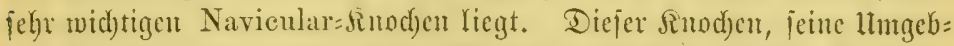

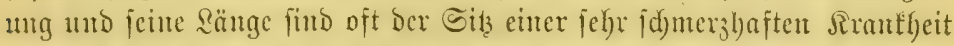

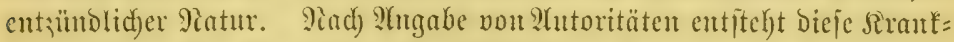

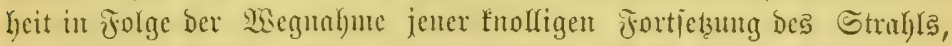

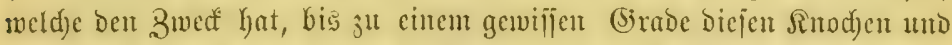

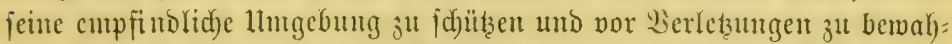

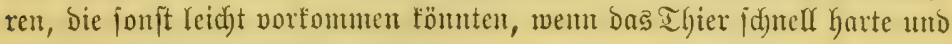

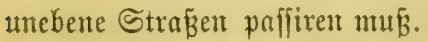

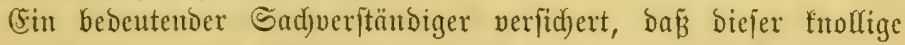
Strabl= Forjetzung fich nid)t wieber ergänze, wenn er eimmal abgejdynittent jei und jo fänden mir aud) biejen jeltjamen Jortjab̧ jelten mebr bei einem 


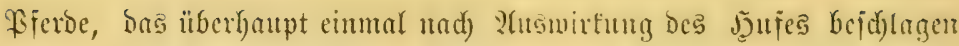

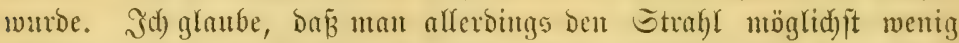
id)nción jolf, bazu bejdylage man jo, dab bie Balfen nidyt frampibait zujammengezogen werben, wente reid)lid) idyarzes Del=Riniment un

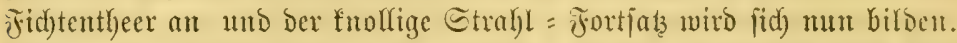
Diejer-ebenjo wie bie gauze Janrmbbitanz im Strahl befdützt nidyt blos

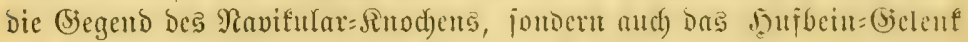
uno bennod) wirb gerabe biejer Theil Der Soble un meijen bejduitten.

Wenu man Den Rnolfen des Borberthutes entfernt, jo wird cine ver=

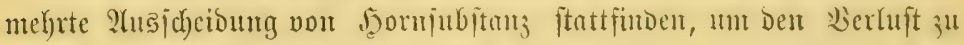

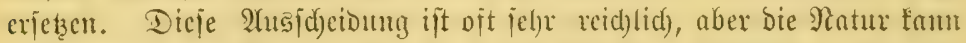
nid)t gegen Den unfuntigen (Sicbrand) Des Diefiers anfäntp fen. Je melnt

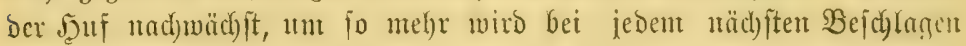

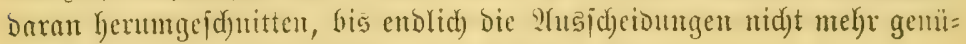
gen und ber Theil unelaptijd und bröcflidy wiro.

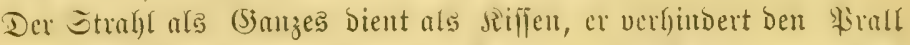

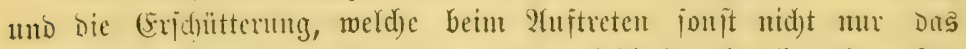

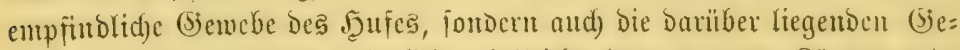
lente trefien würoen und fid) vielleidyt bent ganjen Rörper mit=

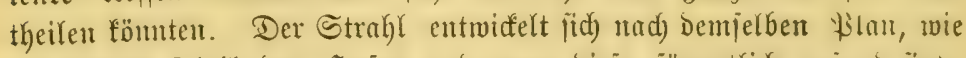

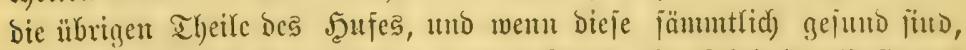

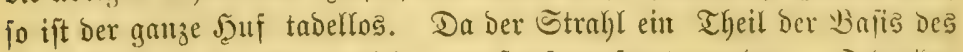

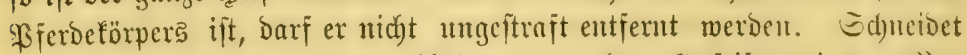

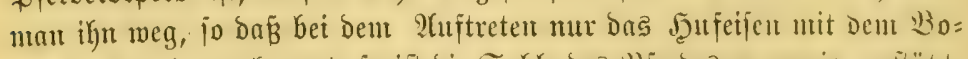

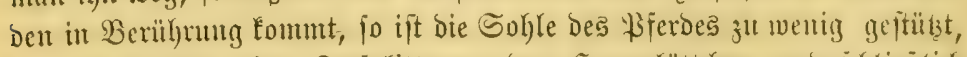

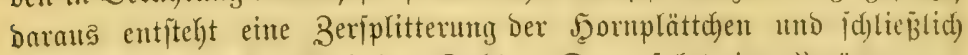
Jerabjenten und Rrantheit Der Soble. Daun folgt eine beründeru ng

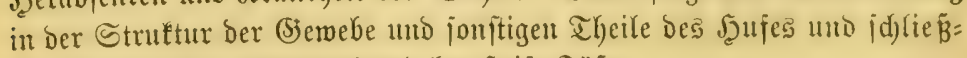

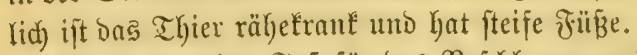

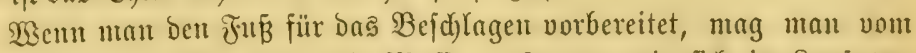

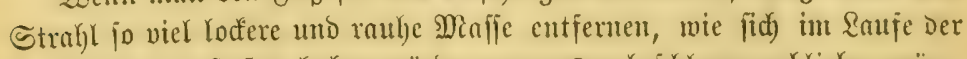

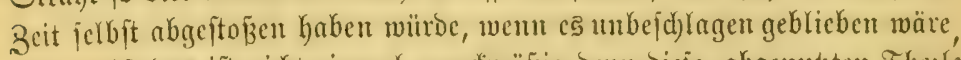

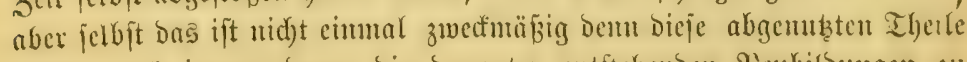
bicuen nod) inmer bazu, bie barunter entfelyenden Sienbildungen ju

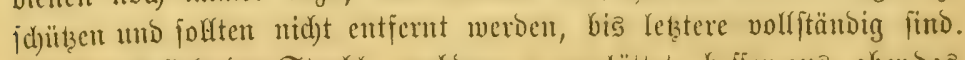

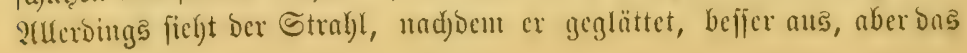




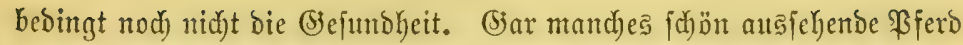
fann in Folge von (5rbanlage und innerer Stantheit fdnell Dem 2rbodfer

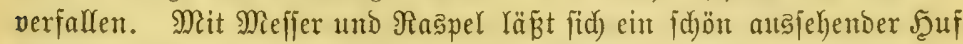
Gerftellen, die Şauptiad)e ift aber, ifn gefund zu balten. (5: gab eine

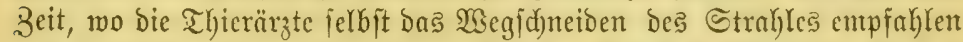
und viele Sdymiede halten baran nod) fejt. (5in @d)riftftelfer fagte, Da ber Strahl burd) feinen Bau, powie bie geringere Widerftumbłtraft förm=

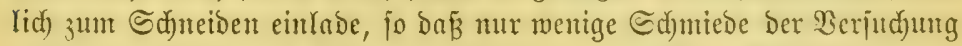
miberitefen fönnten. (Sincr ber tüdtigften englijd)en Militärärs̆te er: flärt, Dẩ er fein Diefier an Den Strabl fomment lafie, ba dic Erfahruntg

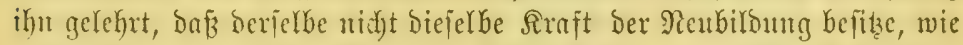

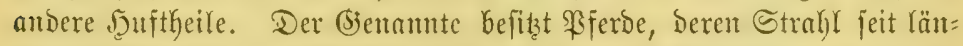
ger als fünf Jahren nid)t bejdnitten murbe. Snt Walyrlycit werbent bie abgentbaten Theile Des Strables idjon non jelbit abgejtojen, nad)bent

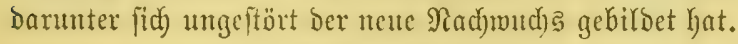

\section{Drud auf ben Strahl.}

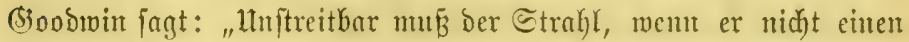
gewifien Drude 3 ertragen hat, entarten und nidjt mefr im Stande jein,

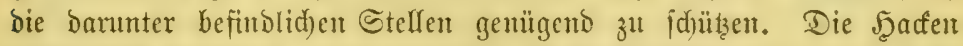
merben fid alfüählig zujammenziehen, ba bie Streben allein bies niddt mehr verhindern fömen, jo jehr fie fich auth ftemmen. Darats folgt

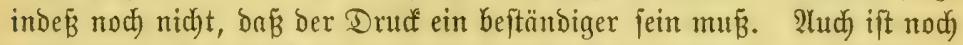

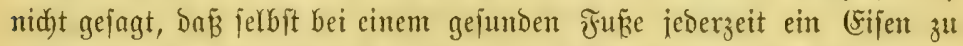
perwenben ift, in weldjem ber Strabl ben Boben berïhren tann, wenn bas Thier auf einer ebenen, harten Sherfläche ftelgt. S̈m natürlidjen Zujtande berührt der Strahl fajt allezeit Den Boben und fühlt feinerlei

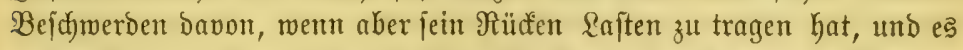
muß auf harter Straßje laufen, liegt bie Sadje anders und mollte man

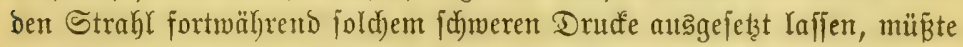
ミabmbeit eintreten." Dennod) ift ein gemiffer Drud nothmenoig, fonit mürbe eine Berfdjebung ber Sormplättduen eintreten. Sn Sdjottland

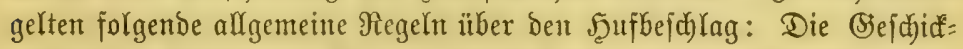

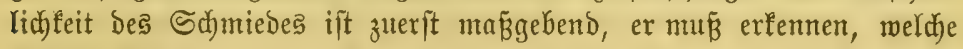
(S)eftalt er Dem eirzelnen Frnbe zut geben hat, ebenjo wie er bie Tragjohle

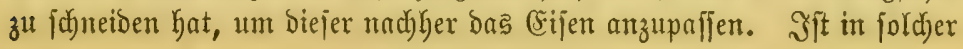




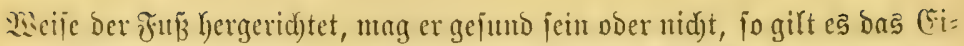

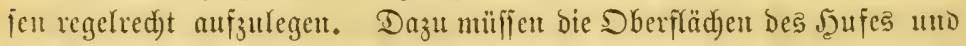

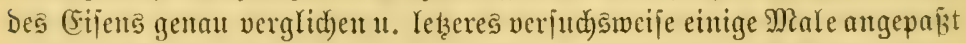
werbert, wobei bald ein wenig Jeormmaffe weggenommen, barb bas Eijen

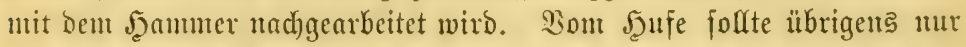

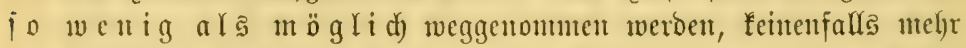

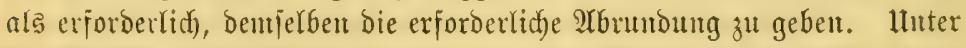
Den franfen Şufen foumt am lyäufigiten bie (Entartung Der Şufmafje an ben Eeitemwänden vor uno ift cimer fel)lerbaften Befd)lagameife zuzu=

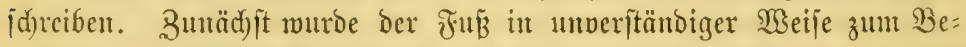
id)lngen bergerid)tet, bann wurbe ganz vermunftwiorig beid)lagen, fo baf Das (5ijen Den ŞuF niederzog, ja nitunter, wie cin Jeebel ber Bewegung

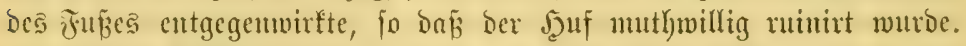
In anderen Fällen fonmt ber Fuß auf eimer Seite böber zu fteben, als

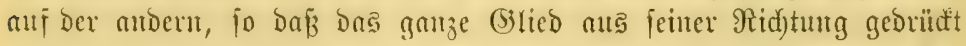

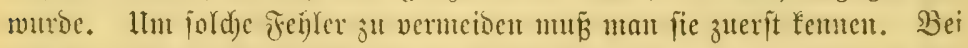

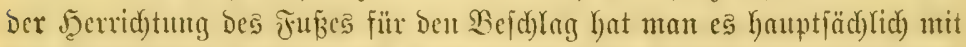

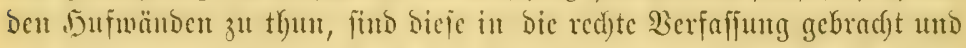

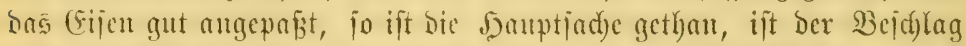

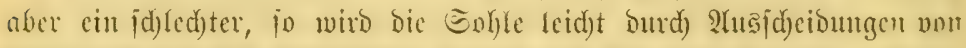

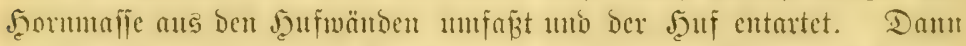
aber idneibe man fente Söcher in bic Soble, iontern itelle bas (bileid)=

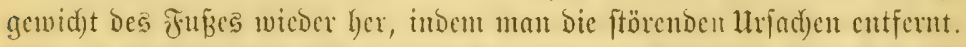
Iie zux Bearbeitung oes seujes vorkandenen (Elemente fund fajt alle umpraftifd) uno es iit nicht waf)r, Daßj cin guter Trbeiter mit irgento mel=

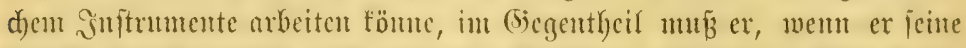
Smede erreid)en will, fich gecignete Siserfacuge erfinnen. SSir baben

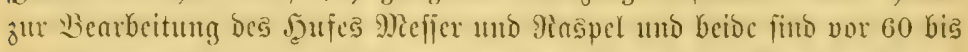
70 Jaluren entitanden, als cine ganz andere Theorie bes \$iferdebejd)lnges f)errid)te, als heute. Jrïler stod) wurbe bas BSirteifen angenommen, weldyes ïberall int (Sibraud) mar. Dem veritorbenen Profejpor Coleman

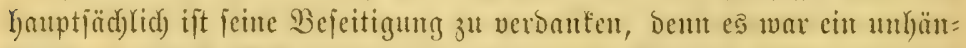

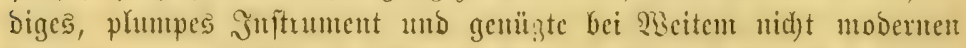

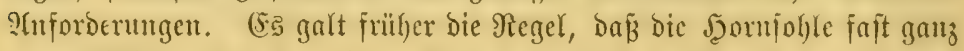
weggeid)nitten ober wenigitents büu ausgerwirft wurbe, fo baj oft bas Bjerd bejd)lagen wurbe, un bic Streben wurden ftel)en gelajןen, zwijd)en 
biejen mbeitete mant mit Dem Mefier, nid)t etwa, un bos (Eijen gut an bic ভohle anzupaffen, jondern um möglidgit viel Sufmaffe zu entfernen.

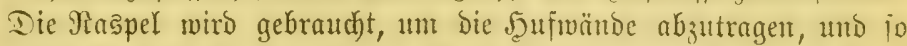

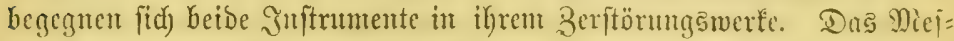

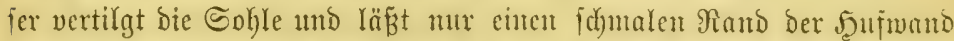

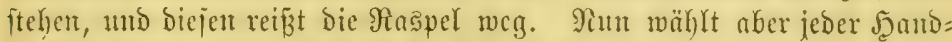

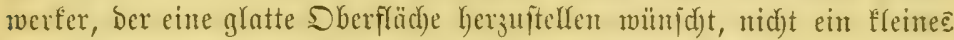

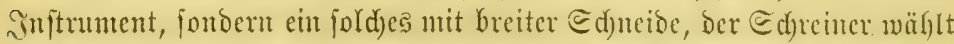
nid)t Dent Meifel, jondern Den Ranghobel, ber Ed)läd)ter greift bei bem

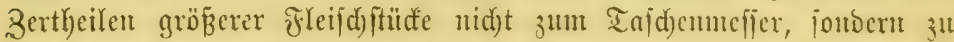

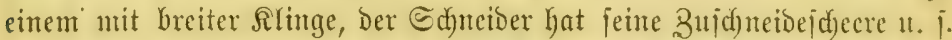

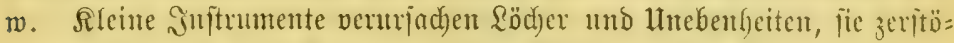

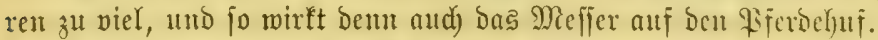

Weahalb man diejes in England trotzoem einfülyte und lange beibe=

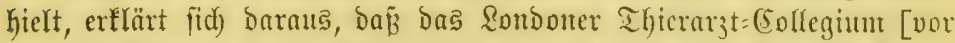

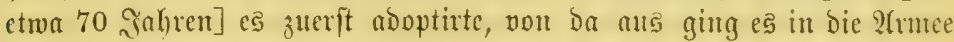

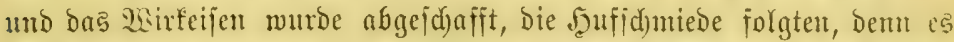

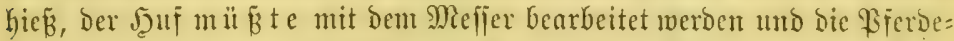

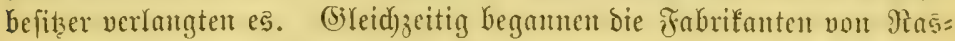

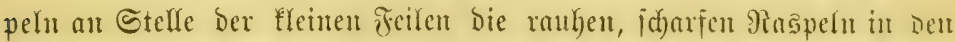
Marft all bringen, mit benen eilt fräftiger Mam Durd tuenige Etrid)e

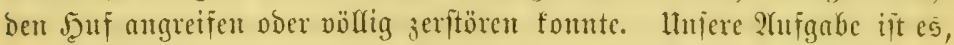
ein rationelfes Eyjtem an die Stelle bes jeţt herridyenden ju jeb̧en.

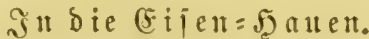

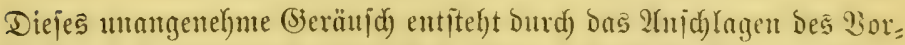
berhufes des Şinterbeites gegen bas Eijen des Borberbeites. Beim

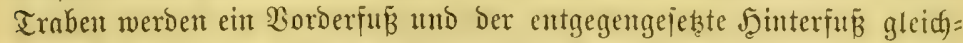

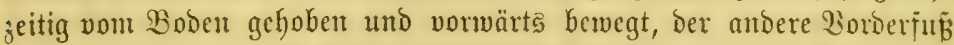

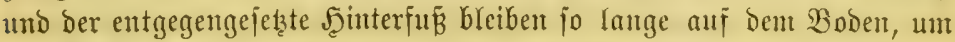

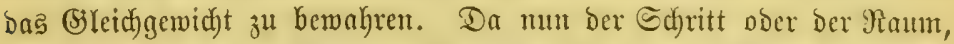

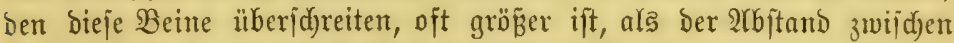

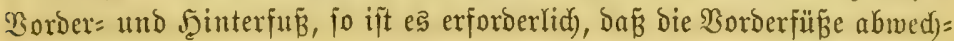

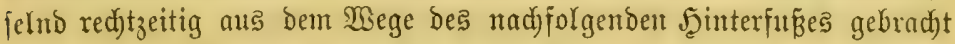
werden. Dit fommt es bann (namentlich bei ungenügend eingebrod)e= 
nen Bierden, bie ifren @dyritt nody nidyt fentu, ober foldyen, bie hobe

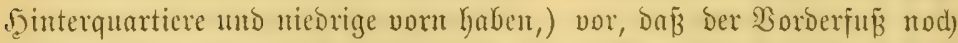

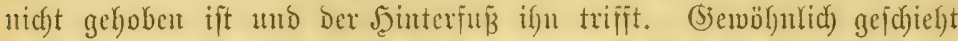
Dies, wem Der Sorderfuß erft halb urfoben ift und Der Borberguf Des

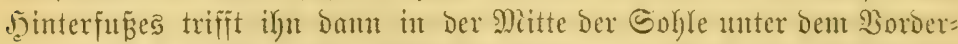

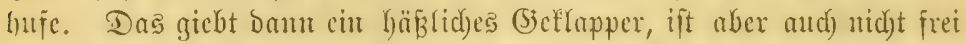

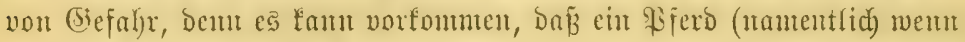

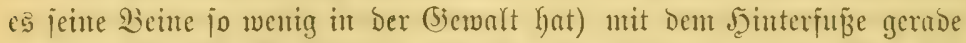

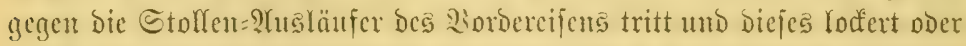

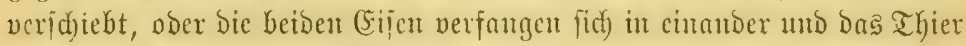
fituzgt zu Boben, ober Der Sdylag trifit höher gegen die Eefnue und 2tu=

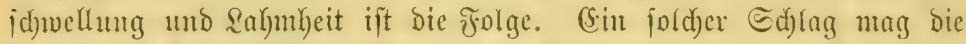

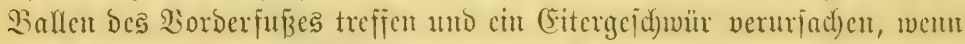
bie Serleł̧ung vernad)läffigt wiro. Die Ballen merden am bänfigften getroffen, mitunter aud) Die Jeffelu, bas (Eijenlauen fonmut am chejten

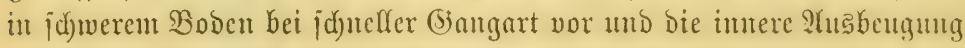
deș (Eifents verurjad)t bie Serletzung. Mau hat verjobiedene Sehand=

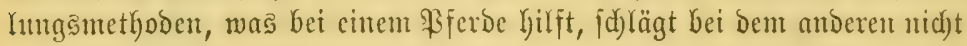
ant.

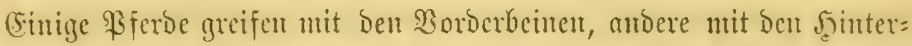

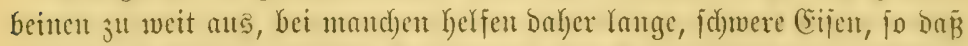

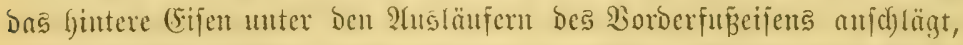

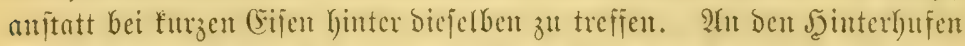
vermende man leidyte (Eijen, bie am Sorberfuje ctwas zurïdigejebt fün, wälyent ber Samb vorjpringend gearbeitet ift. Dicjer Bejolag ift gut

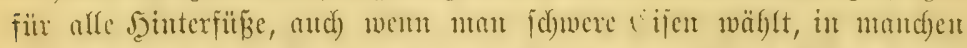

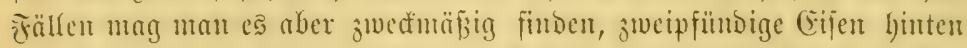

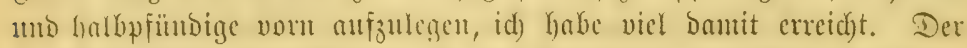

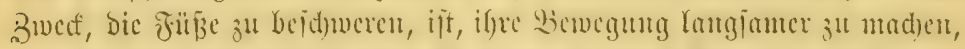
mit leid)ten (sijen verfiel)t man fie, weun man bic Dewegung bejc)lemi=

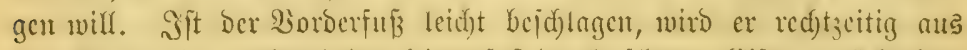
bem S⿱

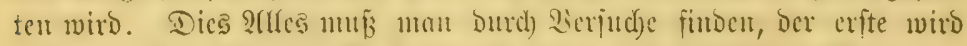

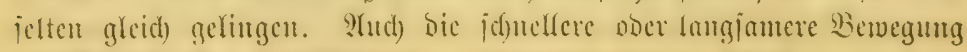

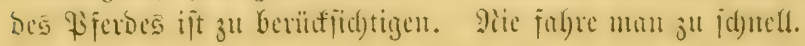




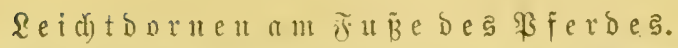

in ben

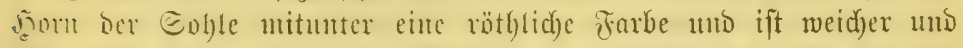

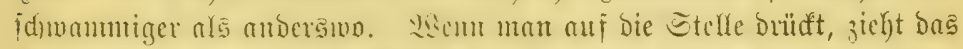

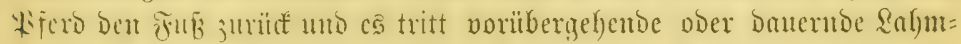

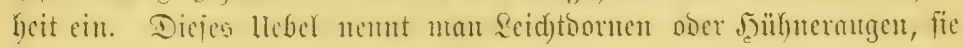

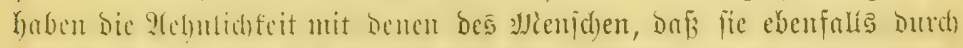

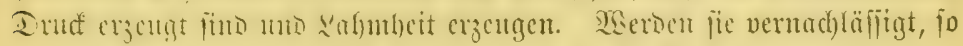

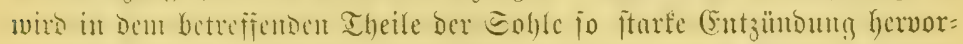

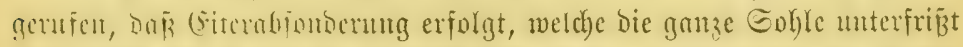
ooer butch bie soufunije ansgeichieben mirb. Dabei wird ein ftarter

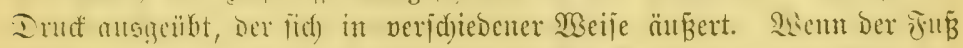

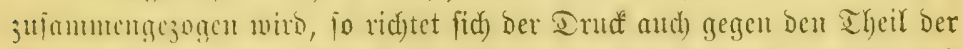

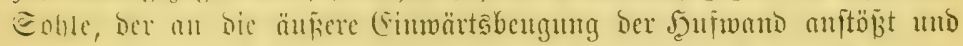

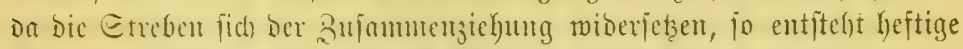

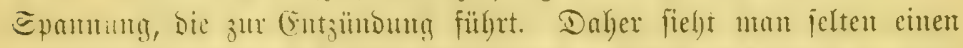

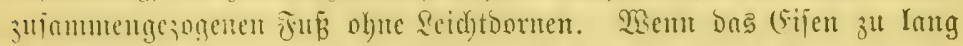

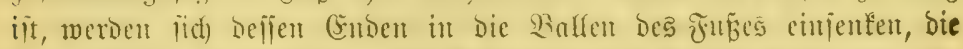

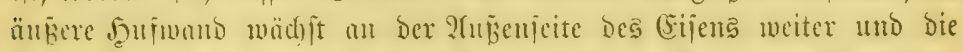

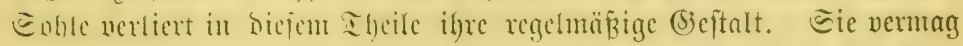

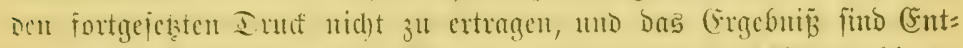

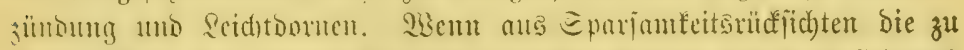

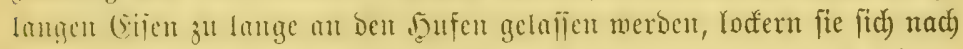

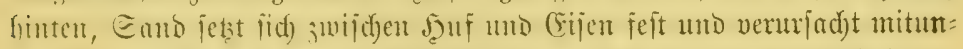

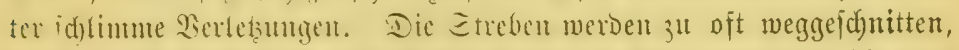

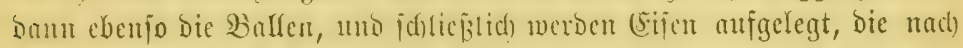

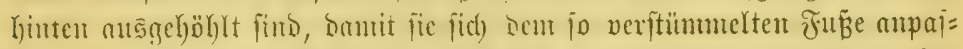
ion. Eo ift vou vorutercin cine sicigut sur Bujamunenzichung gegebent

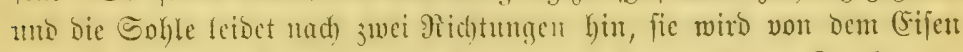

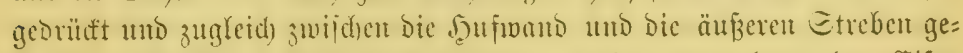

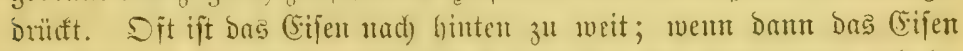

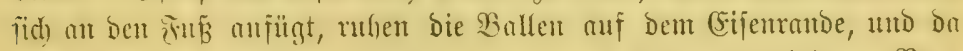

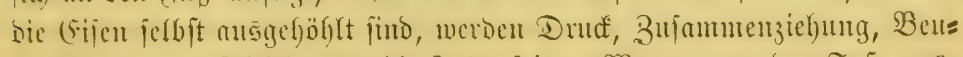

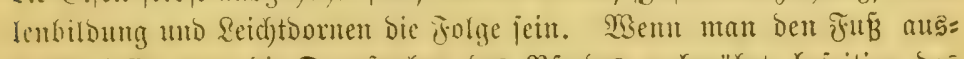

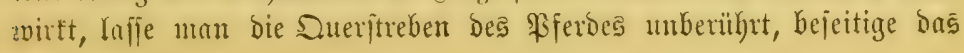




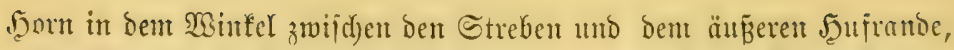

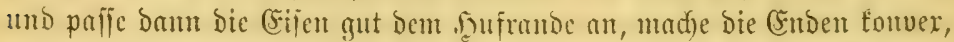

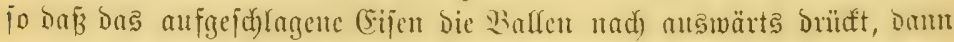

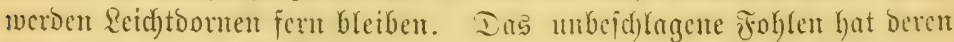

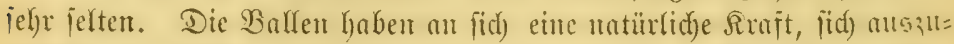

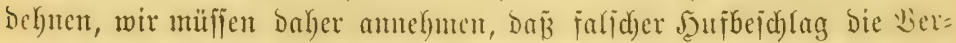

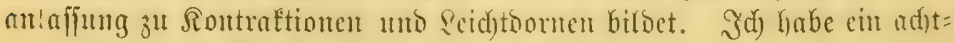

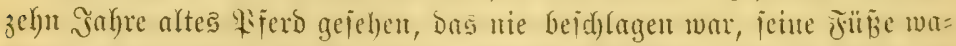
ren in jedem Theile gejuns unb vorjüglid) entwodfert, benn fie waren int

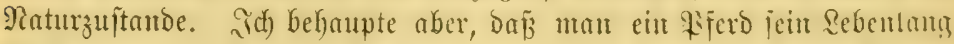

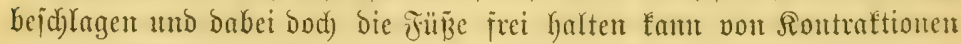

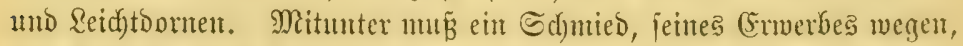

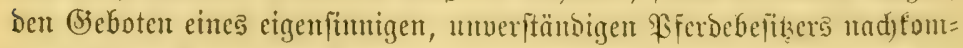

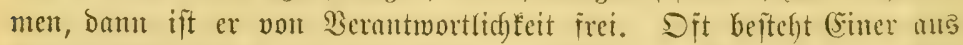
Sparjanfeit barauf, bie alten (Sijen möglid)it Iange beijubchalten, aher

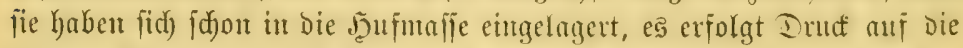

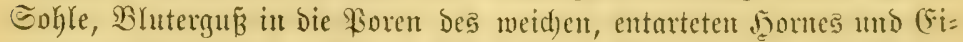

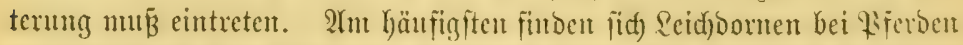
mit bünter, fladjer Sogle und weidjen Baffen. Bei veralteten Peidfons: nen ift bie Jeeilung idjwieriger, aber intuter fidfer. Qeid)tontuen werben

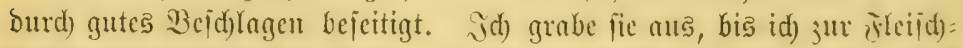

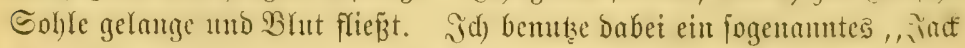

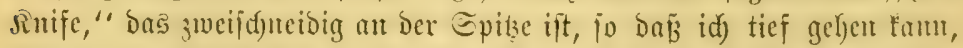

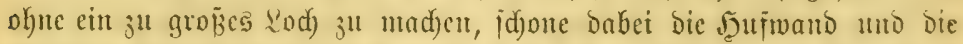

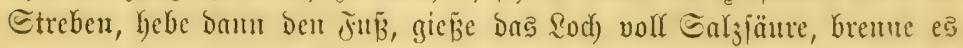

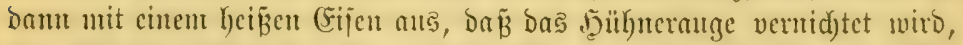

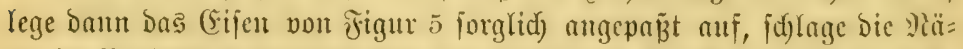

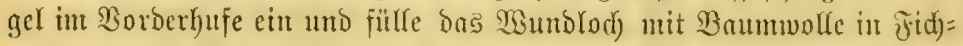

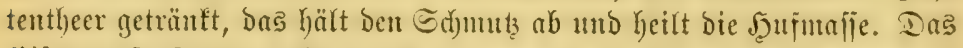

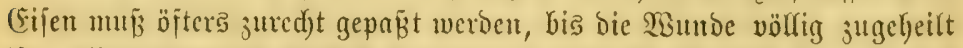

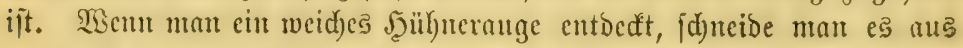

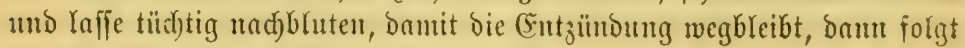
diejelbe Bebanolung, wie zuvor angegeben.

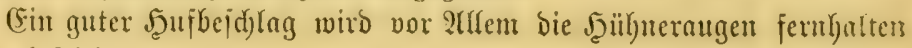
Dber bejeitigen. 


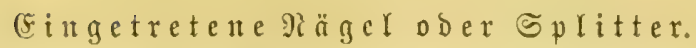

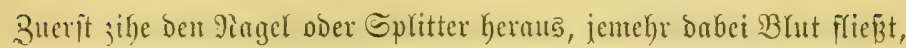
oeito bcifex. (Sicjujeft dies nidft, nimm ein ipitziges Mefier, reinige bie Wumbe und lajie tïd)tig Glutter, bantit bas (5ift entfernt werbe. Sd)neide

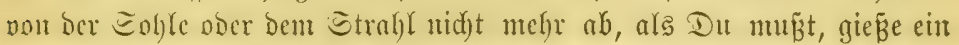
panr Tropfen Ealziäure in bie 2 Bundo und brente fie mit einem heiß̈en

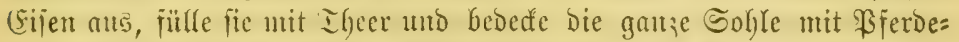

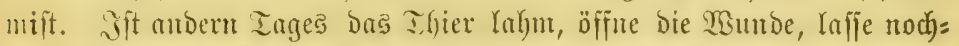
mals bluten und wiederlyole bie Befondung, Damit (Eiterung feru gebal= ten werde. Die Ë̈ure töbtet bas (5ift, Der I Jeer Geilt.

Eollte Das Wferd bod) lahm bleiben, öfme man bie Wumbe abermals bis fie blutet, belege fie alsoann mit einem Reinjanten=\$ultice und ge=

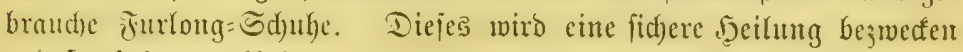
und Lock-jaw verfindern.

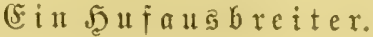

Der beigefïgre $50 l_{3}$ idjnitt repräjentirt eimen நufausbreiter. Das

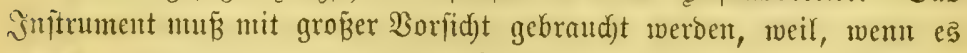

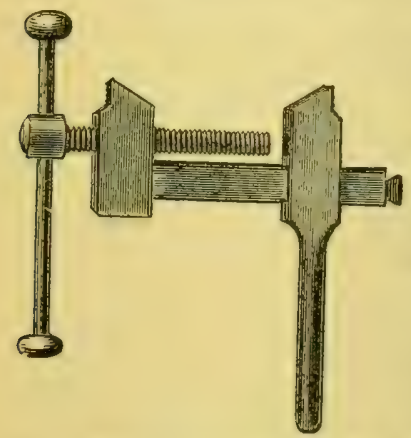

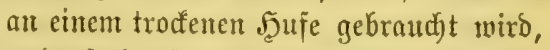
eș benjelben für immer ruinirt. Der Ş山f muß aljo erit erweidjt werden und zwar aui folgende Wreije: Raffe zuerit bie

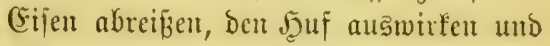
(sijen antegen wie Şufeijen Fig. 5 in Dem Buch. Dann lege Dem \$Fferbe den "furtong Arufmeidhitiefel" an, in Defien Jeöhlung fich ein groß̉er Sdymamm be= finbet, ber mit einer 2 Afflöjung von zwei Suart 5oolzajo in einem (simer voll

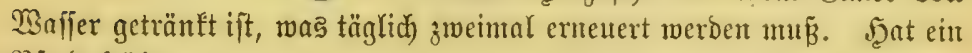
ĐFerd Şüfneraugen, turire bieje zuerit. Daş Bud) wiro Dir jagen was

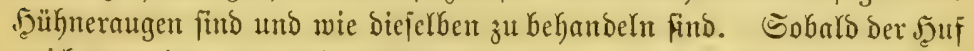
meid) gemorben, wende ben $\mathfrak{A}$ 引breiter an und zwar jeben andern Tag

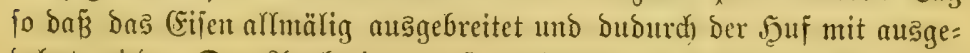

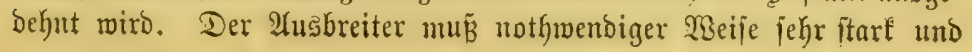


wou Ciijen jeit. Eobald ber Dü bie ridgtige Breite hat, gebrauche bie

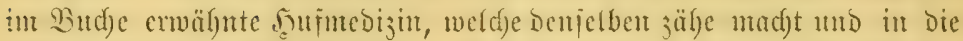
ridftige Stellung Kringen wiro. Befolge bie 2(mweijungen für \$iferbe=

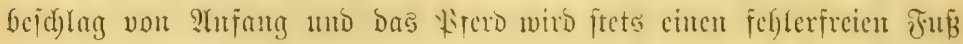

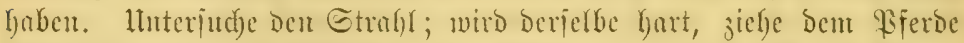
Dent obengenannten Gtiefel mu, den Edywann aber tränte mit ffarem

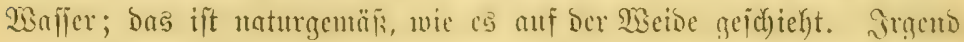

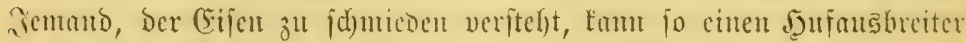
mad)es, ber fich) in jeder Jృufid)miede Gefinden follte.

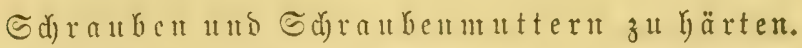

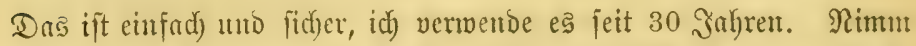
cine Bled)fante, bie cine halbe biallone faß̈t, und fülle fie mit gejantol=

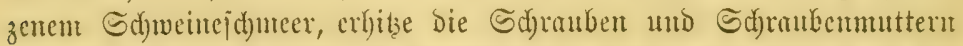

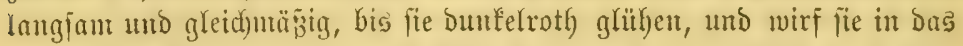
Fett, rïbre fie barin untger und füble fie fo rafd als möglid) ab, jo futo fie gebärtet.

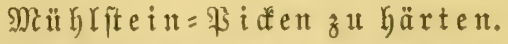

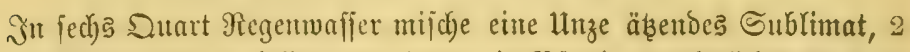
unzen 2̂nmoniaffalj, beioses gepulvert, ein Zifuno gemöhnliches Salz in

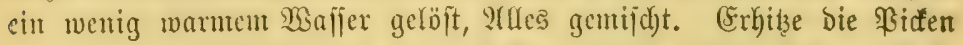
langjam und gleidyuäß̄ig, fo meit als fie gebärtet werben folfen, bis fie Duntelroth funb, ftedfe fie in bie Mifdung uns fithle fie ab. Die Frïfig= feit ift giftig แ⿰ in cinem Stemtruge aufubewabren.

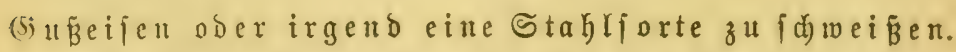

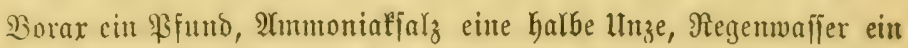

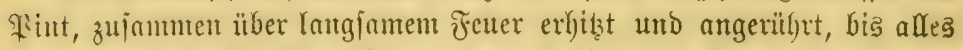
Sisaffer verfodyt ift. Der Bobenfał wirb über bem Feuer gehalten un umigerïlyrt, bis er fein wie Mehl und völig troden ift. Damu laffe man bie Miid)ung abfüblen, jetze eine Unze id)warzes Mangan=Drio hinzu,

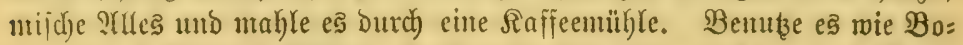

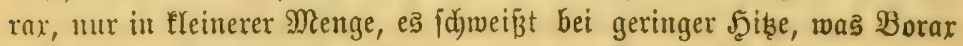
nicht thut. Das MRittel iff billig und viel wirffamer als Borax. 


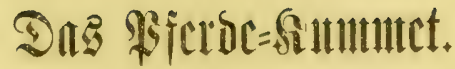

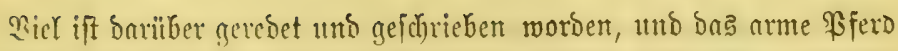
h) at bod) nod) zu leiben, Denn Die Rummete werben uidet rid)tig gemad)t.

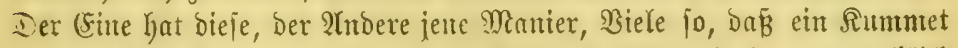

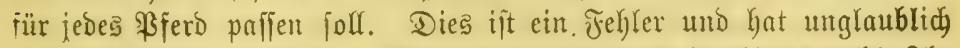

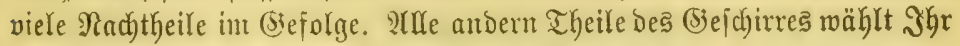

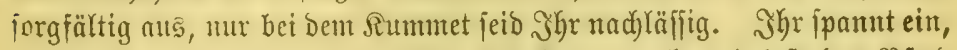

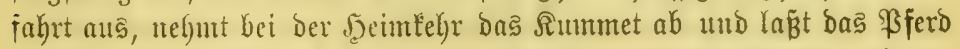

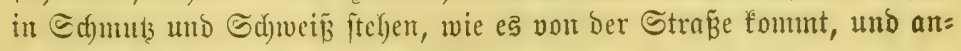
Dern Tnges ift das \$ferd frant.

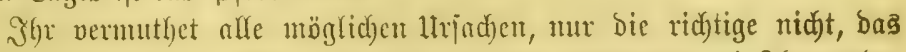

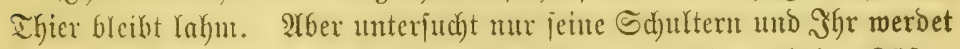

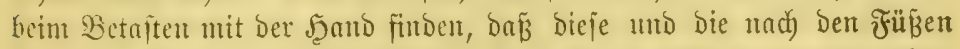

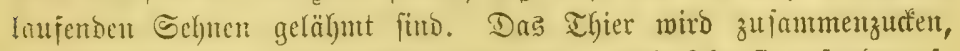

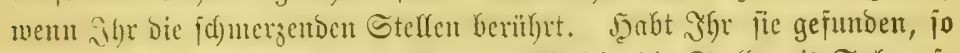
greift jofort uno jwar felbit eir. Mgafdet bic Steffe mit Salzwaj:

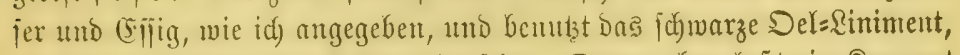

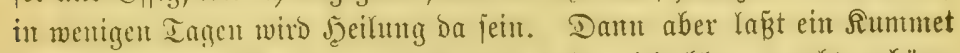

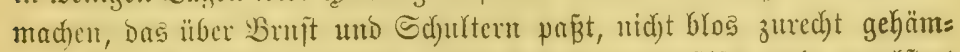
mert ift. Das Sumunet muß an Den Sdyultern elajtifd) und gepolîtert jein, ein nidjt volfitündig paifendes jollte nic verwendet werben. Mit

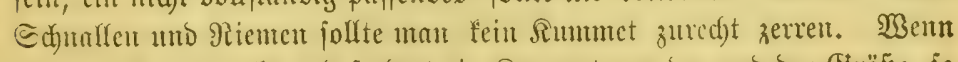

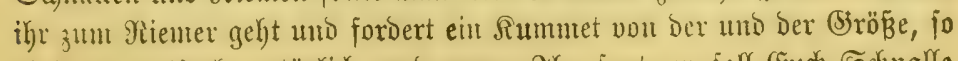

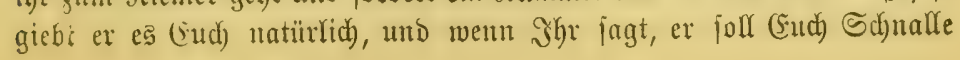




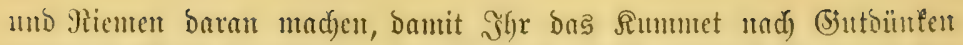

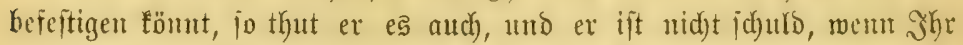

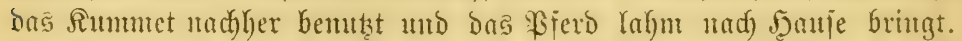
(5s ift gerube jo, mie went (Einer für emen Befannten anf's (Sierathewohl

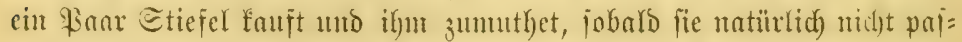

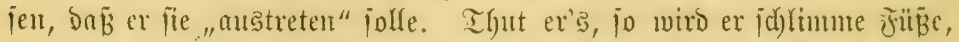

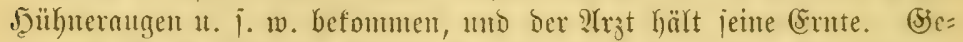

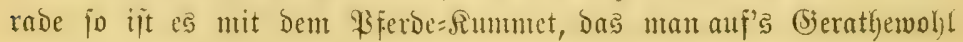
finfte.

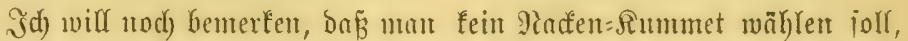

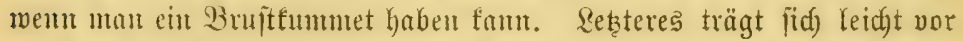

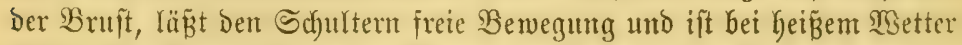

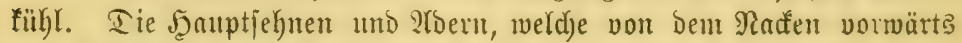

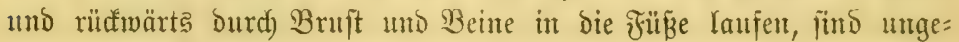
hemmt, ons Błut cirfulirt frei, bie Sdyultern werben nidjt zujamunge= Drindt.

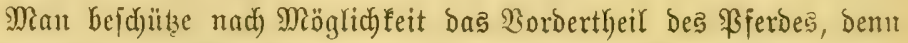
Gier wird bie (5richüttenung beim \&aufen an meiften empiunden, bas

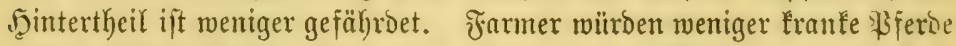
haben, müroen fie bas alte Dentid) Rummet beim $\mathfrak{B}$ flügen und jonjt io

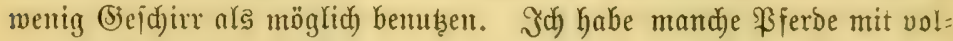

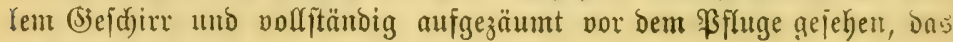
ift ein Miñgriff. 


\section{Pfnhang.}

Zlligemeine beichidhte des pferbes.

Die Erjiehung des Pferdes.

Das Zllter der Pferde.

Regeln unt Dorihriften der 2Tational Trotting 21fifociation.

2lnaabe ber 2ltedicamente in denticher und englifher Sprache. 


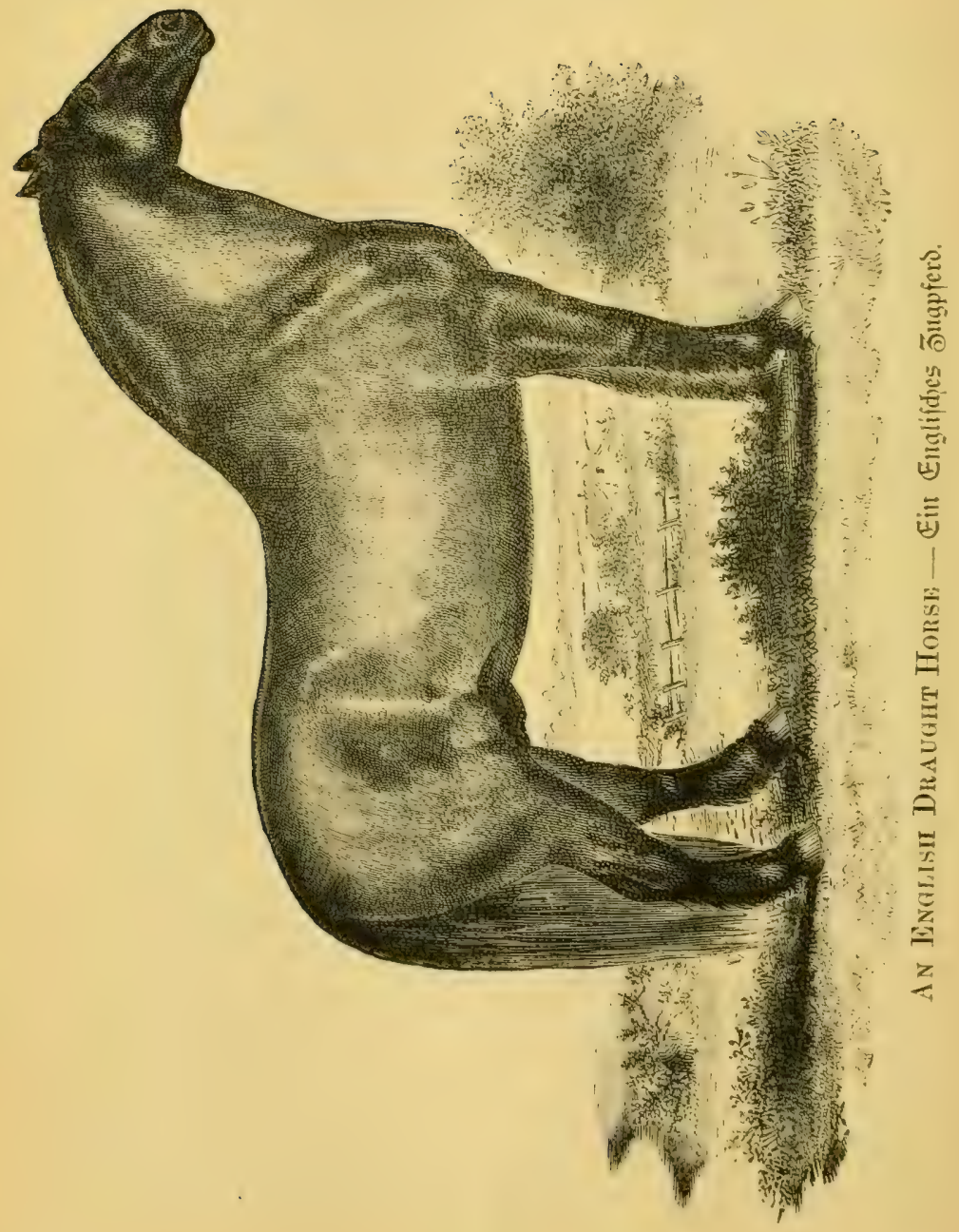




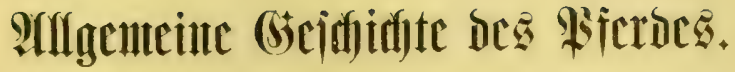

\section{Urg geuciuc Bejdreibung.}

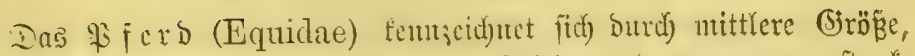

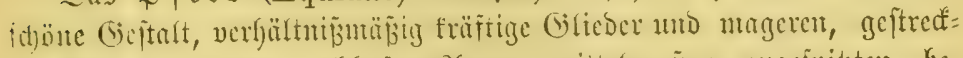

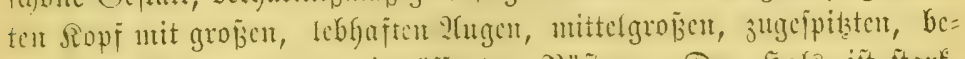

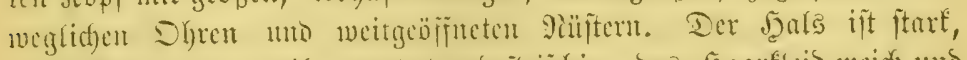

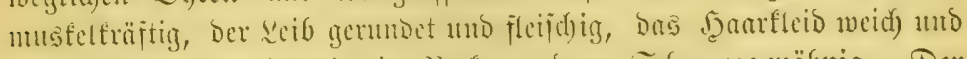

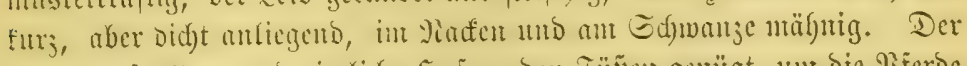

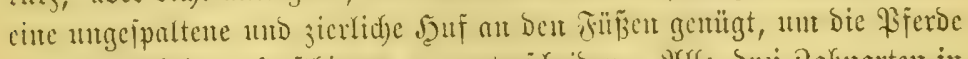

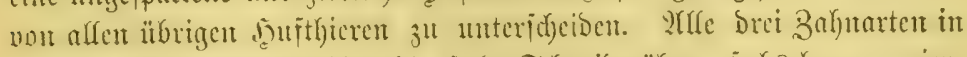

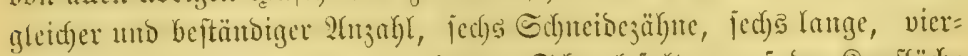

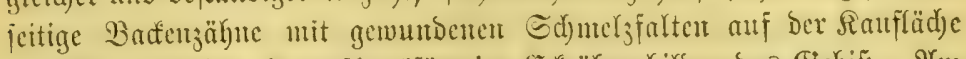

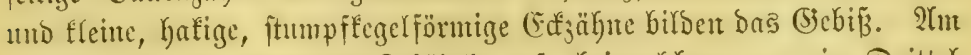

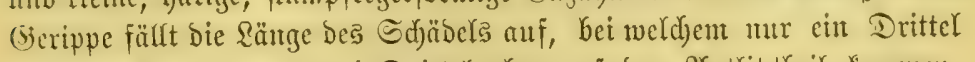

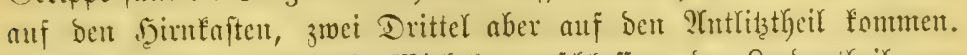

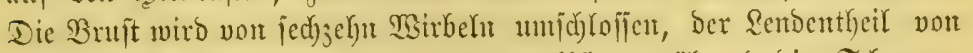

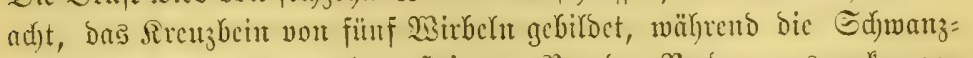

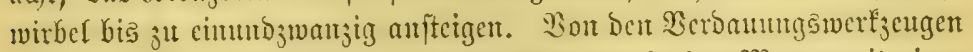
nerbient bic enge Speijeröhre, Deren Münbung in ben Magen uit einer Silappe verjeben ijt, bejondore Bead)tung. Der Magen ferbít ift ein

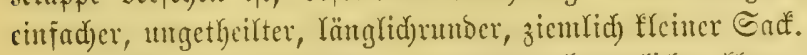

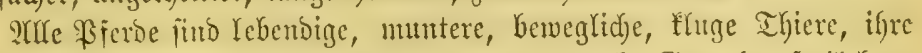

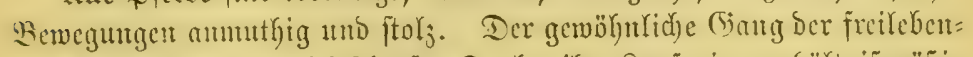

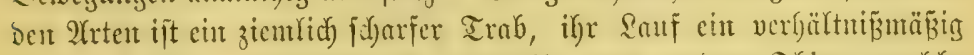
leidster Gatopp. Frieblid) und gutunïthig gegen anbere Thiere, weldie

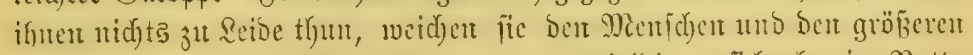

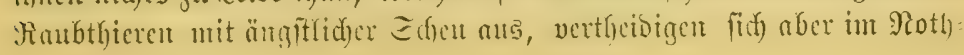




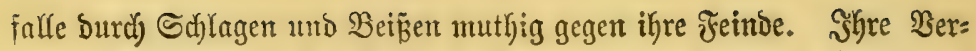
mefrunt ift gering. Die Stute wirft nadh langer Iragezeit ein cinziges 3itunge.

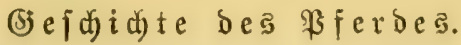

Mindejtens zmei, wahridjeinlidyer brei Frten Der Familie finto von Deut Menjiden unterjodjt morben. Reine (Scjujidjte, feine Sage erzählt

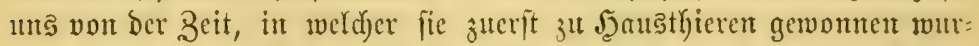

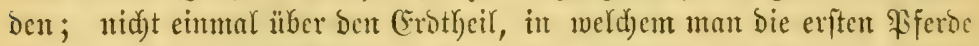

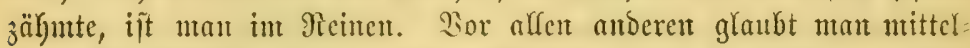

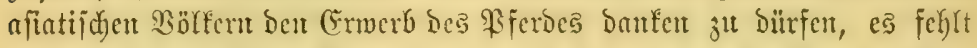

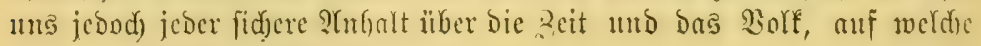
wir utmicre Bliffe ridjten fömnten.

\section{Das arabijde gferd.}

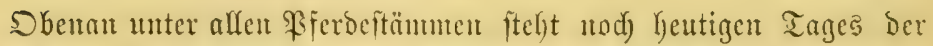

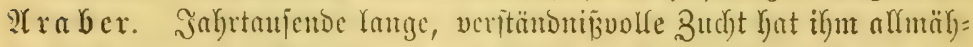

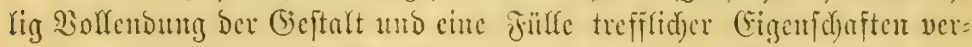

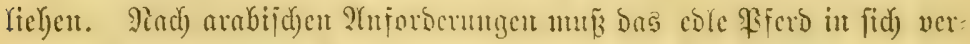

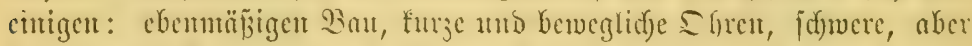

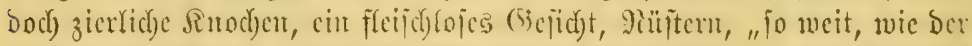

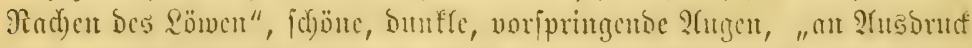

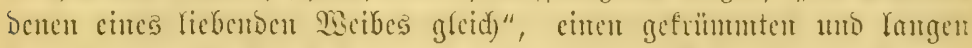

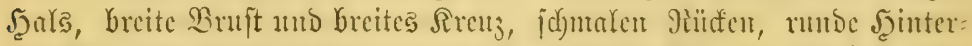

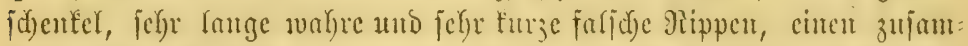

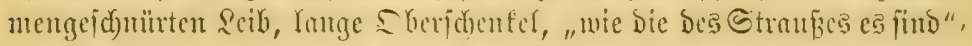

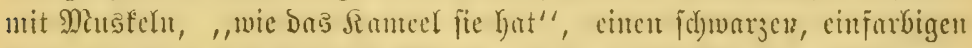

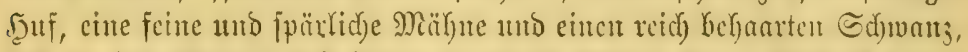

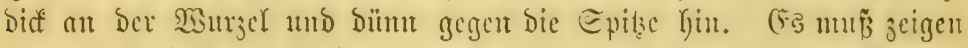

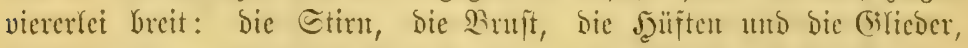

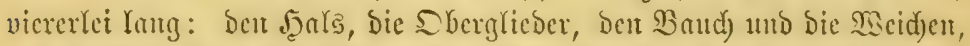

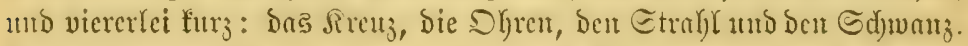

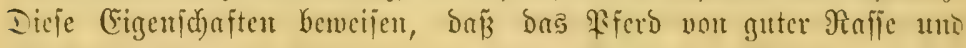

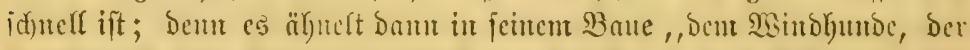
Eaube und Dem Rameele zugleid)." Die Stute muß befitzen: ",en 


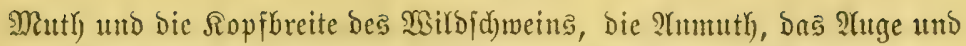

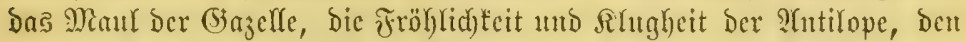

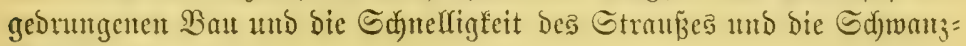
fïrze Der Biper."

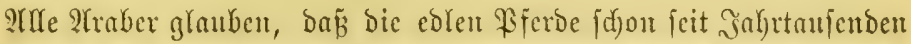

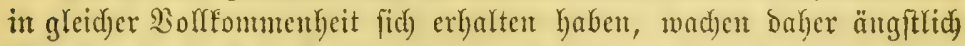

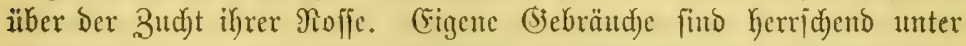

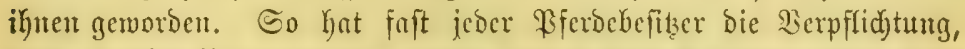

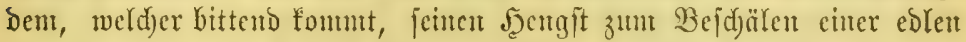

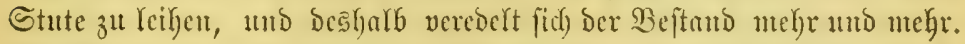
Şengfte vout guter Fafife werben jefre gejucht: bie Stutenbefitzer burd)=

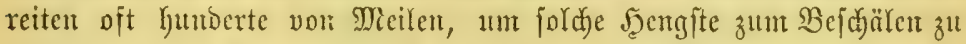

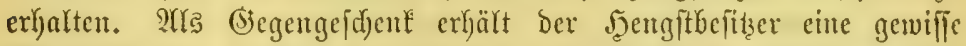

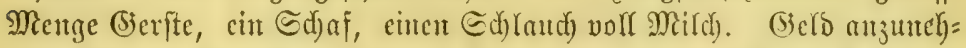

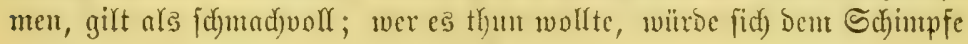

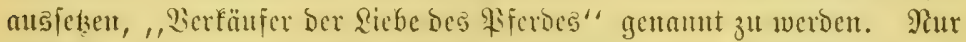

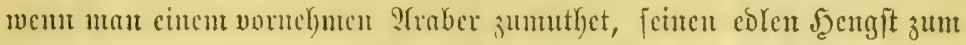

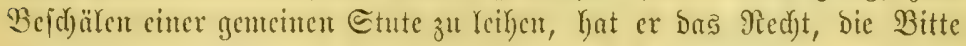

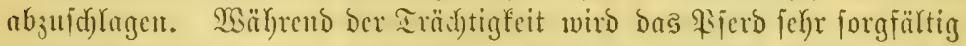

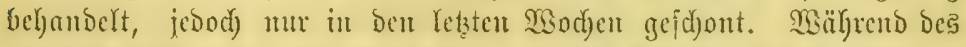

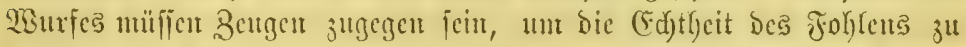
Geftätigen. Ias Johlen wiro mit bejonberer Sorgfalt erzogent unt vont

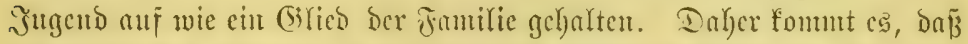

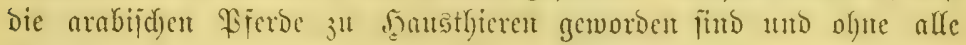

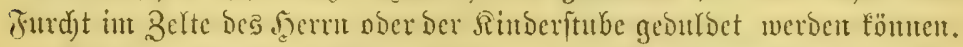

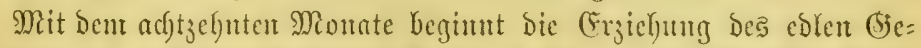

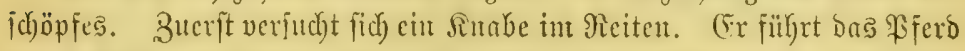

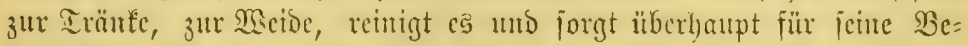
Dürfniffe. Beibe Yernen žl gleidjer Beit: Der Sutabe wird cin ßeciter,

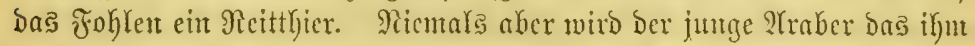

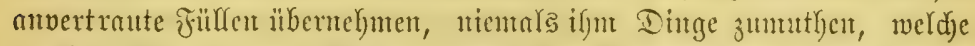

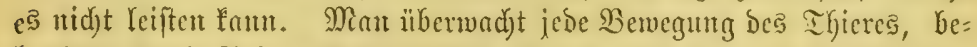

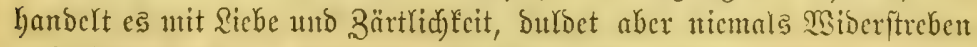

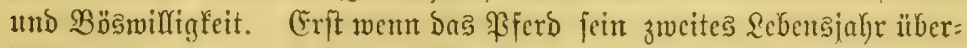

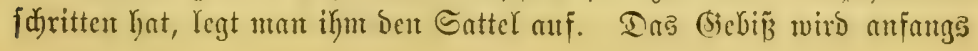




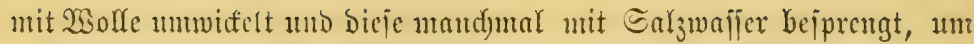

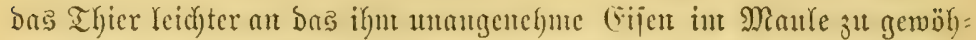

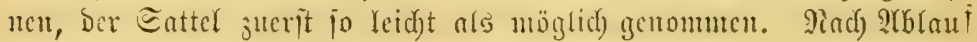
Des britten Jahres gemölnt man es allgemad) Darun, alfe jeine Siräfte ju gebraud)en, lä̈̈t ifm aber Durd)aus nid)ts abgeljen. (Exft went es

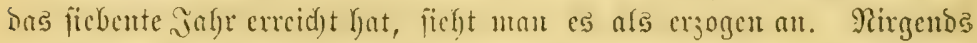

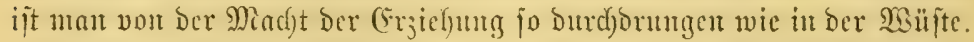

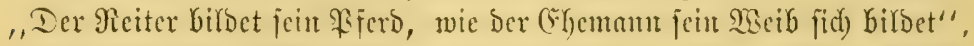

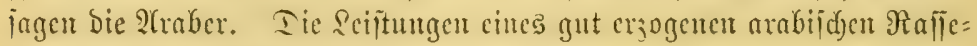
pierbes finto außzerorbentlid).

$$
\mathfrak{P} \text { 千 }
$$

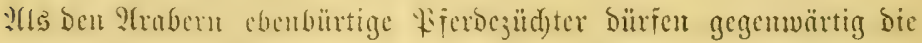

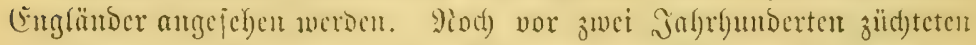
bic Epanier mo jtalicucr beffere \$forde als bie Britten; feitben fint jute ebento juridfgegnuge nls bieje vorgejdyritten. Das gien $\pi=$

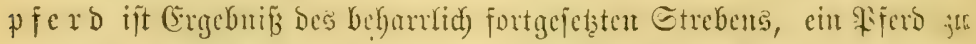
crzielen, weldyes nffe übrigen au Sdynelligfeit im Raufen z̈berbieten

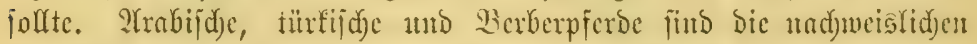

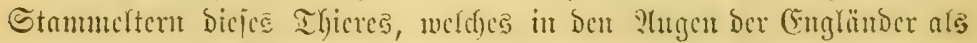

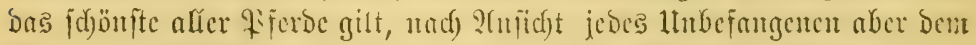

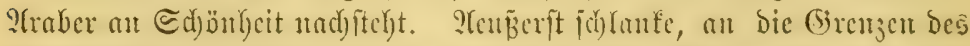

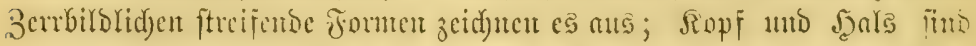

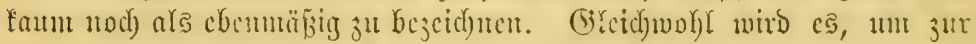
Bercochutg zu bicuen, und) alfen von (Europäcrn bewolnten Päubern

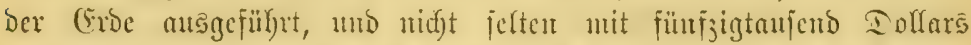

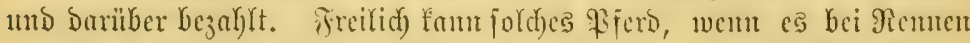

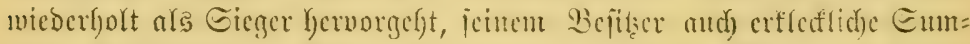

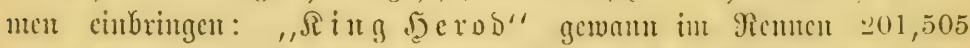

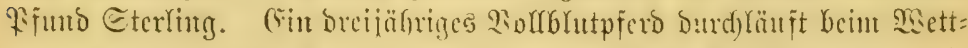

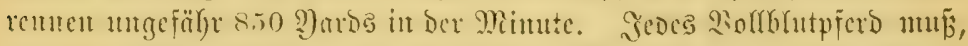

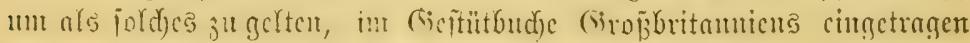

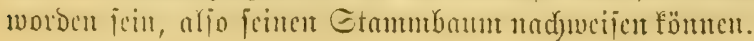

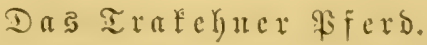

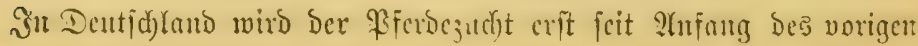




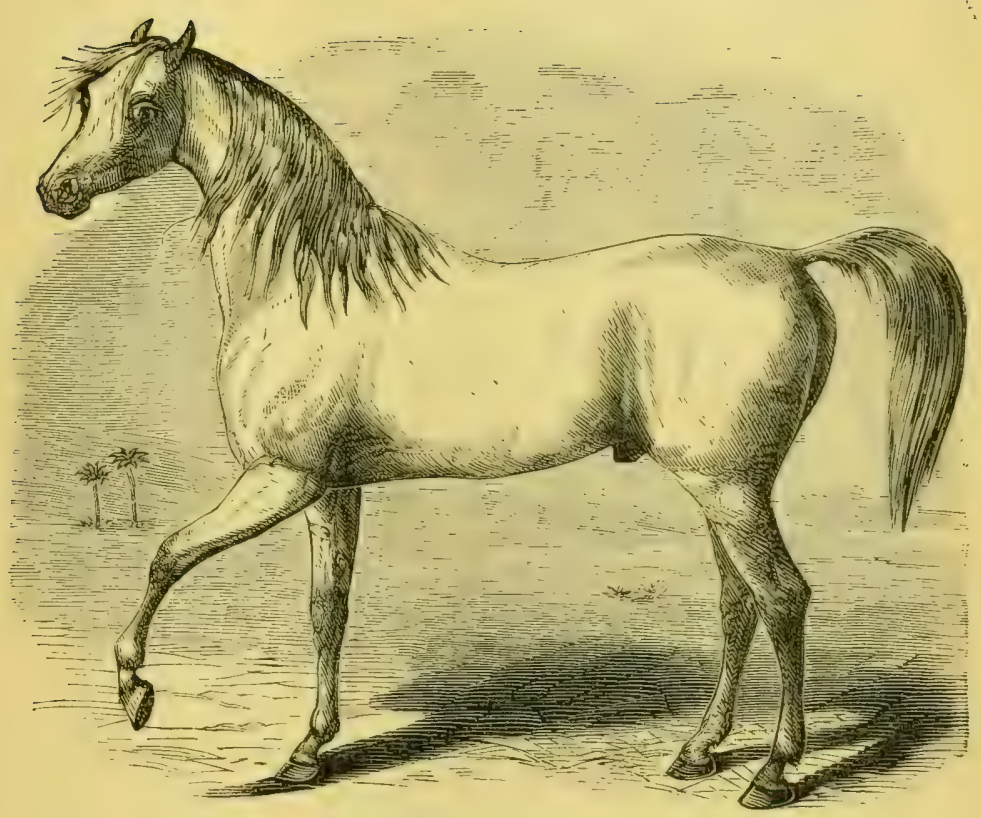

The Arab Honse. - Das Uraber Pferd. 


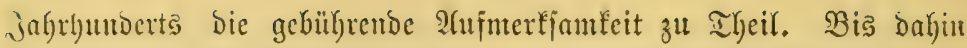
beguilgte mat fich, Bjerbe zu erzielen, obute auf beren Berebelung bejon=

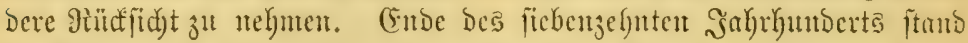

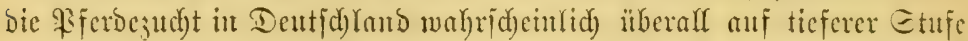
ats in Mittelalter, weld)es, wie befannt, mit bem Morgenlande ungleida

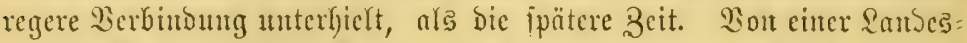

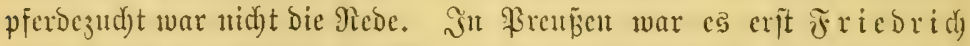

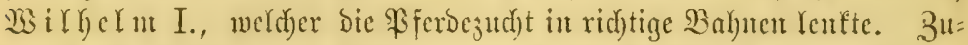
näd) it un jeincu cigenen Marftalf mit guten \$iferben zu verjorgen, er=

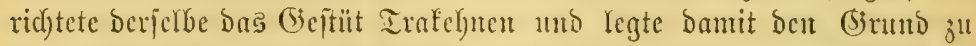

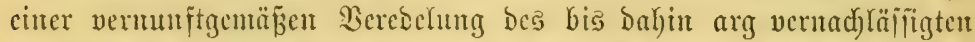

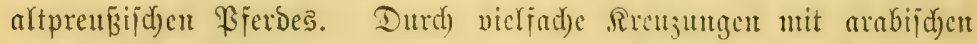

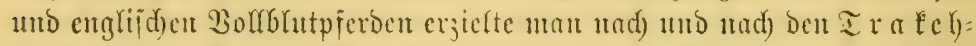

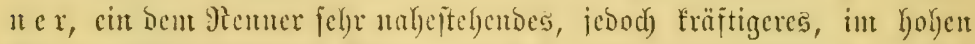
(Srabe Keifuntyşäbiges Thier, weldyes man gegenwärtig wohl bas

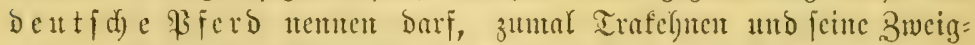

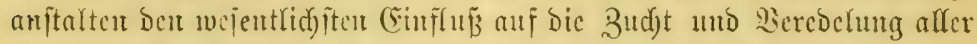

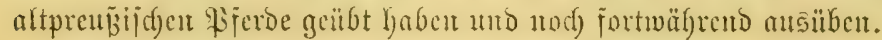

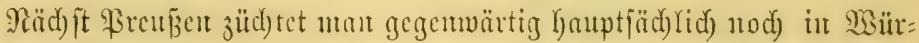

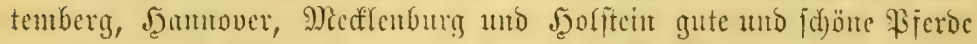

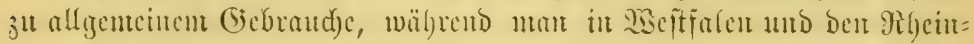

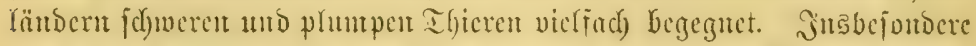

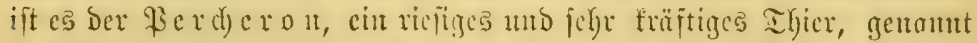

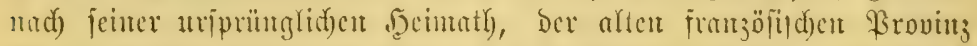

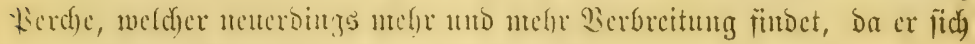

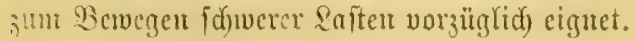

\section{Das ï̆}

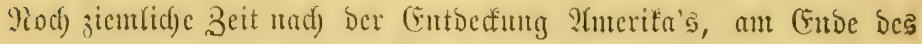

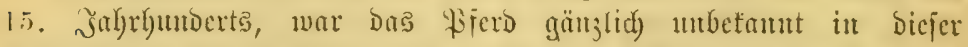

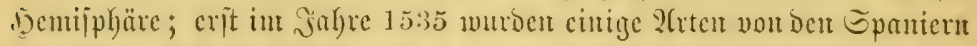

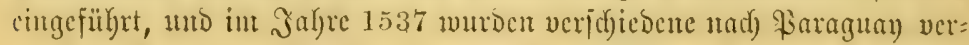

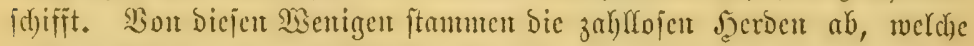
jeitben über ben ganjen fïblichen Theil ber fecmijplyäre unb vou ba \#̈ber 


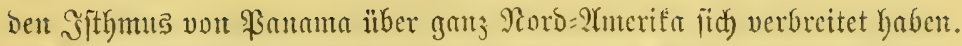

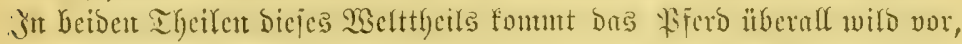

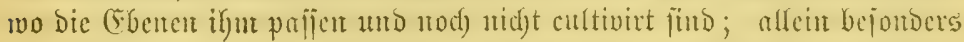

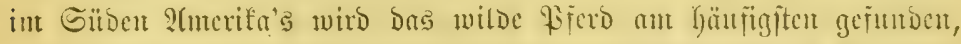

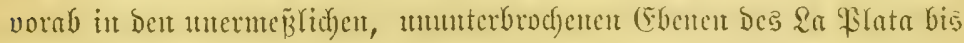

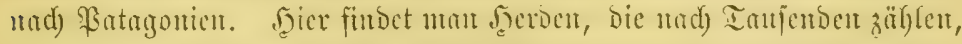

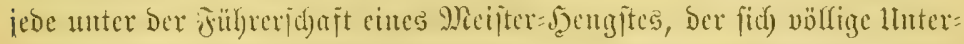

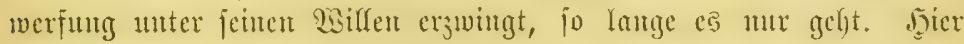

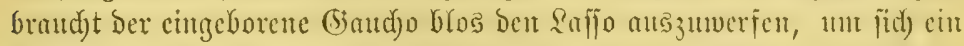

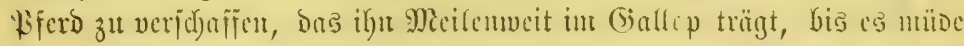

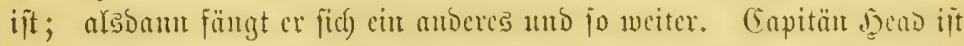
auf bieje Seije von einer Rüfte zur andorn geritten, wobei cr affe 5o bis

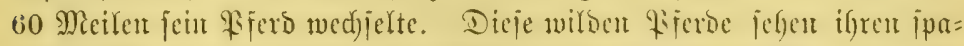

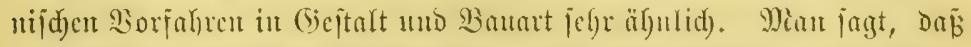

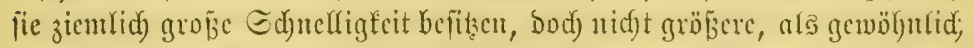

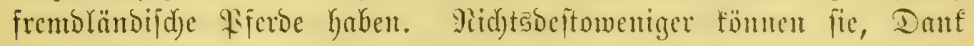

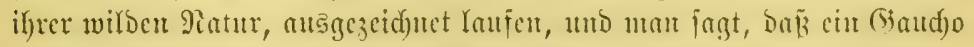

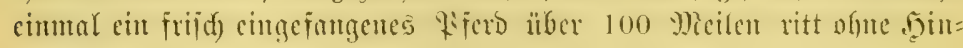
Derniffe.

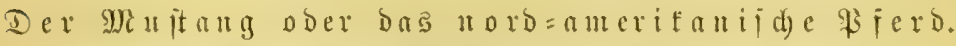

Wie ite wildon Bierde Süb=2lntertfa's ftanmen and biejentigen in

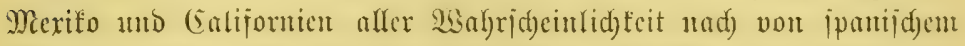

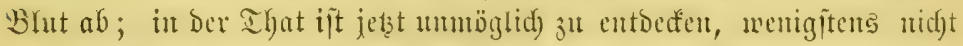

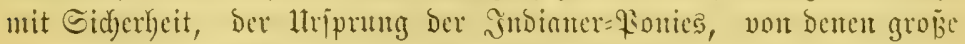

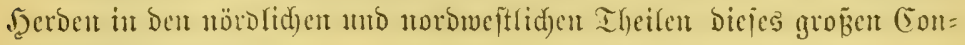
timenta willo laufer.

\section{Da ล}

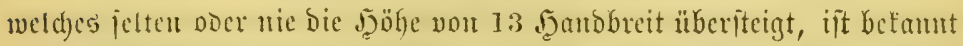

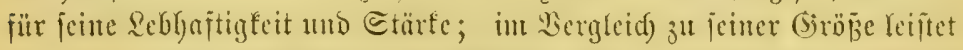

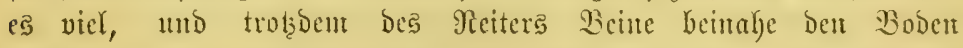

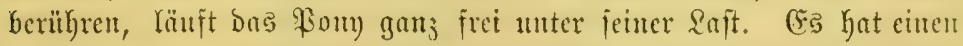

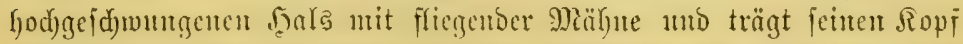

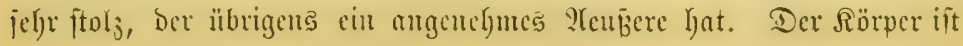




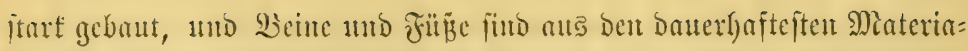

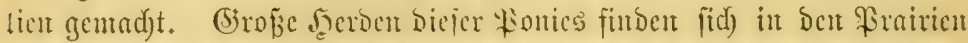

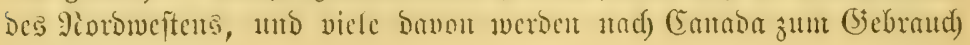
gebract.t.

\section{Das canabijde Biferd}

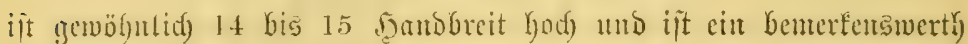

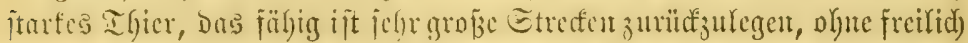

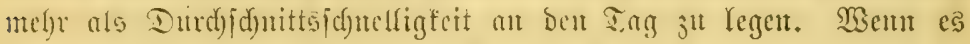
Dagegen mit émen gut gejüchteten Fifrd getrenjt wiro, verbindet es bie

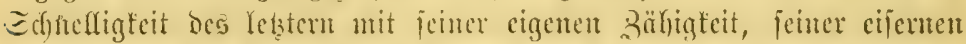

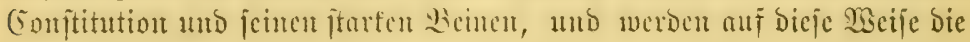
meijten ber beften Miempjerbe gezïc)tet.

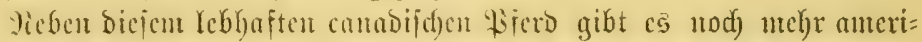

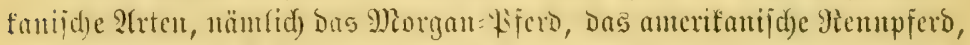

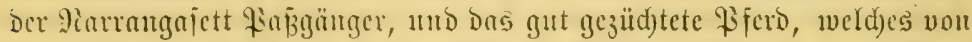
importirten englijden mo franjöfijden Bjeroen abitmunt, nit faum

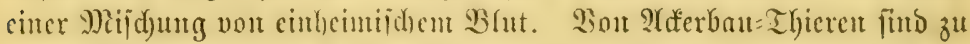

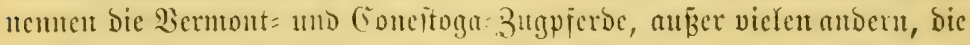

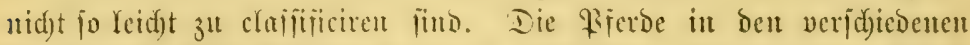

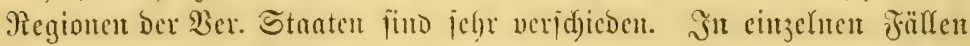
hat man cinzelue Clafjen als unterificolidye Büd)tungen aufgeftefl,

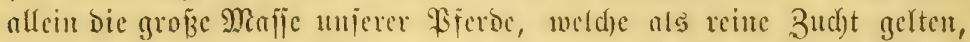

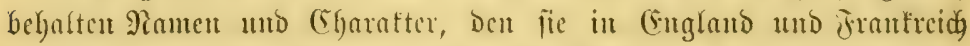
erficlten. (Es war bis jelit meijt ber Wirand), Den Egarafter ber nutritanija

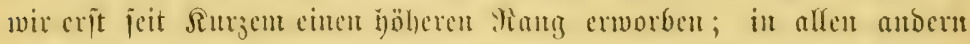

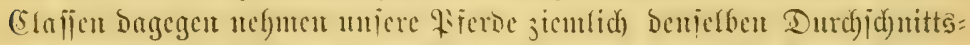

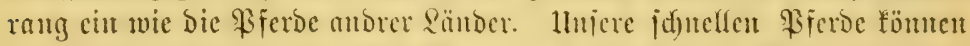

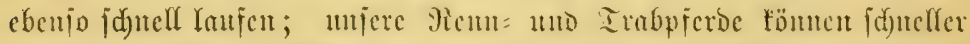

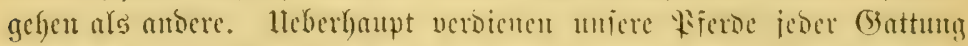

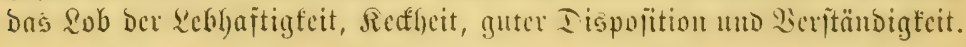

Das

Dne Mort thoroughbred, wem anf Dos Riferd angewant, ift ber

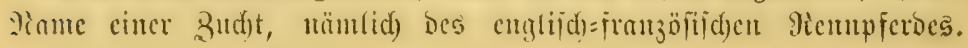




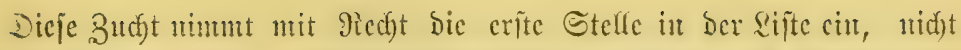

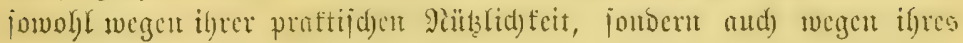

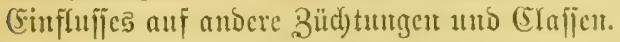

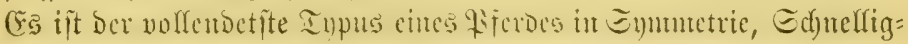

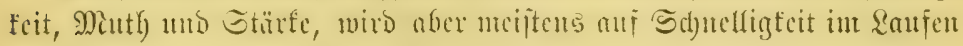

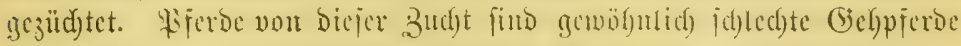

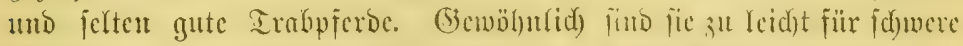

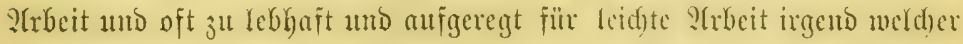

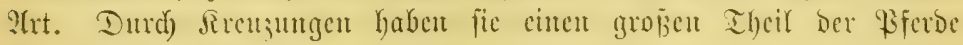
2Herifa's beeinflunt.

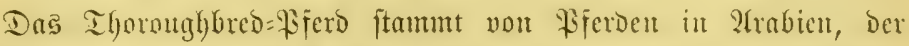

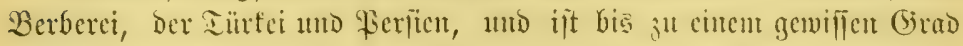

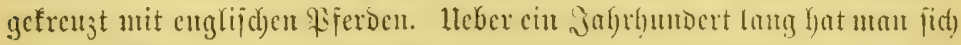

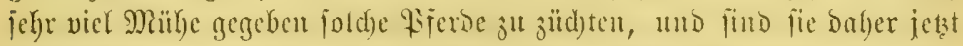

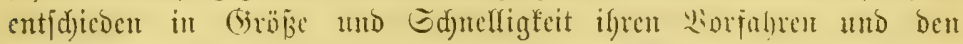

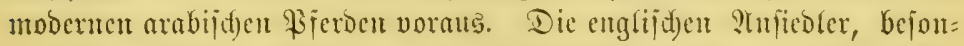
Ders in Den jüblidfen Stanten, imtportirten friffer jefhe vicle biefer 2frt,

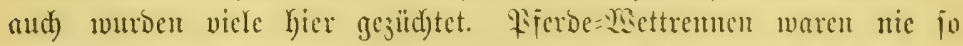

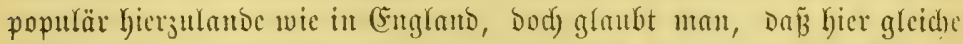

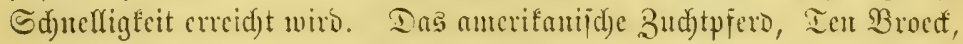
lief cine Mietle in 1 Mimute und 40 Secunbon. Die beliebteftent Farben

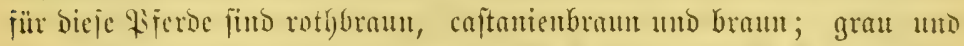

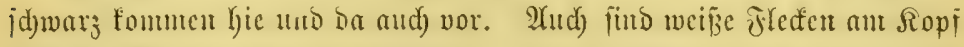

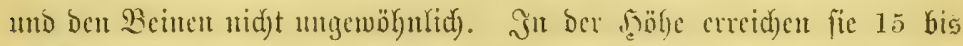

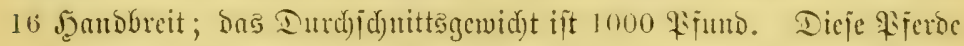

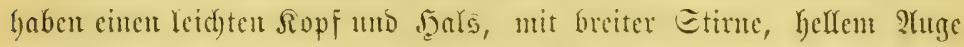

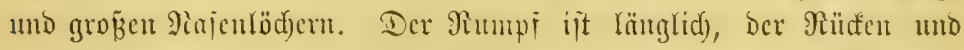
bie Seiten uแL

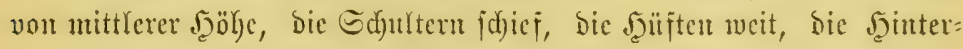
viertef lang utnd fiäftiger als bie vorberen. Die Bscure funt cher lang,

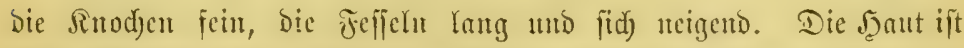

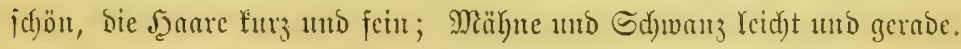

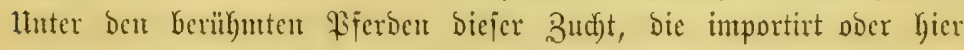
gejogen wurben, f̈̈t ju nemuen: Mefifenger, Diomed, Duroc, Inuftec, 
und jeit Rurzent Rexington, Reamington, Tuptralien, Bonnie Scotłano und Ten Broedf.

Dentzutage ift bas zahme Pferb fait über ben ganzen Eroball ver= breitet. (Es feflt nur in ben fältejten Sanbftrid)en und auf mefreren

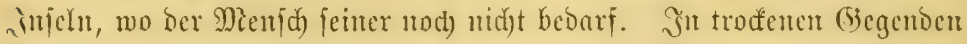
gebeift es entidfeden beffer als in feudften, fumpfigen, obrobl es idyled)tere (5iäjer verzefrt als andere fonathtyere. 


\section{Die Erjichung des Plerdes.}

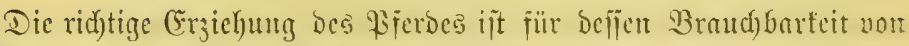

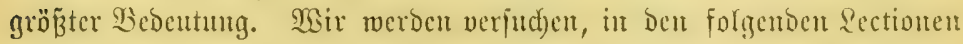

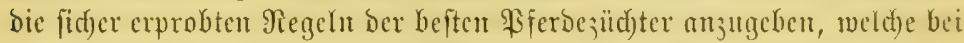
gentuler Befolgung bie beften Rejultate liefern werben; bie beigerügten

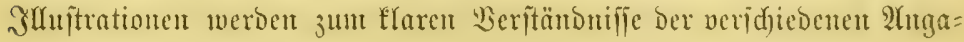
bert mejentlid beitragen.

\section{Das wilbe rür $r$ en.}

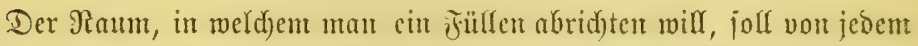

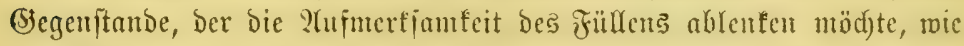

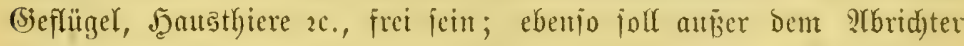

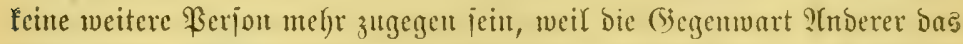

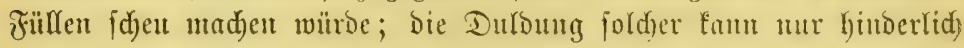

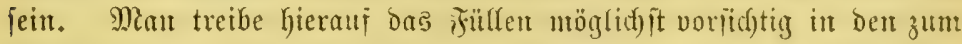
Mrbrid)ten ober (Einbred)en beitimuten Piaum und gege ja red)t janft zut

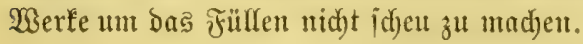

$$
\text { Das Antegen ber bुalfter. }
$$

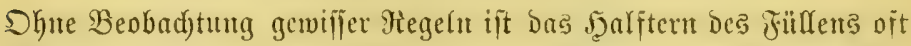

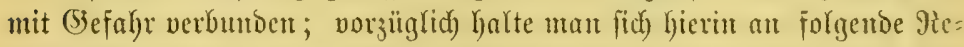

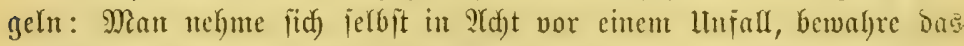

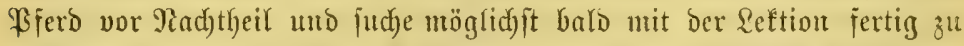

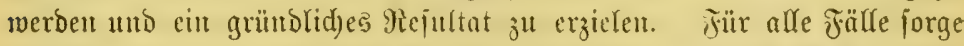

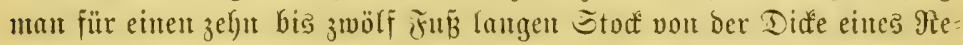

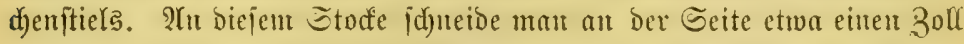

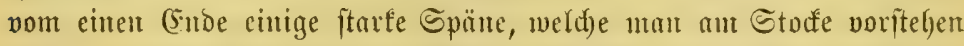
Yäß̈t; einige Boll bavour in Der Mitte Des Stodfes, (etwa foweit entfernt, als bie Diftanz zwiid)en Den Dlren Des Jüllents beträgt) madje mant abermals einige ähullidge (Einjdgnitte und laffe bie Späne ebenfalls vor= fitegen. 


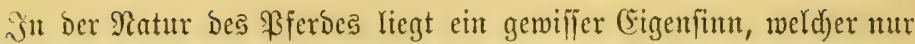

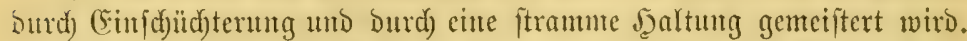

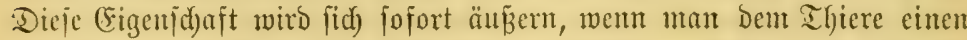
Şut pber ein Tud) an einem Stode entgegentält. P(nfänglich mag fict) bas Füllen beunruhigen; wemn man aber bet ruffiger Jaltung ben Gie=

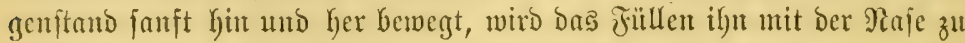
berïfren judden und fid) bald Daran gewöhnen; cbenjo wird es mit Der ந̧alfter Der Falf fein. Man bänge einen offene Etridfalfter (Sd)linge)

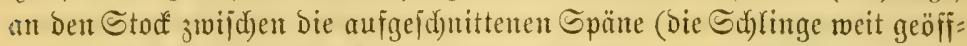

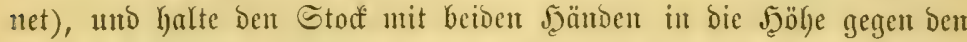

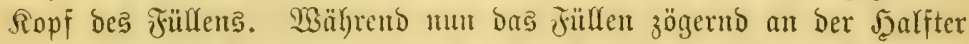
berumidyulfelt, fafre man mit Dent Stode leid)t ̈̈ber feinen Sopf unD wenn bie ganze 2hufmerfjamfeit bes Thieres auf bie Sd)linge gerid)tet ijt, bringe man die Sdylinge an ben Spänen leife über die Shren, brehe Den Stod um und laffe die Jealfter fo herabgleiten, Daß̄ fie nake Ginter bie Dhren zu

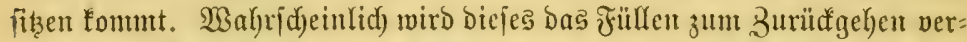

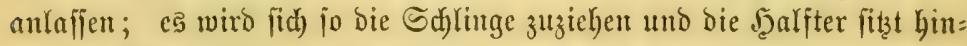
ter bem Ropfe feit. Den Stod́ fan man un weglegen.

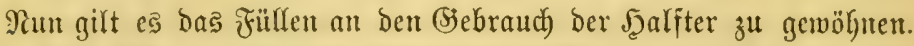

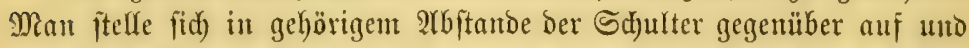
gebe Durd) 2 uzielung Des நalfterbandes bem Thiere einen furzen fräfti= gen $\Re$ ud, ber es von ber Stelfe zu bringen vermag, Iaffe indeffen alabald wieder nad). Şierdurd) mirb das Thier bie frembe Dberband füblen und

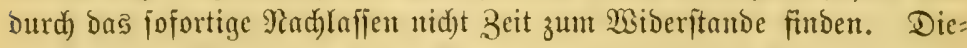
ies Berfahren faun man einige Mal wieberholen bis ber Wiberitand ab= junebmen fodint. Jexuad) verfabre ntan ebenjo auf ber anderen Seite,

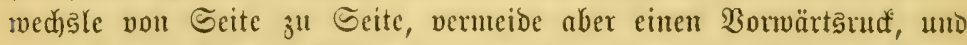
fahre fo fort, bis bas Füllen fid) entmeder willig ziehen läp̈t ober ftörrig

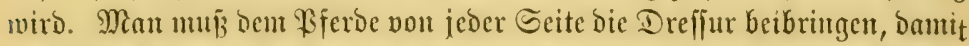

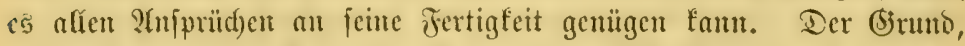
weß̧לalb man cinen Bormärtanud vermeiben foll, ift ber, weil man ein

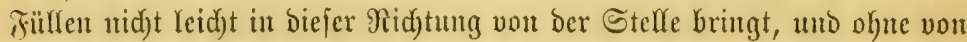

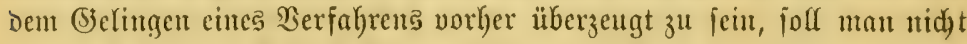

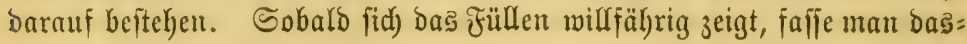




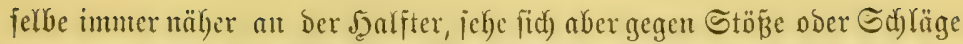

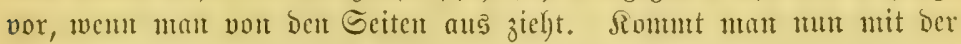

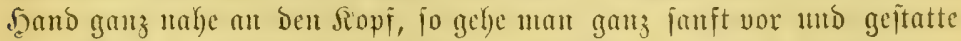

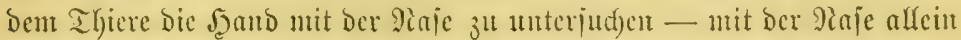

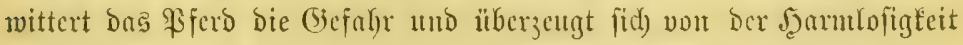

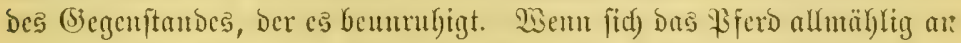
cinen gemölynt bat, was es bei faufter Beband lung fid erlich bald thut, mag

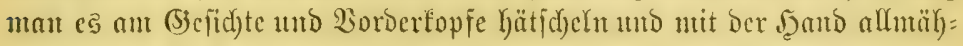
lig bis zun Piafen herabreiben, wobei man aber ja bie Olyen nicht fitrei=

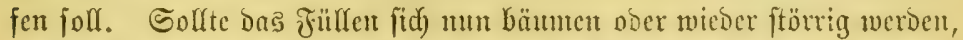

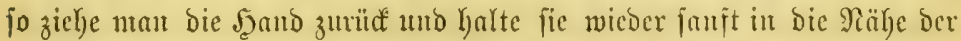

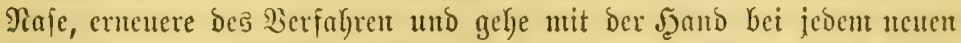

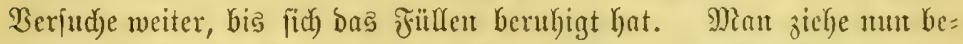

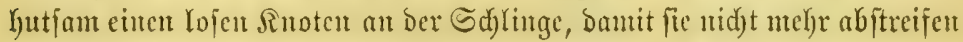
fann, vermeide cs aber bent Füllen bamit wehe zu thun.

Pun trete man wieder zurülf und wiederbole bie Rudübung von Der Seite. Sollte jebodj bas Füllen, währento man vor ihm fteht, bie Nei=

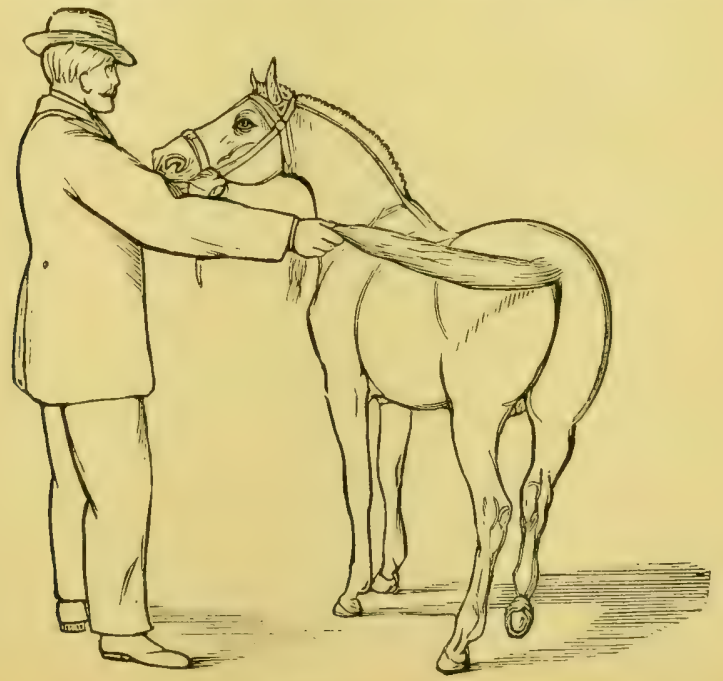

รี่ 1. 


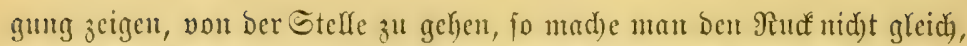
fombern man näbere fid, ifm wieber, ftreidyle ifm, bis fid) wieber bie (5iclegenbeit zun Rude bietet.

Sollte bas Jüllen förriger Ratur jein un fid iperren, nad) Mund

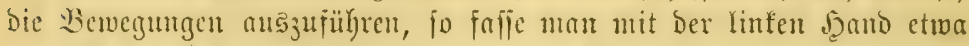

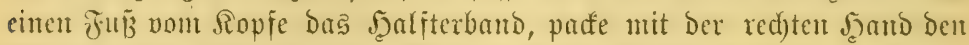

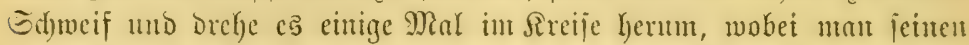
Ropf gegen jid) zicht und ifm gelegentlid) mit ber Fubipibe enten Tritt auf Das Jintertheil verjekzt. (Sieke Fig. 1.)

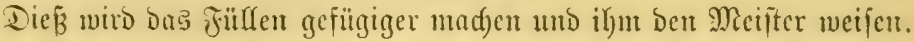

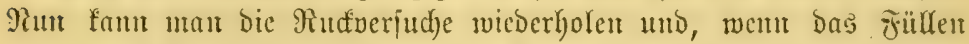
immer nod) ftörrig blcibt, baş] lbe nod) zwei bis brei Mal herumbreljen. Mit ber Beit wird ę bann fider anfgemunterter werben und Miene mad)en, nad) Wunjd) aufäutreten. Solfte es aber nicht ber Fall jein, fo

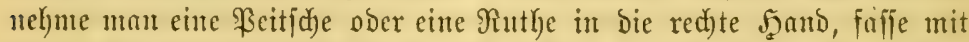

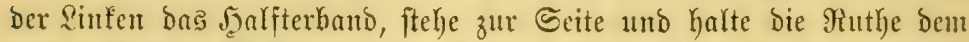

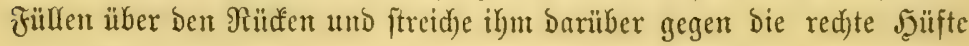

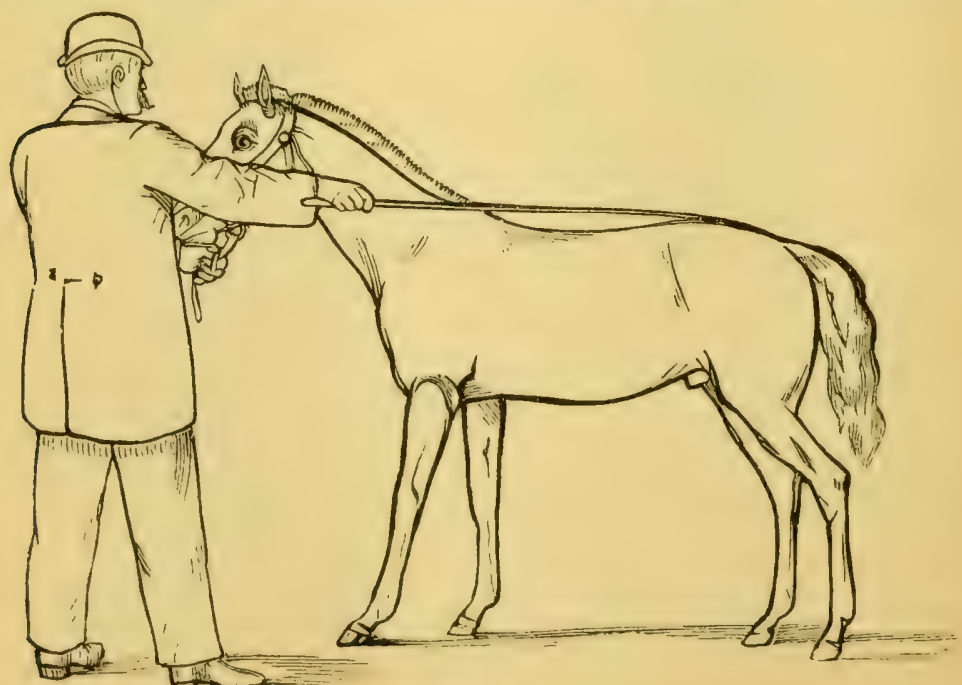

Fig. 2 . 
fin; zugleich gebe man ifm mit ber Jealfter cinten janften Geitenutet. (Sieke Jig. 2.) Wenn Das Jüllen bei biejer Bewegung ftutzig wiro, fo

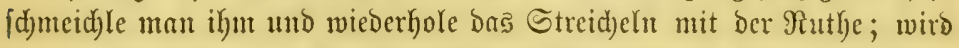

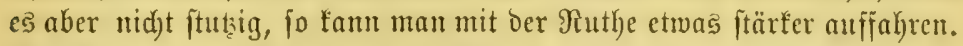

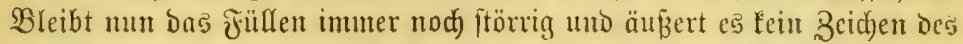
(Siehorjams, fo id)meid)le man ifm durd) cinen fanften Brid ober gute Worte, geke einige Sdyritte zurïa und geitatte ihm, fid zu beruhigen, bevor man im 2rbrid)ten weitergeht. Durd) bas fanftejte Benefmen überfaupt wird man am eriten zum Bicle tommen und Dem Fülfen bei= bringen, baf man ihm nid)t weke thun will. Sobals es mun cinem (eid)= ten Geitenzuge gehord)t, nelyme man ifm bue Jalfiter $a b$, ober lege $1 \mathfrak{b} m$

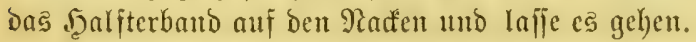

Wenigitens cine halbe Stunde jollte Das Jüllen nun in Rube gefaf= fen merben, bis es fid) vou ber (Erregung erholt lyat; hernad) fum man Die Rection zu irgent ciner Beit fortietzen. Sobald fids das Füfen Dann einmal an ben Scitenzug gewöhnt l)at, aber and) nur erft Dann, 10 bringe

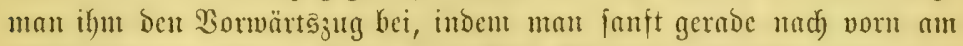

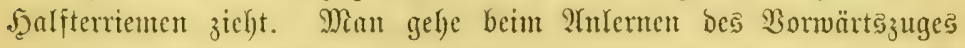

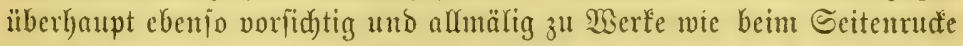
und fahre mit ben nöthtgen Interbredungen fo lange mit Dicjer llebung fort, bis bas Jïllen aud an jie fid) gewöhnt hat.

Wir geben mun über zur

Zcrbringung bes Jürens in ben Gtand (stall) im Starle.

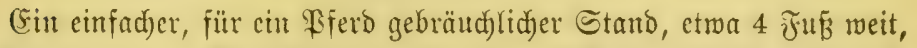
ift Daju geeignet. Man bohre an Dem Ginten Enbe Desfelben Eöd)er, fo Daf́ man eine quer Durd)laufende Gtange ober einen ftranmen Riemen in

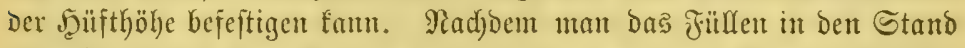
getrieben, forge man ja, Dab bie Sucritange ober ber ßiemen befeftigt ift, elye man bas Fïllen an bie Rrtppe bindet. (E5 mird baburd) am

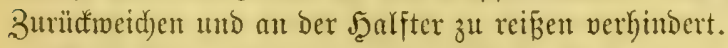

Beim Scerausführen aus dem Stafle binde nan dasjelbe zuerit los, bevor man bie Stange hinten entfernt hat, unto gemöhne fo Das Füflen an cine rubige und fidjere Stelfung uno Bemegung. Wäbrend ber ganzen

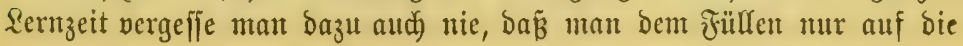


möglid) ft janftefte 2 (rt begegne, jowohl in Stimme als in (3)berben.

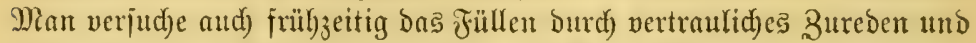
Rofrufe au feine Stimme zu gewöhnen. Man foll nie zul laut ober berb

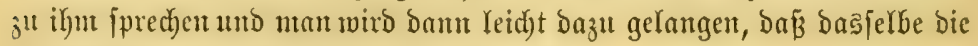
Stimme fennen lernt uno ifyr Folge Yeiptet.

\section{Das Fülleu an bas Tragen bes (5) ebifies zu ge=

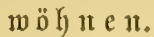

Man gebraude erit einten einfad)en \$aum mit cinem gelenfigen (Se= biffe ohute checkstrap ober Eenfrientent, laffe es cinige Mimuten in Stall

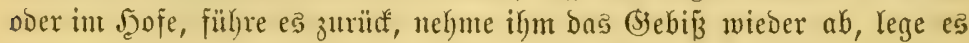
ifut wicberfyolt an, bis fid) jein Maul an bafjelbe gemöhnt hat. Nad) furzer Beit fanm uแn Dem FüUen bas

3 a 4 m g e b i $\tilde{B}$ (Bitting Bridle)

(iieke Fig. 3 unt 4 ,)

angelegt werben. Dabei verfabre man wie folgt: Man nelgme einen

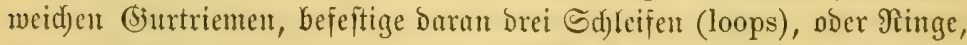
berart, baß̈ eine oben mitten auf Den Mürfen und bie beiben andern an Den Seiten bes \$ferbes, etwa un ein Drittel nad) unten, ju feben fom: men. Siun lege man ben füllen einen einfachen Banm ohne Sdjeu=

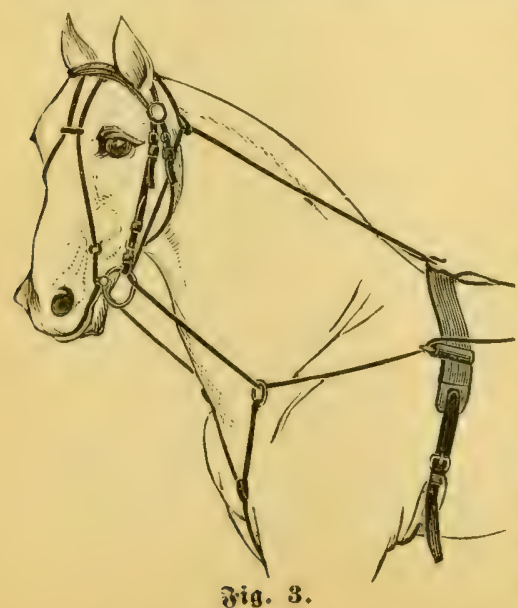

leber an, bebiene fid aber immer eines mit einen (Gielent veriehe= nen Biebiffes (Joint-Bit). (Ein Stïd baummollene Wajd leine, etwa 8 bis 10 Jun $\mathfrak{B}$ lang, wiro mu in ber Şälfte ifrer \&änge an

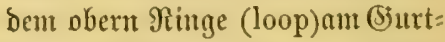
riemen feftgemadyt; nun fülyre man Das cine (5nde Der Reine Durd)

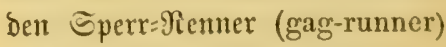
auf ber linten Geite bes झfferdes und von da hinab nad) ben গï̈= ftern von hinten Durd) Den (Stebiß̄ = ring ziebe die Reme mäpig leit an uno befeftige fie ant Ninge 
ober loop am Gurtriemen an ber Seite. Gbenjo verfahre man mit ber Reine auf Der red)ten Seite. Went bie Reine an ber Seite ant (Butrtrie=

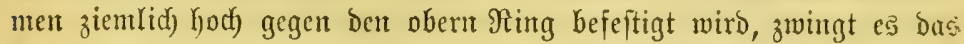

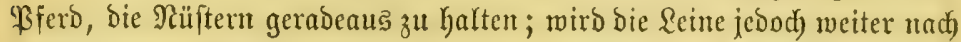
unten an ben Gü̈rtel gebutben, fo wirb bas füffen ben $\bar{R}$ opf jenten uno

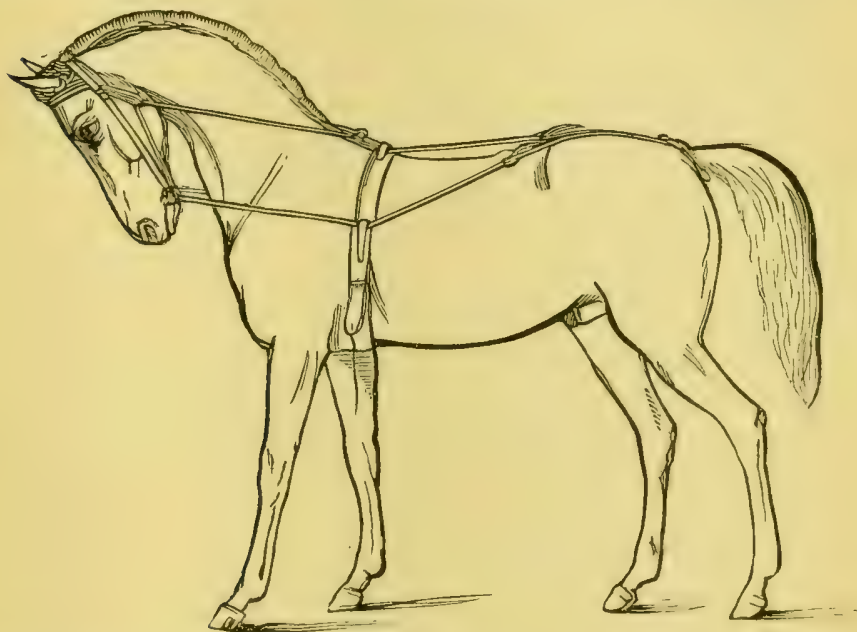

ริง. 4.

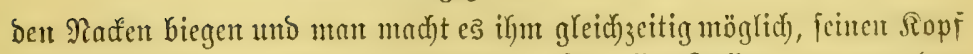

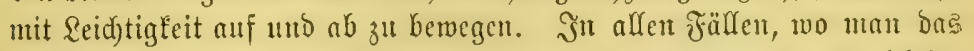

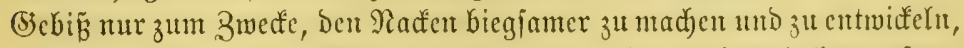
anmendet, follte biejes (Befd)irr genonment werben; niemals hat unfere?

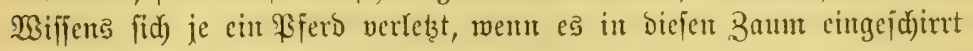
war.

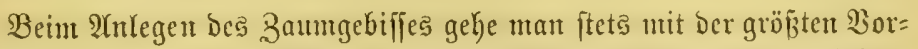

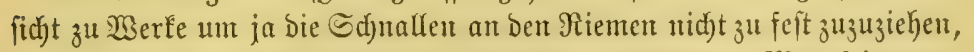
da man jonjt Daß Thjier verlekent und aufregen fömnte. Man fei gertau

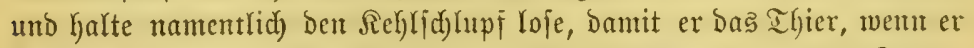
ftramm angezogen wiro, nidjt wïrge. Jun 2(njid)irren trage man Sorge,

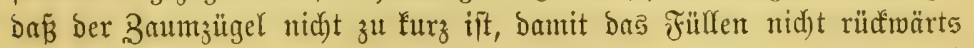

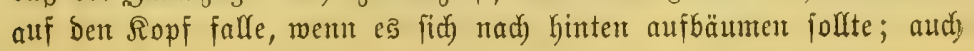


ziro fid) baun bas Füllen eher nad) Den Geitenzügeln ridyten. Dą

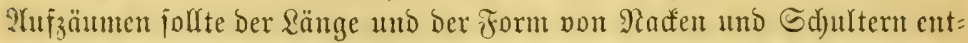
jpred)end gethan werden. Die Settenrienten follten fo feit geidnall

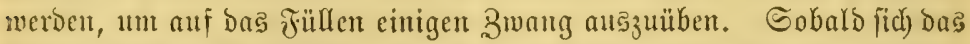

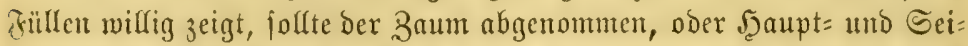
tenriemen gelöst werben. Diē̉ follte wenigîtens fünf Minuten nad, bem Anlegen gejdelgen. Se öfter ber Zaum in ben erften brei Tagen an = und abgelegt wird, befto befier ift es. Jndeffen nehme man ihn nidyt weg, went bas Füllen ftörrig ift unb fid) mit Dem Ropfe fträubt.

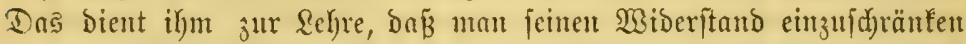
vermag und wirb fich bei Den fommtenden Borgängen bemähren. গun fdjreite man gelegentlid) zum

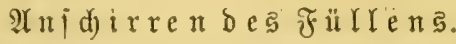

3uförderft fdurre Das Fülfen an und laffe cs fret im 5 ofe poer in ber

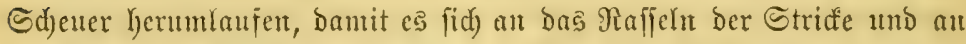

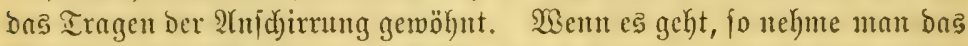
(Sejd)irr wieder für cine furze Meile ab un es bei geeigneter 3eit wieder antzulegen.

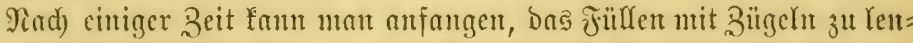
fen; Dan Kalje man es veridjedene Wendungen mad)en, treibe e's lang=

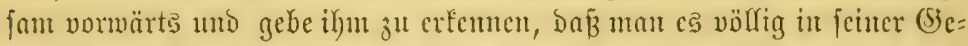
malt habe; fo wiro es lernen fid) und) Den Bügeln ăt ridjten und ohne es

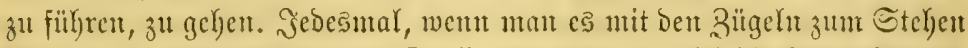

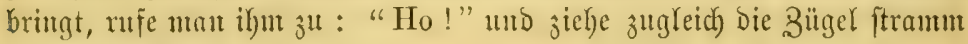
an zun $\mathfrak{Y}$ thalten.

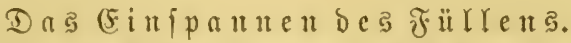

Benu immer möglid), jo vermeibe man, Das Füffen allein einzupan=

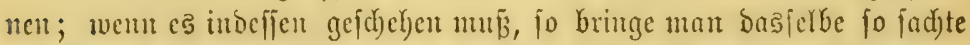
als mur möglid) in bie Sdjecre. Saterbei ift feine bejondere (Scfaht vor=

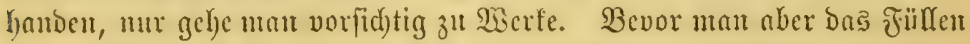
nu Den Wagen ipant, rütrle man an ber Sdjecre, erjoüttere ben $\mathfrak{W a}=$

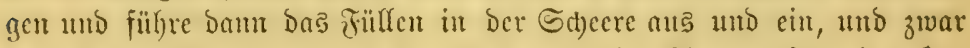

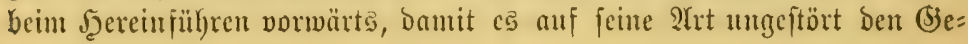


genitand, ber für Dasjelbe cbenjo crid)rectend als utu ift, prïfen fam.

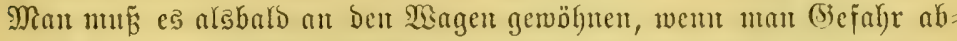
wenben mill. Wird bas Jülfen baburd) in Jutd)t verietst, fo laffe man Daşerbe eine Weile gef)en. Went es indefien nad) cintent ober zwei neuen

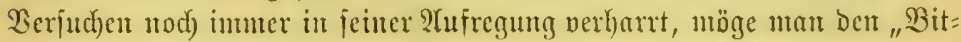
ting Brible" gebraudfen.

Mit bicjen Baume ift man im Etande, bas \$ijerd befier in Feiner (Se= walt zu behaften, namentlich), wenn es von einer plötzliden foucht befal=

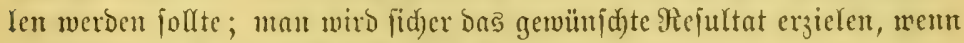
man ihn zwei Gis̄ brei Mal benulzt hat.

Mun fpant man das fïllfen an ben Magen und treibe es mentige Mimuten lang auf cbener Crobe au; Dabei vermeibe man aber it ber er:

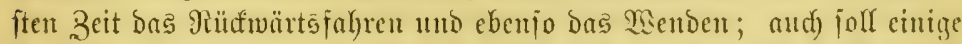

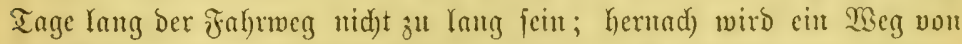
orci Meilen und zurïlf nid)t mebr zu viel fein und man faut banu lang=

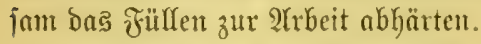

Jummerbin ift es an fidferften, wenn man bas jülllen mit eincm ge= Yernten Bferde und an bellen red)ter Geite cinipant. (5is gibt verjude=

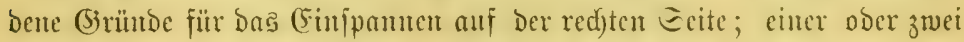
mögen gentigen: Man ipringt gemöhulid) auf ber red)ten Eeite von

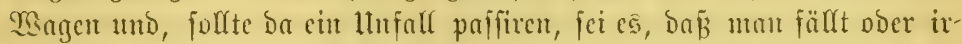

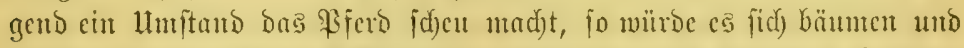
fid) in entgegengejetzter Ridjtung herummenton, und fömte fo Ed)aden

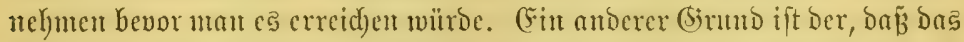
2(brichten beim F̈̈lfen hauptiäd)lid) an ber linfen Eeite geid)ah uto e?

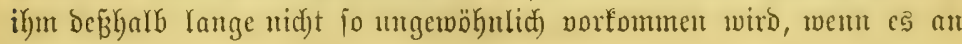
Diejer Seite mu ein \$ferd hat.

Gins mut bic (Sicj)ime bciben Pferben angelegt, wobei man bic in=

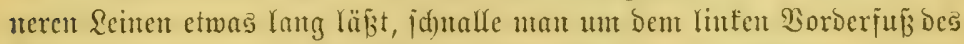

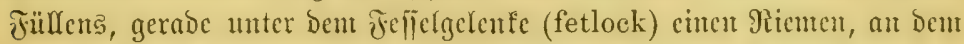

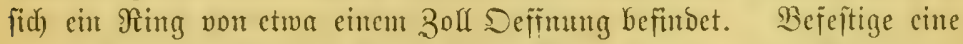

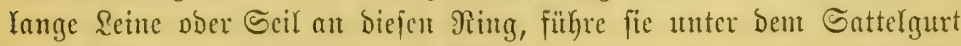

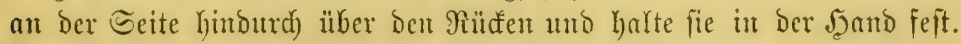

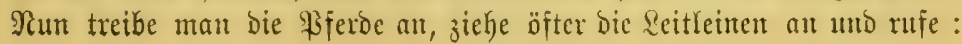


"Ho!", mobci jur gleiden ßeit bas Geil, bas au Den Borberfuß gebut= ben ift, angezogen wirb, Gis das Bferd den Juß bebt uto jo auf Drei Beine zu fteben fommt. Nad) einigen Wieberlyolungen mag bas (Sejd)irr für bie erite Rection abgenommen werben. Das näd)ite Mal ipanne man an ben Wangen an, Den Strič an Fübe wie vorker befejtigt. (Sielje Fig. 5.)

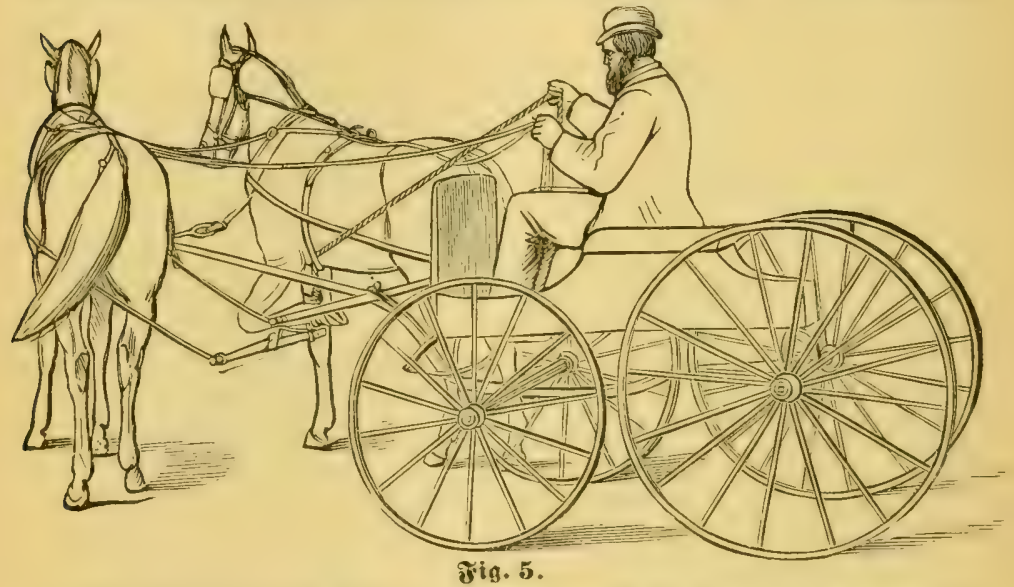

Sä̆lt man jo bas Füllen an bem am Juß̧e befeftigten Stridfe, in

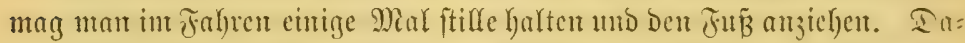

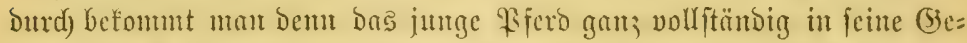
walt mo fam es ipäter ieberzett ofjue Bedenten zum Stehen bringen. So fremb ifm anfünglid) bie Endje criducinen wirb, wirb ç burd)ats

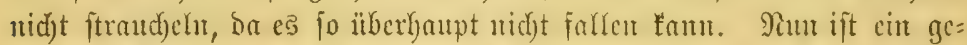

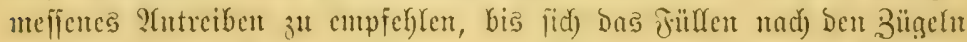

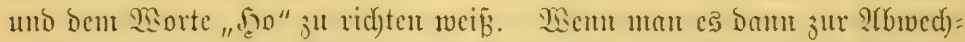
jelung auf bie nnocre Ecite ipant, jo befejtige man Den Fubitriư wieber

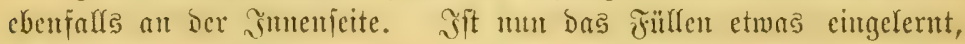
fo fan man ç fpäter cinzelu obcr boppelt eimpanten.

(5) †

Bevor man cin Jïllen in Rärdwärtggehen unterrid)tet, jolfte es min= beftens adjt bis zehn Tage vorker gezogen haben uns jolle bas Gehen 


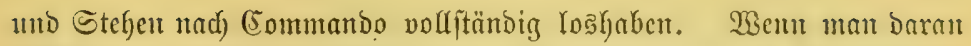
fefthälrt, jo wirb jid) Das Füflen nicmals nieberlegen, went es nngejd)irrt ift, mirs niemals in einen Baun renten ober wälyrend Den Befteigen Des

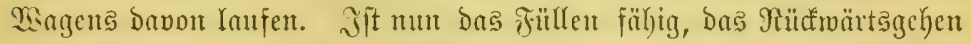

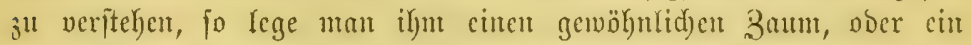
Zaum=(Gicbī̄ (Bitting Bridle) ijt nod) beffer, an, balte es num Zügel und brülfe es fanft nad) hinten, mäfrent man zugleid) "Back!" ruft.

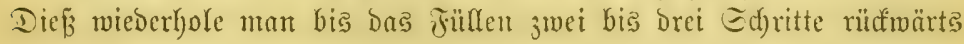
geht. Butäd)ft ftelfe man fïd) unn Ginten auf, ziche bie Bügel burd) bie

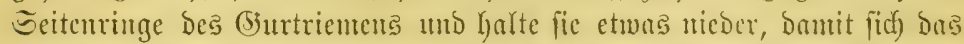

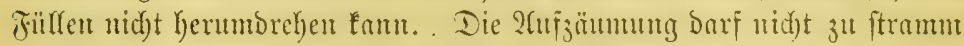
fein. Sobald man finter bas Füllen tritt, jiche mun Yeicht an ben Bü= getu unb fage: "Back!", lafie bie Bügel jebod jofort loje pobarb

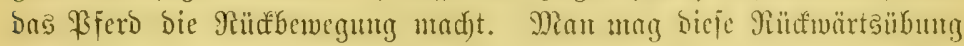

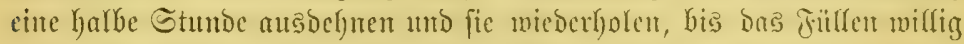
gef)orcht. Ŝnfänglid) verfabre man aber vorfichtig und renfe nicht mit cinem beladenen Magen rïdwärts, nantentlid) went Der Bobeu nod) ut= eben ift. Tie aber vergeffe man Gierin jeine Geduld un Padafid)t.

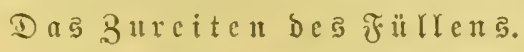

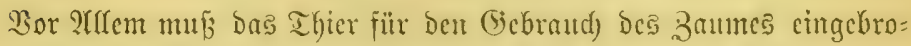
d)en jeit. Die Berjudye mögen bam in .5ofe ober in ber Sd)entue ge=

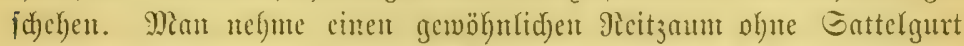
ober Eprutgriemen. Die Bügel fnüpe man oben auf Dent Ratet des

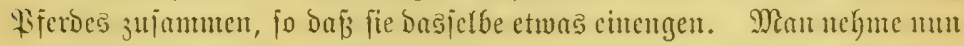
jeine Steflung an ber Yinfen Edjulter bes ßoferbes, werfe cin Murficil über ben siberrift, nahe wo bie Reine jull Yiegen fommt, greife jadjte unter bie Bruft un an bie Borberbeine und wemt es fid) uidjt beumru= Gigt, binto bas Seil an ben Yinfen Borberfuß, gerabe unternt Fūgge= lente, feft. Sollte bas Füllen wiberipenftig werben, fich) lostreiben, oder

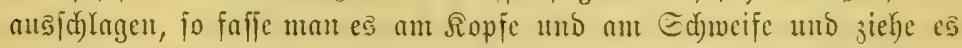
zwei bis brei Mal in Rreife hermm (Fiehe Fig 1.), unb wöhrend es baburdh auper Jafjung geräth, beuge man fid) nieber und binbe das Geil am

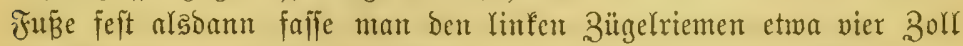

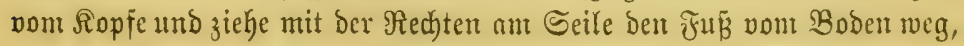


wägrent man gleid)zeitig bic Bügel feft an fidc) reiß̧t, bis bas Füllen auf brei Beinen zwei bis brei Sprünge gemad)t hat. Jeierourd) bezwedt man,

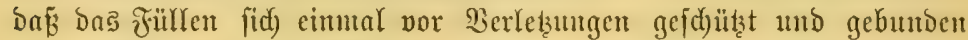
fieft, womit man eimem Sturze vorbengt, wem man es jpäter bercitet;

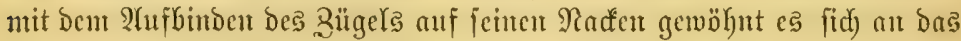
Tragen einter \&aft; es mird fidj nientals überid)lagen nto man wiro

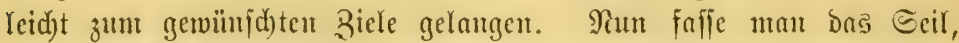

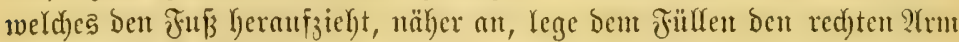

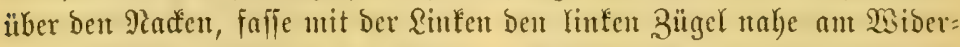

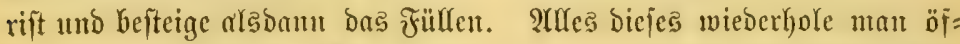

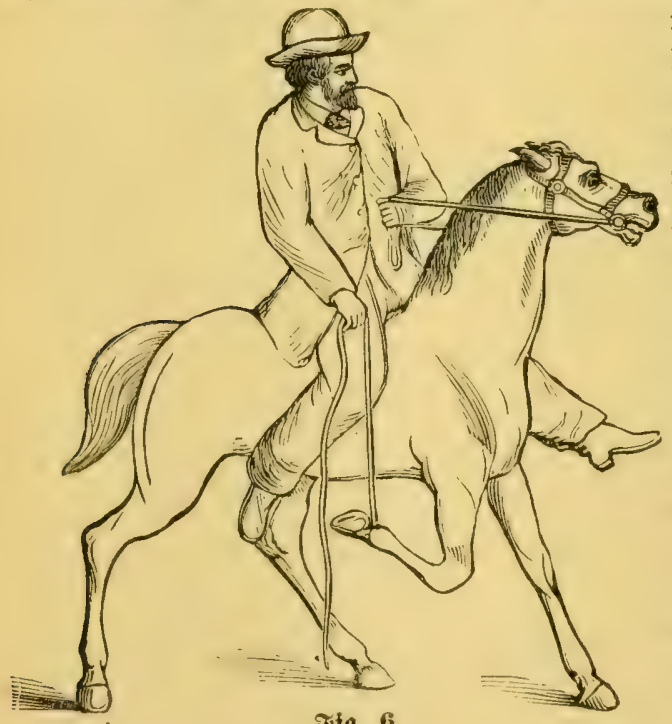
ters, bis fich das foul= len Darangewöhnt hat, beiteige es vorjidytig, Galte ify aber ben JแB nod) immer in dic Jeöbe. (Wie Fig. 6) Rum laffe unat delt Fußz Gerab und rafie bas Füllen fortgeben. Solfte es fidf wider: ipenfitig zeigen oder Delt Reiter abrwerfen wolfen, jo ziebe mat

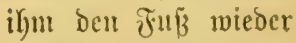

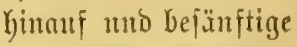
e⿻上. Man halte ja Den Funkriemen feît, ไöje bie aufgebumbencu

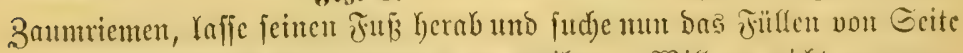
ju Scite zu wenten แn vorwärts ju treiben. Will ç nidjt gern vou

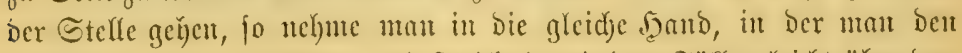

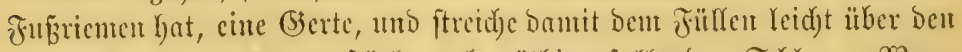

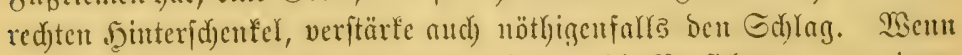
man bas Füllen umwendet, fo gebraude man bic Borficht uur an cinem 


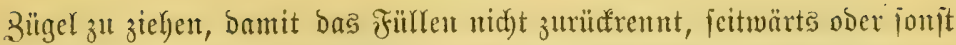

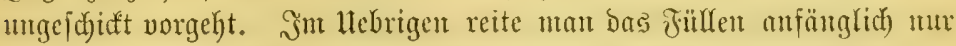
ganz furze Beit und fetze bieje llebungen fort, bis ç gut angewölynt ijt.

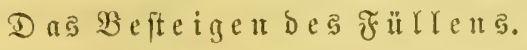

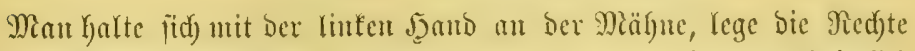

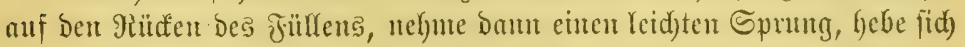

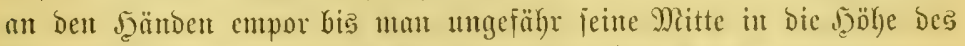

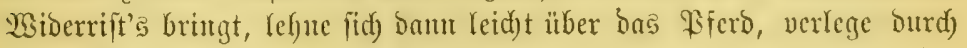

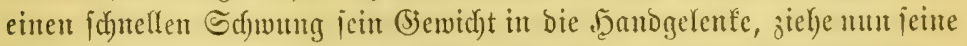

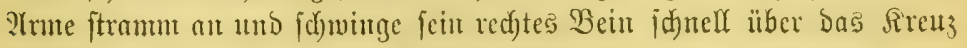
bes Pferbes, Das mait jobaun bejtiegen lyat.

Da a $\mathfrak{A}$ แ

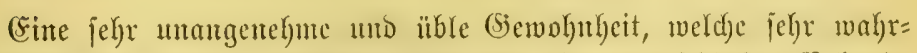

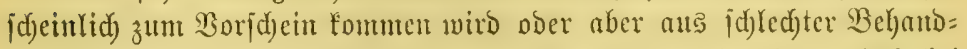

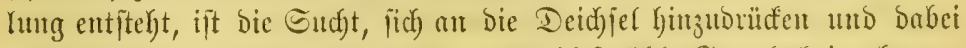

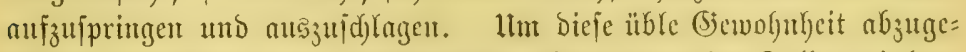

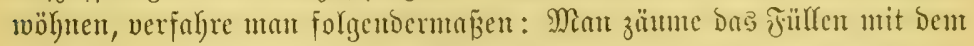
mit Fig. 3. Gezeidjneten Bitting=Brible ftramu auf und bringe baß bereits

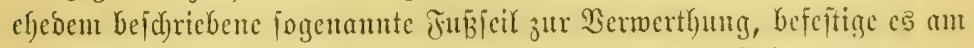

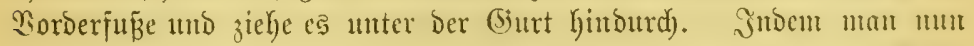

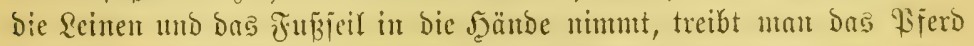

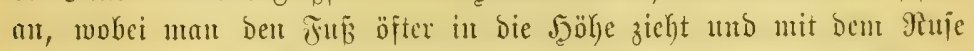

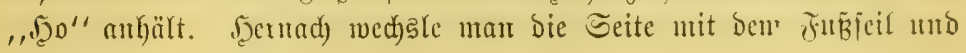
wieberlyole bie Rection.

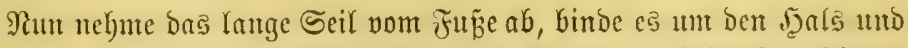

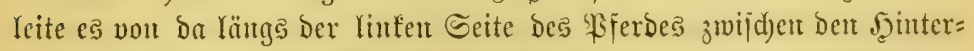

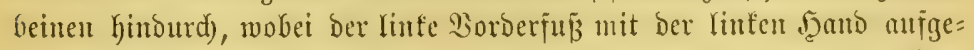

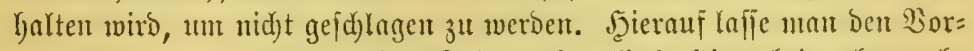

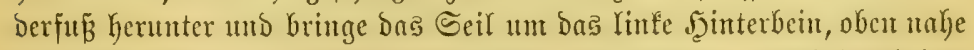
am Reibe, fülyre eз anf ber linfen Seite von Rörper zurür burd) baß

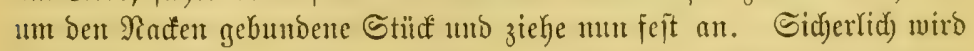

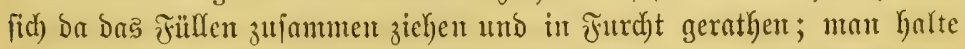
baher mit ber Yinfent Şanto Dasjelbe am Baume feit. Das Seil halte 


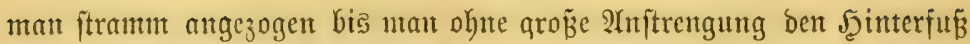

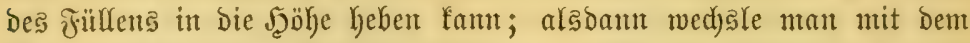
Jube und wiederfole Denfelben Borgang. WSent bas Füllen red)t bos: Gaft ift, follte man bieje llebung mod) zwei bis brei Mal mieberbolen. Sit man bamit fertig, fo fan bả Füllen mit cinen andern Pferde cinge= fpant weroen. Dabei fpame nan es au bie Seite, an ber es gewöbulid)

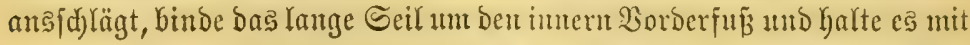

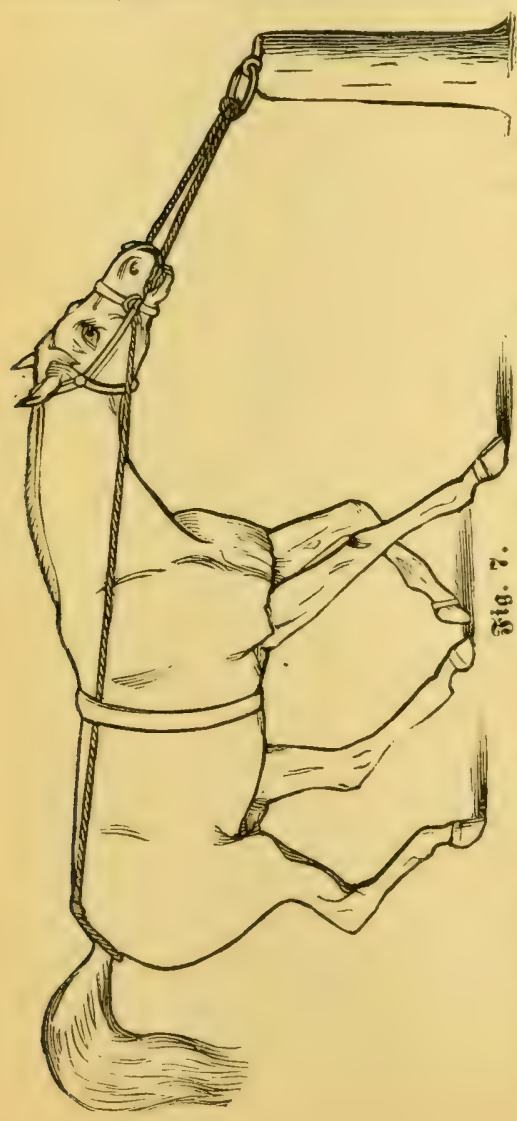
best Bügeln im Baunte. Man fübre bann das \$ferd untlyer, treibe es gerabe vormärts, ziebe ifm ben ซuß̆ Kerauf uno bringe es ge: Yegentlid) zum Stebert, banu fange man an es zu wenden, was red)t idnell geidjelyen jolf; Dabei jorge man bafür, baī es von ber Deid)= jel beläftigt wiro, wälyrento man zugleid) jeinten Fun in bic 5ूöhe heft und es zum 5ூerummenton nöthig. Dieje llebung jollte im= merbin etra zernn Mimuten an= Galten und einige Mal wieder= Golt merden, went die üble (Sie: wohnbeit, namentlidy nad) jeder Wieberlyolung berjelben, nidat nacklafien follte.

Das Biehen an Der Jealfter. (Sieke Fig. 7.)

Man rege den Jüllen eine gemöburiche J̧alfter und eben= jo eine Gattelgurt 1 m, fïlyre eir etwa zwanzig $\widetilde{J}$ zölliges Seil in jeiner Mitte un= ter ben Gdjweife himburd) an Sterle cincs Steiprientens, ver= 
fnüpfe bie beiben Seiltheile oben, zicke auf jeber Seite ben entiprechen= Den Theil Des Geiles unter ber Gattelgurt burd) und ebenip Durd) bic Salfter = Ringe, und binde beide Scilftidfe am Ende und in ctwa

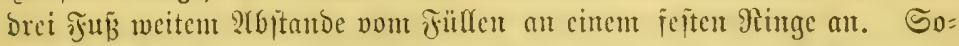

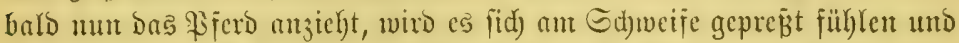
io woird ber Drud, bert es an Edyweife ftatt am Sopje, wie cs ermartet,

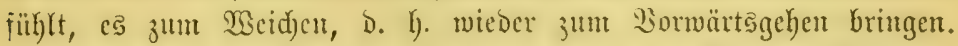

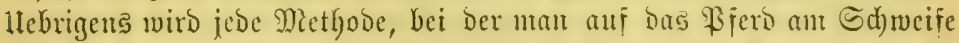

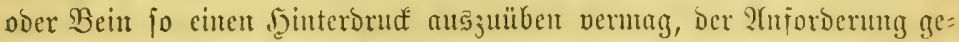
nügen. Man mag Da aud) nad) eigenem Sdarfïun jeite Yrien fuben,

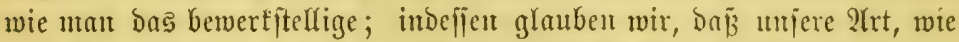
wir fie angegeben, bic beite mo gefabrlojefte ift. Gelbit went man

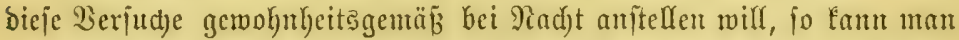

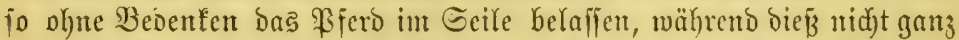
ungefälurlid) wäre, wem Das Geil hinten ftatt un ben Gdjweif um bas

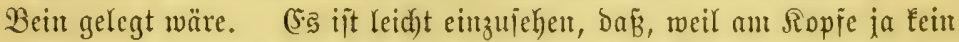

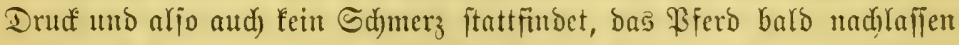

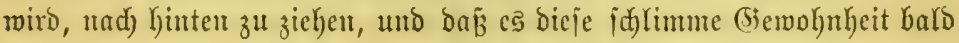
ablegen wirb. Itm bieje Sadje nod) erfolgreidyer zu madhen, reize man das Pferd Durd) aufidrectende Mittel zum Burüdfieben.

\section{Dą 3 i éfen a 3 a me.}

Man Yege bem Pferde, ähnlich wie beim, ,Biehen an ber Şalfter" cin Geil un ben Sd)weif, führe bie beiben Stüfe besjelben aber burdy

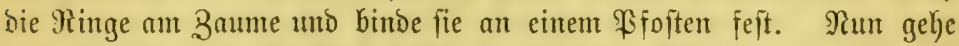

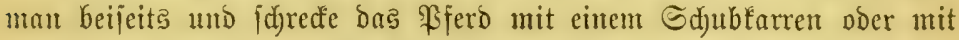
jonft einem geeigneten (Siegenjtande, um ез zum Burüdzichen zu bringen.

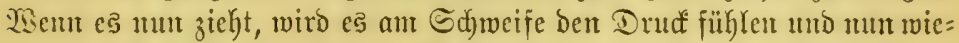

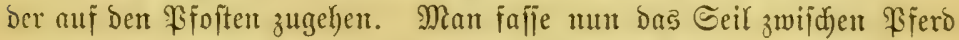

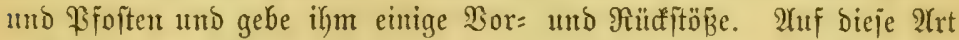

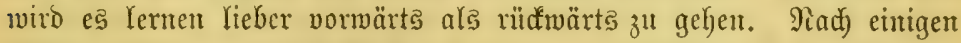
Seftionen fann man bas SFero mit einem gemöhnlidjen Seil nubinden. Man höre mit biefen Utebungen nidjt eher auf, als bis man cin Rejultat erzielt fyat. 
Wíc man e

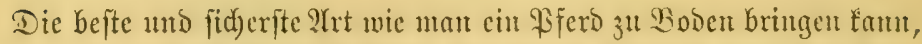

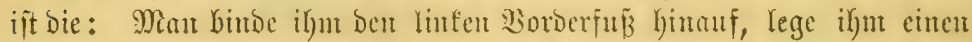

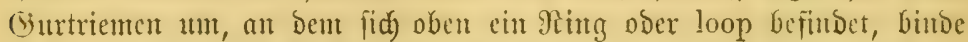

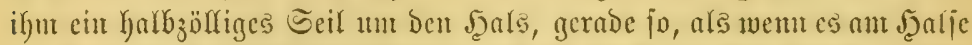
angebunden werben jolfte, fübre bag Ecil Durd fein Naul und an ber

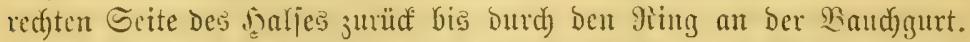

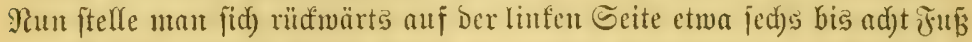

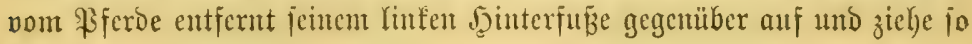

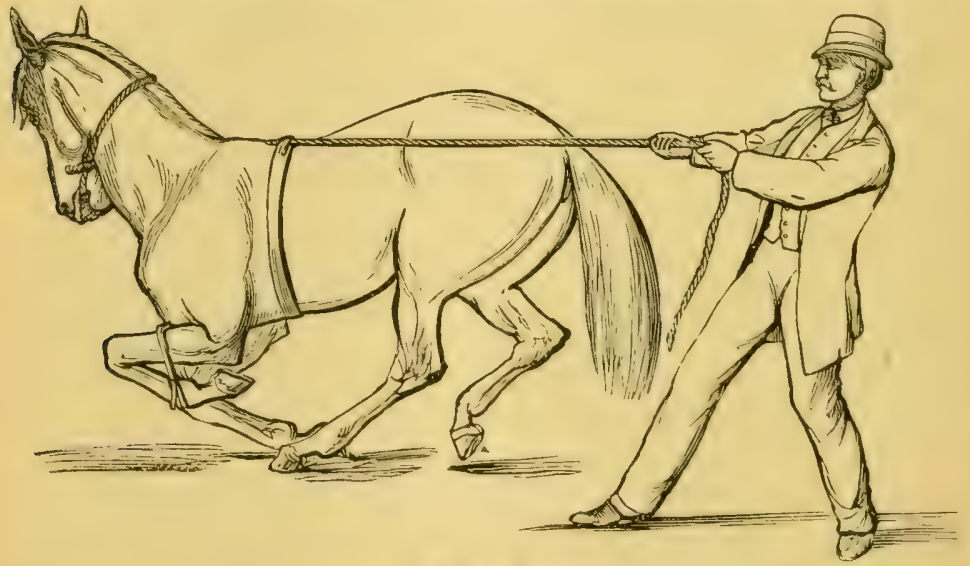

รig. 8.

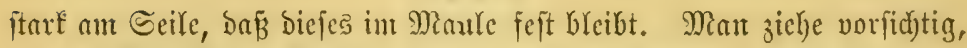

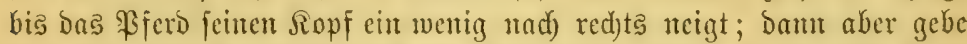

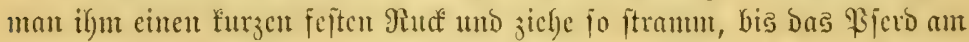
Boben ift (Jig. 8.), woa bimn fün Mimuten gejdehen faum. Sobalo (s lid) nieberlegt unb auf bie linte Seite sul liegent fommt, fam es nid)t

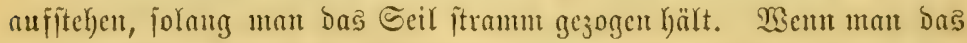
oft wieberfolt, fo wird man bals ein flutges Pferd erzielen, ba man ihm

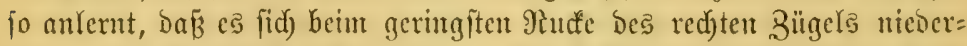

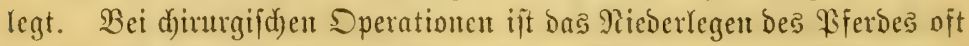

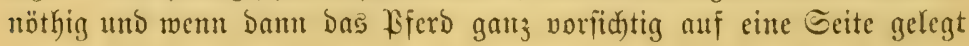




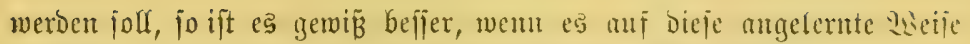

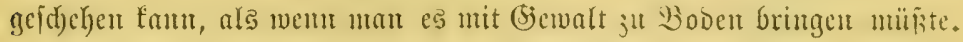

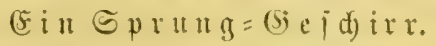

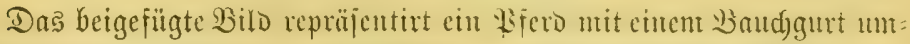

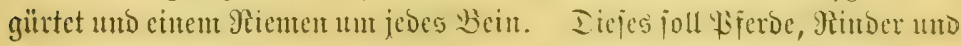

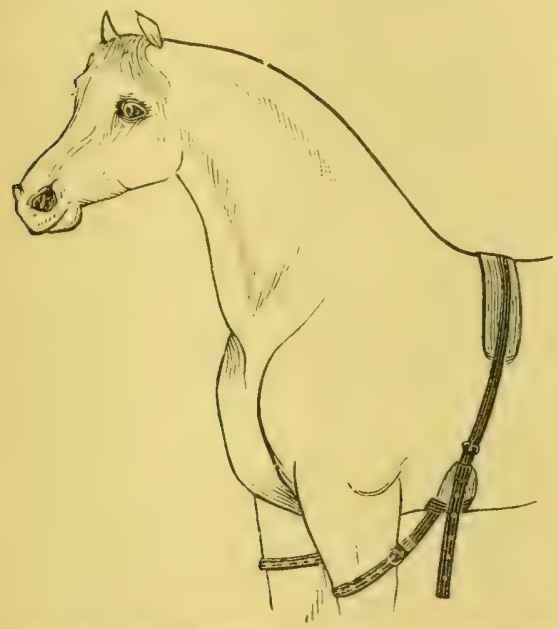

Sd)afe verfinbert über ३äu= Ile ju ipringen voer fort ju laufen, wem man fie muj ber Weibe greifen mill. (5.5 ift einfud) und billig und fanแ von irgend enten Sattler fiür $\$ 1.25$ Gergeftellt werdent.

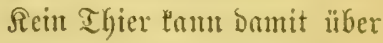

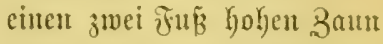

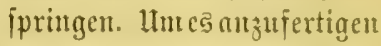
nehme man eine gewöhnlid) Baud)gunt, rafie nake an bie

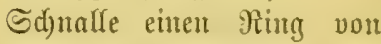
einem 3 oll Durdumefier uno 143 oll bavon ntod fo cinten

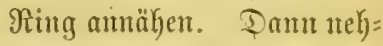

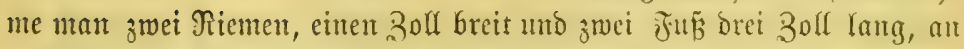
weldyen fid) Sdynalfen befinden, jiebe fie burd) bie Yringe an (Siurt,

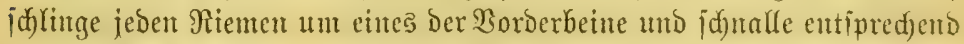
feit, fo ift es gethan. Das Thier fam gef)en, fid) niederlegen uns an = iteben, aber nicht ipringen. 


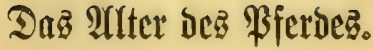

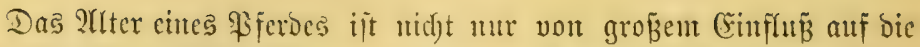
Brandebarteit unt Dientitomer, jonben aud) namentlidy auf ben :Sertl)

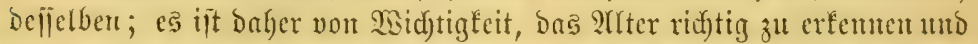

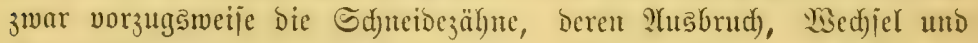

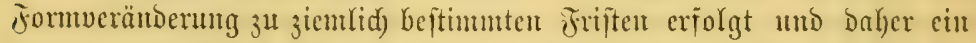

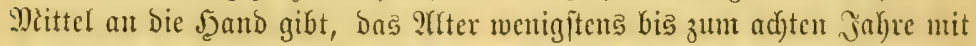

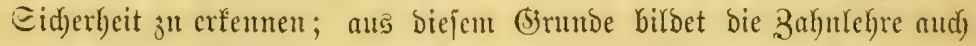

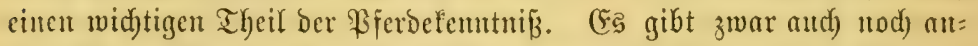

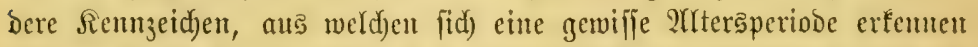

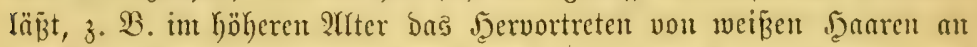

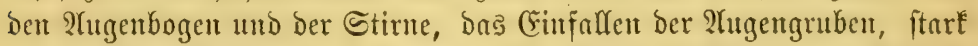

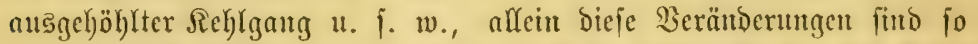

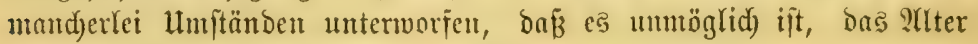
bierntad) gentu zu bejtimmen.

Die Zähne beftehen aus Subjtanjen: Dem

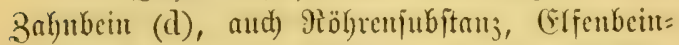
fubjtanz genamt, Dem Edynely (e) (Email, Bina jur) uแ⿰ Der Rund)enjufitan; (e) (Rittjubjtanz, (Eement). Fig. 1 zeigt biefe brei Formationen in

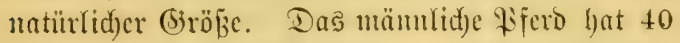

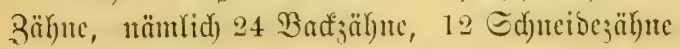

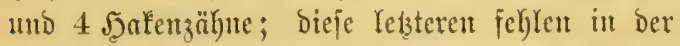

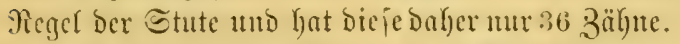
Iic Sdyuciocjähne itelyen in halbtrcisförmigen

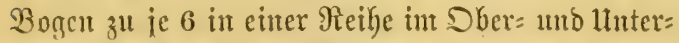

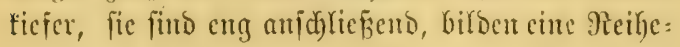
fläd)e unto paffent genau aufeinantoer; fie bientent

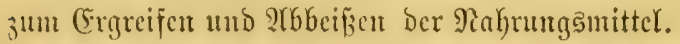

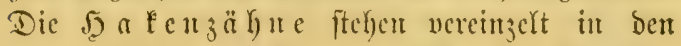
Eaben, alio in beut Raume zwifdent ben Edyncibe:

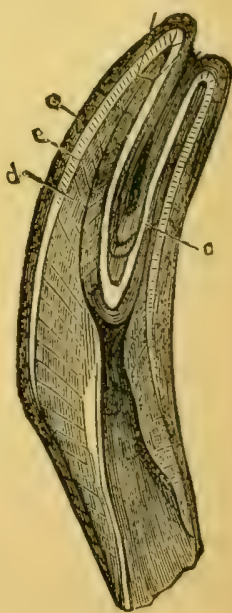

Tig. 1. ভđantetbe;ahy. 


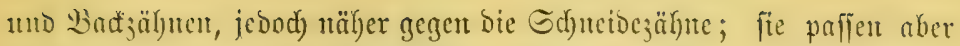

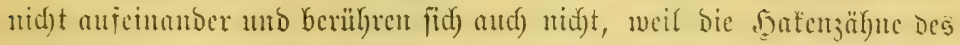
1tutertiefers weiter vorne ftelyen, als bie bes Sberfiefers. Die Band=

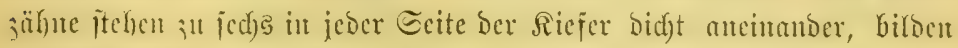

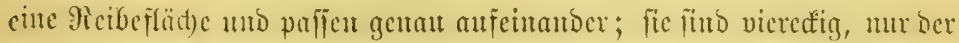

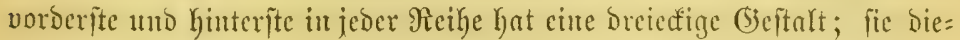

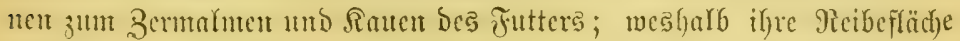
raub und meben ift.

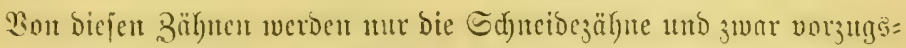

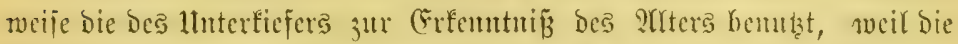

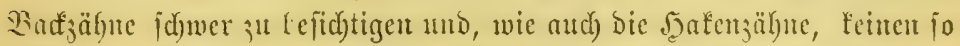

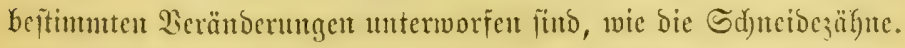

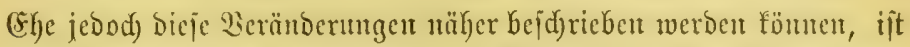

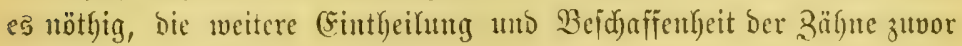
genauer zu betradsten.

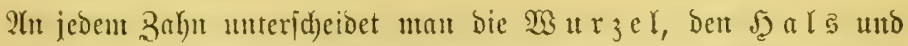

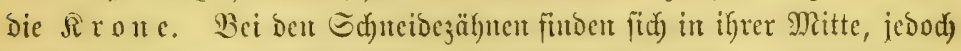

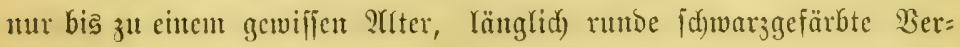

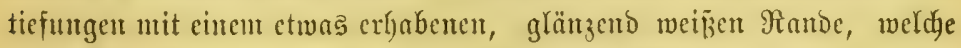

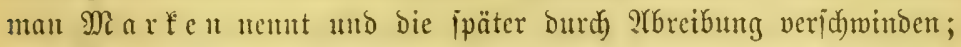

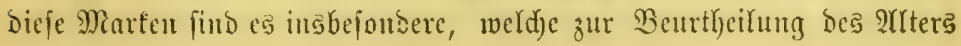
bemulat werbett.

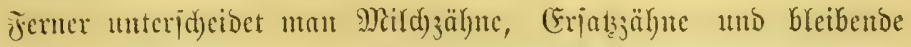

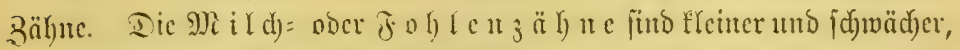

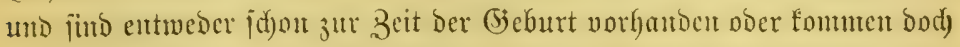

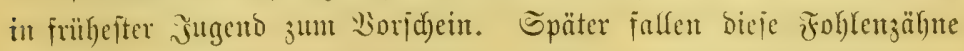

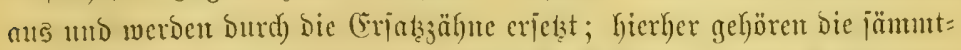

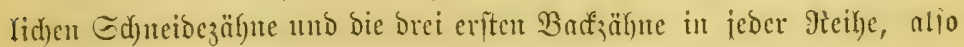

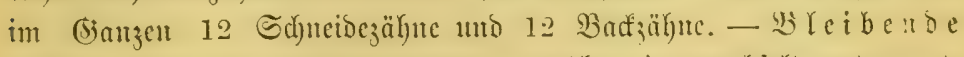

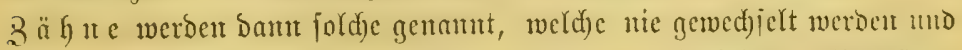

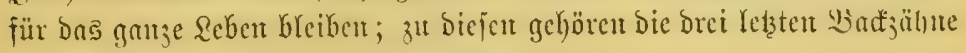

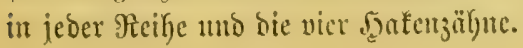




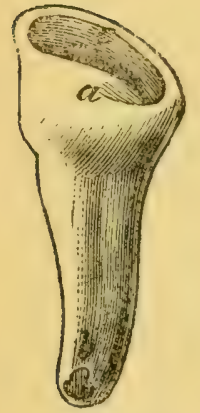

ritg. 2.

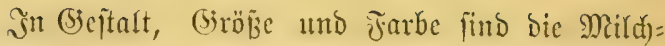

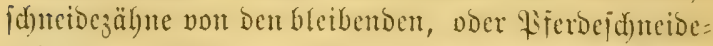

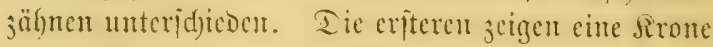
(a) und eine 25 urzel (b) (Fiehe Fig. 2). Die Rrote

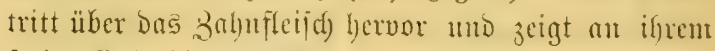
frecen (Enbe die Mecibfläd)e (e), weldye oval uno ivenig= ftents 3 mal jo breit als biaf ift und in ber sititte etwa

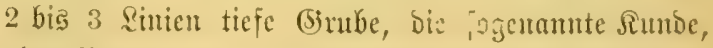
oder Mearte Yat. Dicje wirb Durdy bie Ytbreibung

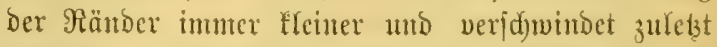

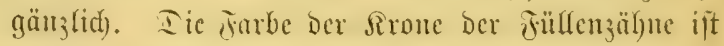

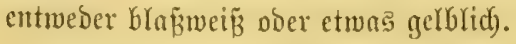

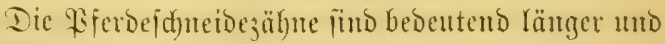

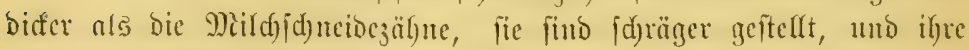

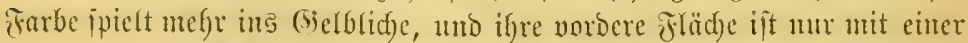

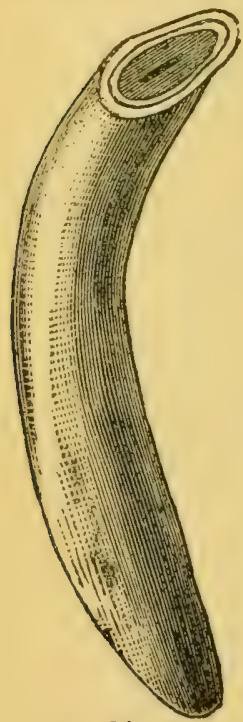

rig. 3. Eängenfurdhe (fiehe rig. 3) verjehen, weldye tiefer uno megr burtel geiärbt ift, als bet ben Mild)=

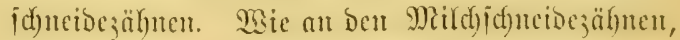

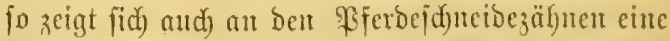

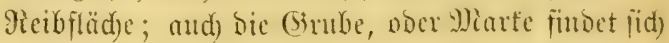

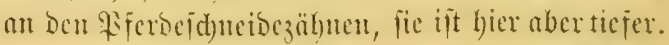

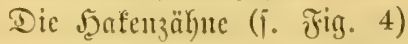
habent eitu fecgelförmtige, ant Enoe zugefpiżte und etwas nad) mißgen geftebrte Rrone, fie find bet jungen Thieren fyogl, füffent fich aber afl=

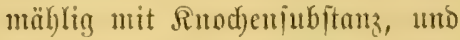

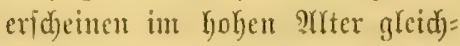
mäßig feit. Sie musen fid alf =

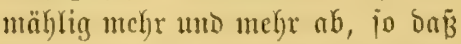
mit 12 bis 13 Jahren bie Rrone fajt ganz veridjwintot.

Bur Crrfentnifß Des Irters bienen: Der Iftşbrud) Der MRild)=

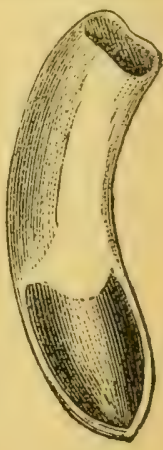

irig. 4. 


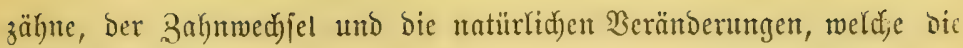
Bähne erleiben.

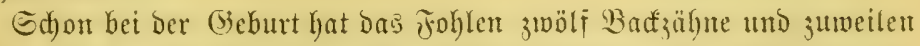

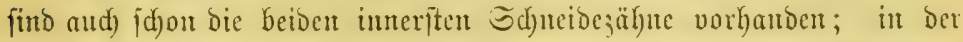

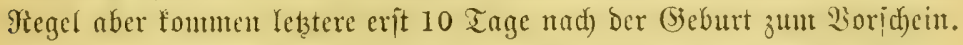

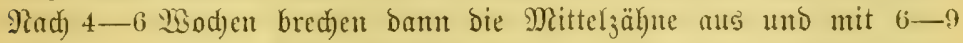
Monntent treten aud) bie (Éḑähne hervor. Jeber biejer Edhneibezähnte

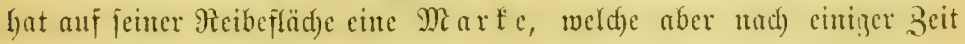
wieder veridjwindet, inbent bie inzwijd)en hervorgewadjenten 马ähne mit Den gegenüberitebenden in Berïl)ung fommen und lid gegenjeitig $a b=$

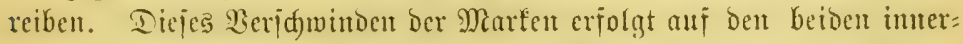

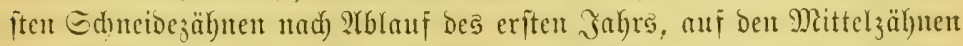

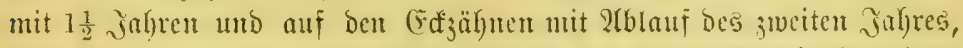

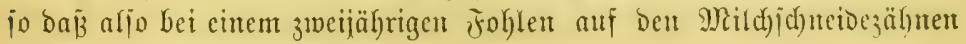
feine Marfen mefre vorhanden fin .

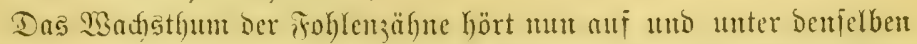

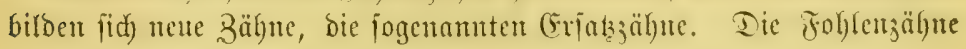

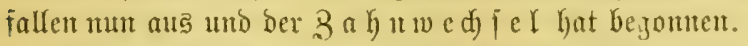

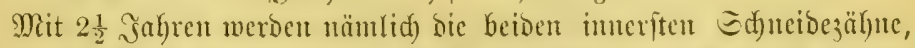

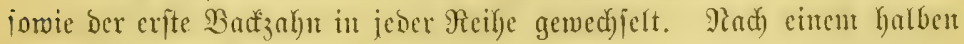

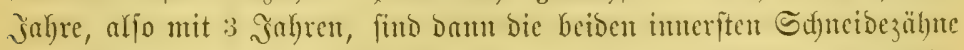

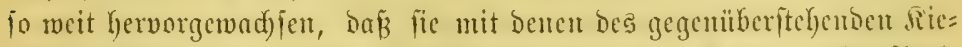

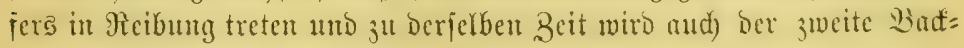
zahn in jeber Reihe gewedjpert.

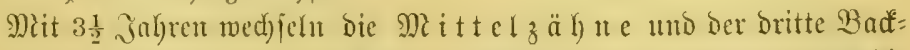

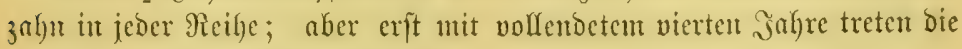
Mittelzähne in gegenfeitige Reibung.

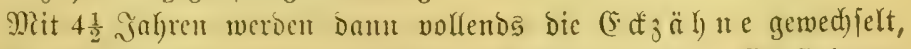

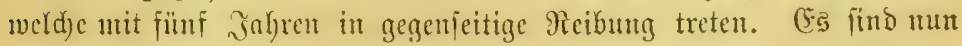

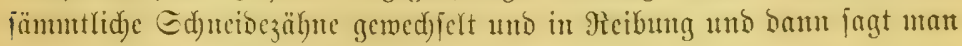
won cinem jolden Pferbe: "Es hat abgezahnt."

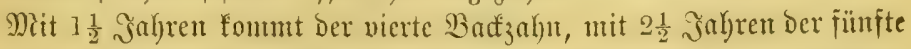

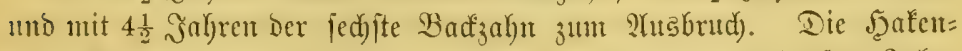
зӓ̆he fomment Daun cbenfalla zwijd)en Dem vierten uno fünften Jahre

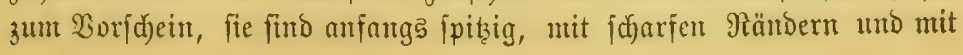




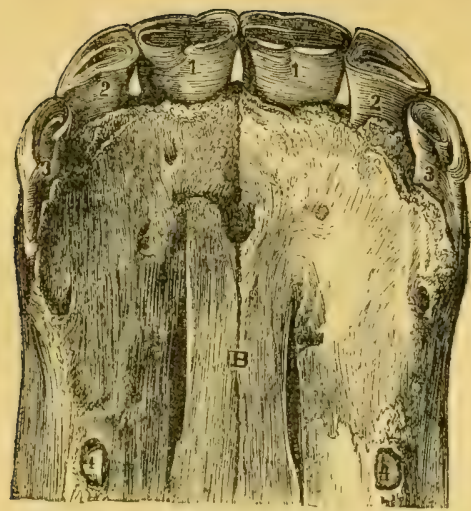

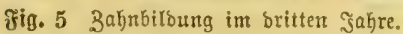

1. 1. Mittlere breibente Ganteibe= zähne, nabezu ansgemadjen.

2. 2. Sd)neibezäbne, mit bereiț et= was abgenubter Meibftäche.

3. 3. Édzähre, welde nod) Die Rirone zeigett.

4. 4. Yiodj verbedte 5̧afenzäbne.

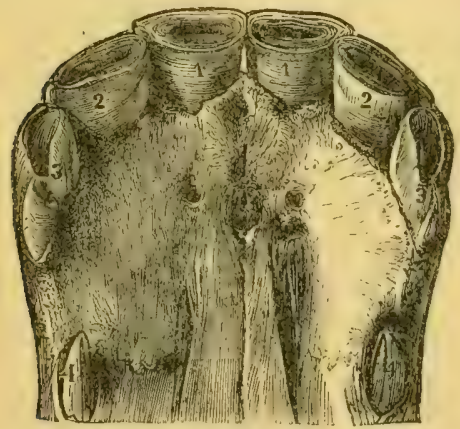

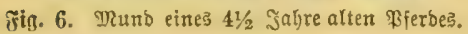

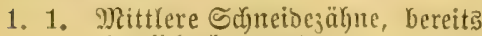
siemlidf abgestubt.

2. 2. Die beiben, an vorige anitopent= ben Bäbne ausgemadjen, mit bereits etwas abgemuter Marfe.

3. 3. Bleibende ( 5 dैäbrte, in $\mathscr{W}$ ad) jen begrifien, die Ranten Der Rronte กod) ld)arf ausెgeprägt.

4. 4. Die \$afenjähue zeigen jid beut= lidjer.

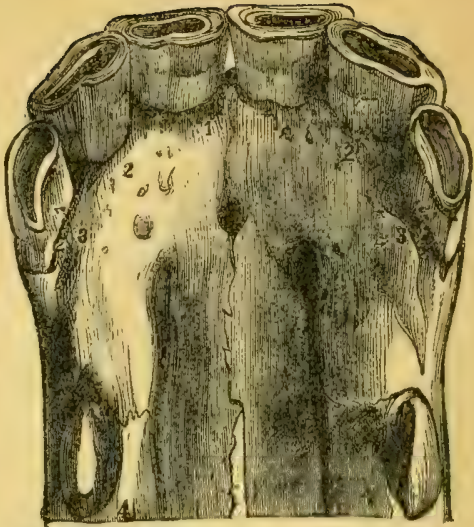

Fig. 7. Sbere Sdneibes uno ફatenzäfne eineş 5jäbrigen Fferbę.

1. 1. Mittlere 巨d)neibezähne, weldje nod) Deutric) Die Marfe (Rube) seigetr.

2. 2. Die antobenden 巨d)uribezäbne mit nod) Deutlid) 3rigender Marfe.

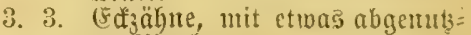
ter 9) rarte.

4. 4. Şafestzähute, voujtänbig her= vorgemadjeu.

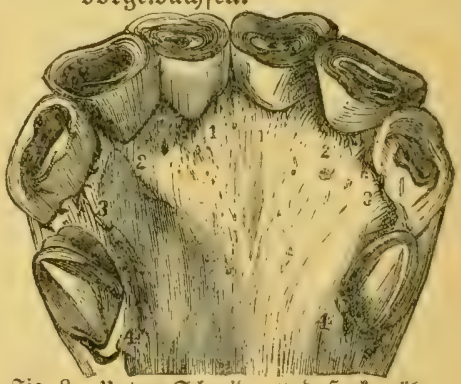

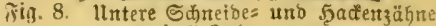
mit 5 sagren.

1. 1. Mitlelzähne, bie Marfe fait gauz verfdimumben.

2. 2. Marfe theilncile abgerieben.

3. 3. (5dzälnte. Miarfe nod) gut er: Galten, mit etwas abgerutbe= tert Jistert.

4. 4. Die 5afertzäbne haben bie int= neren (srub d)en fait gauz abge= nuţt. 
1. 1. Mittlere $\Xi d$ neibezälyne, mit ganz abgeriebenen Marfen.

2. 2. Mit ganz perfdumindenden Mar= fert.

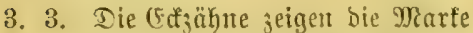
nod) beutlid), ber Fanb derjels ben zcigt fid jebod) f(jou felfr abgenutst.

4. 4. Die 5 afenzähne ftegen etwa $3 / 4$ Bulf vor, bie Spitze seigt fid) nod) gut erfalten.

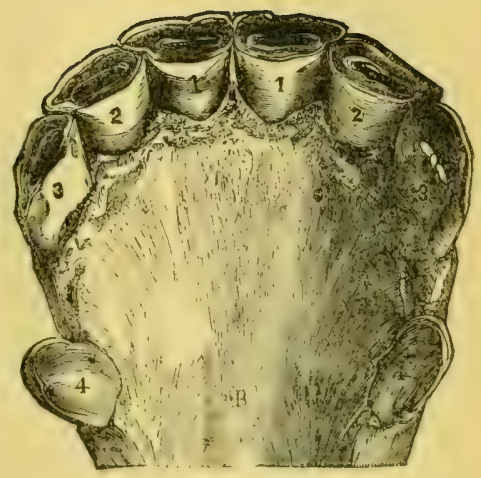

זig. 9.

llntere Zülyne cines fiälutigen Wierbes.

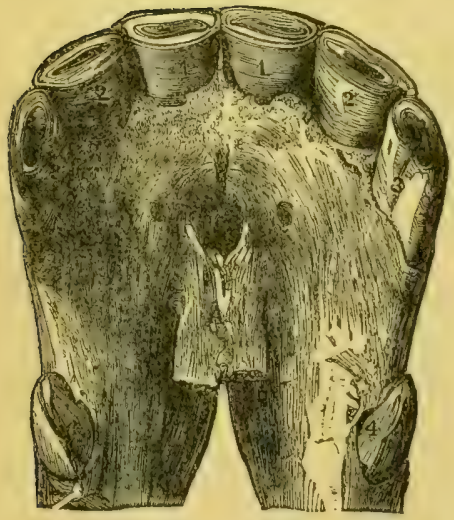

rig. 10.

פit 7 Jahren.

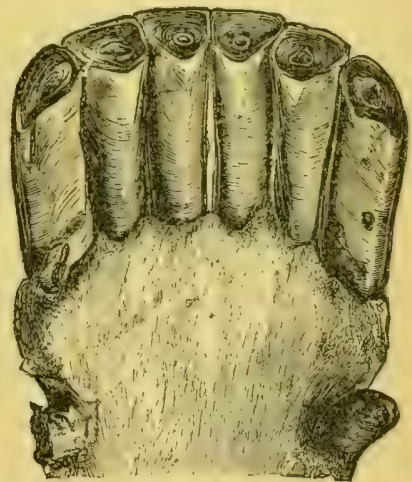

Tig. 11.

mit 9 গăbren. 


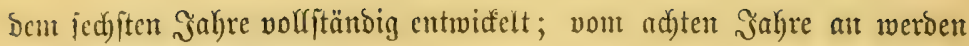
jie allun̈blig abgejtumpft.

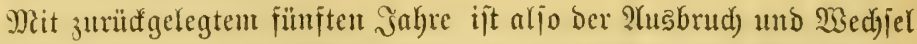

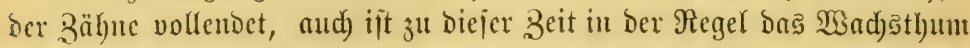
bes হiörpers becubet. Wie nus bem Bisherigen erfid)tlich ift, wirb bas Zllter des Bferbes bis zunt fünften Jahre aus Dem Wedjel ber Bälute beurtbeilt; won ba au aber ift bas arter nut an ber 2tbreibung ber Ed)

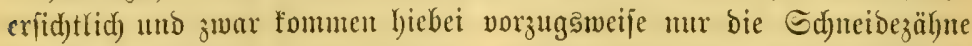

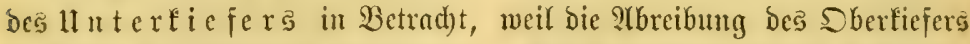

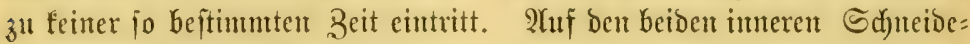
zäfuen veriduvinton bie Marfen mit ben fect)iten Jabre. Mit bem fiebenten Gah̆re verjd)winden die Marfen aud) auj beu Mitteljäl)nen und

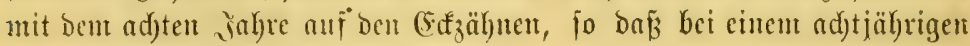
Breroe feine Marte mely fidstbar ift.

(Sine eigenthümlidye Seränderung tritt ferner in neunten Jahte an

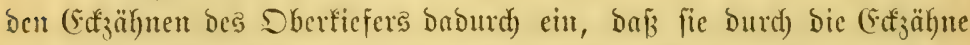
Des Interfieiers nidyt vollftändig abgericben werben in Jolge ciner im fiebenten Jafre begiunenden Etrectung Des Itnterfiejers, woburd) ein

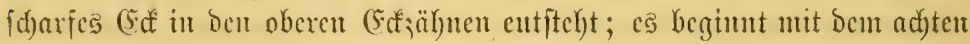

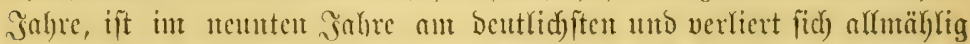
mit Dent cliten Jahre. RBis jum adyten Gahre ift bie Beurtheilung oes

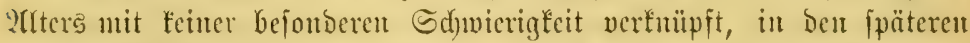

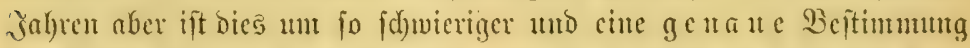

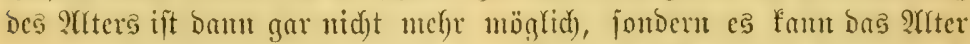

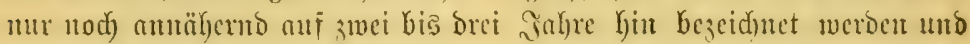

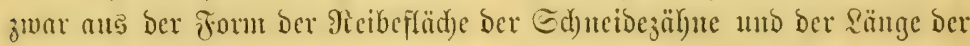
3äbute überbaupt.

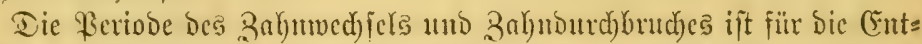
wiffelung bes Thieres von grof̉er Sebentung. Jinsbejondere follte es

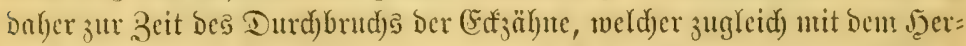

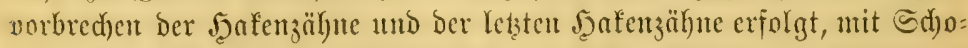
આung behandelt werben. Sd) bu ber mit bicjen Borgängen verbundene Edfucrz verntag Mangel an Freb̆luft, (Fingenommenheit bes Ropfes $u$. 1. 1w. veranlaffen; wirb bas Thier überbies mit fdyerverbaulidem 


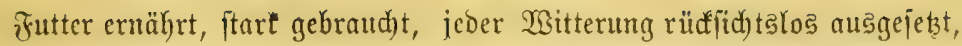
fo barf e's nid)t befremton, went gerade in biejer Beit Der (brund ju manderlei Sirantheiten un $\mathfrak{H e b e l n}$ gelegt wiro, wie namentlid) (Siefirn=

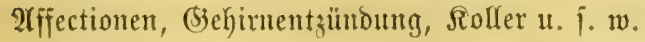

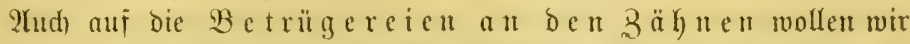
bei biejer (belegenheit nod) minterfian madjen. Wie bereits gejagt, ift

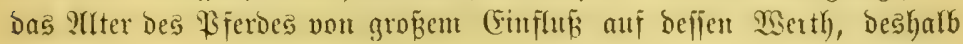
werben an Den Ed)neidezähnent mamnigfad)e Betrïgereien vorgenommen, um bas Wifero theils jüutger, theils älter eríd)einen zu Yaffen.

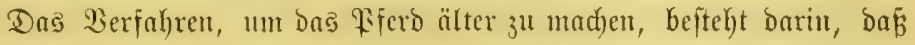

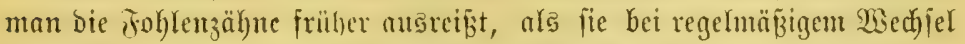

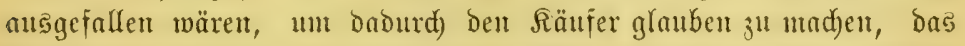

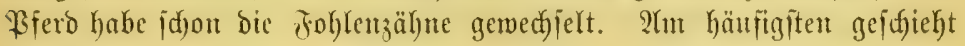

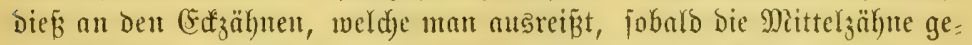

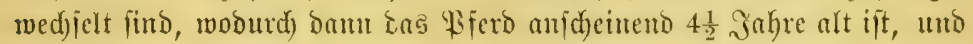

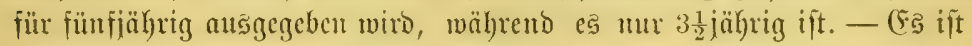
jebod) nidyt fidjwer einen foldjen Betrug z̆l crfenten, Denut bei einer ge=

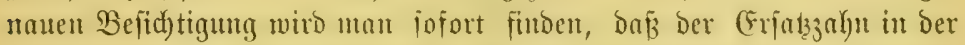

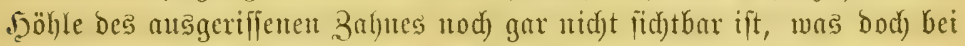

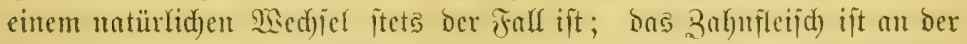

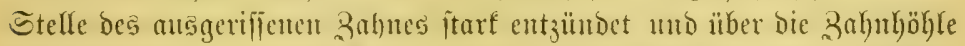

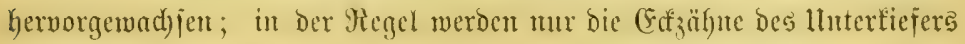
ausgeriffen, wäl)rent bod) meift bie bes Sberfiefers zuerft gewedjelt

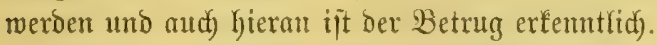

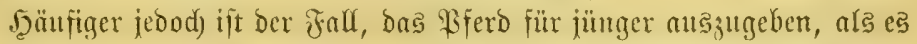

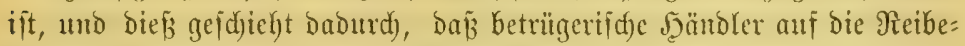

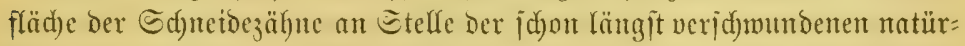

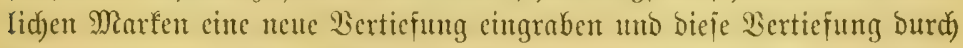

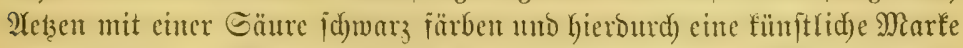

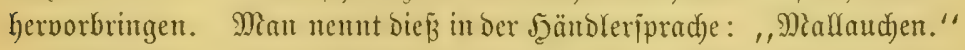

Diejes Mallaudjen geidjeght entweder auf aflen Edyncidezälynen bes

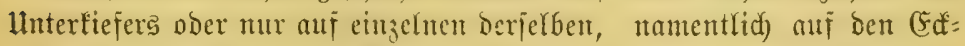

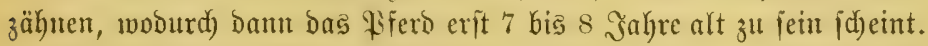

Diejer offenbare Betrug ift jebod ziemlid) leidjt zu entoecten, Denn währeno eine natürfidfe Marfe jtets von einem erbabenen, glänzento 


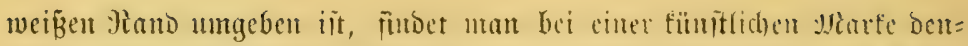

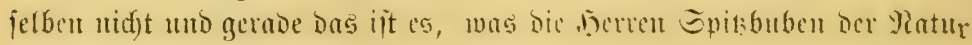
nid)t nad)muduen fömten.

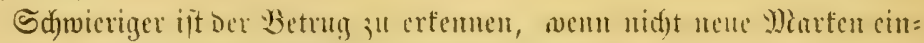
gravirt, jombern bie vorhandenen Dlartenpatuen tiejer gegraben werden

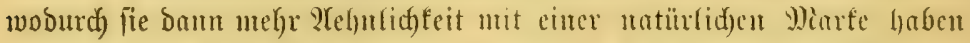

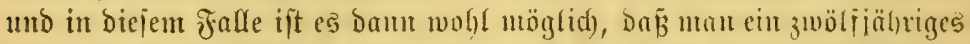

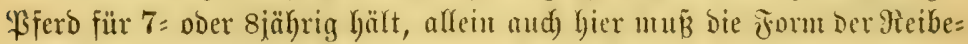

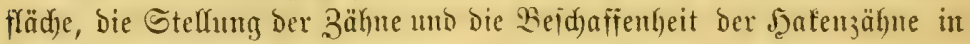
Betradjt gezogen merben.

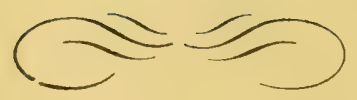




\section{Regelu and Bovid)riften}

\section{ber \\ Mlational Crotting Afllociation,}

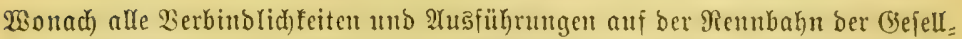

id)ait beurth)cilt werben follen. 2tugenommen von ber "Yiational

Trotting 2 fifociation“ in ber (jeneral= Berjammlung

gehalten in ber Stabt Niew Yyorf, am

12 ten

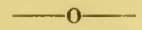

Regel 1. Ma a

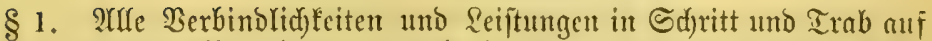

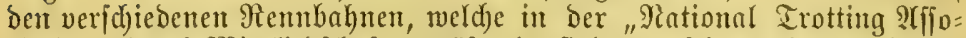
ciation" burd) Mitgliebid)aft reprä[entirt find ober fein werden, und jede

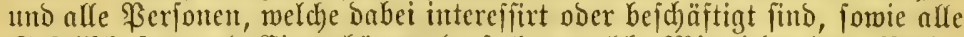
(5) fellid)aften und (Eigenthïmer berjelben weld)e Mitglieber ber , Jiatio= nal Iffjociation" find ober werden wollen, follen fidh on unten folgendoen Regeln zu bittden haben von und nad) Dent 12. Februar 1880.

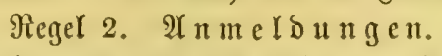

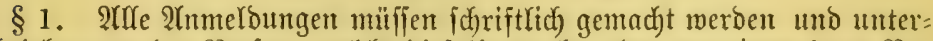

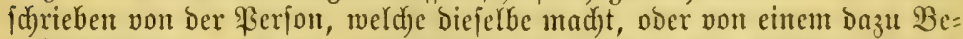

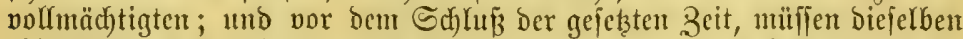
aboreffirt und bejörocrt jein in llebereinftimmung mit ben befanntgentad)= ten Bebingungen, ober beponirt merben beint Secretär ober andere baźl ermächtigten \$ierion, biejelben in (Empfang zu nehmen.

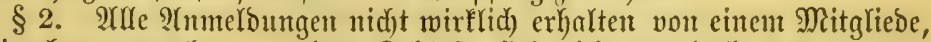
wie obest angegeber, vor bem Sdylub, fins nicht annehmbar, ausgentm= men, $\mathfrak{T}$ mutbungen in regiftrirten $\mathfrak{B}$ riefen beffen $\mathfrak{B}$ oftitempel fein ipäte=

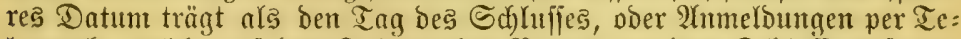
legraph, weldje auf Dem Ielegraphen=Bureau vor Dem Sd)lufie nufgege=

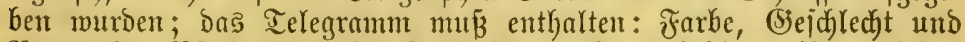

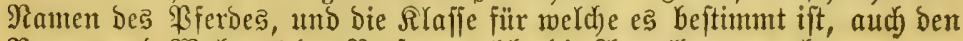

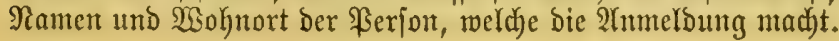




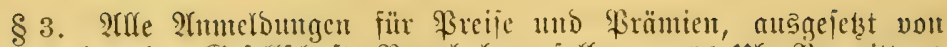

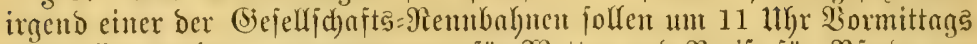
gefd)loffen werben; ausgenommen für \$Setten und Sreife für Pferbe am

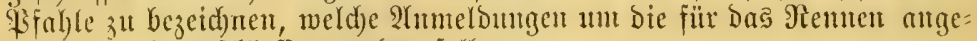
jeb̧te Stumbe gejdyloffent werdent follert.

\$4. Naträge für Den volfen Binjatz Der Mette folfen utidgt angentont= men werben zu concurriten, che bie Bahlungen uad) Den vorgefdricbenen

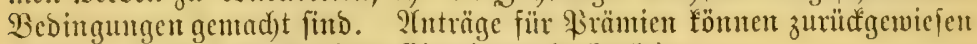
werben, wemt nid)t non Dem (Eintrittagelde begleitet.

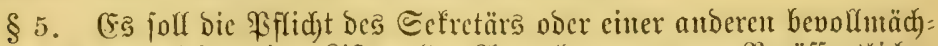

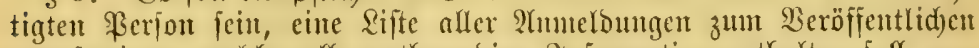
anzufertigen, weldye alle nothmendige Suformation enthalten folf, zur

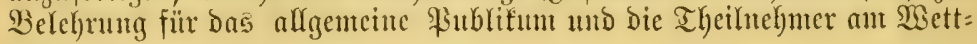
renten.

\section{Megel 3. Eintrittagerd.}

§1. Das (Sintrittagerd folf zelut ßrozent des ausgejetzten \$reifes betragen, weut nidjt anders beftimmt. (5ite Perfon, weld)e es unter:

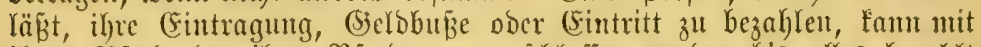

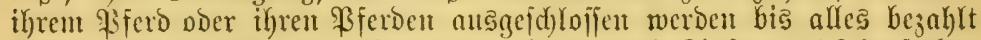
ift mit Jinzufügung von jelyn Sirozent Strafe und Binfen zu $7^{\circ}$ Derferben

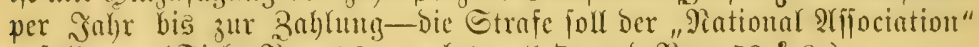

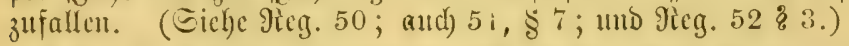

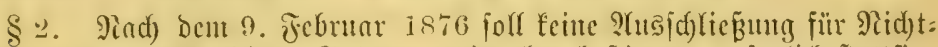

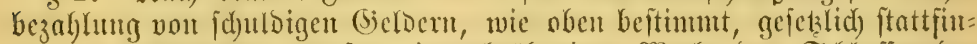

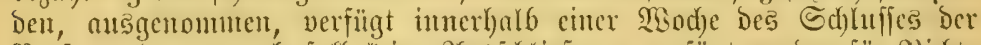

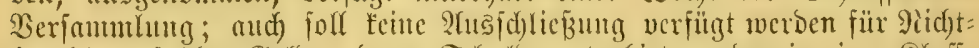

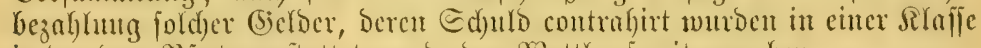
in ber Dent Piferoc gejtattet wurbe ben Mettlauf mitzuntad)en.

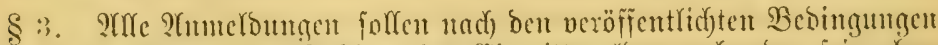
geregelt werben und jut Pablumg bes (Fintrittsgeldes verbunden feiu olye

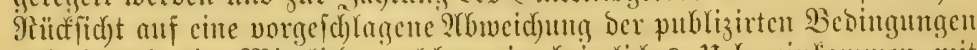

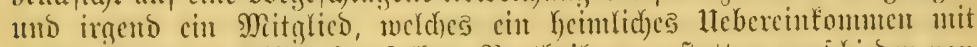

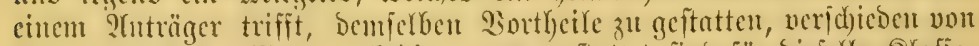

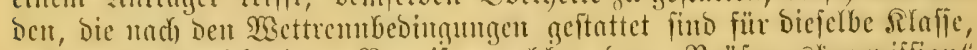

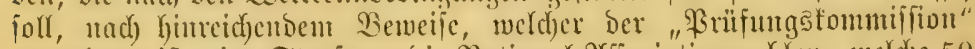

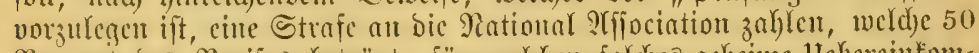

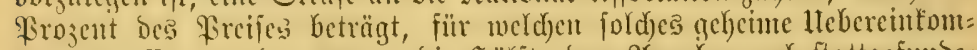

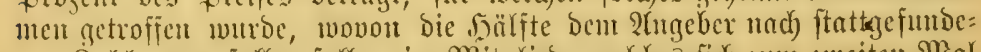

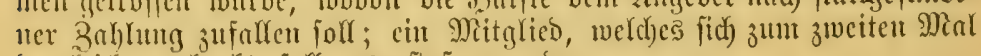
bergleidjeu erlaubt, jolf ausgeftojen werden. 
Regel 4. Wi te viele anzu

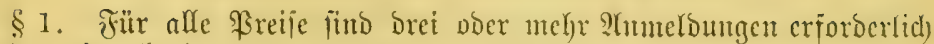

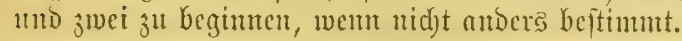

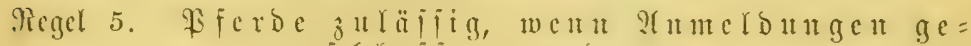
fdy $\operatorname{lofjen~werden.~}$

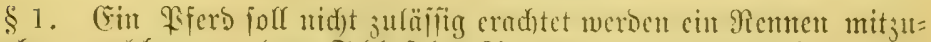

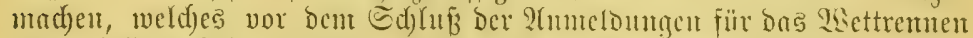
id)on beffere Beit genad)t ala bic, für weldse cis angenteldet ijt, angge:

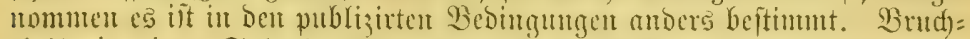

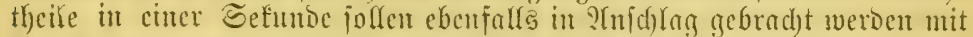

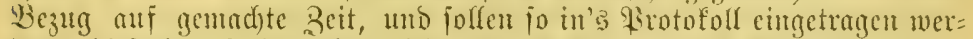

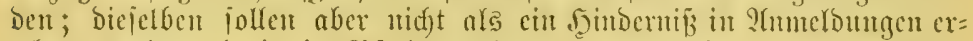

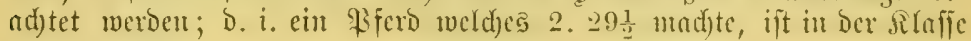
2. 30 zulläifigg.

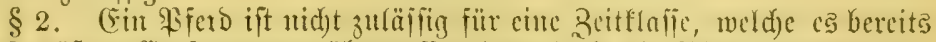
auf größere (Entfermungen übertroffeu hat; b. h). cin \$iferd, weld)es zwei

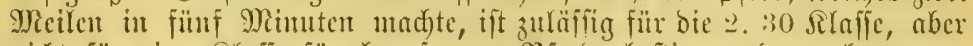
nid)t für ente Rlafie für langlamere Bferde beftimut, Dem oben ange= gebent.

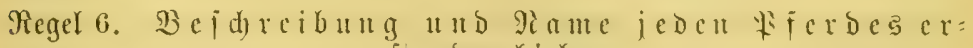

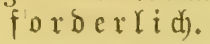

§ 1. Fine genane und genïgente Bejut)reibung für jeses angemeldete Fferd ift erforberlid, , fo Dẩ man bas Shier nad) Derfelben wicber erten= nen fant und joll folgende (Fingelfeiten cutbalten, nänlid):

$$
\left(\mathfrak{F} \pi \mathfrak{r} \mathfrak{b} \in e_{0}\right)
$$

\$2. Die Fुnbe muß itets gegeben werben, und wemu jur (Erfenmung nothwenbig and befondere jarbfentzeid)en, Flecten u. ¡. w.

\section{((5) $e ;$ d) $f \in$ d $t$.}

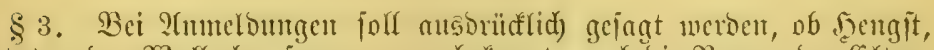
Stute ober Malfad); fermer went befamnt, and) Die Ramen ber (C.ltern

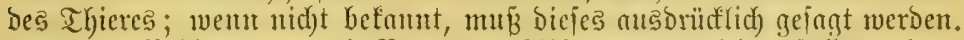

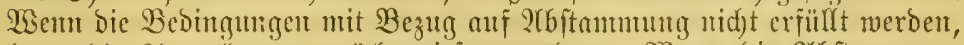

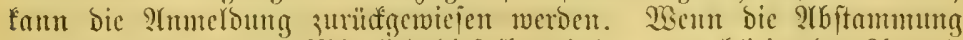
angegeben ift, foll bas Mitglied biejelbe mit ben ju publizimenton 2Tumel= Dungen zuglcid) veröfifentlicisen.

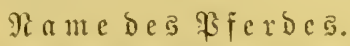

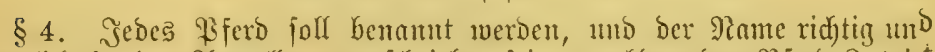

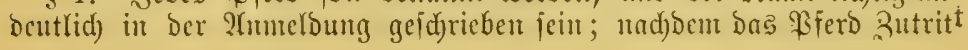




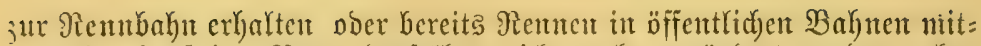
gentad)t, barf ber शame Desfelben nid)t mehr verändert werden, ohne

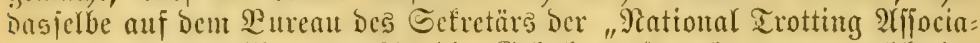
tion" zu protofolliren, wofür bic Gebülyren $\$ 50$ betragen, weldye ber

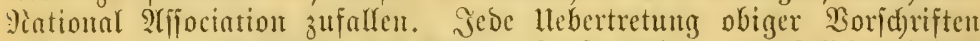
jolf mit einer (Selbbube vout $\$ 100$ geitraft merben, und folf bas \$ferd

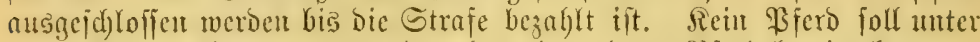
cuten Panten cingetragen werden, Den cin anderes Piferd bereits hat.

3. 5. Wenn cin Pferd D̈frentlidfe Reunen bereits mitgentadyt lyat, foll Der lebte Acame unter bem bies geid)ah, angegeben werden mit ber 2 numel= Dung; wurde Der Name imterhalb Der letsten zwet Jafre gemed)jelt, fo milifen beise gamen, weldje basfelbe gefïfnt hat, angegeben werben.

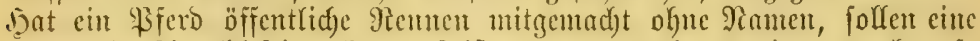

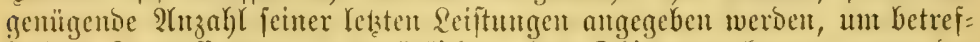

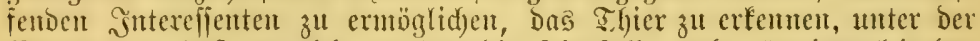

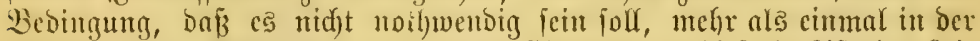
Enijon einer (Sicjellichaft ober einent Cigentbümer biefelbe Rijte der \&ei= jtungen zu gewähren.

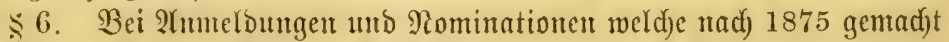

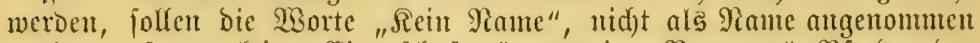

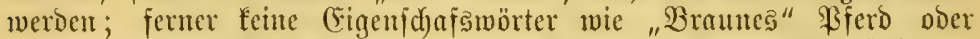

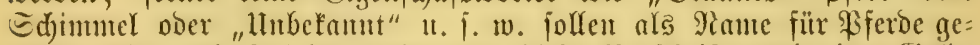
jtattet jein, und joll ber llebertreter biejer Sorjeriften mit einer (Sield: buß̧e belegt werben, weld)e das (sintrittsgelo nidjt überiteigt. Dieje Worfidriften bezielent fid) aber auf fein \$ferd meldes vor 1876 unter Dem शamen "Itnbetamt" (unknown) aufgetreten iit, ober fich einter

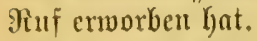

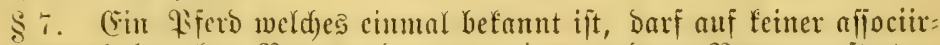

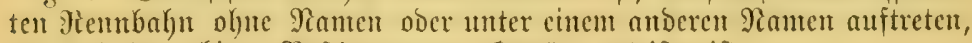
ebe uidut Den bbigen Beftimumungen (Sienüge geleiftet ift.

\section{3 w e i j p a u}

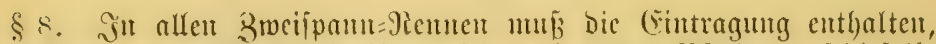

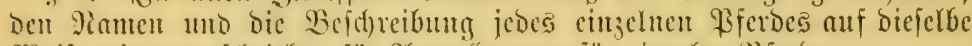

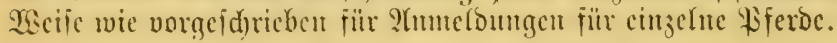

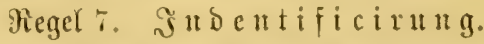

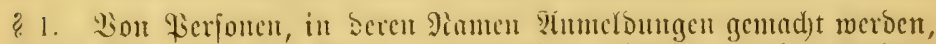

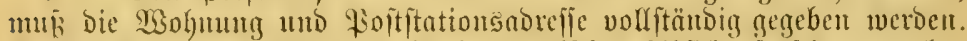

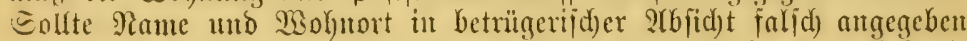
iein, io folf ber llebertreter mit citer (Selobube nidjt über \$100 beftraft

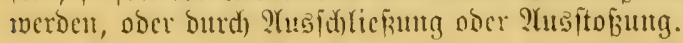




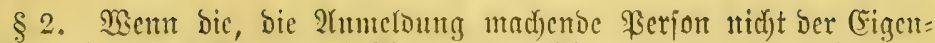

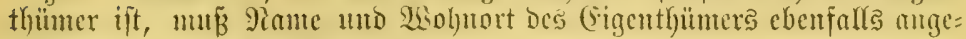
gebent weroen bei der 21nmeloung.

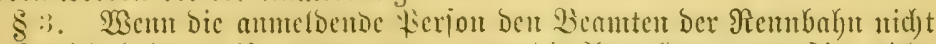

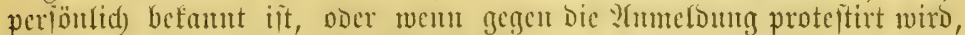
foll ex anf Wertantgen jeine Werjönlidfeit und bic des Wiferdes feftîtellen, Durd) genilgento Weneismittel. Eoluten Den Midutern bie beigebrad)ten

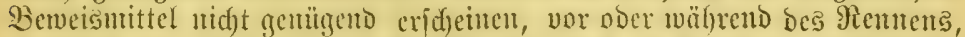

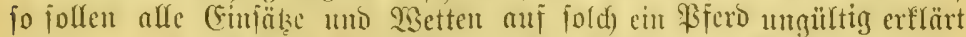
werben, und foll bie? öffentlid) von ber Iribüne verfitubigt werben.

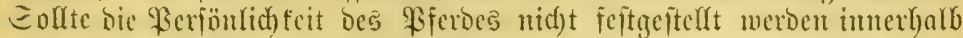

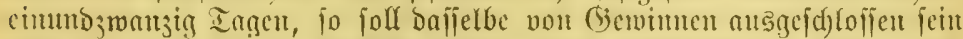

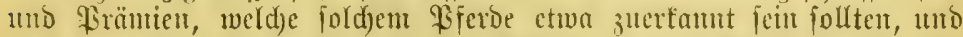
mad) ben bejtefienden (Sicjedsen vou feinem anderen Pferbe beanipratd weroen fömen, follen Der "Pational Irotting Prifociation" sufallen. (Eieke ßegel 16, \& 8.)

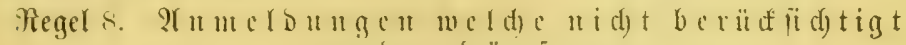

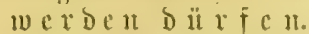

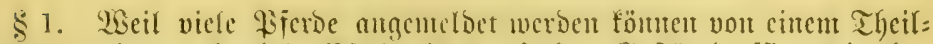
nebmer, ober aud) vicle \&iferde in Demfelben (Sejtït Drefïrt, wie cben gewünjd, wirb, barf bod) Int eintes, bas von cinter Ferjout ober einem

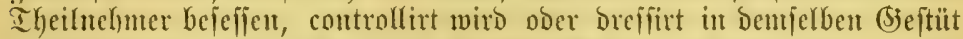

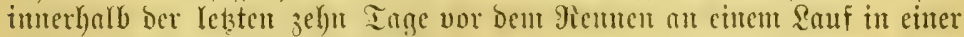
beitimmten genuffafie theiluebuen.

Hegel 9. Secin Breis für Gdrittgang.

$\$ 1$. (5s foll feit \$rcis für Sd)rittgang suctfant meroen, aber in

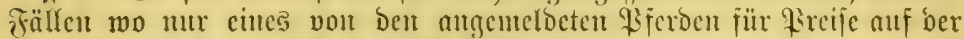

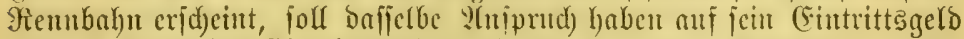

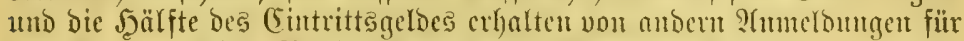

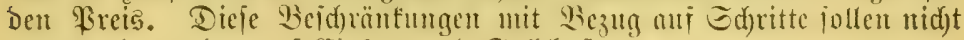
angemanot werben auf (Sinjäze und Bjeldbußzen.

Meged 10. Ju Tode

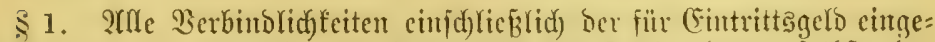
gangenen, fund ungültig, in Tobesfalle bes Theiluebmers felbit ober leines Bferdes, foweit bieferben bie Iheilnehmer ober bas \$ferb betroffen. Yher (GelsbuBert und Metten gemacht "Epiel ober Babl" follen you Dem

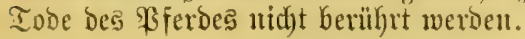

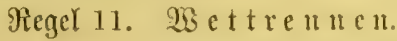

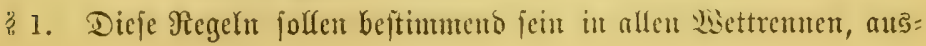




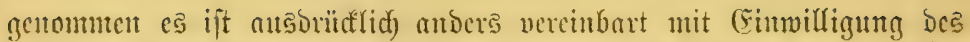

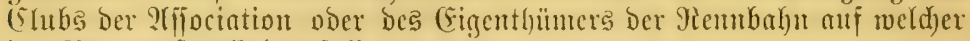
bns Henten ftattfinden foll.

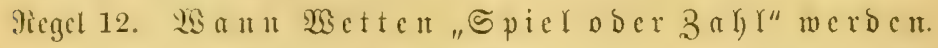

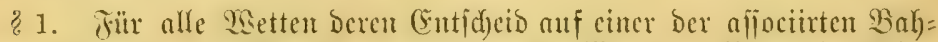

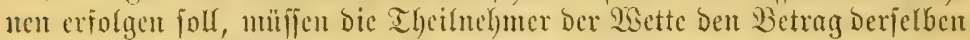

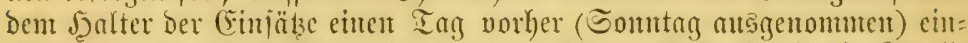

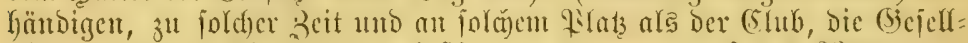

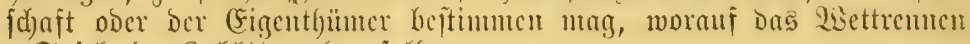
"Spiel ober Babl" werden joll.

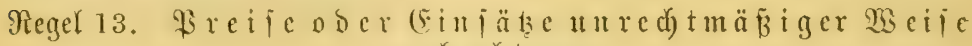
e $r \mathfrak{l} a \mathfrak{l} \mathfrak{t} \mathfrak{e} \pi$.

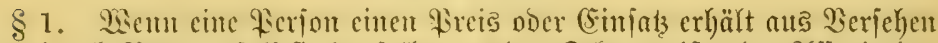
ooer burd) Setrug, foll fie benjelben an ben Sdyamucipter ber 2(jijociation zurïderitatten, woen Daju imterbalb eines Jabres mugefordert, von Mitglicbe ober Durd) Wierfügung von P(ppclfationsmisid)ub (Board of Appeals) ober er foff wic folgt bejtraft werben: (Er, mit affen Theilneh= meru an Dem Setruge, jowie bas Bferd ober bie Fferde follen ausge=

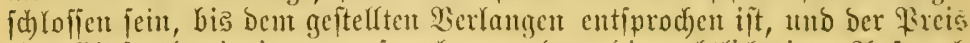
ober (Sinjab Denjenigen jugeiprod)en werden, bie red)tlict) einten 2(mjprud) barauf baben.

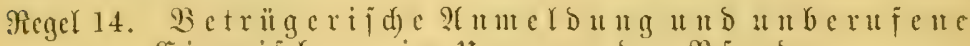
(5) i m

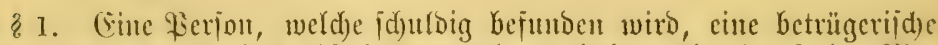

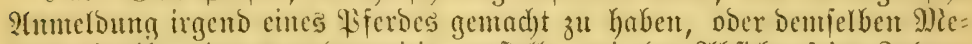

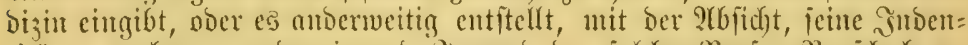
tität ju verbergen, oder irgend jemand ber folder झerjon \$orjdub ge=

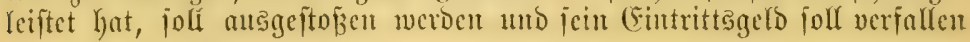
jein.

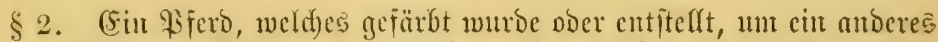
ober veridjicocnes Riferd 3u repräjentiren, ober weld)es für eine \$reistlafic angemeloet wurbe, in weld)e es nidjt gehört, foll ausgeftopenen werben uno Das (sintrittāgeto verfallen feir.

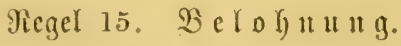

\$1. Eine Belohmug won $\$ 50$ foll Derienige erbalten, Der zuerit fold)e Mittheilung mad)t, in Folge Seren Sheifmelnuter an cimer betrïge=

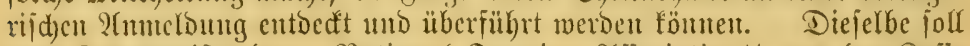

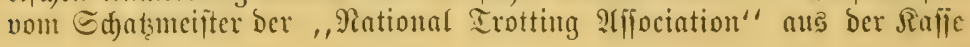




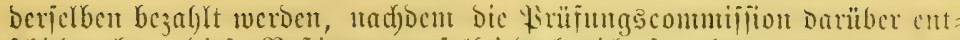

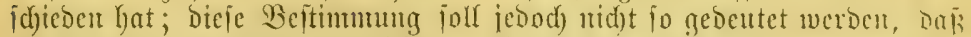

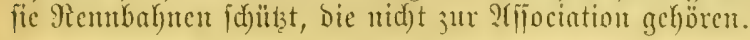

Regel 16. Prote it e.

§1. Frotejte mögen mtïnblich cingelegt werden, vor ober wäl)teno Des

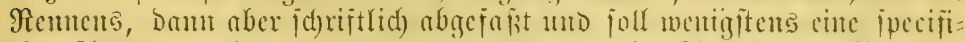

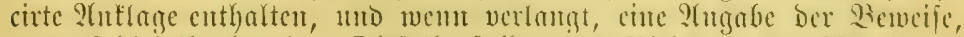
woranf bicjelbe bentht. Dicjelbe folfen ben Midjtern, Der Prifociation

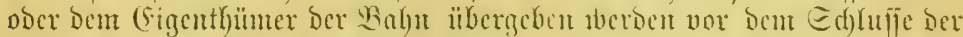

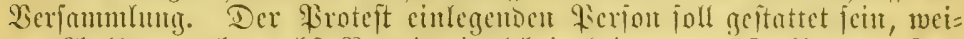

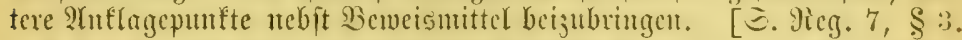

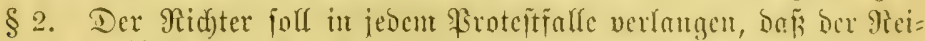

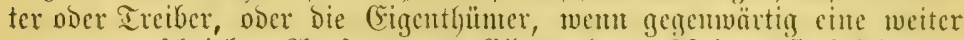

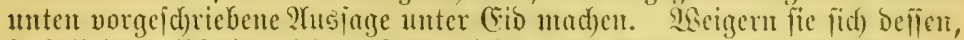

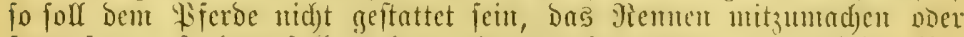
fortzujetsen, fondern foll erad)tet uto angezcigt merben, a(s nad) Der He=

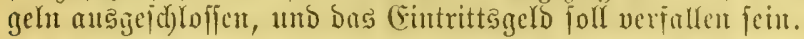

§3. Solften nber bic Theifuchuter bie unter (5ib verlangte 2Gujage

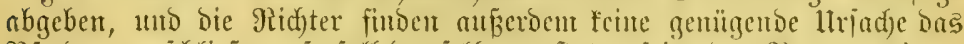

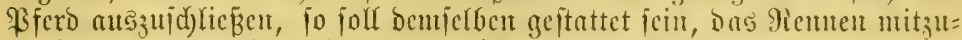

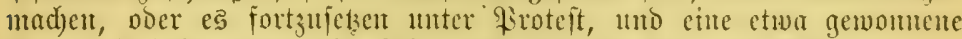

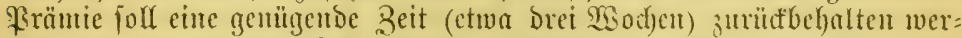

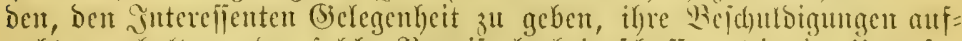

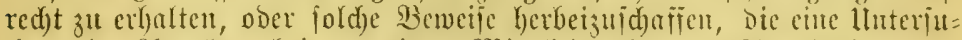

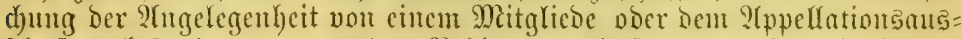

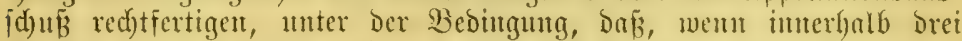

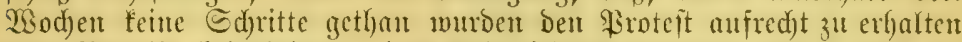
ober Bemeife beizubringen, bas Mitglied foll verfabreu als ob jold ein \$roteft nidjt cingereidgt worben wäre.

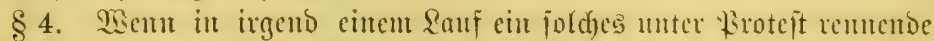

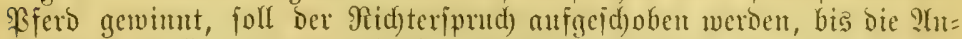

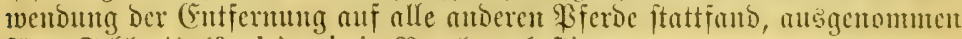
für, , Jeh)ler" (fouls) wie in গegel 48 beftimmt.

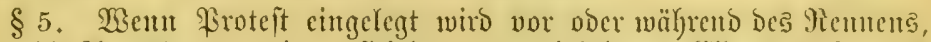

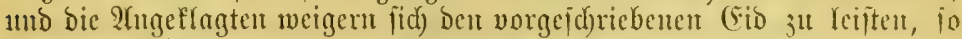
faum Der Siddter, went er 1lrjadje hat ju glauben, Daf bicje Weigerung

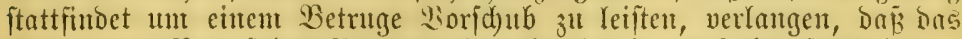

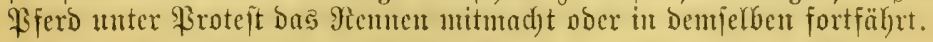

§. Cine Perjon, bie junloig bejunden wirb, gegen ein \$ferd ofue

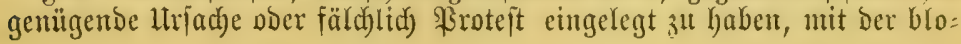




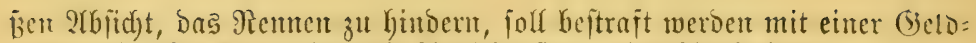

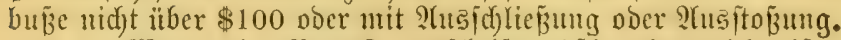

$\$ 7$. Wem ciu Broteit voridyriftsmäfyig eingercidyt ift, ober ben

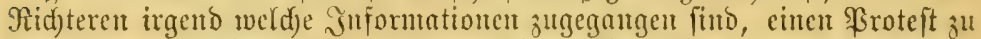

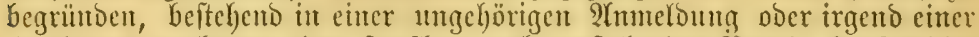
Janblung verboten ober ftrafbar nad) vorftehenten Pegeln, bürien bie: ielben uid)t zurüdfgezogen ober ïbergebent werben bevor brei Wochen ver:

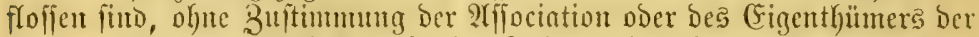

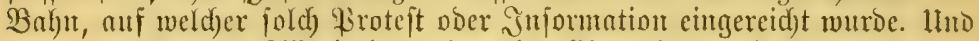

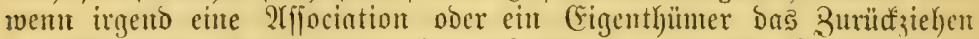
cines Broteftes oder Suformation geitattet, aus el)rlojen Beweggrïmben

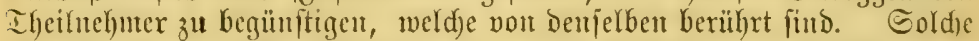

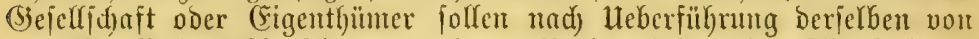

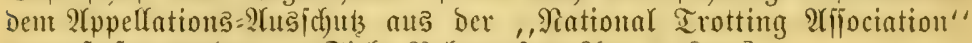

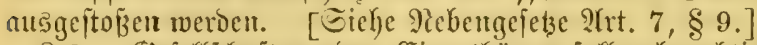

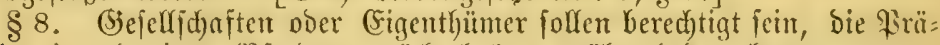

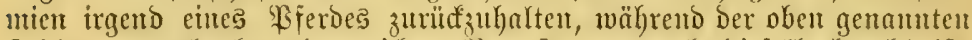
Beitbauter, aud) ofne cingereidyten \&roteit, wenn, che biejelbe bezalt iit, ihnen foldye Sunformation zugeht, woraus fie und ihrem Urtheil auf cinen Betrug fd)lięent mülfen. Soldhe nad) biejer Regel zurüdfbehalte=

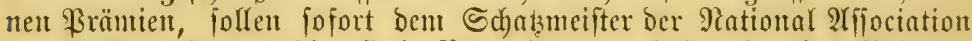

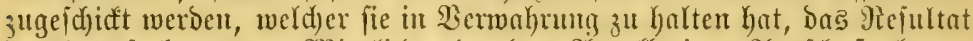

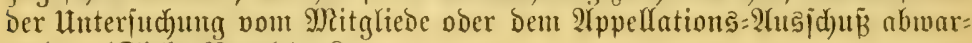
teno. (Siebe Regel 7, §3.

\$. Der im Falfe cintes Firoteftes ju reiftende Cio joll in folgender Form abgefä̧t jein:

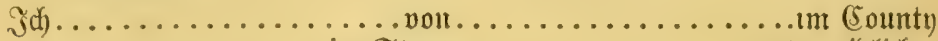
im Stante................ unter eiolidjer

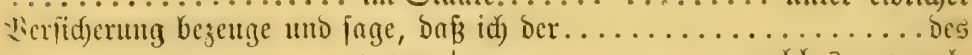

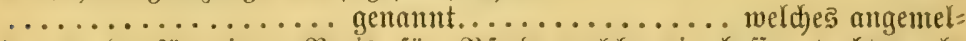
bet wurbe für cinen ßreis für Sferbe welde nie belfer trabten als Mimutent .......... Sefunden, und beute auf biefer Bahu traben jollte, und baffelbe Brero iit, mogegen \$roteit emgelegt worden, in Beattwortung mefien bicje cibliche ?hajage, uno bejeuge uno

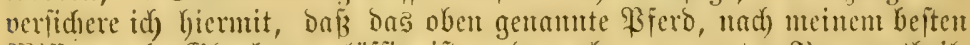

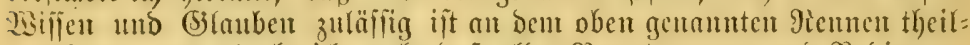

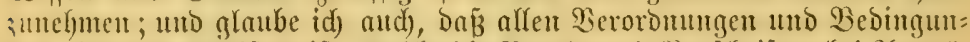

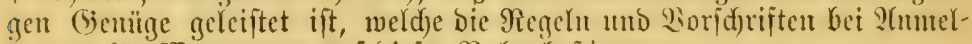

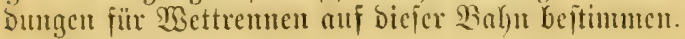

Siegebent zu....................... I. 18. 188..

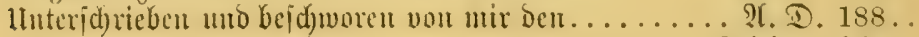




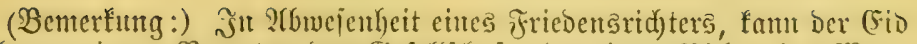

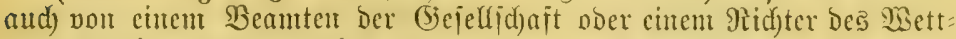
rentents abgentomment werben.

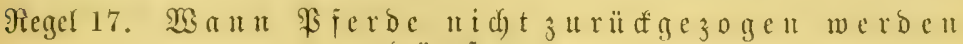
D ü $\mathrm{r} f \boldsymbol{f} u$.

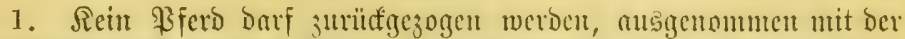

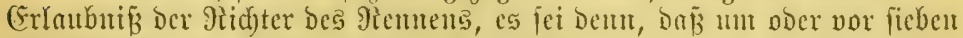

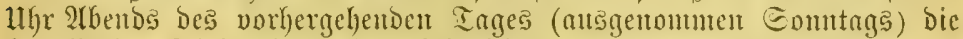

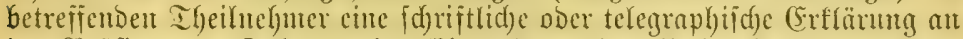

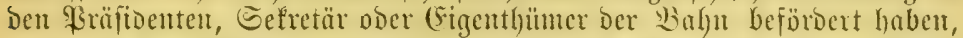

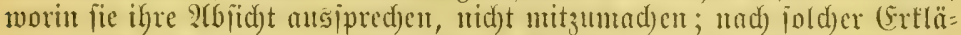

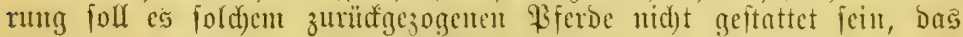

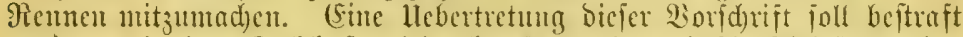

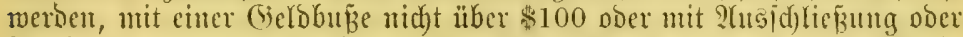

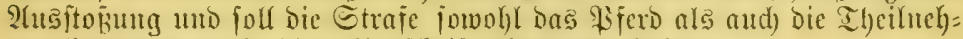
mer betreffent weld)e biefe Borfdorift übertreten haben.

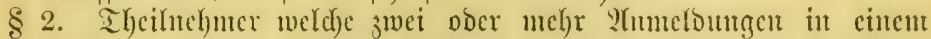

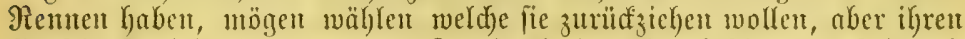
Entij)lub, bei oben genanter Strafe, in Der oben beitimuten Beit un Meife nittheilen.

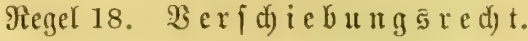

8 1. Jm Fralfe ungüntigen 2 setters ober anderer unermetolidjer $3 u^{=}$

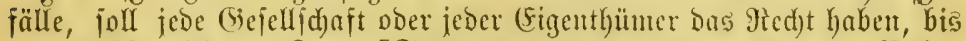

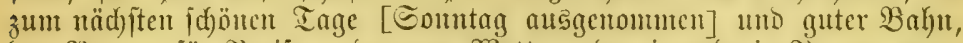

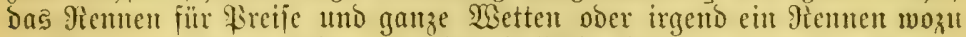

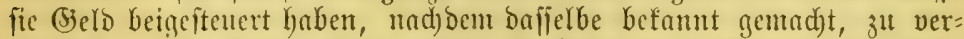

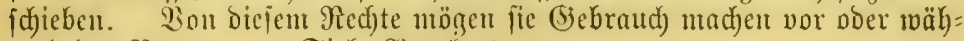

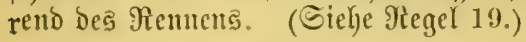

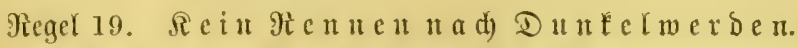

\& 1. Rein surf jolf gemadgt werben, went es bereits jo bunkel ift,

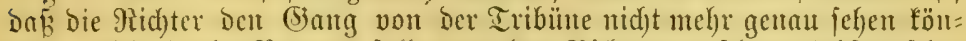

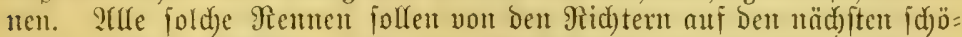
nen Iag verlegt werben, und auf folde Étunde, wie fie felbit zu beftims= ment beliebert. [Somtng nusggenomment.]

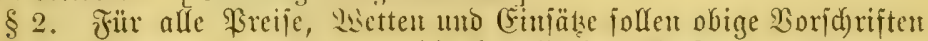

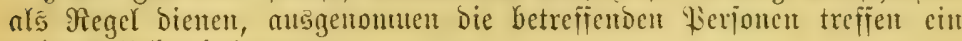
anberes Hebereinfonment.

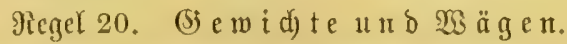

\$. Tenes \$fero, weldhes bie Rembahn betritt für eenten Freis, 


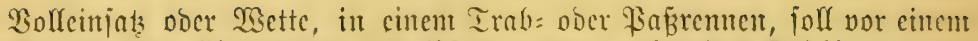
Wagen ober Einjpänter 150 :

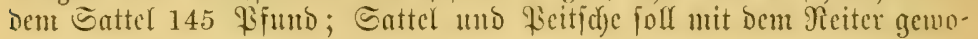
gent wertoul.

\$2. Meiter und Treiber porfen gemogen werden in Giegenwart vou

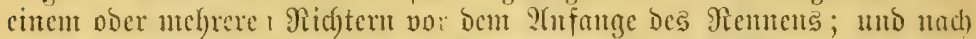

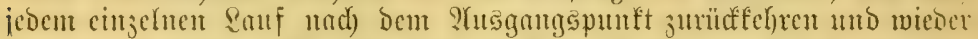

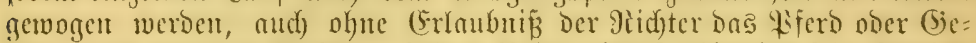

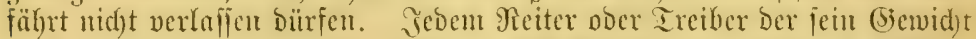
nad) jedem cingelnen ?aufe mitbringt, joll Entfermung abgejogen merden,

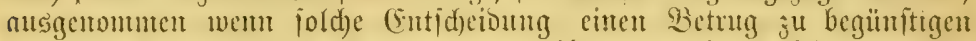

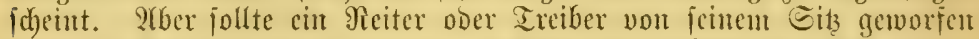

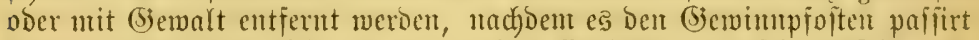

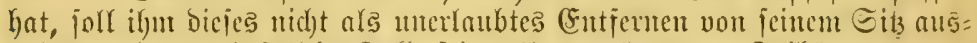

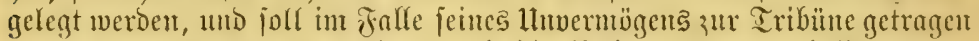

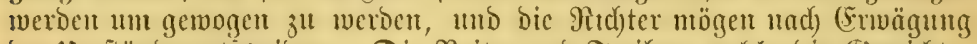

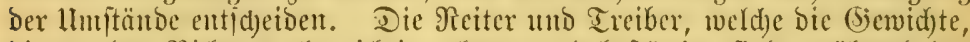

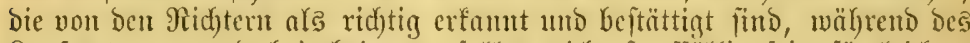
Raufes tragen und heintbringen, follen nidat itraffärlig fein für leidftes

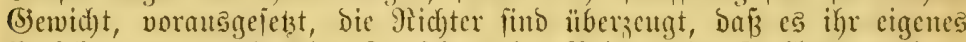

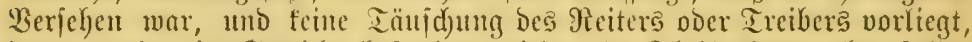
Der zu gering in (Siemid)t befunden wirb, alle Theilnelyuer aber follen Darnad) Das erforberlidje (Siewicht tragent

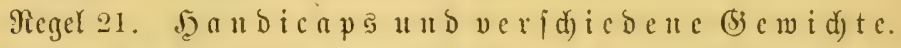

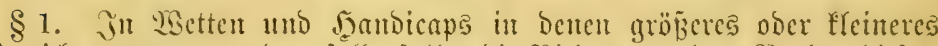

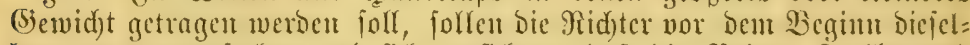

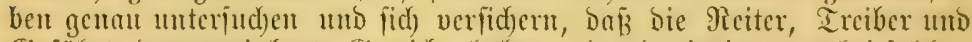

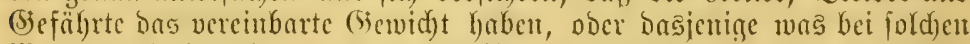
Wetten und Sandicaps erforberlidy ift, und follen bie 9ieiter und Treiber Denjelben Sebingungen und Strafen unterworfen jein, als ob fie bie burd)

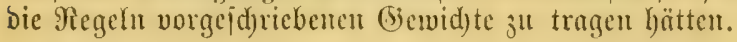

Regel 22. We un Meiter ub Ireiber llebergemide b) $\mathbb{b} \mathfrak{b} \in \mathbb{u}$.

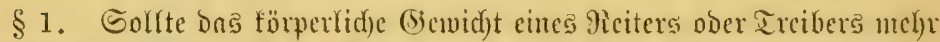

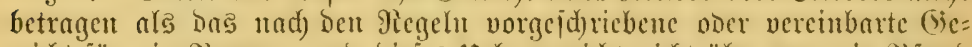

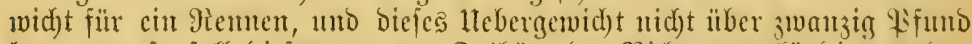

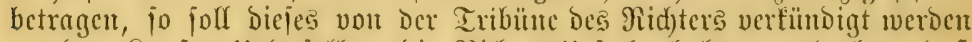

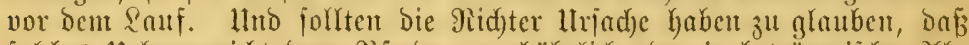

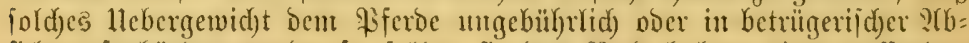
fid)t aufgebürbet wurbe, jo jolfeu fie bas Red)t haben, cinten paffenden 
Neiter ober Treiber zu ermentmen. Solften fie zu ber Arnabme bered)=

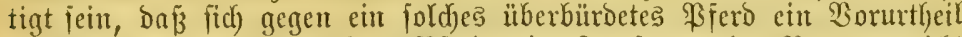

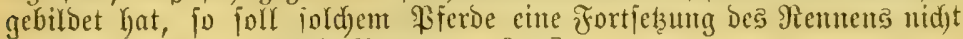
geitattet weroell. [Siehe Regel 28, \& 5.]

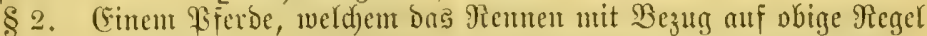
nid)t weiter geitattet ift, folf nidgts an ber (5ntfermung abgezogen werden,

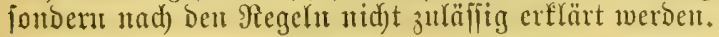

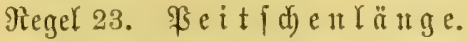

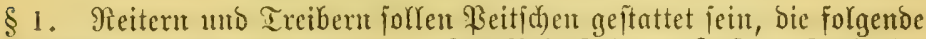

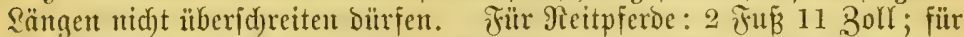

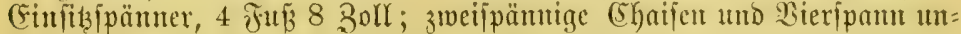

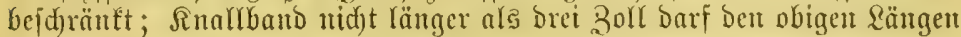
finzugefügt werbett.

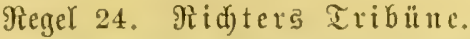

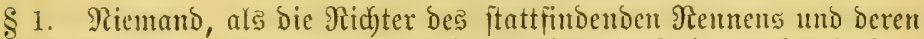
2rififtenten loll e马 geftaltet jeit, auf Der Iribüne berierben wäbreno eines saufes, glats zu mefmer.

\section{Megel 25. Wahl}

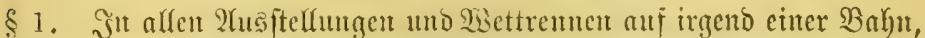
welche it ber "Iational Irotting Prifociation" reprejentirt ift, joll jebe

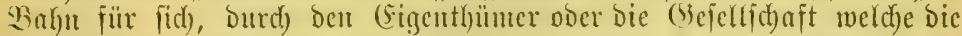
(5ontrolle Dericlben Gat, brei (3) tompetente Middter wäblen, oder

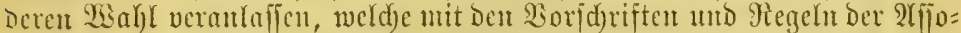

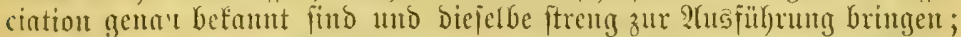

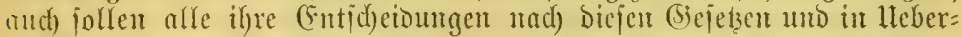
cinftimmung mit berjelben abgegeben werden. [Eiebe 9trt. 1:3 ber 9ie= bengeielse.]

\$2. (Eine Sicrjon, weld)e währento Der Beit unter ber Straje der

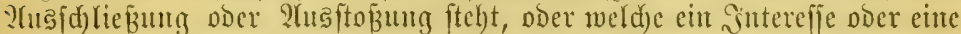

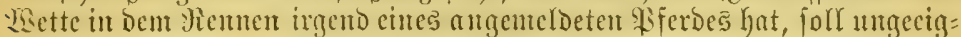

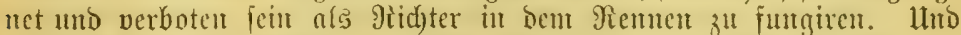
wenn irgento cine fierjon auf obige Weije als ungeeignet bezeidutet, ab=

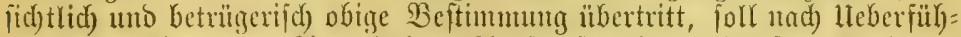

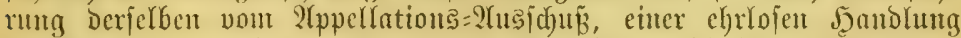

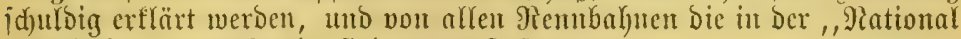

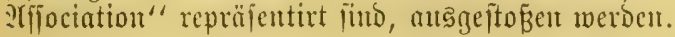

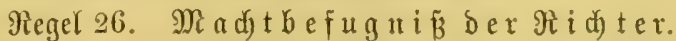
[Siehe aud) Regel 28.]

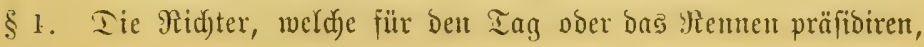


jorren bejugt pein, Entfermung, porvie Watrollirridyter und Beitfalter ;

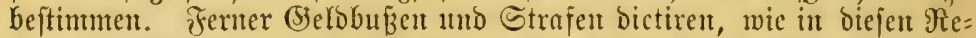
geln vorgejdrteben; forwie alle Fragen über Thatjadjen bejtumen, weld)e fich auf bas Mettremen bejiehen über weld)es fie präfibiren; Streit=

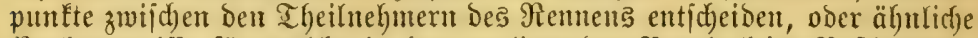

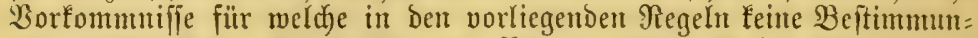
gen gegeben find. Эn Fällen von Betrug mögen fie bie Crinjäbe und isetten ungïltig erfëuren, und joll feime Thpellation nad) beren (Ent:

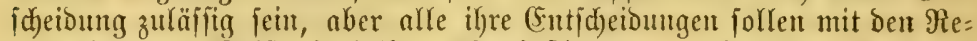
gehn ober bem Siseifte Derjelben überemittimmen. Eie jollen Sontrolle haben über bie Pferbe, meldje ben Rauf beginnen mollen, fowie über bie Reiter, Treiber und Bferbefned)te. Jm Jalle von Ungehorjam gegen

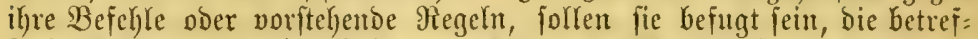

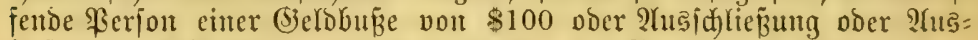

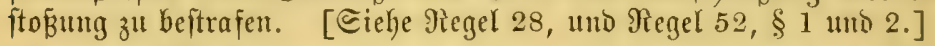

Regel 27. (Entfernuga = u

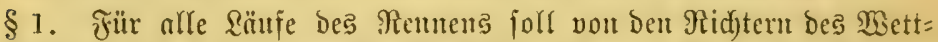
rennen, oder von Denen, weld)e Madtbefugni nungerid)ter crnamnt werben, weld)er auf ber (Entfermungs= Sribüne blei=

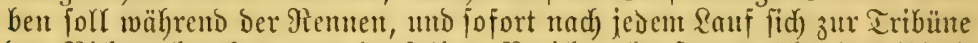

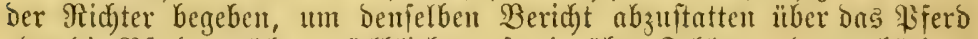

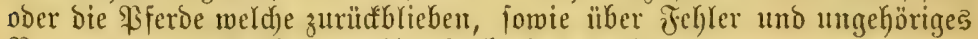
Betragen, wem joldes vou ifm beobadjtet wurbe.

§ 2. Batrollirrid)ter mögen ähnlid) crumnt werben und jolf es beren

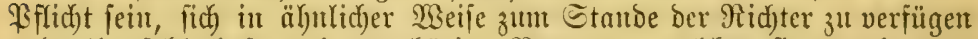
unb alfes fehlerhafte und ungehörige Betragen, meldyes fie gewafyr wer= Den, zu beriduten.

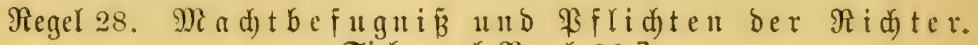
[Giehe aud अiegel 26.]

§1. Die Richter follen fich fün

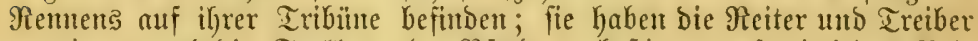

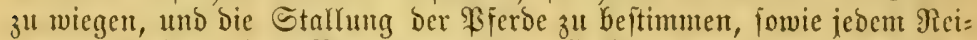

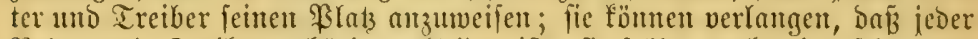
Reiter uns Treiber gehöria gefleidet ift; fie follen vorbereitet jein, von

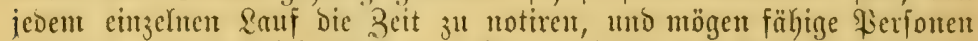
ermenten, ihnen babei Jëllfe zuleiften, unb bie fo notirte 3eit foll per=

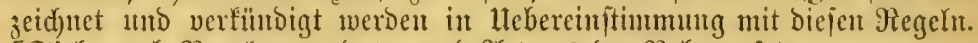
[Siche and) Regel 39 und 40, und 2(rt. 19 Der Nebengejebe.]

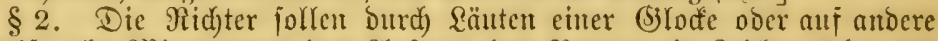

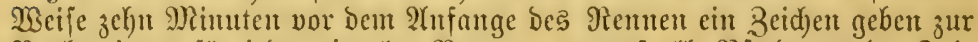

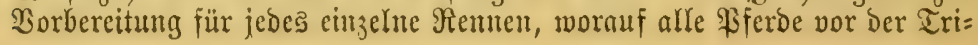


büne erid)einen follen, vorbereitet und fertig zum \&nuf. Jrgend eint Reiter ober Treiber, Der es unterläß̈t Den gegebenen Beiden zu folgen, fau mit einer Gelobuje vou nidjt mem Bferde fann bie Theilunhme an Dem Bemen verjagt werben oder e马

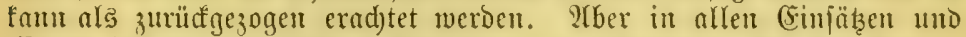
Wetten foll eit unterlnfienes (5richeinen zur beitimmten Beit ben Derfall mit Bezug aữ Die läjïigen Theilnehmer nad) fid) ziehen.

§ 3. Das Repultat eines \&aufes joll nid)t verfündigt werben, che bie

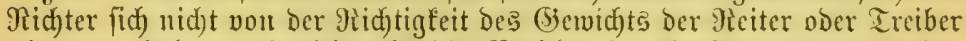

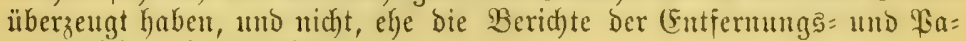
trollirridjter eingebrad)t fint.

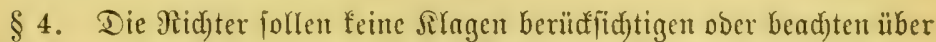
Fehler von andern Berjonen als ben (Entfernungs: und Wontrolfrichtern,

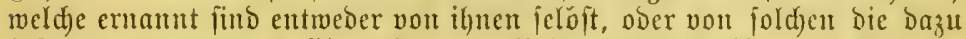

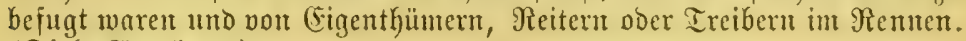
(Siebe Hiegel 48.)

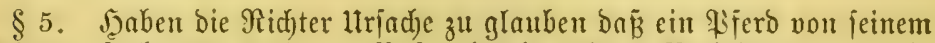
Reiter aufgehalten wurbe [pulled] ober in anderer $\mathfrak{B} e$ żiehung ungehörig

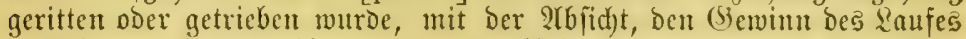
Defifelben zu hintertreiben ober zu verfinbern, weldhen es offenbar int Stande war zu gewinnen, und baj joldjes gethan wurde von Dem Reiter ober Treiber mit ber $2(b f i d) t$, ben Zauf ju verjoblagen (throwing) ober

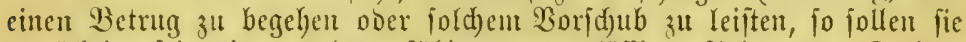
ermäd)tigt jeit einen anbern fähigen, zutuerläfigen Peiter DDer Treiber

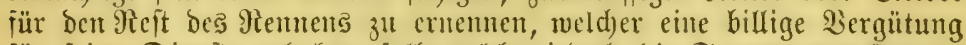
fïr jeine Diente erbalten foll, weldye jedod) bie Summe von $\$ 50.00$ nidgt überiteigen barf, weld)e von Dem Mritgliebe bezablt werben folf, uno ben Betrag von bem \&reije in 2rbjug bringen, wenn fold)er ansgefekt, melden ber nene Treiber gewinnen mag. Jrgent ein profeffitolteller Reiter ober Treiber, weld)er ohne gute unb genügende ltrjadge fid) weigert,

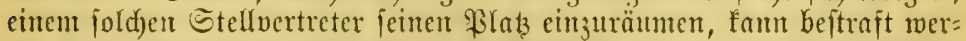

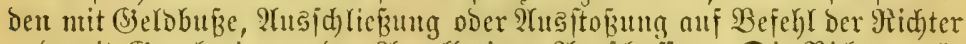

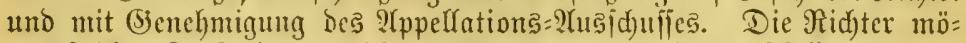

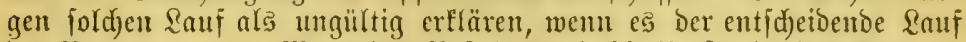

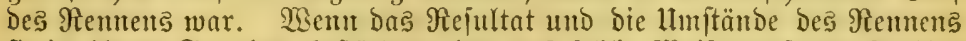
fie in ihrem (Blanben beftätigen, Der auf joldhe Mecije entfernte Ireiber

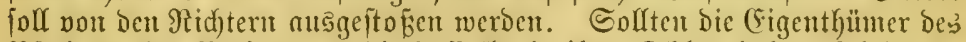
Ziferbes, ober \$erjonen weldje daffelbe in ifrer Dbhut haben, Theilnch)= mer an folden Betruge feir, follen fie famm bem Bjerbe ausgejtopen werben. (Sieke Reg. 22 und 48.) 


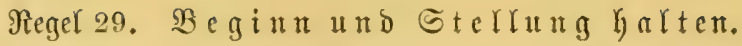

§ 1. Sien Reiter ober Ireiber folf unütbigen $\mathfrak{T}$ ufenthalt verurfadyen

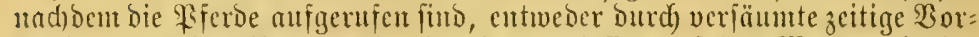

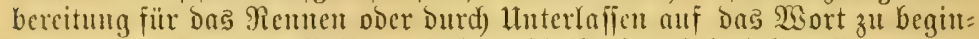

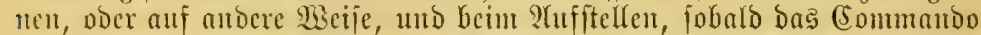
nicht gegeben murbe, jollen alle $\mathfrak{B f}$ ferbe auf eit Beichen mit Der (5ilocte

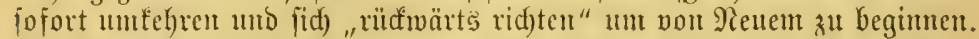

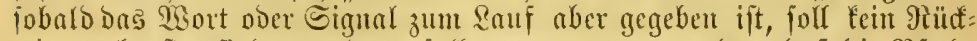

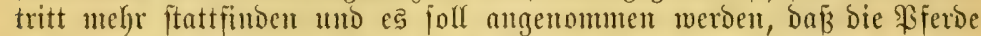

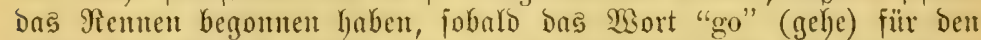
eriten Rmuf gegeben murde, unter ber Bebingung jebod), DaßB, folltent bie

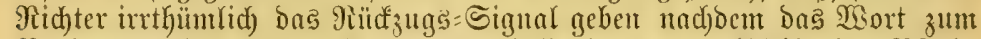

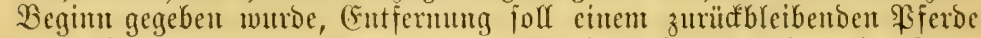

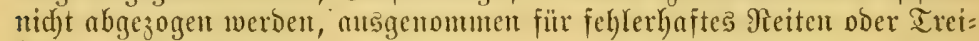
bett.

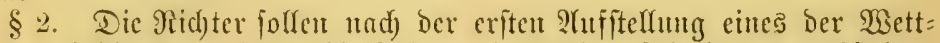
remer beftinmen wie bie Shuftellung ftattfinton foll, Das zunäd)it ben Bfable befindidye Wiferb (role horse) fam bazu beftimmt werben, wem

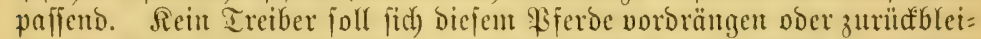
ben bei Strafe ciner Gieldbube auf bie fofort erfant und bezablt werben foll.

\$3. Reinem Treiber joll es gejtattet jein, feit Fiferd oder feitte Pferde öfter als nad) fünfmaliger ?fuffitellung mit Sd)ıamm zu reintigen.

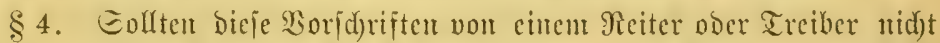

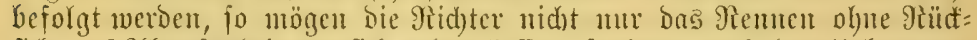
fid)t auf ?(bwejenheit vor fid) gehen Ynifen, fonbern aud Den llebertreter

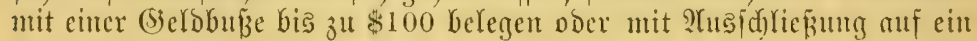
Jahr bejtrafent.

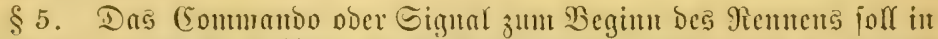
nllen Fällen vou Der Tribüne Der Siduter gegeben werben und it Keinent Falfe joll ein ftebender $\mathfrak{A}$ nfang gegeben werdent.

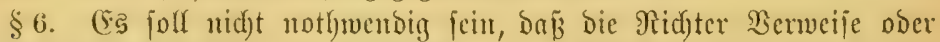

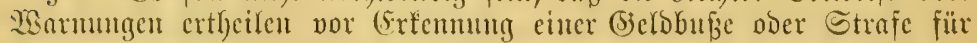

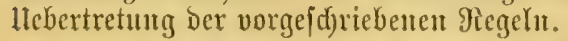

\$7. Das Bifero, weld)es einen \&aũ gewinnt, folf bein mäd)fen, Stelfung am Stmopfaly mebmen, alle mocren folfen biejelbe Stcllumg cinfalten, weld)e fie vorker intme hatten. 2Benn zwei ober melyr Bferbe

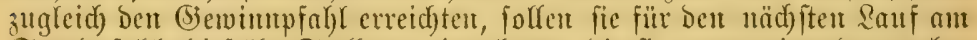
Stanopfable biefelbe Stelfung eintmehmen, die fie gegen einander vorber am Sewimpiofter hatten. 


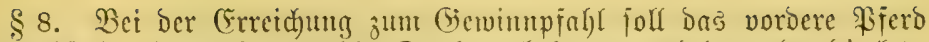

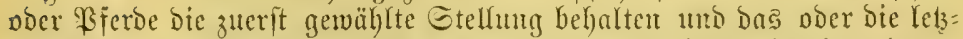

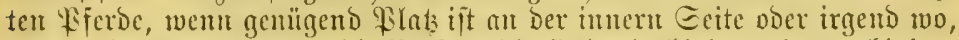
ohne andere zul hindern; bie Perion, Die fie barin Yjubert noer verbinbert joll entfernt werden.

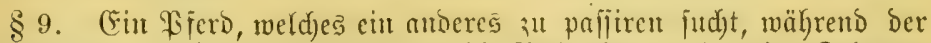

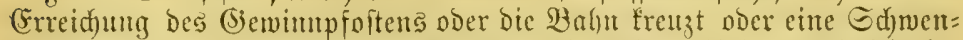

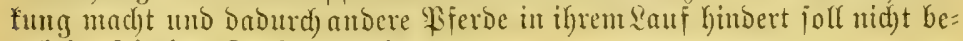
redtigt feit ben Rauf zu gewinnent:

\$10. TBeun aud ein Leitendes Pïerd ju irgend cinem Theil Der Bahn

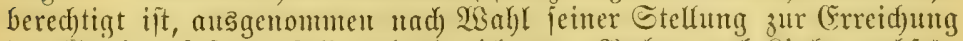

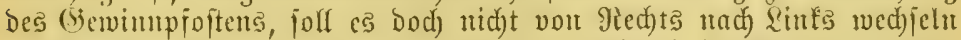

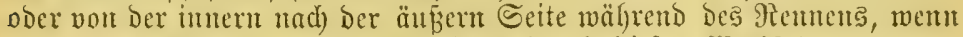

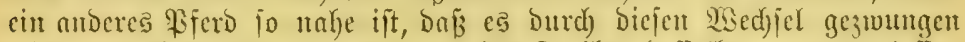

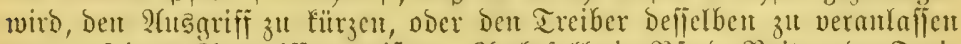

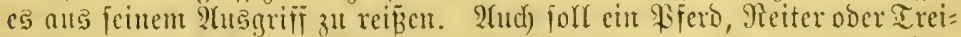

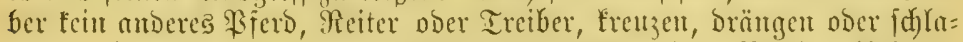
gen, nod) aubbiegen ut babud) Den Rauf emes andern Pferbes hindern.

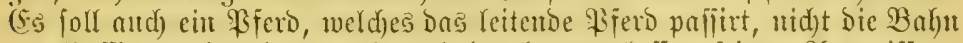

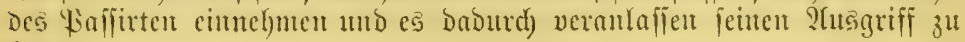
fürzen.

\$11. Golftu bei irgento cincut \&an bieje Megelu ïbertreten weroen, To foll das ïbertretende Pford nid)t bered)tigt jein Den \&auf ju geminnen und joll in bentelben hinter allen antoen Siferden ftehen. Sollte Der Beter ober Ireiber jold)e llngebörigfeit abfidgtlid) begeben, fo fant für Deffen Siferd anf Entfermutg crfant werben und Der Yeiter ober Treiber

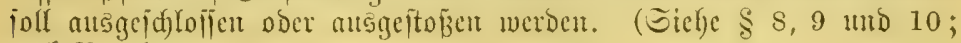
audi) Regel 48.

\section{Regel 30. Sd) rittäuberung Der $\mathfrak{B}$ ferbe.}

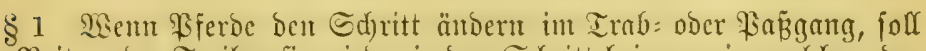
if) $\Re$ Reiter ober Ireiber fie wieder in Den Sd)ritt bringen, in meldyem Der Wettlauf gemad)t werben jollte. Interläbs er Das, jo joll er Den Rauf verloren habet, aud) ment er zuerft hen (bewimpfahl erreidat, und Das

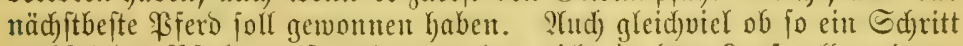
wed) Felnbes Pierd zuerit anfonmt ober nidyt in bem Rauf, alfe anberent

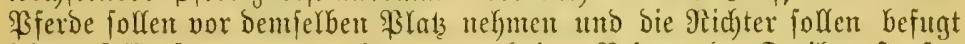
fein nuf (5ntfermung zu erfeumen, anch) Den Reiter ober Treiber itrafent

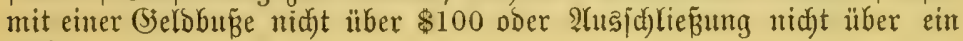
șalyr. 


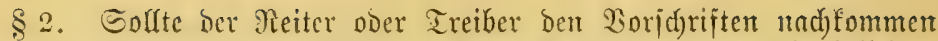

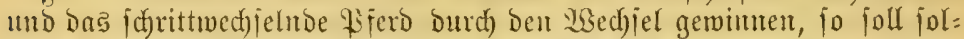
d) Cut Bferde Das Doppelte Des gemomenen Boriprunges abgezogen wer=

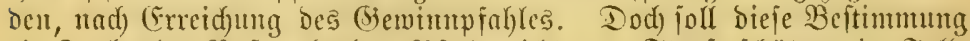

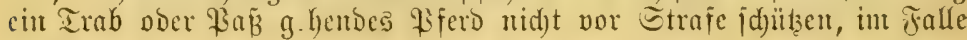
ç่ ไäแก๊t.

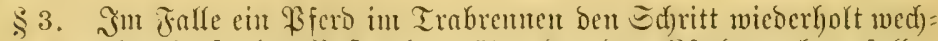
felt, entweber lüut oder Wabj geft, während andere Wiferbe traben, jolfen

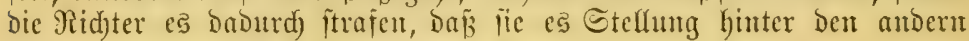

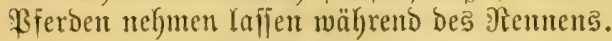

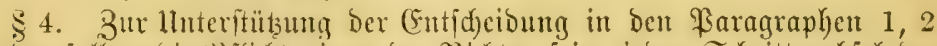

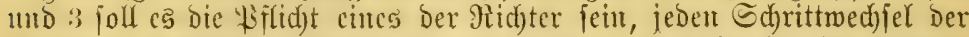
Fiferde zu verfünden und Dos betreffente Pferd Durd) Farbe ober Ramen

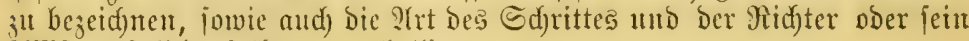
2rifitent joll benielben protofolfiren.

\$5. (Sin \$Ferd, weldes am ober nafe beim Stanopfahle ben Sd)ritt wed)ielt, foll benjelben Strafen untermorfen jem, als ob Dafjelbe auf irgent einem andern Theil ber Bahn gejdefhen wäre.

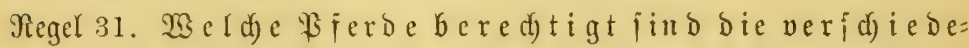

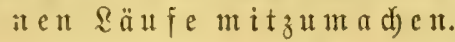

\$1. J゙ \&äufen vou chter, zwei, brei ober vier Meilen, foll ç einem Wferbe, weldyes feinen in ben erîten brei Sänfen mad)t, nicht geftattet jein bet vierten mitjumaden, ansgenommen es ift mit cinem anbern zugleid)

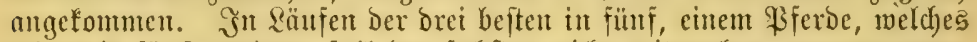
feinen in fünf gewinnt, foll ben jechften nidjt mitmad)en, ausgenommen es it mit einem andern zugleid) angefonmen. Dod) follen jo ausge=

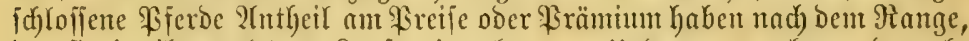

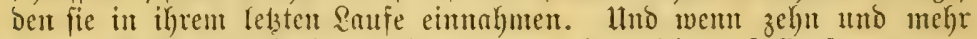
Pferbe in Renten beginnen, jebes, gegen bas nid)t auf (Entfernung er=

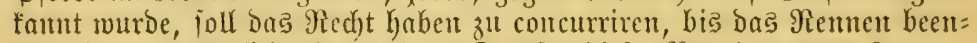

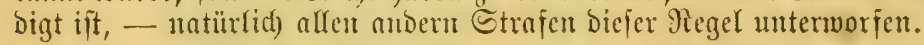

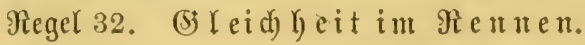

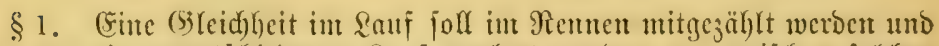

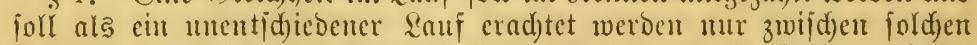
Wiferden bie gleich ausgetommen fund und foll als ein Zauf angejeben merben ben alle andern Piferbe verloren haben, Die ifn mitmad)ten; und bie 3eit, weld)e in bicjem (Gleid) Iauf gemtad)t murbe, foll cine llifunde (record) jein, ober Girenze (bar) für jedes Pferd, weldyes fo eben mit

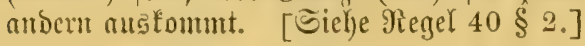


§ 2. Went eines ber Pferde, melde gleid) ausfommen, Das Rennen entidjedent haben witroe, in Falle es in bem \&aufe gerwomten hätte, io follen fie nod) cimmal beginnen.

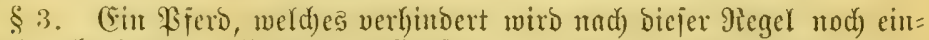
mal zu beginten, folf nidgt auf Entfernuth erfannt werden, fondern ans= rangirt und joll 2(njprud) haben auf einen Theil bes Freijes ober $\mathfrak{B r a ̈ =}$

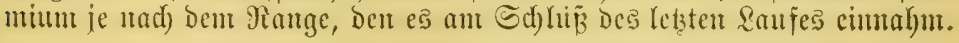

Jiegel 33. Beit zw wif den be n $x$ äu fen.

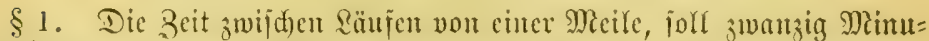
ten betragen; und für Meilculäufe ber be ten brei in füuf, f̈̈nfunbzwan=

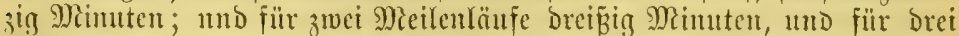
Meilenläufe fünfunboreib̄ig Mimuten und für vier Mcellenläufe fork bie 3eit vierzig Mimuten fein.

\$2. Midut melyr als jwei verjobicone Mettrenten folfen gleidjzeitig abgehalten werben (sandwiched) an einem Tage. TSem aber cine ber

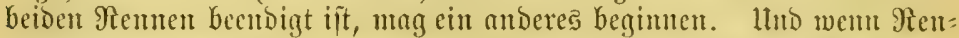
men gleidyseitig ftattfinden, bas zuerft begintmende joll möglid) ft bie ge= jeţte Beit einfalten.

\$3. Эadd) Dem eriten \&auf follen bie Biferde fünf Minuten vor Be= gintm bes nüd)ften aufgerufen werben.

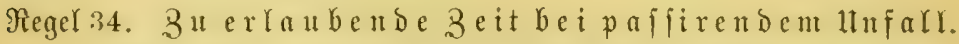

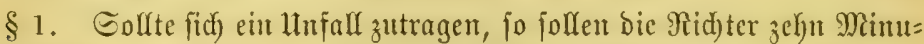
ten geftatten, and) mehr in Falle fie es für uothwentig und rathjam er= adten.

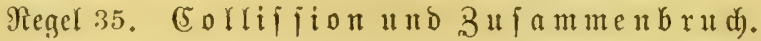

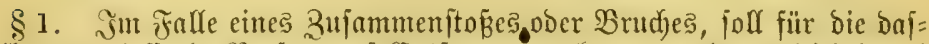
ielbe veranlaffende Perjout auf Sutfermung erfaunt merben, gleidjviel ob mit 2rbjicht ober nur zufällig ber llnfall herbeigejübrt murbe. Gollten

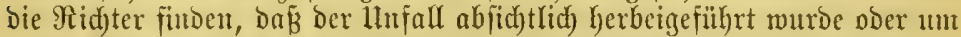
einem Setrug Zorichub zu leiften, fo foll ber jduldoige Ireiber fofort aus= geld)lofien oder alsgeftoken werben, und für fein \$ferd fant auf (Fntfer= ung erfaut werben. SIem aber nothmendig un einen Betrug zut hin=

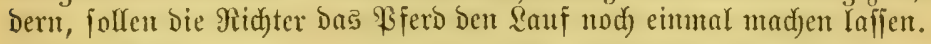

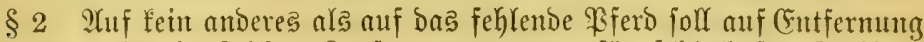
erfant werben in joldyeu $2 a u f$, ausgenommen für feblerbaftes Treiben.

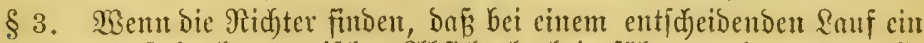
3ufammenito in betrügerifder 9rbjidyt herbeigefübrt wurde, mögen fie Denjelben ungültig erffären. [Siebe auch Regel 48.] 


\section{Regel 36. Rang ber $\mathfrak{B}$ ferde.}

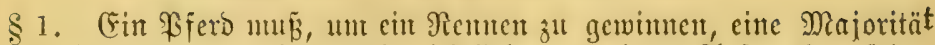

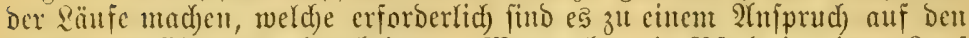
Breis ober (Eimatz zu bered)tigen. Went aber ein \$ïerd un cutem \&auf

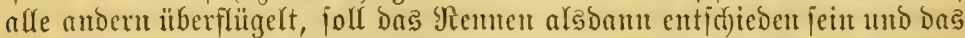

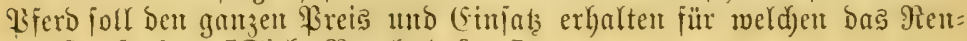

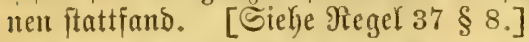

\$2. Wenn mely als ein Bferd bered)tigt jein follte, ben endenten

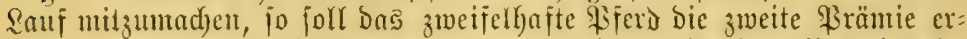
falten, weut eme vorbanden. Ilıb wem britte und vierte \$rämien da

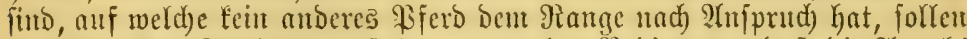

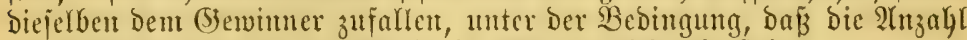

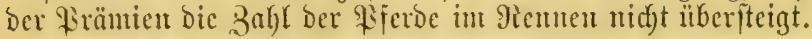

\$.3. Dic vorembälynten Bebingungeu jolfen mu baun aumendbar jein weun feine anderen pubrizint watroen.

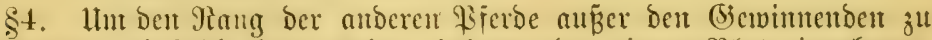
beftimmen, ob joldje Den zmeiten, britten ober vierten \$latzemehmen,

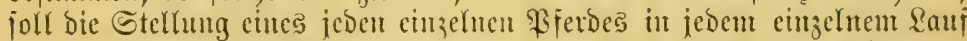

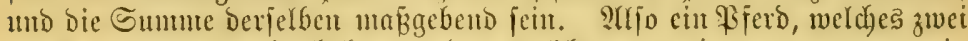

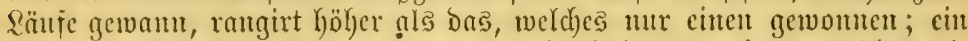
Bfert, weld)es cinten Rauf gewant, rangirt höher als emtes, weld)es mit eitrem andern zugleid) antam, cin ßjerb, weld)es cinen ober zwei \&äufe gewimnt und auserbem it cinem Qaupe mit einen andern zugleid) anfant,

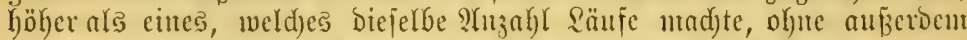
mit einem andert zugleid) cinen Samf zu gemimen; cin \$iferd, weld)es

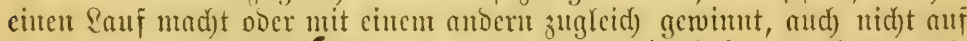

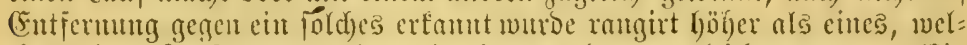

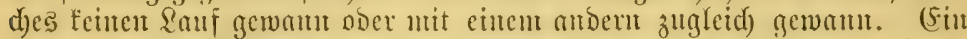

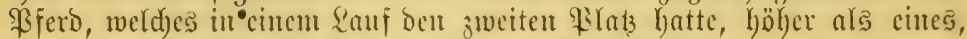

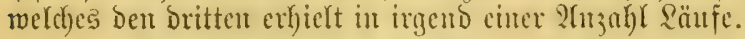

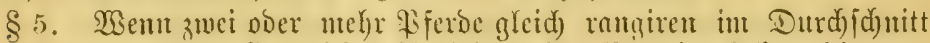

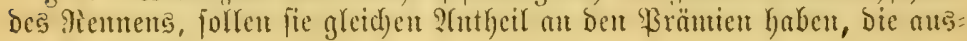
gejetzt murberr.

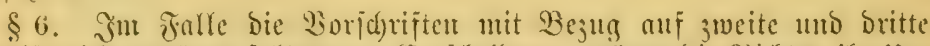

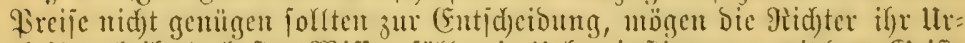

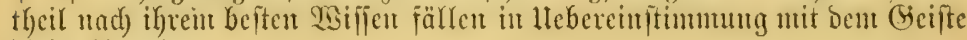
biejer Regeltr.

\section{Regel 37. (E)}

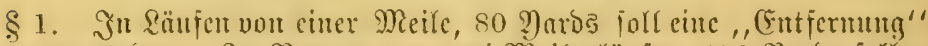

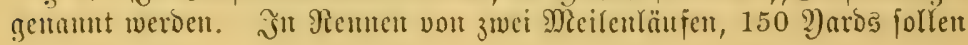




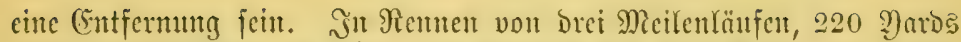
follen eine Entfermung feir. Ju Renuten von cinter Meeile, Der bejten brei in fünf, 100 श)arbs foll cinte Entfermung fein. Sin 'ë̈ufen vou nid)t

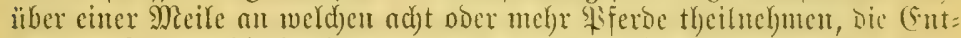
fermung foll un bie すälfte verlüngert werbeu; aber un irgend cincm ¿anf,

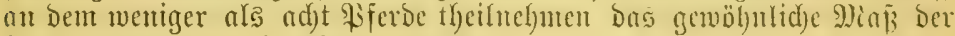
Entfermungen fort eingekalten werben.

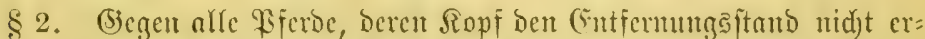

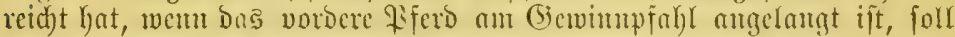
auf (Sntfernung erfannt verben, aubgentommen in fold)en Fällen in Denen

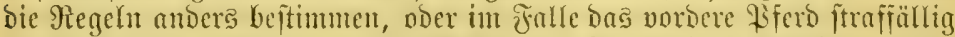
ift für Ranfen, beftehend in Bun̈efietzen bes ftraffülligen Siferdes, wenu

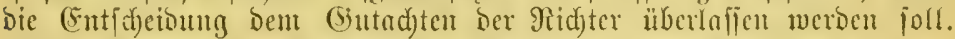

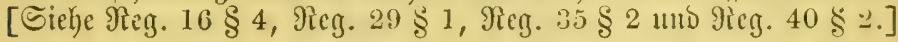

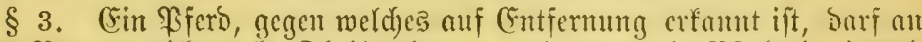

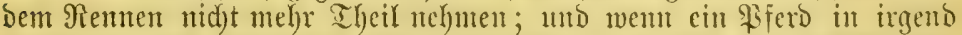

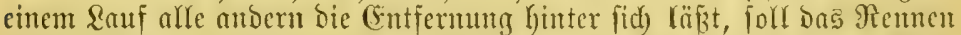

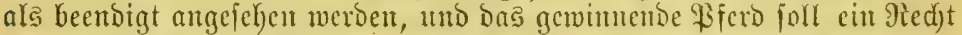

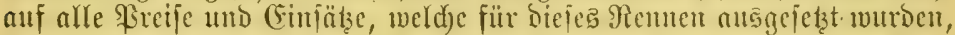

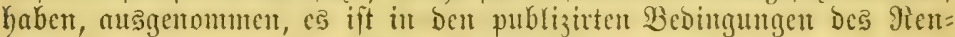
nent anders beftumut. [Sieke Regel $36, \$ 1$.

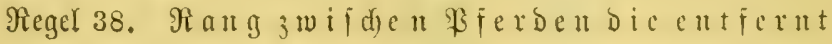
blieben.

§1. Bfferbe, meld)e cine (5ntfermung 3urüdblieben im eriten \&auf bes Wettrentens, jollen gleid) eradytet werden ; aber \$iferde, weld)e eine (Ent= fernung in irgenb cinem ipäteren \&auf zurübbleiben, follen rangiren in berjelben Srbmung zu ber fie beredftigt maren in Dem saufe, in Dem fie zuerjt bie Entfermung zurüdfblieben.

\section{Regel 39. Beit u}

\$1. Sin allen öffentlid)en Saettrennen foll bie 3eitbanter jebes cin= zeluen Laufes gentu vermerft und gebud)t werben; und und ber (Ent=

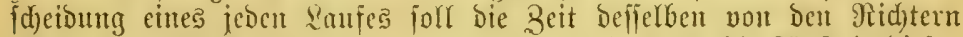
offfentlid verfünbigt merben, ansgenomuten wie es für bic \&äufe in biefen Regeln bejonders beftinmt ift, went feine ber vordeten Pferbe bas ge= ivinuende ift.

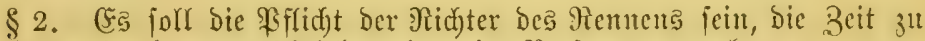
notiren wie oben vorgefdrieben ober eine \$erjon ober melyrere ju ernen= 


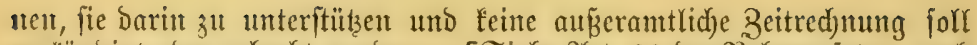

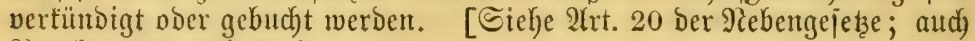
Piegel 40, 41 und 43.]

Hegel 40. Die Beit der reitenden ßerbe fort für jebes bejondera gemert werden.

1. Wou zoei Keitenden \$ferben folf non jedem bejonders bie Seit notitt werben und aur bie Beit besientigen, weld)es ben \&auf gewann foll verfündigt werben unb eine lltfunde ober Girenze fein je nadjoem es ber

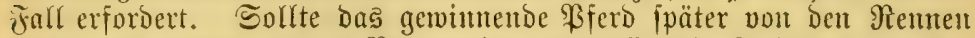

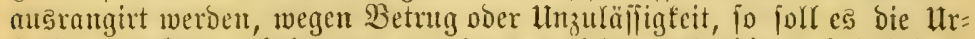
tumbe ober (Sirenze Gehaupten, weld)e es nad) ber vertündigten Zeit fid er: worben. [Siele aud $\Re e g .39,41$ und 43.]

5. 2. Im Jalle zwei ober nehr \$ferde zugleid) anfommen, baher gleiche Beit gemad)t haben, foll diejelbe als llrtumbe ober Sircnze für oie betreffenden \$fferde gelten. Hnd went wegen irgend einer ltrjadje ber

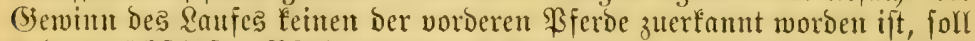
er bent näd)ftbeften ßiferbe zuerfunt merben ohne Beitangabe von Setten

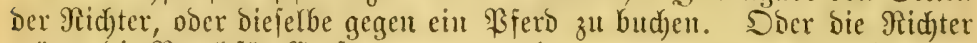

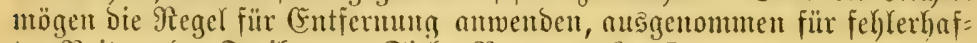

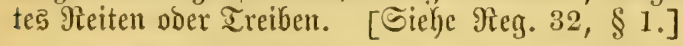

Regel 41. Unterbrü d̛ug ber gemadjteu Beit.

\$ 1. Went in eintem öffentlidjen Wettrenten bie gemad)te Beit irgend

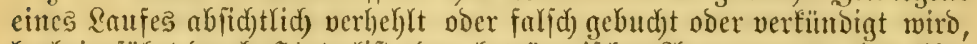

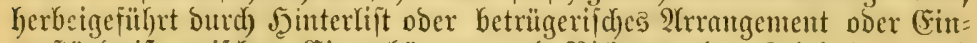

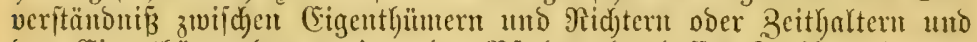

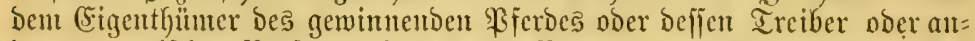

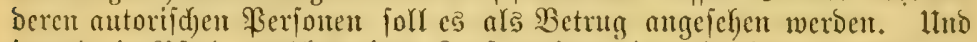

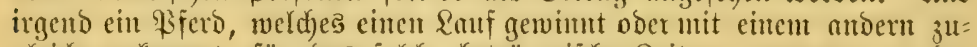
gleid) anfoumt, für bas joldbe betrügerijd)e Beit angenommen wurbe, forl mit alfen Theilnebmern an ben Betuge fofort ausgeidjlofien wer: Den. [@ieke Regel 39, 40, 43 unt 44.]

\section{Regel 42. (5in öffent i id)es $\mathfrak{B}$ ettrennen.}

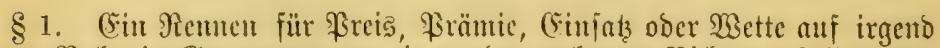

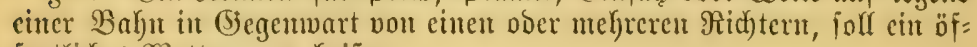
fentfides Mettrentuen Geipen.

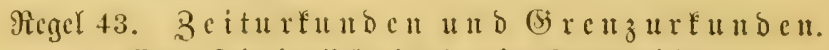

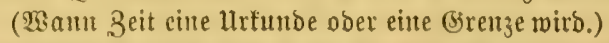

$\$ 1$. Cine Urfumbe fam vou jebt ab mur crbalten werben auf cimer 
Bahn ber Mitgliebe ber Rational Trotting Hjpociation in cinem öffent=

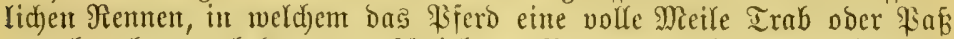

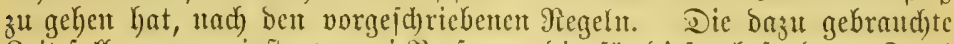
马eit folf von wenigftens zwei \$erjonen, die für biefen bejonderen 马wedt ernannt futo, vermerft werden und beren Namen nebit ber vou hnen be= obadyteten Beit aufbewayrt werden.

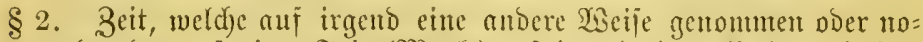
tirt wurbe ober auf einer Fair (Marft) auf irgend ciner bahn, ob fur; ober nid)t, foll unter beu Namen "Sirenze" (bar) befount jein, und foll

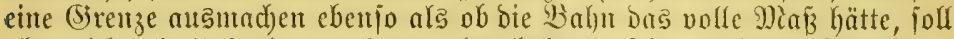
aber uid)t als lltEmbe anterfannt ober befaut jein, aud fein Berveis zu (5)unfen cines Bferdes nit Bezug auf gemad)te Beit.

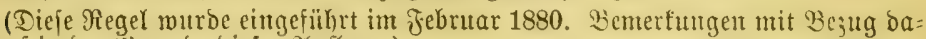
rauf in ber Worrebe biejer \$fuflage.)

Regel 44. We n n Zeit $\mathfrak{f}_{\text {e }}$ ine (5) renze ie in folr.

\$ 1. Beit unter bem Sattel gentad)t, fowohl Beit von zujammenge=

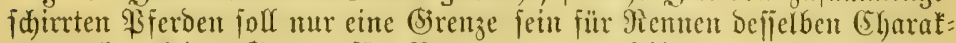

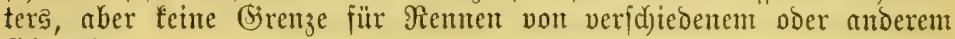
(E)arafter.

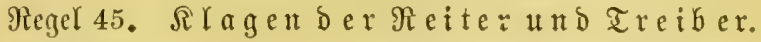

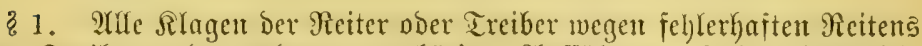
ober Treibetts ober anberer ungehöriger 2 Hfführung, jollen eingereidyt werben nad) Beendigung Des Raufes ehe Der Reiter abjeigt oder ber Treiber fein Gejährt verläß̄t.

\section{Regel 46. Be tragen.}

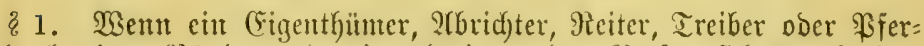
Defued)t cines Sferbes, ober irgend eine andere \$erjon fid) ungehöriger

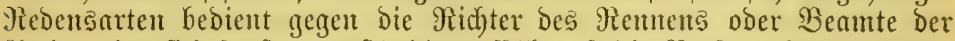
Sabn, oder fich jonft unanitändig aufführt, fold) ßerjon ober ßerjonen jollen beitraft werben, mit ciner (Stersbube nid)t iiber $\$ 100$ ober burd)

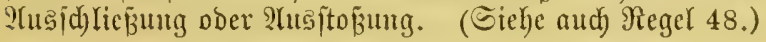

Regel 47. Rautes Schreien.

\$1. (Ein Pieiter ober Treiber, Der fid) erlaubt laut zu Schreien ober anderes unziemtidbes (Sieräujd) mad)t ober ungehörigen (Siebraud) von jei=

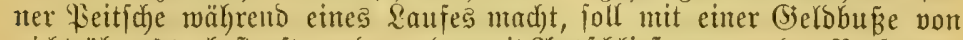

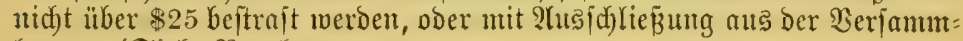
lung. (Siehe ßegel 48.) 


\section{Regel 48. Fe hrer.}

§ 1. Tुent von irgent einent (Eigenty)üner, Feiter, Treiber ober De=

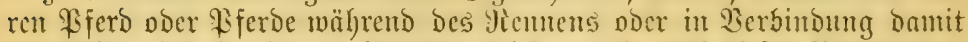
che That ober Samblung Kegangen wird, welde nad) Dicjen Fiegeln ober

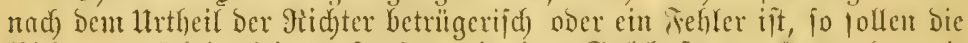

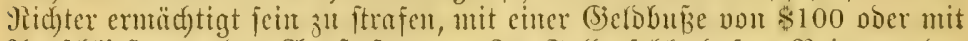
2(แ⿰㇒⿻二丨冂) Ireibens foll gegen bas ïbertretende 2 iferd auf (Entfermutg ertant wer:

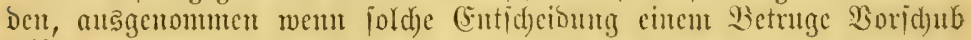
leiptet.

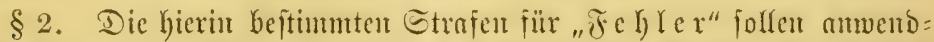
bar jein auf irgento eine Jandung betrïgerifder Siatur ober efgrlojes Betragen, weld)es gecignet jein wïrbe Den (5Garafter ciner Sicubahu in Den $\mathfrak{A}$ ugen bes ßublifume veräd)t(id) erid)einten zu Iafi en.

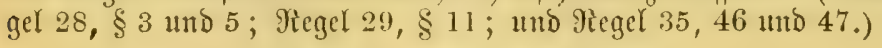

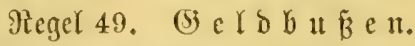

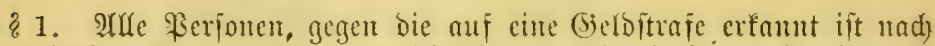

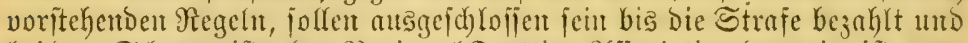
bei Dem Schabmeifter Der 9ational Trotting ?lifociation beponirt iit, aus=

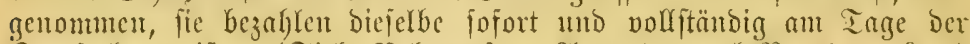

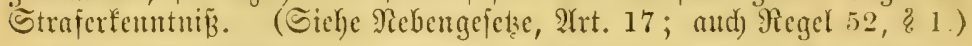

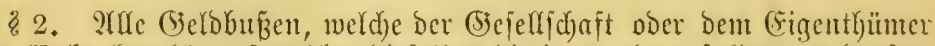

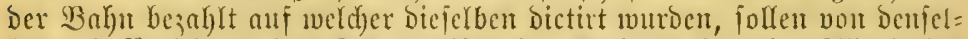

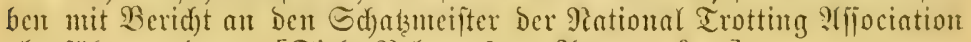
abgefïlyrt merben. [Sielge Mebengeictse, 21rt. 12, \& 4.]

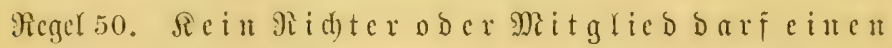
Zergleid) eiugefenbezüglid ber Strafen.

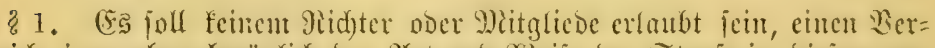

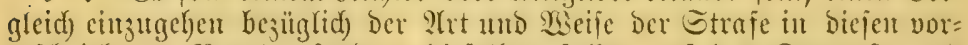
geid)riebenen Regeln, pondern biejerben folfen auf Das Strengite แn

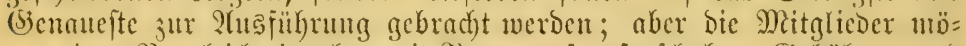

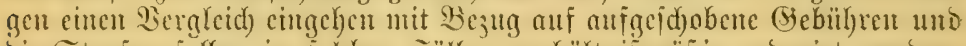
bie Etrafen follen in jold)en jällen verbältnïmtäßig reducirt werden. [Sieke Regel 52.]

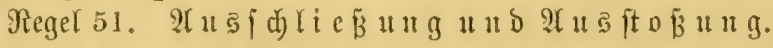

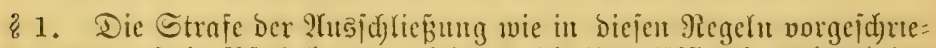

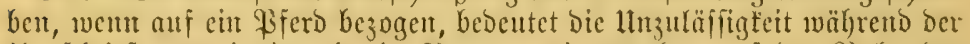

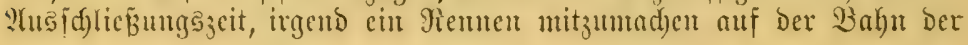




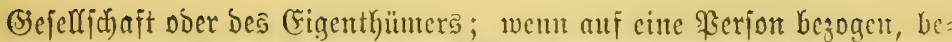

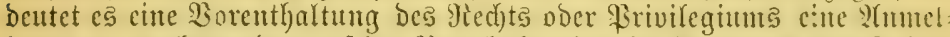

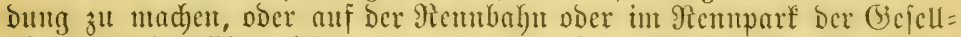
id)aft ober Des (sigentfümerg zu reiten, treiben, abrid)ten ober bülfe lei=

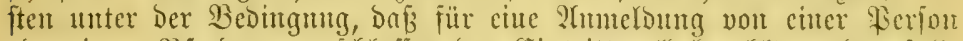

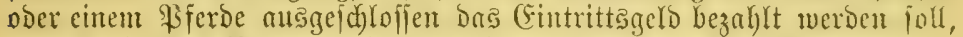

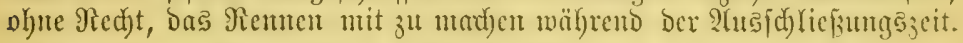

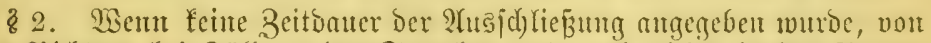

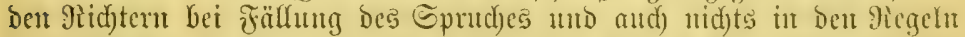
vorgefdrieben ift, was muf ben vorliegentoen Tall paffen wïrbe, foll bie Strafe fidc) auf bic Dauer ber Gaijon befdräuteu, in ber Dus (Frfent= niß̧ gefällt wuroe. [Sieke \& 7. .]

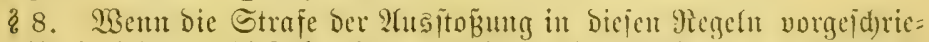

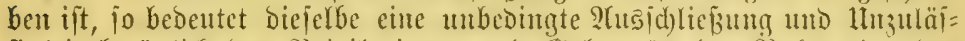

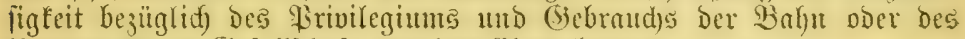
Memuparts Der (Sejelfichajt ober Des (Eigenthümter.

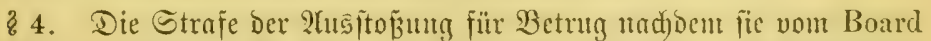

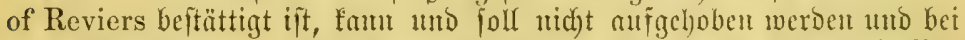
einer Ifppellation an Das Board of Reviers foll Der 2Tpplifant bie Be=

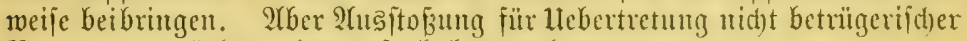
Ratur mag geänbert noer aufgefoben merben.

85. (Sin Mitglied Der Pational Pljociation, weld)es cintent angeitoj= jenen Manu ober Fiferde den (Gebraud) feiner Bahu geftattet, nadjoem er vom Eefretär Der Mational 2 fjpociation Motiz erbalten bat, joll mit eimer Sieldbuje von $\$ 100$ beftraft werben.

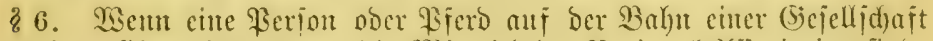

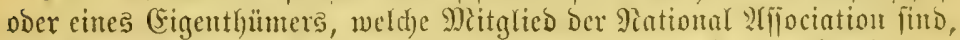
folf Der Sefretär Der Siational 2(fipociatiout fofort burd) gedutffe ober ge= fdrtiebene Notiz benad)ridytigt werben, folgende Nugaben cutfaltend:

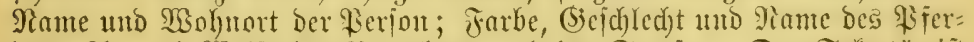

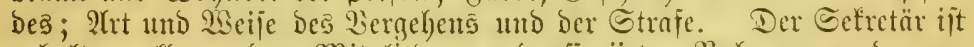
gehalten, alfen amberu Mitghiebern un afjocitrten Babnen von ber cr= baltenen Motiz Mittheilung zu mad)en, woutad Dam ber jo beitrafte Ue=

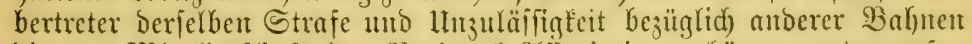
bie zur Mitgliebidaft Der Mational 2rifociation gebören, unterworfen jein jolf.

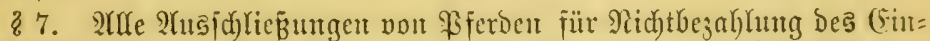
trittsgeldes, jollen jed) Sa Sahre nad) Dem Datum Des gefällten (Erfent= nifjes verjährt jein. [Dieje Bejudräntung bezieft fich aber nidjt aut? ßerionen.] 


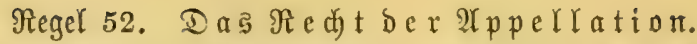

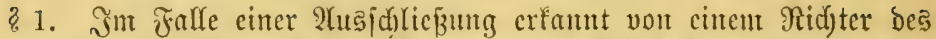
Micnten, ober ftellpertretenden Seamten Des Mitgliebes, fam an eit

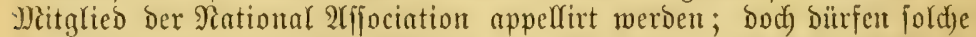

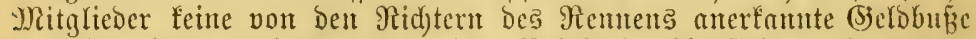

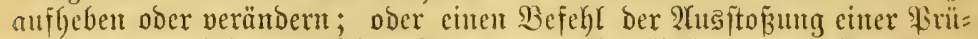

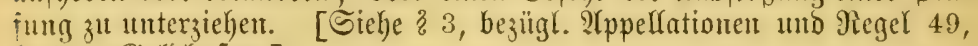
bezügl. (S)

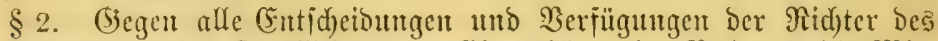

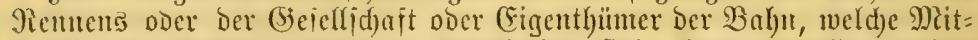

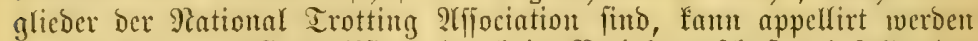

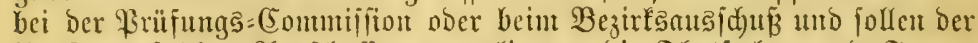
Briffung folden 2(usjdulfes unterlienen, bie Ihatjad)en und Fragen

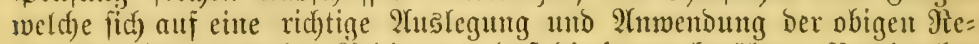
getu bejieben, unter ber Desingung, on bie Davon berïhrten Partien be=

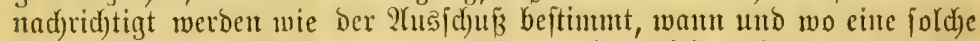
2lppelfation eister Brïfung unterworfent werden wird, und unter ber fer:

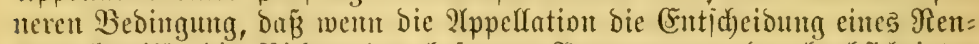

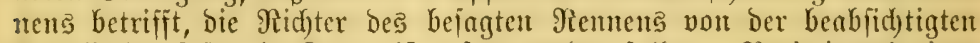
2lppellation fofort in Renntuip gejebt merben follen. Noti; irgend einer

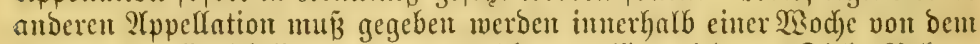

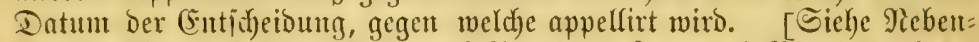

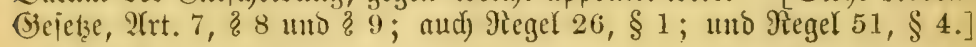

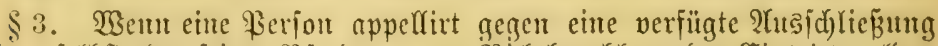

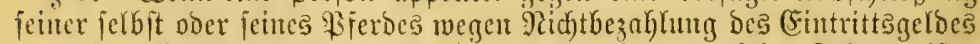

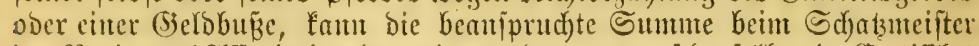

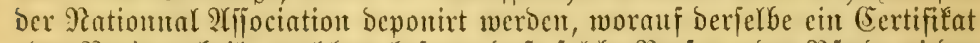

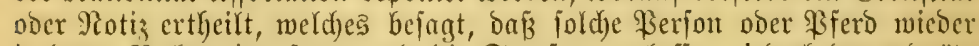
in beren Red)te einzuleben un bie Gtrafe zu erlafien, jebod) Der entogül=

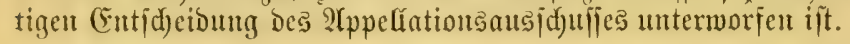

Neger 53. Thtereine

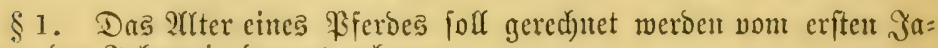
muar bes Jafres in Dem es geboren.

Regel 54. Fürleu u u Stutenfürleu fit g gleid) bered)tigt zur $\mathfrak{A} \pi$ u e lD $\pi \mathrm{g}$.

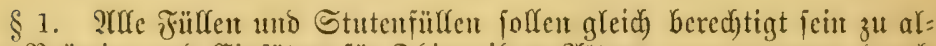

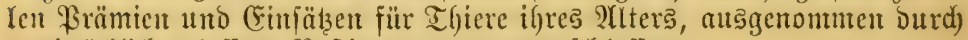
ausorïdfid) etlaffene Beitimmungen ausgeid)loffen. 


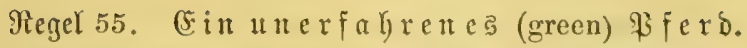

\&. 1. (Ein unerfabrentes Piero ift cin foldyes, weldyes nod) nicmala ein

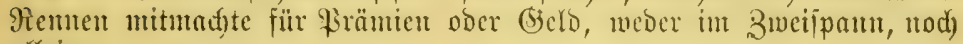
alleitr.

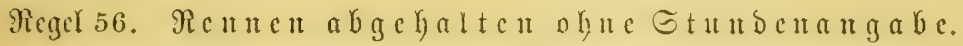

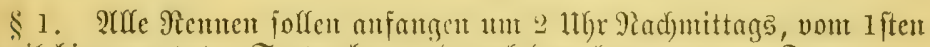

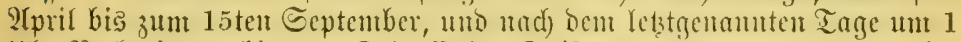

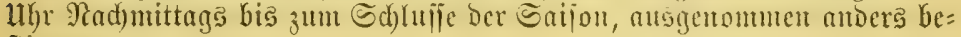
itimmt.

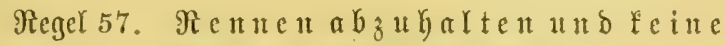

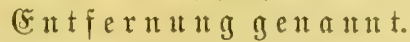

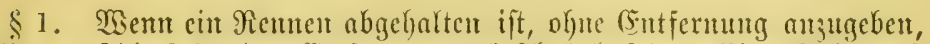

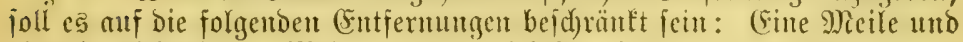

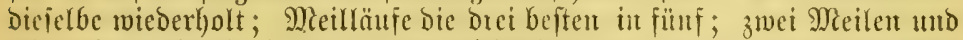
mieberfyolt, ober brei Mecilent unt wicberholt, unb mögett ausgefülyrt wer=

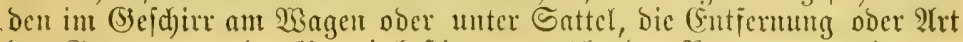

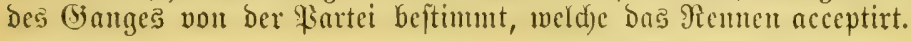

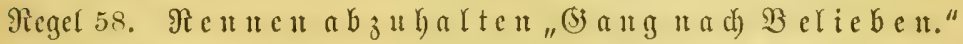

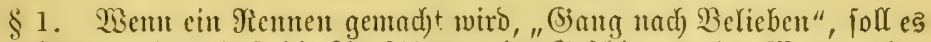

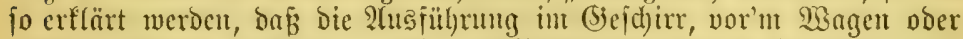

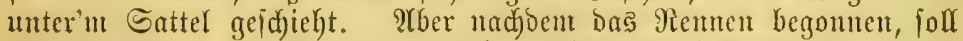

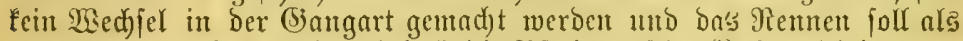

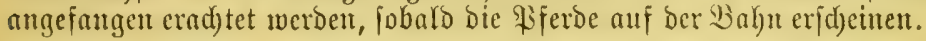

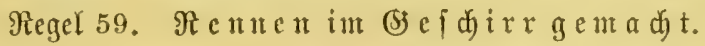

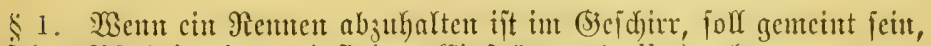

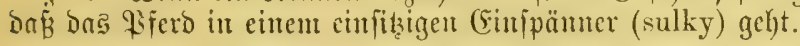

Regel 60. Sienuen gegen 3 eit.

\$1. Bent ein \$iero engrgirt wirb, gegen Beit zu rennen, fo jolf

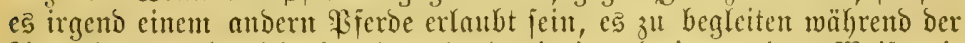

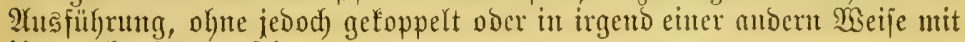
ifm verbunben zu feir.

\$2. In is ngagements gegen Beit, bie \$Bartei weldje baffelbe einge=

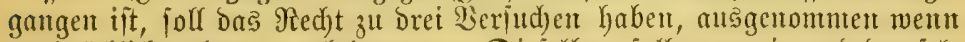

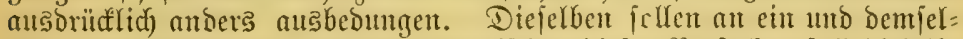
ben Iage ftattfinten uno bie Beit zwifident biefen Berfuden foll biefelbe fein, als bie 3cit zwijden ben \&äufen gleidjer Entfermutg. 


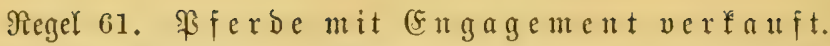

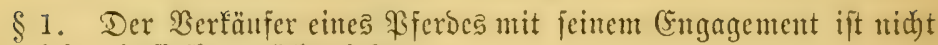
bered)tigt, Daflelbe zurïd̆łuzichen.

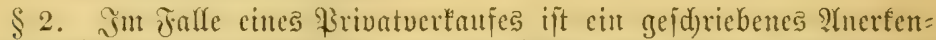

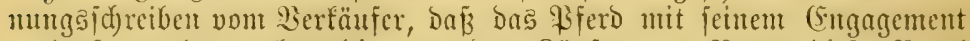

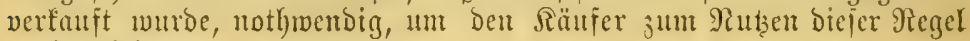
zu berect)tigen.

(Sinte wal)re Ropie Der Urfunde, Den 12 ten Febr. 1880.

Ihom. S. $\mathfrak{B a i r}$.

\section{0 et tregel}

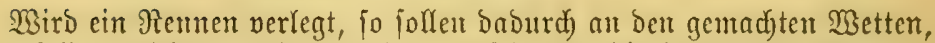
"pools" 2c. nidbts geänbert werben, ę jei benn, bie betreffenden \$arteient

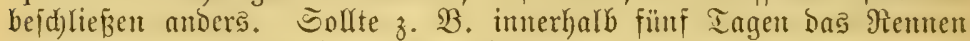
itatfinten, fo find nad) ber Beit alle smetten zc. verfallen, ausgentom= men fie jeien, "Spiel ober Bafll" gemad)t.

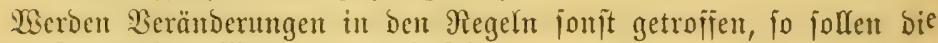
Darauf gemadjten Wetten ungültig jein.

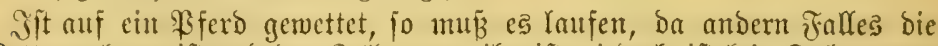
Wette verloren ift uns Dos Feld gegen ign ijt; jebod iit fein Feld, weun nidgt werigitens ein Rauf gemadyt wurbe.

Bei 2 etten fonmen bie "pools" auf für alfe \$fferde, bie laufen; für

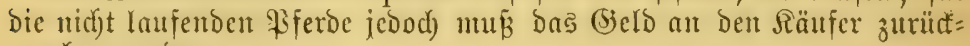
gegebert werdett.

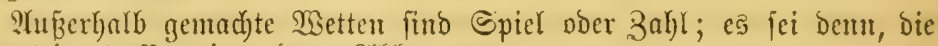
Barteien treffen ein anderes 2rbtommen.

Sn Rrantheitgfafle einer ber wettenDen Fartcien ift bie Wette ungül=

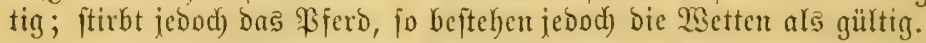

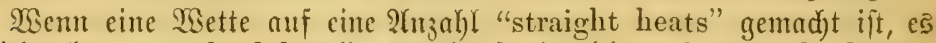
wirb aber mur "dead heat" gentad)t, fo hat bie auf "straight heats" wettende $\mathfrak{\text { Sartei verloren. }}$

(5rtfären bie ßid)ter ein "heat" für ungültig, fo merben Davon nid)t bie Metten betrofien, bie im Falle eines "dead heat' gegen "straight. heat" gemad)t wurden.

Wenn cure Partei mettet, Daß̧ cin Rauf in 2 Min. 30 Sef. gemad)t wirb, und cs twird bie Streffe in Derjelben $(2: 30)$ ober it nod) fürzerer 
Beit zurïdgelegt, jo hat bie \$artei gemonnen. Wettet Dagegen Jentant, Daß̉ ein Rauf in weniger als 2 Min. 30 Sef. gemadyt wird, Der Lauf́ aber genau 2 Min. 30 Eef. nimmt, jo i jit bie Mette verloren. Miadht jemand eine Wette gegen bas Feld auf 2:30 und bie Beit wirs gernde eingehalten von bem \$frerd, jo ift bie 2 Sette für beibe Parteien gleid) (a tie or draw bet). 2ufe Beitwetten find Dem Worjtehenden nad) zu beut= theilen.

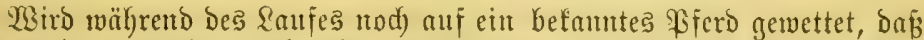
es gewimnen werde, ntad)t aber dead heat, fo ift bie \$isette nid)t guiltig.

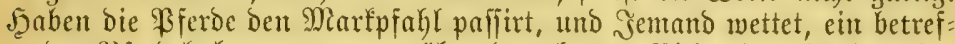

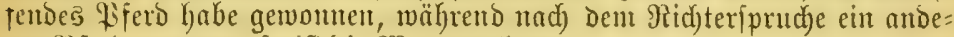
res Bfero gemann, jo ift die Wette verloren.

Benn Jemand Den Pferden in einten Rnupe befondere Blätze antweift,

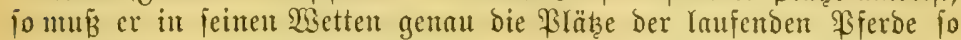
etwa bezcidjen: erftes, zmeites, 2 .

Die \$iferde follen im übrigen fo aufgeführt werben bei cincm Mettlau= jen, wie ber offizielle Bericht fie anzeigt.

Wetten auf nidgt zugelajlene Bferbe gentad)t, fino ungültig; ober bie Metten jeien Spiel oder Babl.

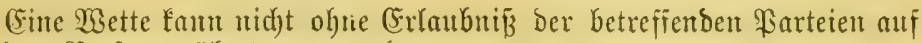
andere \$erionen übertragen merden.

TGent auf bie Raufzeit eimes \$ferbes getwettet wiro, fo foll babei nur bie auf einer öffentlid)en $B a h n$ erreid) te Beit in Betrad)t fommen.

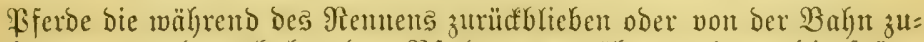
rüafgezogen wurben, Gaben ben \$FFroen gegen̈̈ber verloren, bie ipäter

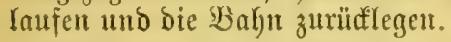

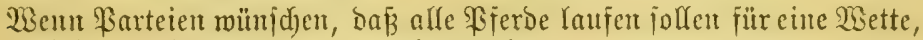
jo mut bas gletc) anfangs angezeigt weroent.

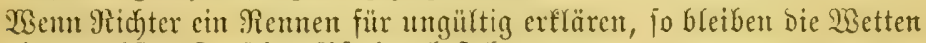
für ben nädhiten Raü dę \$sferdes beitehen.

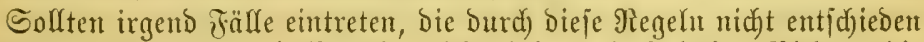

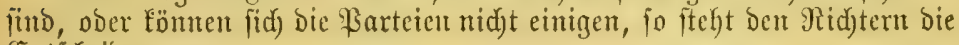
(Entideibung zu.

(Seminnt ein Pfero bie Sette, weldes nidyt an ben "pools" verfauft murbe, jo erhält Das \$Ferd, weldjes an ben "pools" verfauft wurbe uno am beften lief, bas Sieldo. 


\section{Beugnisse.}

Feuerwehrsamt ber Stabt (5hicago,

Bureau bes Feuermaridalls, No. 2 Duincy Straßße, (5) hica g 0, Эแล., ben 10. كept. $187 \%$.

\section{थี $\mathfrak{n} \mathfrak{I} \mathfrak{I e}$, bie es a ngeht:}

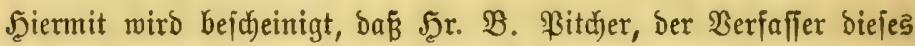
Buches, als ein volfftändig unbefannter zu uns getommen if und feine

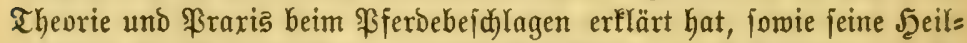

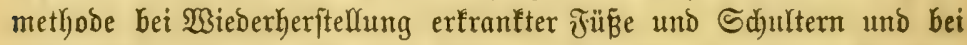
Bebanolung ber fo erfinatten $\mathfrak{P f e r b e . ~ D a ~ m i r ~ i n ~ u n j e r e m ~ B e r n a l = ~}$

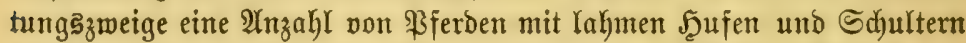
hatten, gaben wir ihm eine (Selegenbeit, einen praftifden Serjud mit jeiner Methode anzuftellen, während er fein Bud Der Deffentlidjete zu übergeben im Begriffe ftand. Wir wollen behaupten, baß̉ er währent ber ßeit, ba bie \$ferde von ihm behandelt wurden, mehr (Erfolg gehabt,

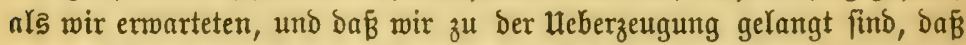

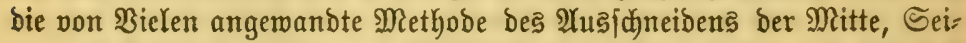

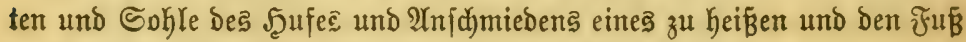

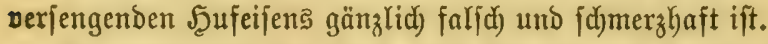

Wir empfeblen jein Buch, feine Theorie uno \$raxis alfen (sigenthü=

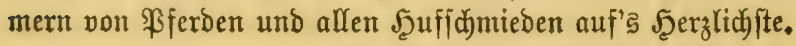

Mr. B e n n e r, Feurmaridjall.

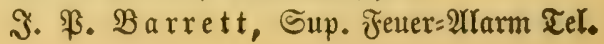


(5omptoir ber Mc Eormid Reaper 2 or

(5 hi cago, ЭU., Den 1. Eept. 1877.

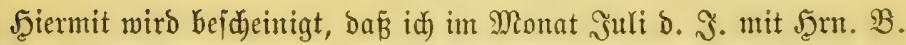

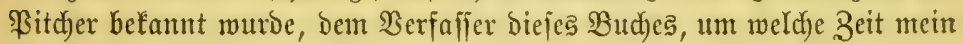

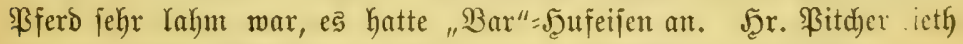
mir, biejelben abnehmen zu \affen und jeine Bejd) Iagungsmethobe anzu=

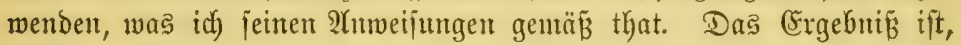

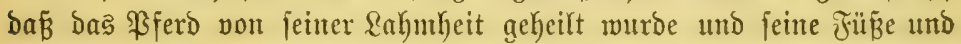

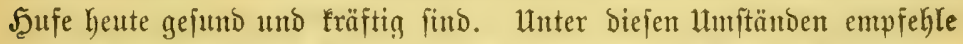
id jein $B$ ud und feine Methode, für gejunde wic für franfe $\mathfrak{B}$ ferde, je= bermann. M. $\Re$. Selted.

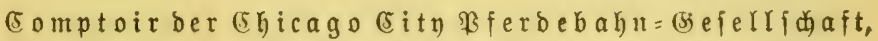
(5)

$\mathfrak{A} n \mathfrak{A} \mathfrak{H}$ e, bie es angeht:

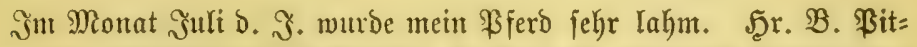

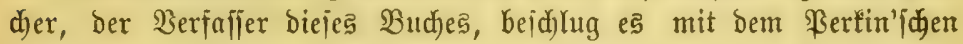
Jeufeijen, nach ber von ifm angewnutoten Methode, und bas Bferd wurbe bald beffer. Jdh tann jein Budd und jeine Methode ofne Sdjeu allen

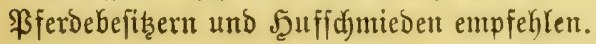

(5. $\mathfrak{B}$. $\mathfrak{y} a \mathfrak{m} m$ ond,

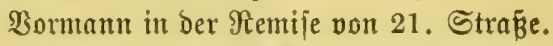

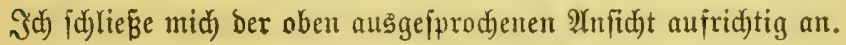

$\mathfrak{B}$ m. M. $\mathfrak{B}$ urt, Thierarzt.

(5omptoir von Reroy

Leih= uno Berpflegungştall, 144 u. 145 Mid). 2lve.,

(5hi c a g 0, Jll., ben \%. Sept. 1877.

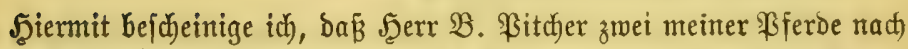

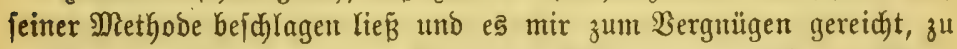
conjtatiren, daß̧ er Damit eine bebeutende Befferung ergielt hat. (5he er jeine Methode anmanote, liefen die Thiere gemöhnlidu lahm, jełt bagegen ift jebe Spur von Rahmbeit veridyunden.

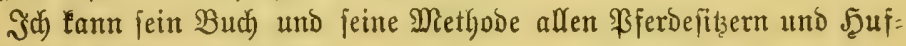
fämieden bejtens empieglen. 
An $\mathfrak{A}\{\mathrm{te}$, bie es a ugeht:

(5hicaģ S.ll, bent 7. Sept. 1877.

STiermit beidjeinige $i d$,

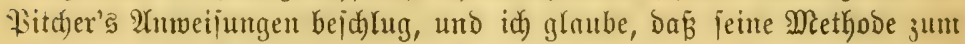

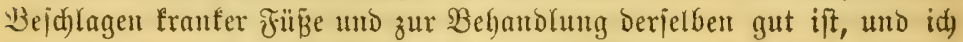

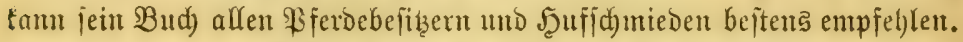
$\mathfrak{A b r a h a m ~}$ S. Beamifh, Jeufidmied,

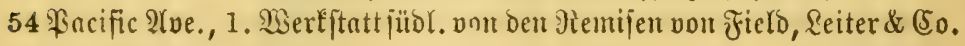

An Ir $r$ e, bie es angeht:

(5 hicago, sul, belt 7. Sept. 1877.

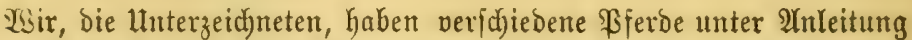

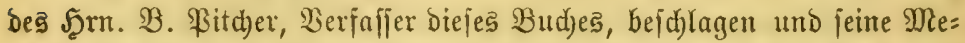
thode für jegr gut befunden, und wir empfeblen dieje und jein Buch aflen

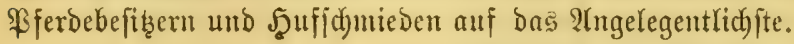

(5) e b r ï der Mc (S) ire,

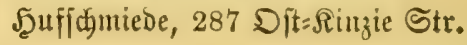

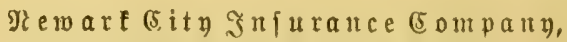
Sitfuratice (Siebäube, 174 Rajalle Straß̧e,

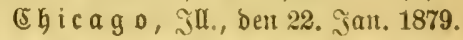

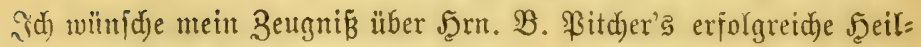
methode bei Bferdeftantheiten anzufügen. Meine Etute "Mielle" ritt

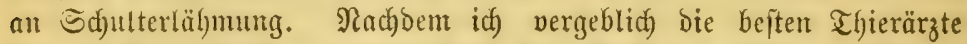
(Shicago's confultirt hatte, wurbe ich Şrm. ßitcher empfohlen. In we= niger als brei Wodken war biejelbe gejund wie ein fild und ift jetther nie wieder frant aemorben.

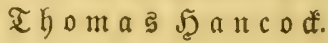

(5 hicago, ben 26. รamuar 1879.

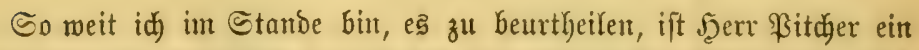

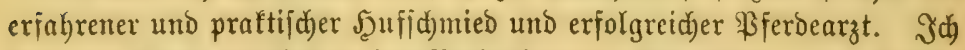

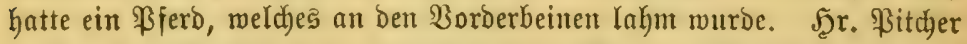

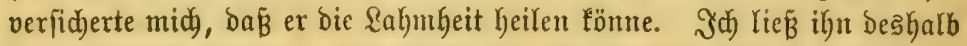

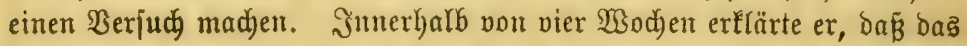
Thier gejund fei, und obwohl bas $\mathfrak{B}$ ferd feither fortwäbrend im Dienft gerwejen ift, zeigt es bod feine Spuren ber früheren Iabmbeit. 
Comptoir von c. 5. Slaf'’ Colonial = Waarenthanblung, en gros u. detail, 119 Mabijon Straße, Ehicago, ben 14. Satt. 1879.

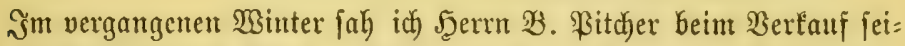

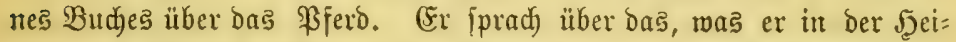
Iung von Pferbefrantheiten, wie fteifen Sdultern, zujanmengezogenen

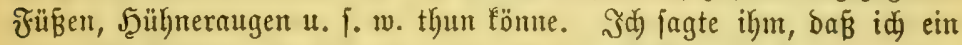

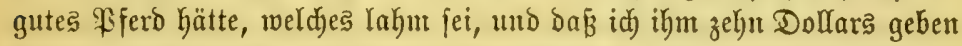
würde, ment er mir ben (Strund Der Sahmbeit fagen und eine Jeeilung vollbringen föme. (5r unternabm die Arbeit unter ber Bebingung:

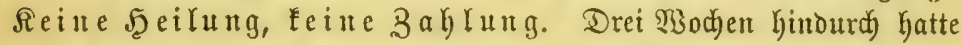

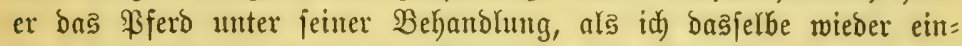
ipante, und jeither hat es jeine $\mathfrak{A r b e i t}$ in ber beften $\mathfrak{W e i}$ e gethan und

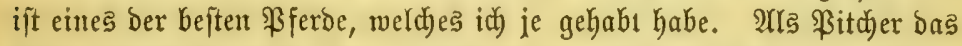

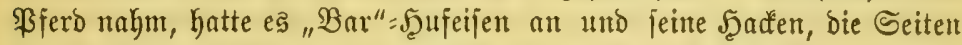
ber Furche bes গ̧ufes waren weggejd)nitten un ber Fuß jelbft perbraut.

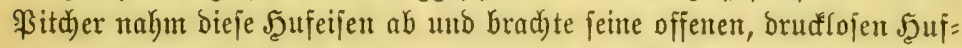
eifen zur : werden würbe, jobald es gejunde Fübe erfalten habe, unt joldje erfielt

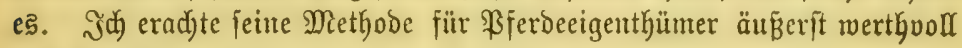
and empfehle diejelbe jowie jein $\mathfrak{B u c h}$ herzlid).

$$
\text { भ. S. ธ a vag e, }
$$

Bormann in Slač's Remije.

(Eomptoir von 29. M. Forbes” "Trute Ställen, 24 tt. 26 2toams Str., (5) i c a g o, ben 14. Januar 1879.

An $\mathfrak{x} \mathfrak{r}$ e, bie es a nge $\mathfrak{t}$ :

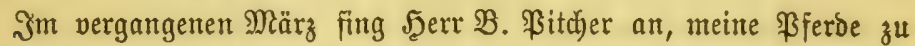
bejalagen. Damals waren ihre Füße im folechten 3ujtande, verbrannt

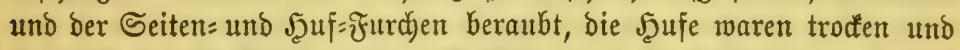
fieberifd und die Bferde lahm. Seither hat er fie bejolagen und jebt

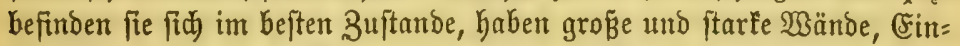
id)nitte und Seiter. Man rürbe glauben, fie feien eben vom Iande

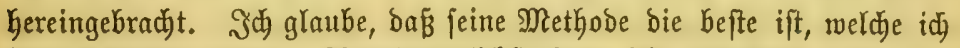
jemals lennen lernte. Arngelegentlichit lann id fein $\mathfrak{B} u d$ und jeine

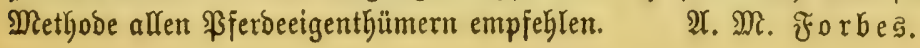


Racine, \$Bỉ., Den 3. Februar 1880.

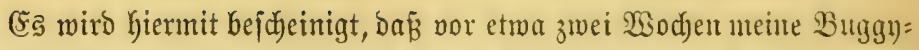

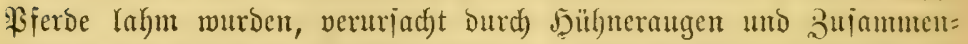

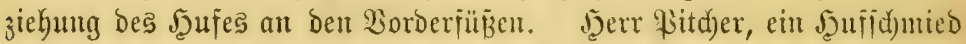

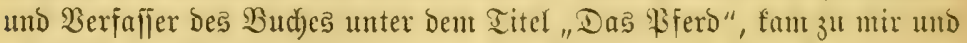

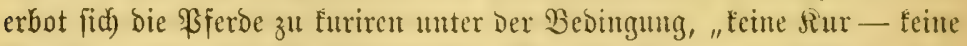
Bezahlung." Durd) beigebrad)te Bemeije überzengt, Daj er jeit (Gejd)äft verjtehe, übergab idy ifm meine Pferde. Seine Methode, ju

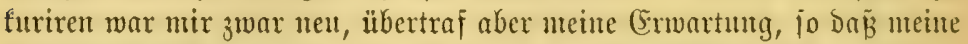
Bferde jetzt beffer gehen, wie nod) je juvor, und möhte id) Giermit bicjent

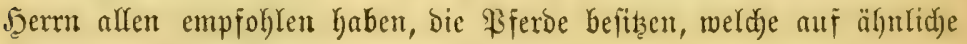
Weije mit franfen Jüüen behaftet find.

M. B. (Erąine.

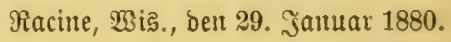

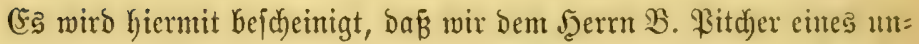
ferer $\mathfrak{B}$ ferde zur Bebanolung übergaben, weld)es au zujammengejdyolle:

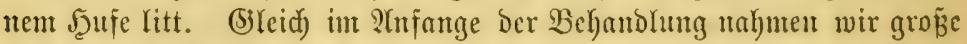

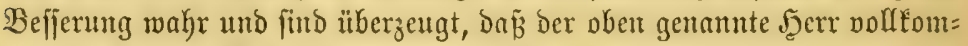
men im Stande ift, zu thun, was er fäligig zu fein vorgiebt, unb empieh= len ifn allen, weldye jeiner Diente bebiurfen.

Die $\mathfrak{B} \mathfrak{l}$ a

Wemes angeht:

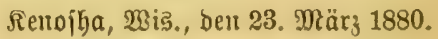

Wix, Die Unterzeidnneten, Gaben lahme und früpplidje Pferde gehabt,

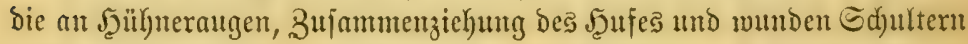

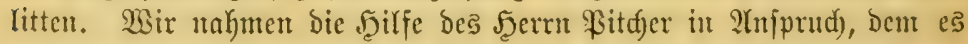
gelungen, unjere Ermartung zแ übertrefien, แn fömten wir biejen Serrn 
allen $\mathfrak{B f e r b e =}$ (Figenthÿ̈mern in ähnllid)er Rage beftents emtpfehlen.
(E). $\mathfrak{B}$ a i $\pi$,
(5. (5). I $i m m e$,
M. A. Mirrer,

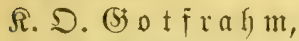
Ut $\mathfrak{b}$. Y. Rewi
(5) e o. $\mathfrak{Y} u \mathfrak{e}$,

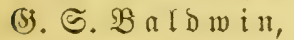
Levi Giant,
D) r. $\mathfrak{g}$. Эun ge,
S. Borny, $\quad$ D. M. Petit.

Wrem es angegt:

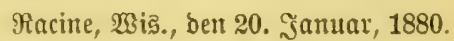

(5⿹ mird Giermit beidjeinigt, ba ber 1879 zu mir fam, mir feine Theorie und \$raxis in ber $\mathfrak{B}$ ehandung

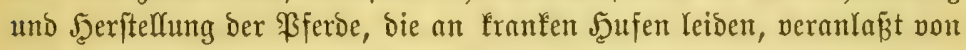

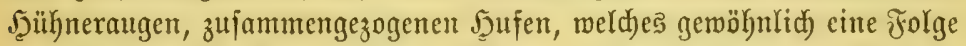

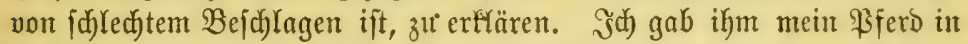
Behanolung, weldes feit langer Beit lahm war, und bisher von feinem

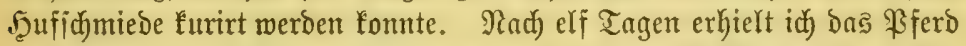
in bebeutend verbeffertem 3uftande zurüd. 5err $\mathfrak{B}$. Bitcher Katte Den

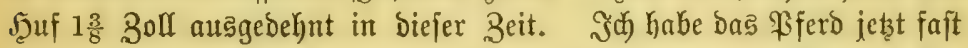

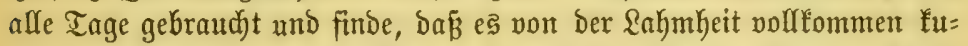
rirt ift; es hat einen guten (Sang und verbefiert fich fortwäbrend. Des= halb fann ich allen Bferbe:(Sigenthümern, welche ßferbe mit ähnlichen Feblern befitien, ben oben genannten J̧errn beitens empfehlen.

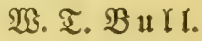




\section{CEnglijüe Benentumgen ber int Budje vorfommentoen Medifaunente.}

2.

Iconit=Tinftur, Tincture aconite. शtraum, Alum.

Ifrcohol, Alcohol

Irloe, Aloe.

2tumonia Muriata, Muriat of Ammonia.

2tmmonia $\mathfrak{f}_{j} \mathrm{I}_{3}$, Sal-ammonia.

Immoniafwafier, Aqua ammonia.

Itnis:Del, Oil of Anise.

2(rttimon Butter, Butter of antimony. Ifruica = Tiuftur, Tincture of arnica. Trienif, Arsenic.

2 2hfajötió, Assa-foetida.

\section{3.}

Barbaboes भroes, Barbadois aloes

Blättertabaf́, Plug tobacco.

3leizucter, Sugar of lead.

Bred) $แ[\bar{B}=$ Tnttur, Tincture of nux vomica.

Bired)weinftein, Emetic tartar.

Bred)wurz̧еl, Ipecac.

Burgutoer=fied), Burgundy pitch.

\section{(5.}

salomel, Calomel.

Eantelle, Canella.

(sarboliäıme, Carbolic acid.

(sosmtolit, Cosmoline.

(5rotont = Der, Croton oil.

(b.

Eifenfulphat, Sulphate of iron.

Englijchez Del, British oil.

Enzian=İnftur, Tincture of gentian

Epiomialz, Epsomsalt.

Efifigfäure, Acetic acid.

Eifigiaures $\mathrm{Sal}_{3}$ Acetate of lead.

(suphorbiumbarz, Gum euphorbium.
ร.

Fidjtenbaljan, Balsam of fir.

Jidftentheer, Pine tar.

(3.

G5elbrwurzel, Golden lial.

(3) auberjalz, Glaubersalts.

(3)Incerin, Glycerine.

Soldenfaamten, Golden seed.

(Srünjpan, Verdigris.

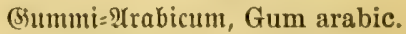

(5ummi=(3utta, Gamboge.

(5)aiacharz, Gum guaiac.

53.

5aaferid) (eim, Gruel.

f̧ammeltalg, Mutton tallow.

Jaarz, Rosin.

Sirfokbort $=$ Tinttur, Tincture of hartshorn.

Solz tohle, Cbarcoal.

ફ̧ut

ร.

Snoifder 5oculos, Coculus indicus.

§ugwer, Ginger.

Sob, Iodine.

$\Im_{0 b}=\Im_{\text {Sintur, }}$ Tincture of Iodine.

s.

Kampferkarz, Gum camphor.

Rauthariben $=$ Tutftur Tincture can tharides.

Raftoröl, Castoroil,

Rated) $1=(3)$ m, Gum catechu.

Rrauenfett, Neatsfoot oil.

Rohlenör, Coal oil.

Sreibe, Chalk.

Rümmelör, Oil of cumin.

\section{\&.}

Laubamum, Laudanum.

Reinöl, rokez, Raw linseed oil. 


\section{Mi.}

Majoran, milber, Origanum.

Miajoran=Del, Oil of origanum.

Meerrettig, Horse-radish.

Mreerswiebel, Nitre.

Merfurialfalbe, Mercurial ointment.

Miıłtatnup̄, Nutmeg.

i.

Nabelbaum= Rinde, Powdered savin.

\section{D.}

Sripenör, Olive oil.

Spiumtintur, Tincture of opium.

\section{t3.}

Bappel-\{inbe, Popalar bark.

Bfeffermünzől, Oil of peppermint.

Botaffia $a$ Ircetat, Acetate of potash. Botajfia= Nitrat, Nitrate of potash. Precipitat, rothes, Red precipitate.

Duaffia, Quassia.

M.

Regentwaffer, Soft water.

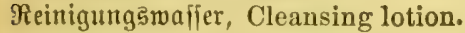
Rhabiumöl, Oil of rhodium.

Rohes Seinör, Raw linseed oil.

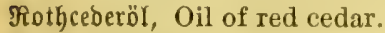

Rothes ßrecipitat, Red precipitate.

\section{$\sigma$.}

Salbei=2(btod)ung, Sage tea.

Saleratus, Saleratus.

Salpeter, Saltpetre.

Salpeteriäure, Nitric acid.

Salpeteriaure Sillber, Nitrate of silver.

Salpeteripiritus, Spirits of nitre.

Salziäure, Muriatic acid.

Salfajrą, Sassafras.

Shierlingtanne $=$ Del, Hemlock.

Sd)meer, Lard.

Sdamierjeifentalbe, Soft soap salve.

Schrofel, Sulphur,

Sdimefeläther, Sulphuric ether.
Sdjwefeliäure, Sulphuric acid.

Seife, flüffige, Soft soap.

Seife, ventianifide, Castile soap.

Seifenjalbe, meidje, Soft soap salve.

Spantifde=\$3feffer Iinftur, Tincture capsicum.

Spat $=$ I) $\ell_{e} \dot{b}_{3} i t$, Spavin medicine.

Spermacetijalbe, Spermacets ointment.

Spieß̧glanz, gefdrmefelter, Sulphuret of antimony.

Spitür, Oil of spike.

Steinöl, Oil stone.

Strndynin, Strychnine.

Sublimat, äłselıes, Carrosive sublimate.

Syrup, Molasses.

\section{$\mathfrak{\Sigma}$}

Talg, Tallow.

Theeröl, Oil of tar.

Terpentin. Benetianifder, Venice Turpentine.

II.

uImentbamm $=$ Rintbe, Slippery - elm bark.

\section{3.}

Bentianijace Seife, Castile soap.

Bentianijace Terpentiu, Venice turpentine:

Bitriol, Vitriol.

Bitriof= Extratt, Decoction of pink root.

Qitriol= Del, Uil of vitriol.

\section{3.}

Wadhyolberöl, Oil of juniper.

Wadt) (Bienten=), Beeswax.

Beide Seijenjalbe, Soft soap salve.

Meidjitein= $\mathscr{R} a l_{i}$, Tartrate of potassa. Wermuth= $=$ Del, Oil of warmwood.

\section{3.}

Bintoris, Oxide of zinc.

Binf:= Sulphat, Sulphate of zinc.

Bugialbe, Liquid blister. 


\section{(Es ift ein

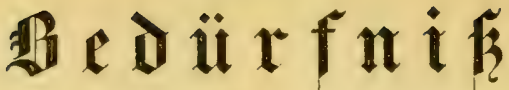

fuir jese bentidye Framilie cinte gediegene, beutidje politiidne 3eitumg zu halten.

\section{Di $\mathrm{i}$ \\ "Deutsche DSarte"}

(5) $\mathrm{i} n$

3 weima $\mathfrak{l}=\mathfrak{m}$ ä

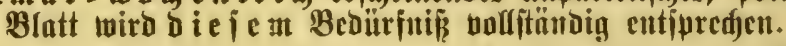

Die "Deutidje Barte" ift bie einzige beutjdye Zeituntg im $\mathfrak{B}$ eften, meldye für nur

$$
\$ 2.00
$$

per Gahr, portosfrei zweimal bie $\mathfrak{3}$ sodje eridgeint.

Die "Wa $\mathfrak{a} t e^{\prime \prime}$ ift eit ed)tes Fanilien=Blatt, und barf jebem Rinte ohne Sorge in bie Şände gelegt merben.

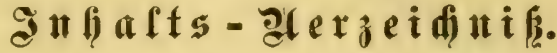

1. Der arontags- dus a a 6 e:

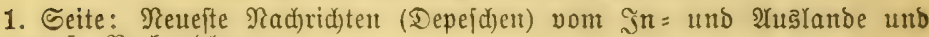
Eongreß = Berbandungen.

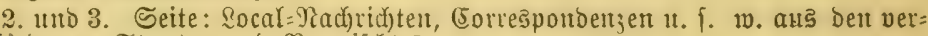
fdiebentr Staatent und Bermijd)tes.

4. uno 5. Seite: Reitartifel, Eorreß̧ponbenjen, furze Rotizen und BeridjieDene?.

6. uno 7. Seite: (Europäija)e F̧oit=Yiad)rid)ten aus allen beutiduent Staaten und eine Erzäblutug.

8. Seite: Chicago und (5oof (Sounty) Rocal Notizen und Martberid)te.

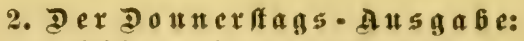

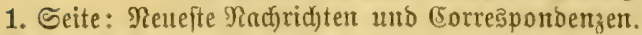

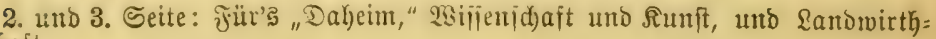
依aft.

4. Seite: Sehr auşührridje Marftberid)te und Beridjiebenes.

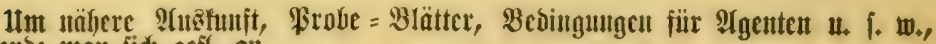
wertbe mtan fid) gefl, an

D. Sunobel, Mintg.,

45 5. Sa Saffe str., Eficago, 3ีts. 


\section{Racer \\ Horse \\ Rasps.}

Patentirt.

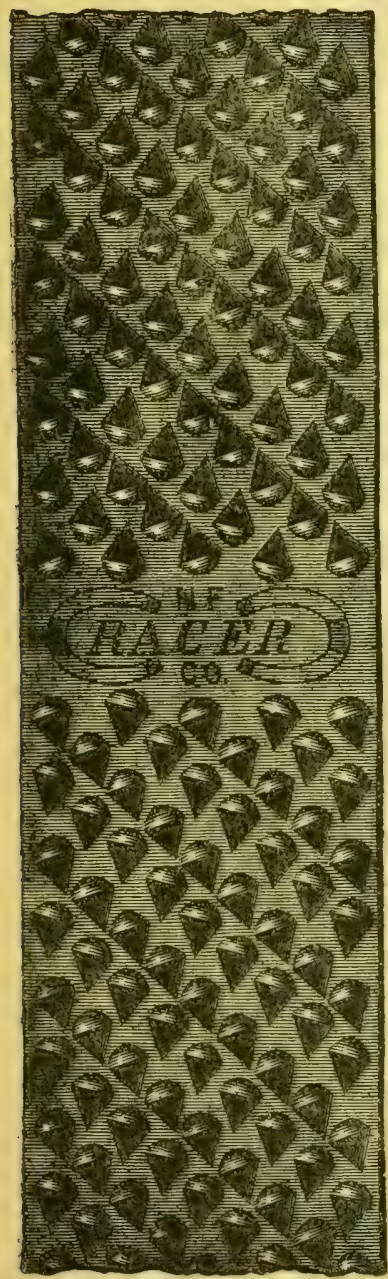

Wir präfentiren hiermit eine SUluftration eittes eingemiejen भitrangements ber 3ähne vou $\mathfrak{B j e r b e r a j p e n , ~ m o r a u s ~ e r f i c j t r i d y ~ i f t , ~} \delta a \bar{\beta}$ Die Bildfläche in ber zroeiten Bahnreige zu Der andern int untgefehrten 23 infel ftehen, wo= burd) bie Sdjutttflädıen fabräge merben und eint gezogenter Schutt heroorg̉ebradjt mirb.

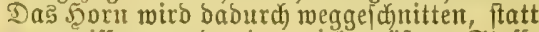
meggeriffen, unt eine diel gröpere Stoff= mafle wird entfernt mit berfelben siraft, als menn mie gewöhnlid bie 3ähnte im redjten

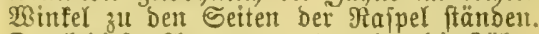
Durb biejes 2Arrangement merben bie 3ähne viel bauterbafter, weil ihre Epizen weniger

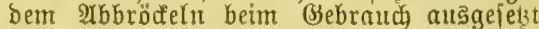
fint, unb wie fich aus bem Srinzip ber (Eolt= ftruftion gleidffalls erjeken läßt, find biejel= bell aud mentiger bem Berftopfen ausgejekst,

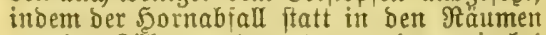
von ben Sâhnen georengt zut merben, wie bei

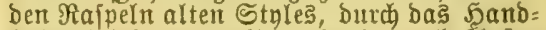

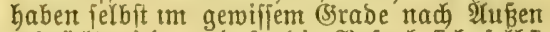
gebrüft twirb, unt fo bie Fajpel fich felbft reinigt. Fïr \$ferberajpen biejer 2 Art jomohl tanged mie einfact), Gaben wir ben Namen "RACER" aboptirt. Diejelben haben bie ge= wökntiden (Sröken, uno werden pon einem Stahl von extra rauker Dualität gemadt. Jeber 3ahn if boppelidnteibig unt bie $\Re a=$ ipen fimb vermittelit eines Prozelfes, ber ih= nen auß̧erorbentliche Thätigfeit verleiht, temporirt. Der $23 a h r i p r u c h$ Alder, meldue

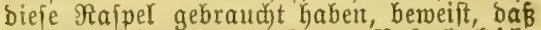

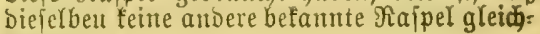
tommt.

\section{Alleinige Gabrikanten \\ Michoflon dile $\mathbb{C}_{0 .}$}

Providerice, 尺. I.

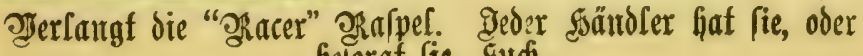
belorgt fie siltdi. 


\section{Die Silobe Diail So.,}

Fabrifanten von

\section{Ǵlobe fuferfen - Mägel.}

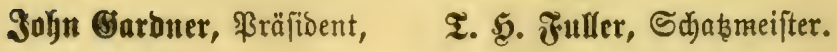

DBoston, D্lass.

Chicago Office, 159 \& 161 Lake Str.

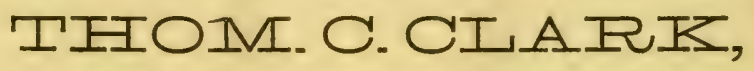

affeiniger Aggent füx die weftidien Staaten und ซerriforien.
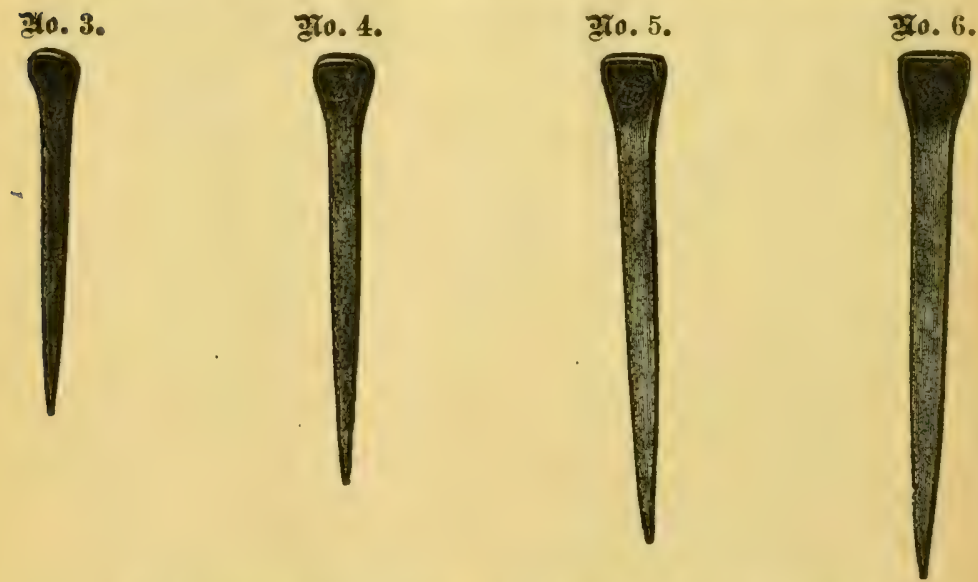

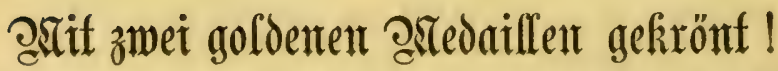

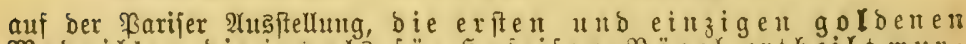
Medaillen, bie jemaļ für $\mathfrak{S} u$ feife

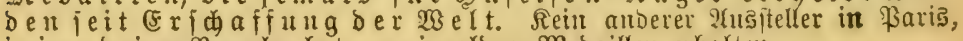
in irgend einer Brandje, bat o w e i goldente Mebaillen erbalten.

frage nach Globe-Mägel umo verwende keime anoeren. 


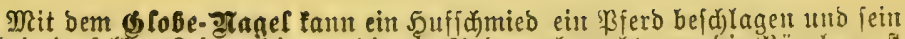
(B)

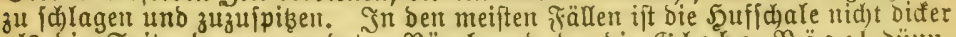
als bie Spike ber verwendeten Nägel, und ba bie $5 l_{0} b e=\Re a ̈ g e l$ büm, glatt unt eben gemadit fint, betraditet mant fie als bie fidderiten, beften, ipar=

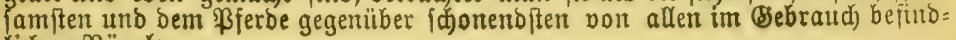
liçen ఇägeln.
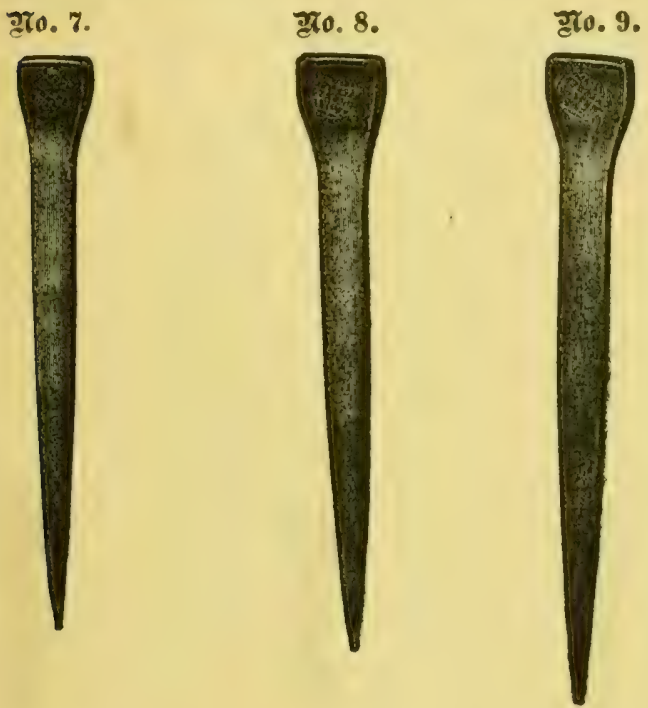

ฐृ०. 10.

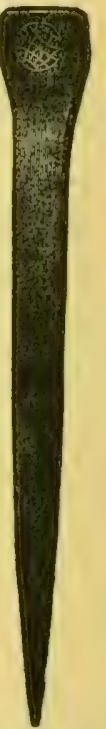

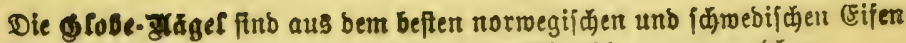
angejertigt, polirt unb gejpist, unb fofort zum (Einja)lagen verwenbbar.

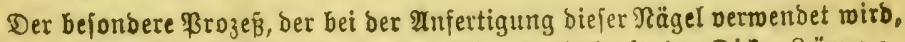

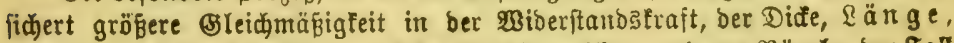
B reite und ber 3 uipipung, als bei irgend weldjen anderen Rägeln ber Fall if, unb biejelben geben leidyter Gintein, fafien beffer unb halten länger.

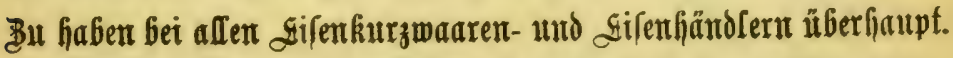

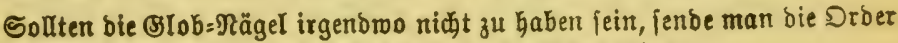

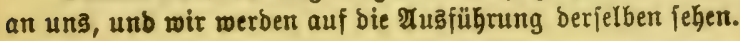

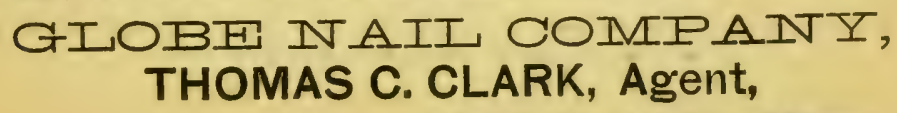

159 und 161 safie str., Egticago. 


\section{Sturlong's \\ verbefferfe

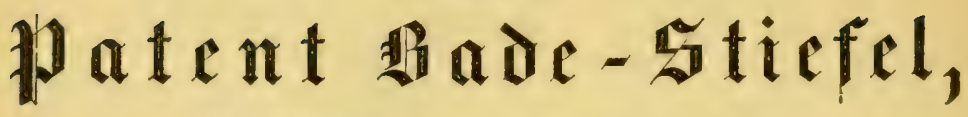

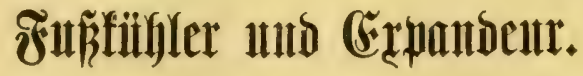

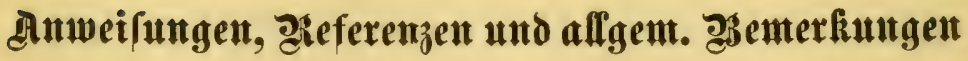

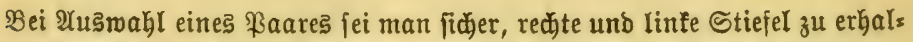

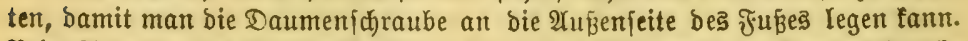

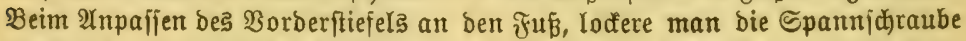

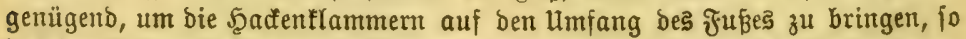
baß ber Stiefel teidjt an unb abgezogen werben fann, unb madje ihn bann ges Görig feit mit ber Daumenja)raube. (5he man ben Babefitiejel bem Fube ans

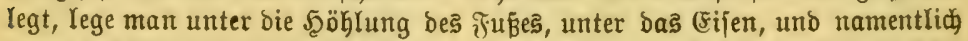

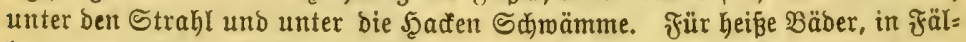
Yen von heftigem Fieber ober (5ntzüntoung, bettube man trođene Sdimämme,

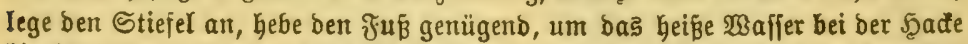

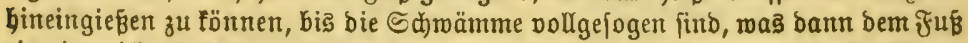
ein eintweidjendes Dampfbas geben uno faft fofortige Rinberung berbeifübren mirb. Lahme Füß̨e geheilt. Fieber gehoben. Füße zäbe gemadit. Reine

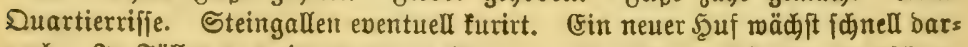

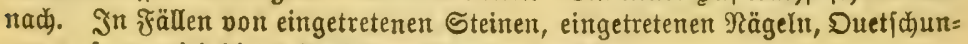
gen u. f. w. miro diejes $\mathfrak{B e t f a b r e n ~} \mathfrak{B}$ under verïben.

Das̉ heipe Bab beugt ber Maulfperre und nervöjer \&ähmung vor, madjt

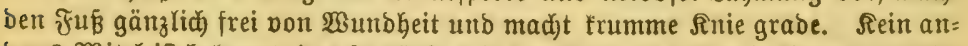
beres Mitel ift befannt, bas fo völlig mit ber Natur in Uebereinftimmung ftebt,

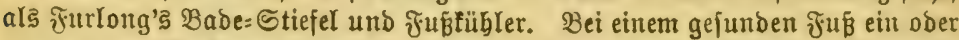
zmeimal per 20 odje angemant, mirb berfelbe frets gejunb bleiben. Niemals beidneibe man ben Strabl ober fanteibe bie Şaden zu weit hinunter. Man

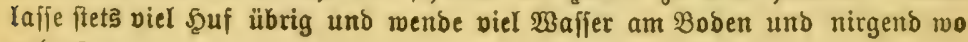
anders an.

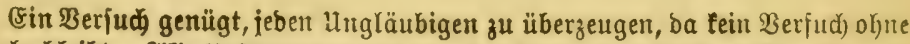
(5rfolg bleibt. YXle Beftellungen auf einzelne \$aare ober größere Inzabl wer= bert prompt effeftuirt merben burch)

\section{I. FURZONG, Satentinbaber,} æreis, $\$ 2.50$ per æån.

162 asastiugfon \$t., Efitrago.

3 immer 14. 


\section{@as \\ Drunder der Dsselt!

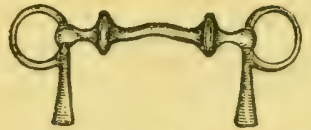 \\ Cin Plerde-(Bebil,}

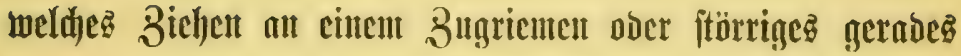
Biehen verljiitet.

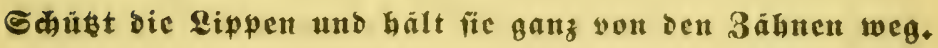

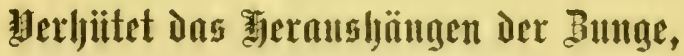

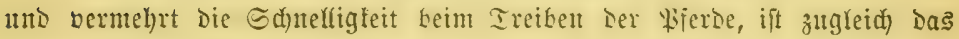

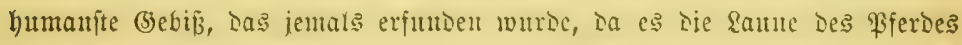

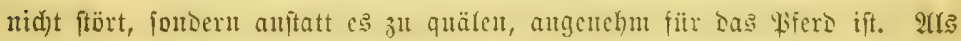

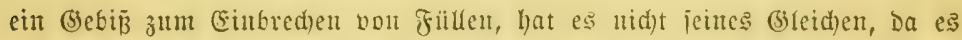

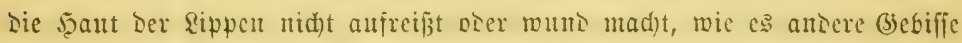

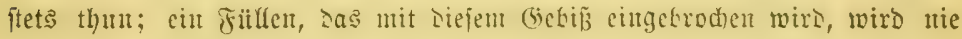

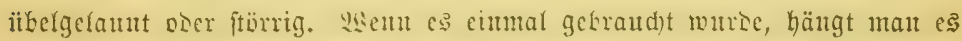

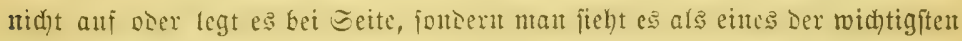
Dinge im Etaff all, zehmmal mehr werth, als cs gefoftet hat. (E) ift patentirt. Man jdide $\$ 5.00$ cilt, nth laife fid) eines fommen, man wirs es nie

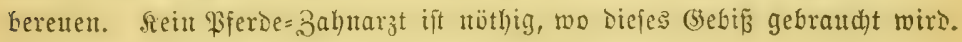

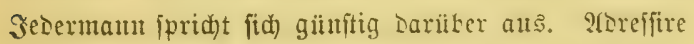

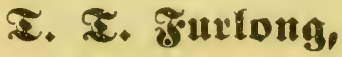

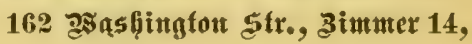
Q $\mathfrak{f} \mathfrak{i} \mathfrak{i} \mathfrak{a} \mathfrak{g} \mathfrak{0}$. 


\section{F. DEWICK \& CO. Fabritanten pon \\ patentirten finferifen-spitien,}

(TOE CATK:)

360 Derohester Arenue.

Soutli Boston, Mass.

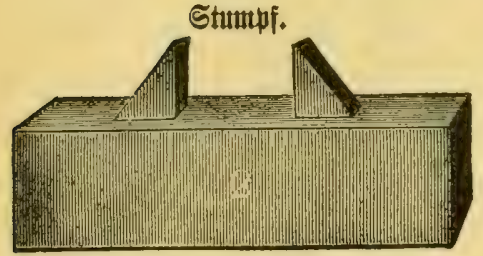

Yo. $1,2,3,4,5$.

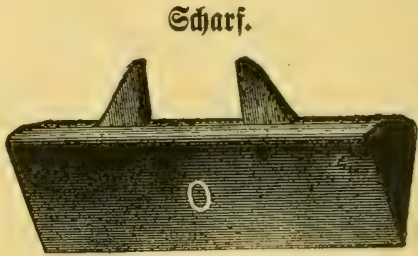

⿰氵. $0,1,2,3,4$.

In siften verpact zu je 25 ßfund.

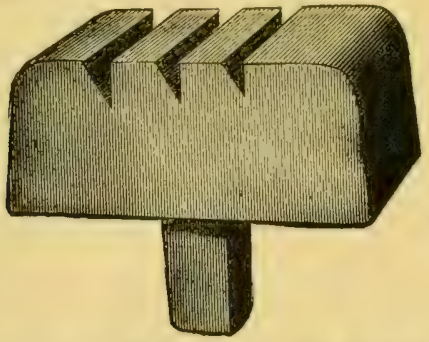

\section{Stempel zum Sdjweiß̄en idjarfer Spiz̨en.}

Wir find jebt im Stanbe, in Berbinbuna mit unjeren befanten einzingi= gen Bebipizen aud smeizingige nad) obigem Mitfer zu offeriren.

Ђieje Spiben eignen fid vorzüglich für bie mit Maidninen gemadten 5ui= eijen, da bie Stellung ocr Sperre ben Eimfanitt trei läßt, und baher bie (5ie= fahr bes Beritens de

Sie finb aus einer bejonder: ausgemählten Dualität Stahl gemad, find gut gebärtet und lailen fich leicht mit Sand id)meißen.

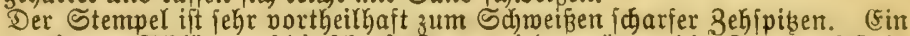
ober zmei gute Schläge auf bie idjarfe ふante mirb gentigen, bie Sporen jeit in

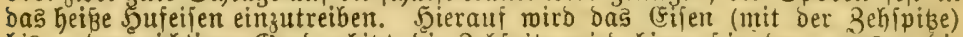
bis zu Dem ridhtigen (Srad erhibt, die Behipibe miro bierauf in ber correspondi=

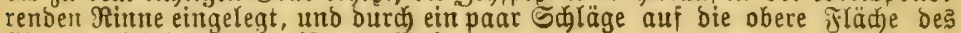
Eijens, mirb bas Sdjtweiben vollendet.

Эูhos. 9. (ㄷark, Plgent, $159 \& 161$ Lake Street,

Chicago. 



LIBRARY OF CONGRESS

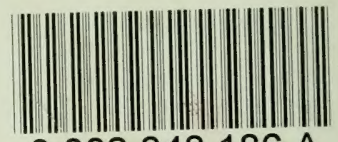

0002848186 A 